\title{
Technology transfer and learning under the Kyoto Regime : exploring the technological impact of CDM projects in developing countries
}

Citation for published version (APA):

Doranova, A. (2010). Technology transfer and learning under the Kyoto Regime : exploring the technological impact of CDM projects in developing countries. [Doctoral Thesis, Maastricht University]. Universitaire Pers Maastricht. https://doi.org/10.26481/dis.20100121ad

Document status and date:

Published: 01/01/2010

DOI:

10.26481/dis.20100121ad

Document Version:

Publisher's PDF, also known as Version of record

Please check the document version of this publication:

- A submitted manuscript is the version of the article upon submission and before peer-review. There can be important differences between the submitted version and the official published version of record.

People interested in the research are advised to contact the author for the final version of the publication, or visit the DOI to the publisher's website.

- The final author version and the galley proof are versions of the publication after peer review.

- The final published version features the final layout of the paper including the volume, issue and page numbers.

Link to publication

\footnotetext{
General rights rights.

- You may freely distribute the URL identifying the publication in the public portal. please follow below link for the End User Agreement:

www.umlib.nl/taverne-license

Take down policy

If you believe that this document breaches copyright please contact us at:

repository@maastrichtuniversity.nl

providing details and we will investigate your claim.
}

Copyright and moral rights for the publications made accessible in the public portal are retained by the authors and/or other copyright owners and it is a condition of accessing publications that users recognise and abide by the legal requirements associated with these

- Users may download and print one copy of any publication from the public portal for the purpose of private study or research.

- You may not further distribute the material or use it for any profit-making activity or commercial gain

If the publication is distributed under the terms of Article $25 \mathrm{fa}$ of the Dutch Copyright Act, indicated by the "Taverne" license above, 


\section{TECHNOLOGY TRANSFER \\ AND LEARNING UNDER THE KYOTO REGIME: \\ EXPLORING THE TECHNOLOGICAL IMPACT OF CDM PROJECTS \\ IN DEVELOPING COUNTRIES}

ASEl Doranova

UNU-MERIT

MAASTRICHT UNIVERSITY 
(C) Copyright Asel DORANOVA, Maastricht 2009

ISBN: 978-90-5278-905-7

Printing: Datawyse / Universitaire Pers Maastricht 


\section{TECHNOLOGY TRANSFER}

AND LEARNING UNDER THE KYOTO REGIME:

exploring the technological impact

of CDM projects in developing countries

\section{PROEFSCHRIFT}

ter verkrijging van de graad van doctor aan de Universiteit Maastricht, op gezag van de Rector Magnificus, Prof. mr. G.P.M.F. Mols, volgens het besluit van het College van Decanen, in het openbaar te verdedigen op donderdag 21 januari 2010 om 14.00 uur

door

Asel Doranova

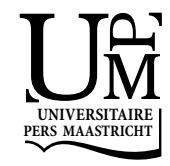


Promotor:

Prof. dr. Geert Duysters

Co-promotor:

Dr. Ionara Costa

Beoordelingscommissie:

Prof. dr. Joan Muysken, voorzitter

Prof. dr. Andries de Grip

Prof. dr. Wilfred Dolfsma, Rijksuniversiteit Groningen

The following institutions supported this $\mathrm{PhD}$ research:

United Nations University, Maastricht Economic and Social Research Training Center on Innovation and Technology, UNU-MERIT

Edmond Hustinx Foundation, Maastricht, The Netherlands 


\section{ACKNOWLEDGMENT}

Every exit is an entry somewhere else said Tom Stoppard... At this moment I do not know yet what I am to enter, but I am very grateful to my destiny for what I am exiting. My four years of $\mathrm{PhD}$ life were not the easiest, but they were surely some of the best years of my life. I went through lots of worries, stress, sometimes regrets, but at the same time there always was space for a nice time, great fun, amazing people and happy events. I guess this is a pretty standard experience for every $\mathrm{PhD}$ student, but it was a bright experience for me. How would I forget arriving in Maastrich, Tekyo guesthouse (and the 'ghosts' living there), classes, assignments (and pretty well organized joint work on them), the Ivory Tower, parties with Salsa and Persian dances, Turkish breakfasts, cooking, 'multinomial gang meetings', more cooking, first Stata results (a big deal for someone who had never done statistics before), Flavia's cakes, my first empirical paper and lots of comments from journal editors. Time flies so fast...

The most important people who helped me get through the $\mathrm{PhD}$ jungle are my supervisors Geert Duysters and Ionara Costa. My very first and biggest thanks should go to them. I don't know how I ended up working with Geert, but I am very happy that it happened. I think such an efficient supervisor could not be found anywhere else. His main style of working with $\mathrm{PhD}$ students is very structured work combined with lots of positive encouragement, strengthening your confidence, praising every small achievement and cheering you up when you are facing a problem. My work largely progressed thanks to his positive approach. I wish all my future bosses will be like him!

Ionara is not only my supervisor but also a good friend with whom you can talk about much more things beside the thesis. I am especially thankful to her for helping me four years ago to find my way when I was lost in the process of defining my proposal. She was always there for me with her new ideas, references, thousands of remarks on my three pages of writing and plentiful enthusiasm about my project. I will always remember my work meetings with Ionara, because she would always try to make them as cosy as possible, offer a nice herbal tea and cookies, or invite me to some lovely place. This kind of work style I will probably miss a lot.

I should not forget to thank my friends from the "Multinomial circle". Branka and Fernando, you are my amazing teachers, friends, colleagues, advisors, co-sufferers - all in one! I am so thankful for everything you've shared with me. It was really great to have this little circle and learn from you.

I also need to thank my dear friend Semih for several things, but I will highlight two: 1) for teaching and helping me with Stata, 2) for his beautiful Turkish breakfasts that many people enjoyed.

I would like to thank all people from our research group who gave their advice, feedback, and help on my work on the thesis and the book chapter. I am glad I had a chance to be in one team with you.

I would like to acknowledge the thesis reading committee members Professor J. Muysken, Professor A. de Grip, and Professor W. Dolfsma for their valuable comments and suggestions, which helped me to improve my thesis. 
I am also very grateful to my teachers and researchers at UNU-MERIT who taught classes or helped me with their advice so many times. Dear Rene, Eddy, Théophile, Adriaan, Luc, Kaushalesh, Michiko, Jojo, Robin, Bart, I thank you all.

I would like to thank Eveline for her help in the many issues that we $\mathrm{PhD}$ students had. Along with that my many thanks are addressed to the rest of the administrative staff: Eric, Mark, Mitie, Wilma, Monique, Carmen, Silvana, Herman, and Mourik Jan. Thank you for your support and making office running smoothly. My special thanks to Ad. He is the best and the most efficient librarian ever!

My deep appreciation goes to UNU-MERIT for providing the opportunity and funding to come to the Netherlands, to study and do research, to meet new people from so many countries, and to have this great experience.

I am immensely grateful to the Edmond Hustinx Foundation for providing me with funding for my research. Without this grant I would not have been able to conduct my survey, attend some important conferences and meetings, and have this beautiful and efficient computer that I have been extensively using in my work.

Let me also tell words of appreciation to my friends, the $\mathrm{PhD}$ students at UNUMERIT. I feel so special and extremely lucky that I am part of this amazing crowd of amazing people, who became very important people in my life! Radhika, Tina, Big Don, Sergey, Evans, Eze, Abraham, Semih, Anni, Philipp, Fernando, Ekin, Branka, Zak, Natasha, Giulia, Francesco, Christian, Lina, Flavia, Shuan, Daniel, Nora, Marion, Luciana, Ibrahim, Ying, Iman, Rodolfo, Jun, Lilia,... and all the others. Life here would have been so boring without you guys! I wish you all success with your work and to become 'Big Fishes' in the nearest future.

Special thanks go to the crowd of $\mathrm{PhD}$ students of the Maastricht School of Governance, particularly the 2005 batch with whom we shared not only classes, but many more pleasant events. I also want to thank my friends for their support, keeping in touch and visits during my stay in the Netherlands. Chopa, Kazbek, Inna, Almaz, Azik, Leila, Nurgul, Aigul, Nebilay, Sharon, Luba, Jana, Aziza, Maia. Many thanks to you guys for being with me!

I also want to thank Nico's parents Wilma and Larry for giving me and Nico loads of help, as well as Gaby and Bert, for all the encouragement you kept giving me!

And the last but not the least, actually the most important people that have to be thanked are my father, my mother, and my Nico. I devote this thesis to them! I think these people wanted my success in $\mathrm{PhD}$ way more than I did. My parents always wanted me to study, to opt for better education, to have an interesting job and life. It was a dream of my father that I get $\mathrm{PhD}$ degree one day. I am glad I am finally fulfilling his dream!

I don't know how much I owe to my dear Nico for all his tremendous support, patience, help with many things, including cooking, helping with data, programming my survey, putting my "the's and a's" in the correct places in my text, carrying me on his bike, keeping me comfortable, getting me flowers,.. and so on and so forth. Thanks heaps and bunches!

Asel Doranova, Maastricht, November, 2009 


\section{TABLE OF CONTENTS}

PART I. INTRODUCTION AND RESEARCH DESIGN 1

CHAPTER 1. INTRODUCTION

1.1 Introduction 1

1.2. Study object and background of the research issue 2

1.2.1 What is CDM? 2

1.2.2 CDM and technology transfer in climate change mitigation 4

$\begin{array}{ll}1.3 \text { Analytical framework and research questions } & 6\end{array}$

1.3.1 National knowledge base and technology sourcing in CDM projects:
Macro level perspective

1.3.2 Technological learning in CDM projects: micro level perspective 9

$\begin{array}{ll}1.4 \text { Contribution of the study } & 11\end{array}$

$\begin{array}{ll}1.5 \text { Thesis outline } & 13\end{array}$

CHAPTER 2. Data SOURSES

$\begin{array}{ll}2.1 \text { Introduction } & 17\end{array}$

2.2 Building the CDM project documents database $\quad 18$

2.3 Data collection through survey $\quad 19$

2.3.1 Survey preparation $\quad 19$

2.3.2. Sample selection $\quad 21$

2.3.3 Questionnaire design $\quad 22$

2.3.4 Representativeness of the sample 23

2.4 Data from other sources $\quad 25$

2.4.1 National economic indicators $\quad 26$

$\begin{array}{ll}\text { 2.4.2 Science and technology indicators } & 27\end{array}$

2.5 Interviews with CDM experts 28

PART II. MACRO LEVEL VIEW ON CDM AND

TECHNOLOGICAL KNOWLEDGE 31

CHAPTER 3. TECHNOLOGY SOURCING IN CDM PROJECTS: THE OVERVIEW

of ProjeCt Design DoCuments 31

$\begin{array}{ll}3.1 \text { Introduction } & 31\end{array}$

3.2 Description of the sample of CDM projects $\quad 32$

3.3 Technology sourcing in CDM projects: aggregated and

$\begin{array}{ll}\text { disaggregated analysis } & 35\end{array}$

$\begin{array}{lr}3.4 \text { Summary } & 40\end{array}$

CHAPTER 4. KNOWLEDGE BASE DETERMINANTS OF TECHNOLOGY
SOURCING IN CDM PROJECTS

4.1 Introduction 43

4.2 Theoretical grounding and main arguments $\quad 45$

$\begin{array}{ll}4.3 \text { Data and Methods } & 48\end{array}$

$\begin{array}{ll}\text { 4.3.1 Data sources } & 48\end{array}$

$\begin{array}{ll}\text { 4.3.2 Constructing variables } & 49\end{array}$

4.3.1 Multinomial Logit Model estimation $\quad 57$ 
4.4 Results $\quad 58$

$\begin{array}{ll}4.5 \text { Discussion } & 62\end{array}$

4.6 Conclusion and implications $\quad 64$

PART III. MICRO LEVEL VIEW ON CDM AND

$\begin{array}{ll}\text { TECHNOLOGICAL LEARNING } & 67\end{array}$

CHAPTER 5. TECHNOLOGICAL LEARNING PATTERNS AND INTENCITY IN CDM PROJECTS: OVERVIEW OF THE SURVEY RESULTS

$\begin{array}{ll}5.1 \text { Introduction } & 67\end{array}$

5.2 Framework for measuring learning outcomes of CDM projects 67

5.3 Patterns in technological learning in CDM projects 69

$\begin{array}{ll}5.4 \text { Differences across technology groups } & 72\end{array}$

$\begin{array}{ll}5.5 \text { Cross country differences } & 74\end{array}$

5.6 Project host companies characteristics and technological learning $\quad 75$

5.7 Involvement of project hosts and technology provider in CDM

\begin{tabular}{lr}
5.8 Summary & 82 \\
\hline
\end{tabular}

CHAPTER 6. ABSORPTIVE CAPACITY AND TECHNOLOGICAL LEARNING IN CDM PROJECTS $\quad 85$

$\begin{array}{ll}6.1 \text { Introduction } & 85\end{array}$

6.2 Theory and hypotheses $\quad 87$

6.2.1 The role of absorptive capacity in technological learning 87

6.2.2 Hypotheses $\quad 89$

6.3 Methods 94

$\begin{array}{ll}\text { 6.3.1Data } & 94\end{array}$

$\begin{array}{ll}\text { 6.3.2 Definition of variables } & 94\end{array}$

6.3.3 Regression model $\quad 99$

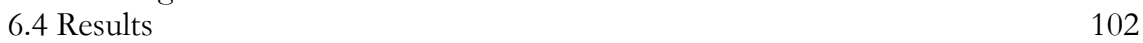

$\begin{array}{ll}6.5 \text { Discussion } & 105\end{array}$

$\begin{array}{ll}\text { 6.6 Conclusion and implications } & 108\end{array}$

CHAPTER 7. LEARNING BY DOING AND LEARNING THROUGH
INTERACTION IN CDM PROJECTS

$\begin{array}{ll}7.1 \text { Introduction } & 111\end{array}$

7.2 Theory and hypotheses $\quad 112$

7.2.1 Learning modes in CDM projects: analytical framework 112

$\begin{array}{ll}\text { 7.2.2 Hypotheses } & 114\end{array}$

$\begin{array}{ll}7.3 \text { Methods } & 121\end{array}$

$\begin{array}{ll}\text { 7.3.1 Data } & 121\end{array}$

7.3.2 Definition of variables 121

$\begin{array}{ll}\text { 7.3.2 Regression model } & 126\end{array}$

$\begin{array}{ll}7.4 \text { Results } & 131\end{array}$

$\begin{array}{ll}7.5 \text { Discussion } & 133\end{array}$

$\begin{array}{ll}\text { 7.6 Conclusions and implications } & 136\end{array}$

$\begin{array}{lr}\text { CHAPTER 8. CONCLUSIONS AND IMPLICATIONS } & 139\end{array}$

$\begin{array}{ll}8.1 \text { Introduction } & 139\end{array}$ 
$\begin{array}{ll}\text { 8.2 Major findings } & 140\end{array}$

8.3 Contributions and Implications $\quad 144$

$\begin{array}{ll}\text { 8.3 Limitations and future research } & 146\end{array}$

APPENDIX A Distribution of CDM projects across countries and

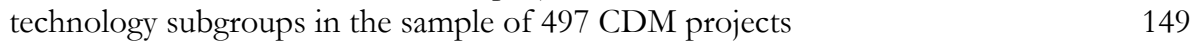

APPENDIX B Statistics of technology origin in CDM projects 151

APPENDIX C Survey Questionnaire 152

APPENDIX D COMTRADE Export data: Code Description 160

APPENDIX E Patent data: USPTO 161

$\begin{array}{ll}\text { REFERENCES } & 162\end{array}$

$\begin{array}{ll}\text { SUMMARY OF THE DISSERTAION } & 175\end{array}$

$\begin{array}{ll}\text { SAMENVATTING (SUMMARY IN DUTCH) } & 179\end{array}$

$\begin{array}{ll}\text { CURRICUlum VitAE } & 183\end{array}$

\section{LIST OF TABLES}

CHAPTER 2

Table 2.1: Response comparison across countries and technology groups 23

Table 2.2 Response rate across countries and technology groups 24

Table 2.3: Geographic distribution of sample and response rate in each country group 25

Table 2.4: Distribution of sample across technology groups 25

Table 2.5: National economic and energy data and data sources $\quad 27$

Table 2.6: Patents and publication data and their sources 28

\section{CHAPTER 3}

Table 3.1: Categories of technologies used in CDM projects 33

Table 3.2: Technology sourcing across technology groups 37

Table 3.3: Countries of technology origin and number of projects in
which technology was used

CHAPTER 4

Table 4.1: Indicators proposed to measure the knowledge base specific to

CDM technologies

Table 4.3: Correlation matrix of variables

Table 4.6: Effect of independent variables on the choice between different technology origins 


\section{CHAPTER 5}

Table 5.1: Technological Capabilities taxonomy applied in the research

Table 5.2: T-test results comparing differences among Basic, Intermediate and Advanced TC groups

Table 5.3: TC building progress estimates for each technology group

Table 5.4: CDM related technological learning: Country level estimates

Table 5.5: Characteristics of CDM project host companies

Table 5.6: TC building in companies with and without experience in technology

Table 5.7: TC building estimates for each group of organizations with

different ownership status

70

73

74

76

78

79

CHAPTER 6

Table 6.1: Measurements of absorptive capacity components and references

Table 6.2: Distribution of project host companies according to size

Table 6.3: Distribution of CDM project host companies according to their ownership status

Table 6.4: Quality of policies relevant to CDM (based on evaluation of respondents)

Table 6.5: Definition of variables and summary statistics

Table 6.6: Correlation matrix of variables

\section{CHAPTER 7}

Table 7.1 Explanation on deriving Interaction variable for each activity

Table 7.2: Measurements of independent variables and references

Table 7.3: Definition of variables and summary statistics

Table 7.4: Correlation matrix of variables

Table 7.5: Results of OLS regression

\section{LIST OF FIGURES}

\section{CHAPTER 1}

Figure 1.2 Structure of the dissertation

\section{CHAPTER 2}

Figure 2.1 Data sources and application in chapters

\section{CHAPTER 3}

Figure 3.1 Geographical distribution of CDM projects sample

Figure 3.2 Distribution of small and large scale projects across technology types

Figure 3.3.Technology sourcing in CDM projects: aggregated statistics 36

Figure 3.4 Technology sourcing in small and large scale projects 


\section{CHAPTER 5}

Figure 5.1 A progress in technological capabilities as reported by survey respondents: mean values and standard deviations

Figure 5.2 Impact of CDM experience on technological capabilities: counts of cases in each score group

Figure 5.3 TC building differences in younger and older companies

Figure 5.5 Involvement of CDM project host companies in various stages of project realisation

Figure 5.6 Involvement of technology providers in various stages of project realisation

\section{LIST OF ABBREVIATIONS}

\begin{tabular}{|c|c|}
\hline $\mathrm{ArCo}$ & Archibugi and Coco index \\
\hline $\mathrm{CDM}$ & clean development mechanism \\
\hline CER & certified emission reduction \\
\hline CFCs & chlorofluorocarbons \\
\hline CFT & climate friendly technologies \\
\hline $\mathrm{CH}_{4}$ & methane \\
\hline $\mathrm{CO}_{2}$ & carbon dioxide \\
\hline COMTRADE & Commodity Trade Statistics Database of the United Nations \\
\hline $\mathrm{EE}$ & energy efficiency \\
\hline EIA & Energy Information Administration \\
\hline EU & European Union \\
\hline FDI & foreign direct investment \\
\hline GDP & gross domestic product \\
\hline GHG & greenhouse gases \\
\hline HFC & hydrofluorocarbon \\
\hline НPP & hydropower plant \\
\hline HS & Harmonized Commodity Description and Coding System \\
\hline IEA & International Energy Agency \\
\hline IPCC & Intergovernmental Panel on Climate Change \\
\hline ISI WoS & Institute for Scientific Information, Web of Science \\
\hline JI & Joint Implementation \\
\hline $\mathrm{N}_{2} \mathrm{O}$ & nitrous oxide \\
\hline NGO & Non-governmental organisation \\
\hline OECD & Organisation for Economic Co-operation and Development \\
\hline OLS & ordinary least squares \\
\hline PDD & $(\mathrm{CDM})$ project design document \\
\hline PFCs & perfluorcarbons \\
\hline REN21 & Renewable Energy Policy Network for the 21st Century \\
\hline SCI-E & Science Citation Index Expanded \\
\hline $\mathrm{SF}_{6}$ & sulphur hexafluoride \\
\hline $\mathrm{TC}$ & technological capability \\
\hline TERI & Tata Energy Research Institute \\
\hline
\end{tabular}




$\begin{array}{ll}\text { TPES } & \text { total primary energy supply } \\ \text { UN } & \text { United Nations } \\ \text { UNDP } & \text { United Nations Development Program } \\ \text { UNEP } & \text { United Nations Environmental Program } \\ \text { UNESCO } & \text { United Nations Educational, Scientific and Cultural } \\ & \text { Organization } \\ \text { UNFCCC } & \text { United Nation Framework Convention on Climate Change } \\ \text { UNU-MERIT } & \text { United Nations University - Maastricht Economic and social } \\ & \begin{array}{l}\text { Research and training centre on Innovation and Technology } \\ \text { USPTO }\end{array} \\ \text { United States Patent and Trademark Office } \\ \text { WDI } & \text { World development indicator }\end{array}$




\section{PART I. INTRODUCTION AND RESEARCH DESIGN}

\section{CHAPTER 1. INTRODUCTION}

\subsection{Introduction}

In the first decade of the new millennium, the debates regarding the threat and humanmade nature of climate change reached a general consensus (IPCC, 2007). The current focus of the global political discussion is on further industrialization and economic growth and impact of these processes on global warming. While the most economically advanced countries are held responsible for triggering global climate change, international economics forecasts points at the growing share of developing countries in energy consumption and associated carbon emission in the next several decades (IEA, 2007; EC, 2008). Therefore the talks preceding Copenhagen 2009 Conference of Parties of the United Nations Framework Convention on Climate Change (UNFCCC) have been increasingly focusing on designating an active role to developing countries in the following decades. This would require immense efforts in directing them towards a more climate friendly growth trajectory by stimulating adoption and diffusion of cleaner technologies.

This dissertation is an effort to shed more light on perspectives related to developing countries under the climate change mitigation agenda with particular focus on their sustainable and technological development opportunities. Current international climate change mitigation activities are institutionalized under the Kyoto Protocol of UNFCCC, which introduced the largest international emission trading scheme. Central in this research is Clean Development Mechanism (CDM), one of the mechanisms of the Kyoto Protocol facilitating the generation of tradable emission credits by implementing carbon emission cutting projects in developing countries. In addition to the primary goal of reducing greenhouse gases (GHG), CDM is also expected to simultaneously assist developing countries in achieving sustainable development. In this respect, along with other socio-economic benefits, CDM projects are believed to promote the transfer of modern GHG abatement technologies to developing countries (UN, 2003; Forsyth, 2003). Despite being frequently claimed, the potential of technology transfer via CDM projects has been under-investigated in the academic research (Hansen 2008). One of the reasons being the fact that CDM is a recent initiative $^{1}$ and those CDM projects that have been put into operation have a rather short history. Yet assessment of their technological impact is an emerging issue in the development agenda. 
Our research aims to address this issue by studying the technology-sustainable development prospect of the CDM, with particular focus on technological learning and capability building. Central in our approach is the argument that technology cannot be transferred easily and costless among countries, and more important, a successful technology adoption requires recipients to have capabilities to assess the need, select, import, assimilate, adapt, and develop the appropriate technologies (Aslam, 2001). Moreover, sustainability of the technological development is ensured only if these capabilities are in place.

In addressing the issues of technological development related to CDM, we have to consider the complexity of the issue; therefore to avoid a one-sided perspective we study it from macro and micro level angles. The macro view allows assessing the climate change mitigation relevant technological knowledge available in the developing countries, which is important in order to understand the country specific conditions in which CDM initiatives emerge, as well as to understand the role of technological knowledge in a CDM framework. The micro level perspective is helpful in understanding the impact of CDM projects on knowledge and expertise building, in context of organizations and companies dealing with these projects. Targeting to study very specific outcomes on the level of concrete companies is an advantage of micro level approach. In the end, it is the companies that are the final users of technology, who channel the final environmental, social, and economic impact of it in society.

This chapter provides the introductory information about the study object, discusses concepts applied, and presents research design. The following section briefly informs the reader about CDM projects. Section 1.3 discusses the technological solutions to climate change problem and highlights technology transfer, learning and capability building in the perspective of CDM projects. Section 1.4 presents the analytical framework and research questions leading the study. The last section presents the outline of the thesis.

\subsection{Study object and background of the research issue}

\subsubsection{What is CDM?}

Before plunging into discussion of the research framework of the thesis it would be helpful to provide some background information about CDM projects. This will help the reader to understand better the phenomena that are the centre of our research. $\mathrm{CDM}$ is one of the three emission trading mechanisms of the Kyoto Protocol, others being Joint Implementation and International Emission trading scheme. The CDM is a project based mechanism, allowing entities from countries with carbon emission

\footnotetext{
${ }^{1}$ Except for few pilot projects, the dominating majority of the CDM projects have been registered after
} 
reduction targets (also called Annex I Parties) to implement projects that reduce emissions in countries with no emission reduction liabilities. The resulting certified emission reductions (CER's), also known as carbon credits, can then be used by the Annex I Party to meet its emission reduction target. CDM projects must be approved by all parties involved, lead to sustainable development in the host countries, and result in real, measurable and long-term benefits in terms of climate change mitigation (UNFCCC 1997). Obtaining CDM status for a project is a rather long and bureaucratic process requiring multi-steps validation and approval by the special national authority, auditing agency, and CDM Executive board at the UNFCCC office. Only after the project is operational, the auditing agency produces a verification report and certifies the amount of CER's generated by the project. Only after that CER become a tradable commodity (UNEP, 2004).

Large varieties of technologies are used in CDM projects. Some of them are end of pipe emission cutting technologies (e.g. waste methane capture, destruction of hydrofluorocarbons in industries), others involve process efficiency improvement that directly or indirectly cut GHG emission (e.g. energy saving, combined heat and power generation). A greater part of the CDM project portfolio is represented by clean energy generation projects. Box 1.1 presents the categories and brief description of technologies used in CDM projects.

\section{Box 1.1 Technologies and sectors in which CDM projects are implemented.}

\begin{tabular}{|c|c|}
\hline $\begin{array}{l}\text { End-use energy } \\
\text { efficiency improvements }\end{array}$ & $\begin{array}{l}\text { initiatives on improving energy consumption at the industrial facilities, } \\
\text { transport and service sectors and households. }\end{array}$ \\
\hline $\begin{array}{l}\text { Supply-side energy } \\
\text { efficiency improvement }\end{array}$ & $\begin{array}{l}\text { reduction of energy losses, introduction of the combined heat and power } \\
\text { generation, improvement of production cycle at power plants }\end{array}$ \\
\hline $\begin{array}{r}\text { Renewable energy } \\
\text { projects }\end{array}$ & solar, wind, small-scale hydropower, geothermal, biomass energy generation \\
\hline Fuel switching & $\begin{array}{l}\text { substituting carbon intensive fuels with less carbon intensive one (e.g. from } \\
\text { coal to natural gas); or switching from fossil fuels to biofuels (wood chips, } \\
\text { bioethanol, etc.). }\end{array}$ \\
\hline Agriculture/biogas & $\begin{array}{l}\text { reduction of } \mathrm{CH}_{4} \text { and } \mathrm{N}_{2} \mathrm{O} \text { emissions generated during decomposition of } \\
\text { agricultural waste. }\end{array}$ \\
\hline Waste management & $\begin{array}{l}\text { capturing and destruction of methane emissions released in landfills. In } \\
\text { some projects captured methane is used for further electricity and heat } \\
\text { generation. }\end{array}$ \\
\hline Industrial processes & $\begin{array}{l}\text { e.g. reduction of } \mathrm{CO}_{2} \text { in clinker process of cement industry, reduction or } \\
\text { destruction of } \mathrm{HFCs}, \mathrm{PFCs}, \mathrm{SF}_{6} \text { in chemical and other industries. }\end{array}$ \\
\hline Sinks projects & afforestation and reforestation initiatives. \\
\hline
\end{tabular}

Source: based on UNEP, 2004

Kyoto Protocol entered into force in February 2005. 
While some of these technologies have been used in a number of developing countries (e.g. hydropower, biomass-to-energy), the majority of technologies is rather new in the developing world. Like many environmental technologies most of GHG cutting technologies need special stimulus in the form of regulatory instruments in order to be deployed and CDM has been seen as a new instrument that will use market incentives to promote transfer of these technologies to developing countries (Wilkins, 2002; Metz et al., 2000).

\subsubsection{CDM and technology transfer in climate change mitigation}

The beginning of the industrial revolution and the introduction of a large number of new technologies is considered to be a major cause of the emission, and the accumulation in the atmosphere, of greenhouse gases (Trindade, 1994). However, with the recognition of the climate change problems nowadays, there is again a big hope for new technologies in helping humanity to address these problems (Thorn, 2008). Different countries' capacities to respond to climate change, vary greatly. In this respect developing countries, and among them also the least developed countries, need special attention. While industrial countries have the knowledge and the financial resources necessary to better respond to these challenges, most of the countries in the world are small developing countries, which have limited capacity to take initiatives and require assistance in moving towards a sustainable development path (Metz et al, 2000). Achieving global scale sustainable development will require radical technological and related changes in both developed and developing countries. Economic growth is most rapid in developing countries, but it will not be sustainable if these countries simply follow the historic polluting trends of industrialized countries. To avoid bad past practices and move more rapidly towards better technologies, techniques, and associated institutions, it is urged that developing countries get assistance in developing human capacity including knowledge, techniques, management skills, developing appropriate institutions and networks, and with acquiring and adapting specific technologies (Metz et al, 2000). Moreover, current state of knowledge in more efficient and environmental sound technologies is argued to be able to provide opportunities for ecological leapfrogging for developing countries (Goldemberg, 1998).

The transfer of environmentally sound technologies from the countries and companies that developed them, to other countries and entities that could put them to good use in reducing GHG's, has been an important theme in international deliberations leading to the UNFCCC. Article 4.5 of the convention states:

'The developed country Parties ... shall take all practical steps to promote, facilitate and finance, as appropriate, the transfer of, or access to, environmentally sound technologies and know-how to other Parties, particularly developing country Parties, to enable them to implement the provisions of the Convention. In this process, the 
developed country Parties shall support the development and enhancement of endogenous capacities and technologies of developing country Parties. Other Parties and organizations in a position to do so may also assist in facilitating the transfer of such technologies' (UNFCCC, 1992:5).

The Kyoto Protocol of the UNFCCC reinforces the provision of the convention regarding technology transfer and cooperation in general, and more specifically, under its flexibility mechanisms. Furthermore, the Marrakech accords, accounting for the detailed modalities and procedures of the CDM, state:

'...the CDM projects activities should lead to the transfer of environmentally safe and sound technologies and know-how in addition to that required under the Kyoto Protocol...' (UNFCCC, 2002:20)

Achieving the ultimate objective of the Convention requires technological innovation and the rapid and widespread transfer and implementation of environmentally sound technologies, both for mitigating the effects of greenhouse gas emissions and for adapting to climate change. Technology development and transfer is more than the installation of hardware, but also covers the software, in other words knowledge, to make technology work. (UNFCCC, 2003). In the language of the UNFCCC transferring experience, knowledge, skills, and practices is defined as capacity-building.

The report of the International Panel on Climate Change (IPCC) suggests their interpretation of the term 'technology' as encompassing hard and soft technologies (IPCC, 1996). The given examples of soft technologies are capacity building, information networks, training and research, while examples of hard technologies included equipment and products to control, reduce or prevent anthropogenic emissions of greenhouse gases in the energy, transportation, forestry, agriculture, industry and waste management sectors, to enhance removals by sinks and to facilitate adaptation (Metz et al, 2000). Furthermore IPCC (1996) defines "technology transfer" as the broad set of processes covering the flows of knowledge, experience, and equipment amongst different stakeholders such as governments, private sector entities, financial institutions, NGO's and research/educational institutions. The broad and inclusive term "transfer" encompasses diffusion of technologies and technology cooperation across and within countries. It comprises the process of learning to understand, utilise and replicate the technology, including the capacity to choose it and adapt it to local conditions.

Earlier academic discussions on the transfer of climate friendly technologies had reflected debates focusing on legal, institutional, and financial arrangements governing developing countries' access to the technologies developed in the developed states. These discussions put upfront the issues related to the type of needs of a developing country, the requirements of appropriate or better technologies to meet those needs; the available expertise, i.e., the capacity building needed to ensure effective transfer; the 
factors affecting adoption, assimilation, and adaptation of imported technology (Kathuria, 2002; Aslam, 2001; Metz et al, 2000). It is often argued that developing countries face the difficulty of matching their needs with appropriate technological solutions that reduce GHG emissions. In early critiques of technology transfer, the developing countries focused mostly on reducing the high costs of technology transactions and the many restrictive clauses imposed by the suppliers. Lately, focus has shifted from the costs and characteristics of imported technologies to include the factors affecting the creation and maintenance of technological capabilities in the developing countries. Thus we face a growing recognition that the ultimate goal of any action in the field of transfer of environmentally sound technologies should be not only to apply particular technological solutions but also to enhance the capabilities of developing countries to assess the need, select, import, assimilate, adapt, and develop the appropriate technologies (Aslam, 2001; Kathuria, 2002; Van der Gaast et al, 2008). This is clearly a matter of learning and enhancing local technological capabilities rather than pursuing technical actions (e.g. purchase, import) related to specific environmental technologies. This perspective of technological learning as a crucial component of technology transfer is a foundation of the research framework of our thesis and we discuss it in details in the section below.

\subsection{Analytical framework and research questions}

Although technology transfer is not among the rigid requirement of the CDM project, it is seen as an important element contributing to the sustainable development goal of CDM. As in the case with foreign direct investments it is presumed that CDM can be an important channel through which the transfer of climate friendly technologies and diffusion will take place in developing countries (Carraro, 1999; Grubb et al., 1999; Jepma and Van der Gaast, 1999; Oberthur et al., 1999). Understanding the technology transfer requires understanding of technology's nature and characteristics. Two distinct concepts of technology have evolved over time. The first one treats technology in a simplified and narrow manner. It regards technology as a freely available (public) good, in forms of operating manuals or blue prints, and the transfer of it is a matter of 'picking up from a shelf and starting applying it. The second and the more current concept of technology carries endogenous perspective and views technology as a knowledge possessed by individuals, firms, or organizations and has strong tacit elements that cannot be explicitly expressed or coded (Rosenberg, 1982; Ernst et al, 1998; Kranzberg, 1986). This knowledge accumulates through experience including production, design, investment, improvement, etc. Thus, the broad view of technology means not only machines and equipment, but also the skills, abilities, knowledge, systems and processes necessary to make things happen. Furthermore, technologies are meant to be composite systems that include know-how, procedures, goods and 
services, as well as organizational and operational measures. Transferring technologies would require transfer of this system, which would take place only if all its components are acquired, which can take place only through the process of learning.

Technology transfer and technological learning aspects have been predominantly addressed in various industrial sectors in developing and developed countries (Westphal et al. 1985; Ernst et al. 1998; Acharya, 1999; Kim, 2004; Katz et al, 1987; Sercovich, 1987) and to some extent this issues have been investigated in case of environmental technologies (Mytelka, 2007; Clark, and Paolucci, 1997; Parto et al, 2007; Chudnovsky and Lopez, 2007). Despite recognition of the importance of technologies and knowledge, technological learning and capability building in climate change mitigation, technology transfer and especially technological learning has not been addressed to an adequate degree. Existing empirical studies on technology transfer in CDM are mostly focused on evidences of hardware transfer and reported training component (e.g. Haites et al, 2006) De Conninck et al, 2007; Seres, 2008; Puyeo Velasco, 2007; Dechezlepretre et al, 2008). To the best of our knowledge, except for one case study of Malaysian projects (by Hansen, 2008) there is otherwise a large gap in CDM literature covering technology transfer and learning issues. Considering high expectation and promises of technology, knowledge and expertise transfer, the attempts of studying these issues have been regrettably few. While vast data and information is available on achieved emission reduction and methodologies applied to estimate emission in each project, information on technology transfer is limited to simple mentioning of source and specifications. The learning process in CDM projects remains to be largely unexplained. Furthermore, the UNFCCC framework still lacks any type of system for the evaluation of the technological impact of the projects. Therefore we attempt to contribute in filling this gap, and try to explain technology transfer and technological learning in CDM projects using empirical data and methodology. The main research question guiding our research is:

How do technology transfer and learning take place in CDM projects and what are the causes and outcomes of these processes?

This research question has several components and in order to answer it we should address a number of research sub questions. First, we start with investigating trends in technology involvement in CDM projects by analysing technology sourcing patterns and investigating causes that can explain these patterns. In doing so we apply a macro level perspective by introducing country level indicators of technological knowledge in the specific field of climate friendly technologies and investigate their relevance to technology sourcing in CDM projects. Second, we study technological learning or capability building patterns in CDM projects and try to explain this through testing a number of factors. The first group of explanatory factors is related to internal characteristics of technology user organizations, particularly in their absorptive 
capacity. The second group of factors includes different modes of learning that can channel knowledge and prompt accumulation of technological capabilities of the technology recipient. In doing this analysis we will focus on studying the effect of cooperation with technology provider and endogenous effort of the technology recipient. The following sections describe research sub questions in more details.

\subsubsection{National knowledge base and technology sourcing in CDM projects: Macro level perspective}

As has been stated earlier, CDM projects involve implementation of various clean technologies that either directly cut GHG emissions in industry and agriculture or avoid these emissions by deploying carbon neutral renewable energy technologies. Availability of these technologies in different developing countries varies tremendously. The general assumption is that these technologies are new or not widely diffused in the developing world and the newest knowledge and technology are in the premises of economical advanced nations (Aslam, 2001; Forsyth, 1998; Blackman, 1999). However there are well known cases of developing countries being among leaders in certain clean technologies, for example biofuel in Brazil and wind energy in India (Lewis and Wiser, 2007; Lemos, 2007). REN21 (2008) reports that developing countries produce around $40 \%$ of the global renewable electricity capacity. Indeed, the capacities are not equally spread across developing countries; some countries are able to implement a full cycle including R\&D, manufacturing and exploitation, while others do not have even simple technology based generation. In our study we attempt to investigate this issue by analysing the current state of the technological knowledge base of developing countries in climate friendly technologies and analysing whether this knowledge base has implications for CDM based technology transfer. Thus the research question leading the analysis is:

Can local technological knowledge existing in CDM recipient country explain technology sourcing in CDM projects?

In defining the country knowledge base in climate friendly technologies we need to distinguish two types of technological knowledge. First, the knowledge associated with the production and operation of these technologies. By assessing how many of these technologies are already being deployed in and exported from the country, one can envisage how much practical knowledge exist locally. Second, the scientific knowledge associated with research and development in climate friendly technologies, which usually takes place either at companies developing these technologies, or at universities and public research labs. Both types of knowledge, practical and scientific, are building blocks of the country level knowledge base. However they might have different effects when it comes to decision-making about where to acquire technology from for a new project. Therefore the further question to be tackled is: 
What are the role of practical and scientific knowledge in this process and how these roles differ?

The first part of the thesis will be guided by the above stated research questions and explain cross country differences in technology sourcing in CDM projects. It will have a macro level perspective in terms of measuring country level knowledge and linking it with project level developments.

\subsubsection{Technological learning in CDM projects: micro level perspective}

A very important emphasis of the present research is on technological learning processes under CDM projects. It is necessary to note that the locus of learning is the $\mathrm{CDM}$ project host organization. In this regard understanding the technological learning process can largely benefit from the organizational learning literature which has provided enhanced discourse about company level knowledge acquisition processes and factors influencing them. Technology transfer is considered largely as a learning process in the literature (Gupta and Govindarajan, 2000; Cusumano and Elenkov, 1994). Learning outcomes are not immediate and depend on various internal and external conditions, characteristics of an organization, its position, efforts and objectives, its interaction with external knowledge sources, as well as the technology newness and internally available knowledge about it, and several other factors (Dahgfous, 2004). The framework applied in this study has a micro level perspective focusing on factors associated with company's ability to acquire new knowledge (absorptive capacity) and effects of learning modes like interaction and internal efforts on final learning outcomes

\section{Role of absorptive capacity in technological learning}

Knowledge resources being the major contributor to the organization's ability to assimilate new technology and knowledge are proven to be a key aspect in successful technology transfer. Many authors recognize the lack of absorptive capacity in recipient as a friction, which slows or prevents learning and technology transfer (Lin et al., 2002; Davenport and Prusak, 2000; Kim, 1997; Wong et al., 1999). Cohen and Levinthal $(1989,1990)$ who were first to introduce the concept of absorptive capacity, observed that organizations cannot benefit from external knowledge flows just by being exposed to them; instead, they must develop absorptive capacity, which authors define as the ability to recognize the value of new external knowledge, and then assimilate and utilize such knowledge for commercial ends. A firm's absorptive capacity builds on its existing stock of knowledge, much of which is embedded in its products, processes and people (Cohen and Levinthal, 1989), and it has become a key driver of a firm's competitive advantage because of the increased importance in the context of external knowledge sourcing (Cockburn and Henderson, 1998; Zahra and George, 2002; Escribano et al. 
2009). Generally the positive influence of absorptive capacity on technological learning outcomes has been well proven in the literature. However, absorptive capacity is a complex factor, representing company's knowledge, gained through experience and training, and embedded in its employees (Cohen and Levinthal, 1990; Zahra and George, 2002; Van Den Bosch et al., 2005). It is necessary to acknowledge this multidimensional feature of absorptive capacity, therefore in studying its impact in CDM related learning we consider such dimensions as prior knowledge, human capital, and training efforts. Absorptive capacity, neither in general, nor in its singled out elements have not been addressed in the CDM context yet, assuring our contribution to filling this gap. Moreover, the independent effect of each of these dimensions has also been under-investigated in the general literature on organizational learning. Thus, in this aspect as well, we aim to make a contribution. The research question leading the analysis is formulated as follows:

How does the project host organization's absorptive capacity, -represented by its prior knowledge, buman resources and training efforts- explain technological learning dynamics resulting from CDM projects?

Important consideration here is that one should not expect the effect of absorptive capacity, or its elements on further acquisition of knowledge, to be always straightforward or, in other words, linear. Excessive internal knowledge might make arriving knowledge less valuable, because it is not new to the company (Noteboom, 1992, 1999; Mowery et. al 1996, 1998). Therefore companies with larger experience and knowledge resources might not find new CDM project related activity new, which in the end decreases learning outcomes. This diminishing effect of the higher absorptive capacity is also taken in consideration in this study.

\section{Learning modes and role of technology provider}

In further analysing the learning under the CDM project we built upon the perspective that technological learning is a combination of several modes of learning such as learning by doing, using, training, interaction (Jensen et al, 2007; Lundvall 1988). In a new project, technological knowledge and expertise is often expected to be supplied together with the hardware; thus, the role of technology providers, in the mastering of the technology and the understanding of its specificities by the recipients, is regarded as very important. Therefore, more intensive interaction with technology providers, and their more active involvement in the project activities should be beneficial in delivering more knowledge, and especially the tacit and socio-cultural components of it. Levin, (1993) argues in this regard, that a successful transfer is achieved when it bridges the gap between two parties, clarifying, for the user, the potential of the technology, 
and facilitates the supplier's ability to provide the necessary cultural skills for operating it.

On the other hand a large share of learning in organisations takes place internally through learning by doing and using; in other words, through one's own learning efforts, dealing with technology on a daily basis and tackling challenges in adjustments. The idea behind the learning by doing concept, is that knowledge is accumulated through day-to-day operation as employees face on-going changes that confront them with new problems, regardless of the extent to which the knowledge is ultimately codified (Tyre and von Hippel, 1997; Jensen et al, 2008). Finding solutions to problems enhances and extends the scope of employees skills and know-how which adds to á company's aggregate competence level. Dahlman and Westphal (1981), in their work on technology mastery, suggested that in a technology acquisition process, (disembodied) knowledge associated with the technology can be transferred, but the ability to make effective use of it cannot.. This ability develops through indigenous technological effort, leading to technological mastery. In fact, in the process of undertaking activities on product engineering, project execution, and capital goods manufacturing, those carrying them out often find themselves involved in the solution of technical problems not previously encountered, which becomes an exercise of technological effort leading to a higher level of technology mastery (Dahlman and Westphal, 1981).

In analysing learning by the CDM project host company we consider that learning by doing is represented by the overall active involvement of this company in the project and accumulation knowledge from own experience, problems solving, etc., while learning through interaction and training is built around cooperation with the technology provider throughout project stages and is more about knowledge sourced from the technology provider. The research question addressed in this regard is:

What are the roles of interaction with technology providers and own efforts in technological learning by the CDM project host organizations?

Thus in our study we attempt to investigate if any of these modes play a prevailing role in technological learning under CDM project.

\subsection{Contribution of the study}

This dissertation contributes to the literature in a number of ways. First of all, it is obviously input to the literature addressing technological development in CDM projects. A major part of the CDM related academic studies deal with environmental, economical, political and methodological aspects of this instrument. There are a 
growing number of studies devoted to the linkage between CDM and sustainable development in developing countries ${ }^{2}$. Among them is the group of studies addressing various aspects of technology transfer under CDM. For example, a number of papers looked into dimensions such as technology needs, technology selection and subsequent profit performance, and domestic policy frameworks (Kaneko, et al., 2006; TERI, 1997; Forsyth, 1998) or comprise the analysis of technology transfer promotion programs implemented within the framework of international and domestic climate change initiatives (Aslam, 2001; Kline et al., 2004). There is a distinct group of studies by Haites et al, (2006) De Conninck et al, (2007); Seres, 2008; Puyeo Velasco, 2007; Dechezlepretre et al, 2008 which are primarily based on analysing statistics of technology transfer claims made in the official CDM project design documents. However, despite the coverage of technology transfer issues and recognition of importance of various capabilities for successful transfer, there have been very limited attempts to investigate the impact of CDM projects in terms of technological learning by recipient countries. Study by Hansen (2008) so far, is the only research with a specific focus on technological learning capability building and spillovers from CDM project based on in-depth investigation of a few Malaysian firms implementing biomass to energy projects. However this study is narrow in its geographical and technology sector coverage and may be representative only for this narrow case of projects.

Thus it is clear that the existing literature on CDM and technology transfer, lack a more rigorous focus on technological learning and capability building, as well as on the role of technological knowledge. This dissertation contributes to filling this gap not only by applying concepts of technology transfer, but also by studying technological capability building, which is widely used in the context of developing countries. It is also novel in terms of introducing the concepts from organizational learning theories, and in this way it enriches the CDM related literature conceptually and methodologically, Our research also contributes to the $\mathrm{CDM}$ literature by applying unique and more comprehensive data collected through the survey of CDM project hosting companies. The data collected through survey contains information that is not otherwise available in the project design documents. This allowed us to study factors barely addressed in CDM literature previously, this includes company level characteristics and their interaction with technology providers (Chapters 6 and 7). On the other hand, by applying these data in the explicit case of CDM projects, it contributes to the empirical literature on organizational learning, technology transfer, and knowledge bases.

Within the discourse of relevant studies investigating patterns of technology transfer and determinants of it, our study stands out by presenting a new group of factors explaining technology sourcing in CDM projects (Chapter 4). This study showed clear

\footnotetext{
2 Olson (2007) presented a comprehensive literature review on CDM's contribution to sustainable development
} 
indications of a methodological contribution in measuring the knowledge base of countries in the specific niche of climate friendly technologies. Results of the study demonstrated that the knowledge base indicators proposed by us could be used to explain to a certain extent the technology transfer patterns in CDM projects.

\subsection{Thesis outline}

The body of this dissertation consists of three parts, the first being an introductory, the second and third being empirical parts, each focusing on different levels of analysis. Figure 1.2 provides an overview of the thesis structure. Part one consists of Chapter 1 and 2. Chapter 1 presents the background for present research, the analytical framework, and the research questions. Chapter 2 introduces sources of data used in the research founding this dissertation, describes the ways the data were collected, and checks the representativeness of the survey sample.

Part two of the dissertation, consisting of Chapters 3 and 4, presents a macro level view on interplay between the country-level knowledge base and technology sourcing in CDM projects. Analyses in these chapters are of an exploratory nature. They are based on the data from 497 projects implemented in 42 developing countries, collected through careful revision of project documents merged with country level data. The collected data show an interesting trend in technology sourcing: despite an extensively highlighted north-south technology transfer potential, the majority of CDM projects appear to rely on domestic technology sources. In chapter 4 we introduce the country knowledge base indicators for measuring scientific and applied knowledge existing in the CDM recipient countries and investigate their relevance to the CDM case.

Part three including Chapters 5, 6 and 7, presents a micro level view on technological learning / capability building taking place through CDM projects. The focus here is on CDM project host companies. The analysis is based on data collected through a survey of $104 \mathrm{CDM}$ project host companies. Chapter 5 describes the data collected through survey, and analyses technological learning patterns and trends at the aggregated and disaggregated levels. Chapters 6 and 7 follow the purpose to explain technological learning performance of project host companies. These chapters benefit extensively from the organizational learning literature which has proven to be a very enriching complement to international technology transfer literature. Chapter 6 investigates how the project host organization's absorptive capacity can explain technological learning dynamics resulting from a CDM project experience. Because absorptive capacity of a company is a complex multidimensional phenomenon, we attempt to capture some elements of it, namely company's prior knowledge in technology applied in CDM projects, human resources, and training efforts leading to building the internal knowledge of organizations. In addition, we consider factors, such as characteristics of 
a technology acquirer organization that may determine learning outcomes. We also investigate the exogenous effect of institutional factors working as an enabling environment for building organizational absorptive capacity and technological learning as an end result. In Chapter 7 we propose a more inclusive analytical framework for studying technological learning in CDM projects by considering also factors associated with technology providers. One set of issues addressed in the chapter concerns technology providers' characteristics and their involvement in the project. Another set of factors is associated with technology recipient's active position in initiation and implementation of the project in overcoming challenges in technology acquisition and assimilation. The analytical framework in this chapter captures two perspective of learning or technological capability building: first "learning through interaction" with technology provider and second "learning by doing" the project and adopting the technology.

Chapter 8 presents the conclusions and discusses major findings of this thesis and provides an answer to our overall research question. In addition, this chapter will state the limitations of our study and offer some suggestions for future research. 
Figure 1.2 Structure of the dissertation

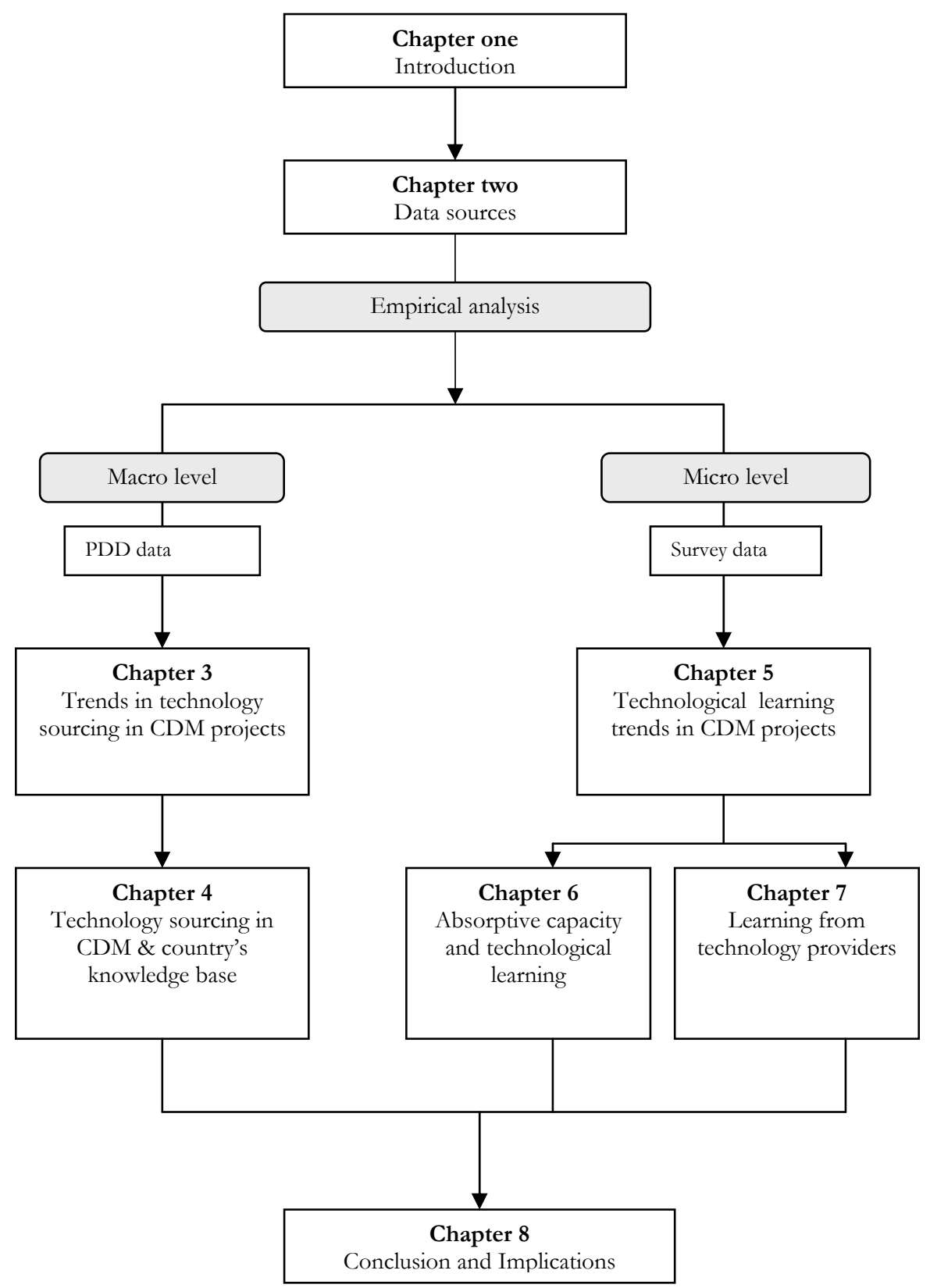





\section{Chapter 2. Data sources}

\subsection{Introduction}

The data collection methodology of this thesis employed three main sources: (1) CDM project documentations, (2) survey of CDM host companies, and (3) country statistics including economic and science and technology indicators. Furthermore, additional information and insights were obtained from a number of meetings and interviews with local and international experts and participants of CDM projects. This chapter describes each of the data sources and data collection processes. The chart below indicates the data sources and in which chapter of the thesis these data were used.

Figure 2.1 Data sources and application in chapters

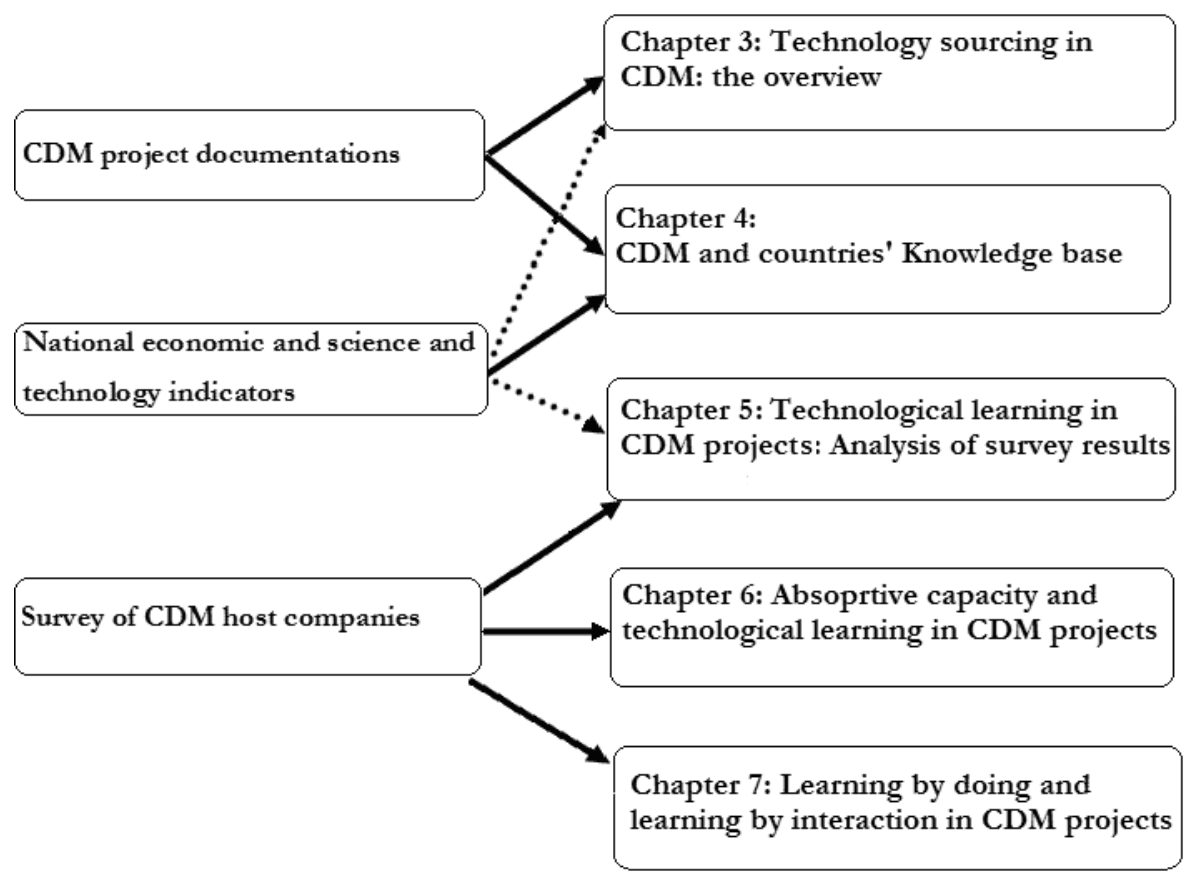

The chapter is organized as follows. The section following this one describes the procedures of building the dataset based on CDM project documents and provides brief overview of this database. Section 2.3 describes the survey related procedure, including questionnaire design, survey process and non-response analysis. Description of sources for country-level data on economic and science and technology indicators is 
provided in section 2.4. The last section provides information about formal and informal interviews and discussions that were undertaken during the research project.

\subsection{Building the CDM project documents database}

The purpose of creating the CDM project database was to access and organize data according to the number of aspects of technology and technology recipients for further analysis. It was furthermore necessary to explore all available information about the CDM project before designing the survey of CDM project implementers. We started reviewing available project documentation in the beginning of 2007, and the database building work took place around seven months. As we wanted to focus on projects that had already started and made progress in implementation we scrutinized documentation of projects registered up to February 2007. In is necessary to note that the majority of the projects underwent registration as early as 2005 , when the Kyoto Protocol was enforced, while a small number of projects was registered before 2005.

Secondary data sources used in this stage were (1) CDM project design documents (PDD) from the UNFCCC available on http://cdm.unfccc.int and (2) aggregated database of CDM projects of the United Nations Environmental Program (UNEP) Risoe center on Energy, Climate and Sustainable Development, which is available on http://cd4cdm.org. The first provides access to a package of project design documents for each project that has been submitted for registration; the latter is an aggregated database in Excel format containing data regarding the CDM projects such as name, location, registration status, technology employed, project size (estimated as amount of annual and total emission to be reduced), power to be generated, credit buyer(s), PDD consultants, etc. The database is updated on a monthly basis. UNEP Risoe data was useful especially as a reference database for organizing the sample and getting preliminary information. Revision of the PDD's was necessary for extracting additional information about technology and project participants. In addition, other documents from the UNFCCC office's intranet, and various Internet resources were consulted for additional information that was missing in PDD's.

One of the advantages of this work was that it allowed us to obtain direct contact details of CDM project companies (or of their partners), including the name of the project specialist, email, fax, and address. We also looked for information about the project implementing company, its name, affiliation with any project partner, organizational status (business, state, non-governmental), technology transfer claims including equipment sourcing (local, foreign, combined), initiation information, project participants, and their functional roles and responsibilities (although the availability of this information differed from project to project). However, the project documents provided only partial information about project host, other participants, and 
technology. For example, the source of technology (i.e. if it is foreign or local) was specified in $93 \%$ of PDD's, the name of the country of origin only in $86 \%$, and the name(s) of technology provider companies were mentioned for only about half of the cases. Searching internet and other documents, such as monitoring reports, stakeholders' meetings notes helped to fill these gaps to a limited extent.

As a result of this work we were able to build a database containing information about 497 projects located in 41 countries and covering various renewable energy generation technologies, industrial emissions reduction through energy efficiency measures, emission capture and destruction, and waste management technologies based on capture and utilization of biogas. However, for the econometric analysis in Chapter 4 we had to exclude 37 observations, constituting projects in five countries, due to missing data on technology sourcing and/or country-level data. The list of the projects and the data that have been used in the analysis is presented in Appendix A. Data about technology origin by country are given in Appendix B. Detailed descriptive statistics, technology source and provider-related analyses are presented in Chapter 3.

\subsection{Data collection through survey}

Analysing micro-level impact of the CDM projects in terms of technological learning, of understanding the importance of characteristics of project recipients and of the role of technology providers required us to collect specific information and data that are not available in project design documents and any other sources. We designed a survey that aimed at obtaining these data and information directly from companies and organizations involved in CDM project implementation. Due to technical, time and resource limitations it was decided to run surveys in four countries: Brazil, China, India and Mexico, which altogether host over $70 \%$ of all CDM projects implemented worldwide.

\subsubsection{Survey preparation}

The survey preparation process involved a number of activities including design of the questionnaire, consulting with experts, choosing a method of questionnaire distribution, preparation of the address list, testing questionnaire in pilot survey stage, after test improvement, surveying, and activities for increasing the response rate. The whole survey related activities lasted for ten months (November 2007-August 2008). In the first three months we developed the first draft of the questionnaire. Following the methodology suggested in Dillman (2007) we consulted with on-site experts who are directly involved in CDM projects or deal with CDM related capacity building work or 
consultancy ${ }^{3}$. Suggestions and comments of experts were incorporated into the questionnaire.

Due to the international scope of the CDM hosts the original English version of the questionnaire had to be translated into Spanish, Portuguese and Chinese. All four language versions of the questionnaire were programmed for online use and placed on the server of UNU-MERIT. Unique ID's and passwords were created for each respondent. The online survey mechanism was programmed in such a way that every entry would be automatically transferred to a single data sheet.

The pilot survey covered a sample of 30 projects located in all four countries. Following the methodologies in Dillman (2007) the respondents in the pilot stage were contacted by telephone and e-mail and asked about their willingness to participate in the survey. They were also invited to give comments and to make suggestions for improvement of the questionnaire, which was taken into account in further development of the questionnaire. From the pilot survey we also came to understand that some respondents prefer to receive an electronic version of the questionnaire, rather then accessing it via the website.

Additionally the questionnaire was tested during the field visit in Armenia in April 2008, during which five CDM projects were visited. We asked representatives of each company running the project facility to fill in the paper version questionnaire and to make a note if any question was ambiguous, unclear or irrelevant. We addressed and incorporated the feedbacks of this exercise in the final version of the questionnaire.

In the actual survey process the respondents were contacted in three rounds: first by electronic letter and/or phone-call inviting them to take part in the survey; second by e-mail containing a link to the online questionnaire, a unique ID and a password and the attached Word version of the questionnaire; and third , 10 to 15 days after the second contact, we sent a reminder to the respondents who had not yet responded. In some cases back-up calls were made to increase the response rate. Because the response rate from India and Mexico was still very low we sent the paper version of the questionnaire via post service and fax, which helped to increase the response rate from these countries.

A team of colleagues from UNU-MERIT, who are native speakers of the Portuguese, Spanish and Chinese languages, helped us with translation, and in contacting respondents by phone, fax, and/or e-mail.

More detail on interviews with experts is given in section 2.5 of this chapter. 


\subsubsection{Sample selection}

In the present research the units of analysis are the CDM project host companies (also called as CDM project operators), which are independent companies, daughter companies or units in the bigger company that operate and maintain the CDM facility. From the perspective of learning and acquiring new expertise and skills the CDM facility operators are the main and direct beneficiaries. The number of personnel involved in operation of each CDM facility could range from 5-10 and up to a thousand people depending on the facility size, technology type and automation and computerization level of the technological process. The size of the personnel team often also defines the organizational / hierarchical structure of the CDM project host company. Usually there is the leader (manager/director/chief engineer) and his subordinates, such as engineers, workers, technicians, etc. This group is considered to be a human resource of the project host company and is the core recipient of the knowledge in technology transfer and acquisition processes.

Size of the sample:

In studying the learning impact of the CDM projects it is more logical to contact companies that are beyond the stage of installation, and have already started day-to-day operation of the CDM facilities. However it was difficult to define from the available information (project documents, CDM databases) what the status of the project at the moment of survey was. Since the number of projects was constantly increasing, we decided to restrict our sample to the number of projects that had been registered by February 2007. In this way we tried to approach projects that had a higher probability of being on the advanced stage of the project realization. The size of the sample was thus restricted to the population of the project host companies that had registered their CDM projects no later than Januari 2007. As was mentioned earlier the focus of the survey was on the four countries, that are involved in about $70 \%$ of all CDM projects: Brazil., China, India, and Mexico. They gave us a total of 380 projects. Given the limited population of the CDM projects and the presupposed risk in achieving a high response rate we attempted to contact all CDM project hosts in above four countries that had registered their projects before February 2007.

Examination of documentation of these 380 projects revealed several cases when two or more CDM projects were run by the same company. This fact tells us that the number of operators, our potential respondents, is less than the number of facilities. Preliminary estimates of the number of operators gave us the sample size of 361 companies with the following distribution across the four countries: 88 in Brazil, 153 in India, 48 in China, and 72 in Mexico. 


\subsubsection{Questionnaire design}

Appropriate design of the questionnaire is essential for obtaining high quality study results (Dilman, 2007). In designing the questionnaire our main guiding aspect was to reflect the research questions, the hypotheses, the variables which were intended to be operationalized for statistical analysis, and the information that was not available in the project documents. The questionnaire was constructed in such a way so that it would consist of closed questions, multiple choice answers and scoring. The questionnaire form is presented in the Appendix $\mathrm{C}$ at the end of the thesis.

The questionnaire starts with an introductory part stating the purpose of the survey, followed by a glossary of terms used in the questionnaire. Three major parts, each addressing certain aspects follow. The first part is aimed at collecting background information about each project's operator responding company. It contains questions about characteristics of the company hosting the CDM project such as the year of establishment, the number of employees and their qualifications, the ownership structure, its experience, prior to CDM, in the application and development of the technology, the number of CDM projects it is implementing, and the role of the CDM project in it overall activity ${ }^{4}$. The second part of the questionnaire was designed to acquire information about involvement of the project host in every stage of the project and about capability building in technical and organizational aspects. The respondents were asked to assess the progress on matters concerning technological capabilities related to operation of CDM technology, improvement and modification alongside the operation, and technology development and design ${ }^{5}$. A seven-points scale was used as assessment tool, "0"(zero) indicating no progress, 1-6 categories for the range between very little and very strong progress in capability building. In the same manner the respondents were asked to assess their progress in competence related to managerial practices, organizational development, cooperation with various stakeholders, and PDD design.

The third part focuses on characteristics of the technology and technology supplier(s). It contains questions regarding origin of the technology used in the project, availability of the technology prior to CDM project experience, availability of high-tech elements, technology access related issues. Technology supplier related questions address their origin and ownership status, parental links with a project's host company, age,

\footnotetext{
${ }^{4}$ The role of the CDM project in the company's overall activity can differ in the following ways: it can be a major activity of the company, in other words the company was established to operate one or several specific CDM projects; in other cases the CDM project is an additional (nonmajor) activity for a company, it is aimed rather at cutting greenhouse gas emissions in its production process or in a certain part of it (e.g. in coal power plants, other industries, animal farms)

${ }^{5}$ Taxonomy of technological capabilities assessed in the survey is presented in Table 5.1 in Chapter 5
} 
experience in developing countries and with other CDM projects and involvement in each stage of the project cycle. The concluding section of the questionnaire asks if research organizations were involved in any stage of the project and asks to assess the domestic policies related to $\mathrm{CDM}$ and renewable energy promotion, education, the incentives for foreign companies to be involved in CDM, and the increasing awareness of state and private actors about CDM.

\subsubsection{Representativeness of the sample}

The survey covered 361 project host companies in Brazil, China, India and Mexico. Excluding the not-responded questionnaires and the ones that had incomplete answers, we acquired a final dataset containing 104 observations, representing a 28.8\% response rate.

Table 2.1 and Table 2.2 present the cross country and cross project distribution of the surveyed companies and their respective response rates. Response received from Brazil is in comparison noticeably more than from India, China or Mexico. This was due to the help of a company that offers expertise to various agricultural companies in Brazil, in a large number of biogas projects. They ensured us a high response for their projects (sixteen) that were part of our initial sample.

Since we have the varied response rates across countries and technology groups we need to highlight the issue of representativeness of the sample before we go on with any statistical analysis. Representativeness expresses the degree to which sample data accurately represent the characteristics of the initial sample. Any survey data collection with a response rate less than 85 percent is strongly recommended to be evaluated for the potential magnitude of non-response bias before the data or any analysis using the data is released (Werner et al, 2007).

Table 2.1: Response comparison across countries and technology groups

\begin{tabular}{|c|c|c|c|c|c|c|c|c|}
\hline country & \multicolumn{2}{|c|}{ Brazil } & \multicolumn{2}{c|}{ China } & \multicolumn{2}{|c|}{ India } & \multicolumn{2}{|c|}{ Mexico } \\
\hline $\begin{array}{c}\text { Technology group } \\
\text { Initial } \\
\text { sample }\end{array}$ & $\begin{array}{c}\text { Respon } \\
\text { se }\end{array}$ & $\begin{array}{c}\text { Initial } \\
\text { sample }\end{array}$ & $\begin{array}{c}\text { Respon } \\
\text { se }\end{array}$ & $\begin{array}{c}\text { Initial } \\
\text { sample }\end{array}$ & $\begin{array}{c}\text { Respon } \\
\text { se }\end{array}$ & $\begin{array}{c}\text { Initial } \\
\text { sample }\end{array}$ & $\begin{array}{c}\text { Respon } \\
\text { se }\end{array}$ \\
\hline $\begin{array}{c}\text { Renewable Energy } \\
\text { generation }\end{array}$ & 50 & 13 & 35 & 9 & 92 & 26 & 4 & 2 \\
$\begin{array}{c}\text { Emission reduction in } \\
\text { industry }\end{array}$ & 7 & 3 & 10 & 2 & 54 & 8 & 0 & - \\
$\begin{array}{c}\text { Waste management } \\
\text { /methane capture }\end{array}$ & 31 & 24 & 3 & 2 & 7 & 1 & 68 & 14 \\
\hline Total & $\mathbf{8 8}$ & $\mathbf{4 0}$ & $\mathbf{4 8}$ & $\mathbf{1 3}$ & $\mathbf{1 5 3}$ & $\mathbf{3 5}$ & $\mathbf{7 2}$ & $\mathbf{1 6}$ \\
\hline
\end{tabular}

Source: tabulation from own survey data 
Table 2.2: Response rate across countries and technology groups

\begin{tabular}{|c|c|c|c|c|}
\hline & $\begin{array}{c}\text { Brazil } \\
\text { (percent) }\end{array}$ & $\begin{array}{c}\text { China } \\
\text { (percent) }\end{array}$ & $\begin{array}{c}\text { India } \\
\text { (percent) }\end{array}$ & $\begin{array}{c}\text { Mexico } \\
\text { (percent) }\end{array}$ \\
\cline { 1 - 4 } $\begin{array}{c}\text { Renewable Energy } \\
\text { generation }\end{array}$ & 26.00 & 25.71 & 28.26 & 50.0 \\
\cline { 1 - 1 } $\begin{array}{c}\text { Emission reduction in } \\
\text { industry }\end{array}$ & 42.86 & 20.0 & 14.81 & - \\
\cline { 1 - 1 } $\begin{array}{c}\text { Waste management } \\
\text { /methane capture }\end{array}$ & 77.42 & 66.67 & 14.29 & 20.59 \\
\cline { 1 - 4 } TOTAL & $\mathbf{4 5 . 4 5}$ & $\mathbf{2 7 . 0 8}$ & $\mathbf{2 2 . 8 8}$ & $\mathbf{2 2 . 2 2}$ \\
\hline
\end{tabular}

Source: tabulation from own survey data

In order to investigate the representativeness of the sample, we use the correlation value and Chi-test to examine whether the distribution of the collected data correlated with those originally targeted. The comparison of final sample and initial population distribution between profiles, or characteristics of samples will give an indication of whether the sample biased or not (Blaikie, 2003). Because the unit of our analysis was not the project, but the company implementing the CDM project ${ }^{6}$, we lacked very specific information about characteristics of the companies, such as size, age, ownership status, etc. in the initial population. Therefore the dimensions that we could use to check representativeness of the sample were the country where the company was located, and the technology that was applied in the project. All technologies in the sample were grouped into three groups such as renewable energy (electricity) generation technologies from hydro, wind, biomass resources; industrial emission reduction through prevention (e.g. energy efficiency measures or fuel/material substitute) or direct capture or/and destruction of greenhouse gas emissions; improvement in waste management by capturing and utilization of biogas methane in animal farms and landfills.

In Table 2.3 and 2.4 we examine whether the distribution of valid respondents of the two dimensions (country and technology group) are the same as the distribution of our original sample. The correlation values 0.6954 and 0.8939 indicate that our dataset has similar characteristics to the original sample, with stronger similarities in technology group representation and slightly less for country group, but still sufficient, for making an appropriate analysis. The results from the Chi-test also show that the dataset we collected is not significantly different from the original sample. In other words, the results of the analysis of our dataset should be trustworthy enough in explaining technological learning results of CDM projects across the countries of our focus, as well as across the given technology groups. We can therefore conclude that the working sample is quite representative of the initial population and can be used without much statistical bias for further analysis.

\footnotetext{
${ }^{6}$ Our project document related database contained more comprehensive information about characteristics of projects, but not the characteristics of companies implementing projects.
} 
Table 2.3: Geographic distribution of sample and response rate in each country group

\begin{tabular}{|c|c|c|c|c|c|}
\hline & $\begin{array}{c}\text { initial sample } \\
\text { (number) }\end{array}$ & $\begin{array}{c}\text { Percent in } \\
\text { initial sample }\end{array}$ & $\begin{array}{l}\text { Response } \\
\text { (number) }\end{array}$ & $\begin{array}{c}\text { Response rate } \\
\text { (percent) }\end{array}$ & $\begin{array}{l}\text { Percent of final } \\
\text { sample }\end{array}$ \\
\hline Brazil & 88 & 24.38 & 40 & 45.5 & 38.46 \\
\hline India & 153 & 42.38 & 35 & 22.9 & 33.65 \\
\hline China & 48 & 13.30 & 13 & 27.1 & 12.50 \\
\hline Mexico & 72 & 19.94 & 16 & 22.2 & 15.38 \\
\hline TOTAL & 361 & 100 & 104 & 28.8 & 100.00 \\
\hline $\begin{array}{l}\text { Correlation } \\
\text { P-value of } \mathrm{Cl}\end{array}$ & $\begin{array}{l}t \text { in initial ar } \\
=0.9997\end{array}$ & final samples & & & \\
\hline
\end{tabular}

Source: tabulation from own survey data

Table 2.4: Distribution of sample across technology groups

\begin{tabular}{|c|c|c|c|c|c|}
\hline & $\begin{array}{l}\text { initial sample } \\
\text { (number) }\end{array}$ & $\begin{array}{l}\text { Percent in } \\
\text { initial sample }\end{array}$ & $\begin{array}{l}\text { Response } \\
\text { (number) }\end{array}$ & $\begin{array}{l}\text { Response rate } \\
\text { (percent) }\end{array}$ & $\begin{array}{l}\text { Percent of final } \\
\text { sample }\end{array}$ \\
\hline $\begin{array}{c}\text { Renewable Energy } \\
\text { generation }\end{array}$ & \multirow[t]{2}{*}{181} & 50.14 & 50 & 26.56 & 48.08 \\
\hline $\begin{array}{c}\text { Emission reduction } \\
\text { in industry }\end{array}$ & & 19.67 & 13 & 17.61 & 12.50 \\
\hline $\begin{array}{l}\text { Waste management } \\
\text { /methane capture }\end{array}$ & 109 & 30.19 & 41 & 36.17 & 39.42 \\
\hline TOTAL & 361 & 100.00 & 104 & 27.70 & 100.00 \\
\hline $\begin{array}{l}\text { Correlation (percent in } \\
\text { P-value of Chi-test } 0.9\end{array}$ & tial and final s & aples) 0.8939 & & & \\
\hline
\end{tabular}

Source: tabulation from own survey data

\subsection{Data from other sources}

Complementary data that have been applied in the statistical analysis in Chapter 3 and 4 include macro level data of $41 \mathrm{CDM}$ projects recipient countries. These data included a number of national economic, energy, and science and technology indicators acquired from databases of various institutions. Below we describe these sources and the procedures in accessing these data. 


\subsubsection{National economic indicators}

Table 2.4. indicates the type of indicators and data we used for the analysis. Sources of the data are the online database of international agencies, to which access is open. We took the year 2005 as orientation year, as this is the year when the Kyoto Protocol and it project-based mechanisms like CDM and Joint Implementation started working. In case of export/import of data we observed large fluctuations from year to year; and we therefore used average numbers for the years 2002-2005.

The International Energy Agency (IEA) database contains data on production of energy from various energy sources for each country. We extracted the data on electricity from renewable energy sources and calculated its share in the total national energy production mix. Data on renewable energy sources is given in the following three categories that we aggregated for the analysis: (1) hydro, which includes data for large and small hydropower production, (2) grouped solar, wind, and geothermal energy, and (3) energy from combustible biomass and waste.

In order to calculate the Trade indicators for each country we made use of the UN Commodity Trade (COMTRADE) Statistics Database which contains data on annual import and export values for each country. The database uses the Harmonized Commodity Description and Coding System (HS1996) for different categories of commodities. In order to get data on export of green energy we followed (2005a, b) and consulted OECD's typologies of technologies and specifying codes for environmental technologies in various sectors. We restricted our search to codes covering the energy sector, such us energy production and saving. Appendix D has the list of technologies and respective codes we used in data export and data extraction. We then calculated the share of climate friendly technologies in the total value of exported goods. 
Table 2.5: National economic and energy data and data sources

\begin{tabular}{|c|c|c|}
\hline Indicator & Description & Data source \\
\hline Population & population in million (2005) & $\begin{array}{l}\text { World Development } \\
\text { Indicators of the World }\end{array}$ \\
\hline GDP & $\begin{array}{l}\text { Gross Domestic Product (GDP) in } \\
\text { billion USD (2005) }\end{array}$ & $\begin{array}{l}\text { Bank, } \\
\text { www.worldbank.org/data }\end{array}$ \\
\hline TPES & $\begin{array}{l}\text { Total primary energy supply of a } \\
\text { country indicates indigenous } \\
\text { production of energy +import - } \\
\text { export (in Mtoe - Megatons of oil } \\
\text { equivalent) for } 2005\end{array}$ & $\begin{array}{l}\text { available on the website of } \\
\text { the IEA } \\
\text { http://www.iea.org/Textbas } \\
\text { e/stats/index.asp }\end{array}$ \\
\hline $\begin{array}{l}\text { Renewable energy } \\
\text { share }\end{array}$ & $\begin{array}{l}\text { Percent of renewable energy in the } \\
\text { country's TPES for } 2005\end{array}$ & $\begin{array}{l}\text { Renewable energy } \\
\text { production data (in Mtoe) are } \\
\text { available on the website of } \\
\text { the IEA } \\
\text { http://www.iea.org/Textbas } \\
\text { e/stats/index.asp }\end{array}$ \\
\hline Trade & $\begin{array}{l}\text { Share (percent) of country's exports } \\
+ \text { import values in GDP (average for } \\
\text { 2002-2005) }\end{array}$ & $\begin{array}{l}\text { Export and import values (in } \\
\text { billion USD) were acquired } \\
\text { from the COMTRADE } \\
\text { Statistics Database } \\
\text { http://comtrade.un.org/db/ }\end{array}$ \\
\hline $\begin{array}{l}\text { Export share of } \\
\text { climate friendly } \\
\text { technologies }\end{array}$ & $\begin{array}{l}\text { Percent of renewable and energy } \\
\text { efficiency technologies in total value } \\
\text { of exported commodities in a } \\
\text { country (average of 2002-2005) }\end{array}$ & $\begin{array}{l}\text { Export values (in billion } \\
\text { USD) for renewable and } \\
\text { energy efficiency } \\
\text { technologies were acquired } \\
\text { from Trade Statistics } \\
\text { Database (COMTRADE) } \\
\text { http://comtrade.un.org/db/ }\end{array}$ \\
\hline
\end{tabular}

\subsubsection{Science and technology indicators}

These variables indicate the general countries' scientific effort in the field of climate friendly technologies, which is measured through counts of patents filed and scientific articles published.

We used the United States Patent and Trademark Office (USPTO) database to search data on each country because this office receives a greater number of foreign patent applications than any other patent office (Archibugi and Coco, 2004). The international patent classification (IPC) codes for specific renewable energy technologies have been sourced from Johnstone et al (2008). Others covering such technologies as landfill gas recovery and energy efficiency were identified by us. USPTO contains patent data from 1976 on and is available for full text search; therefore we acquired the patent data from this whole period, 1976 till July 25, 2008 (the last day when we extracted the data). The 
complete list of IPC codes used in the search is presented in the Appendix E.

The variable indicating the share of scientific articles on climate friendly technology studies in the total number of scientific articles was obtained from publication counts from the Science Citation Index Expanded (SCI-E) database in Web of Science of the Institute for Scientific Information (ISI WoS). This database is known to be the most comprehensive and validated, and believed not to be heavily discriminating against developing countries (Archibugi and Coco, 2004). For the search strategy we employed a lexical query consisting of a set of keywords (biomass, biogas, solar energy, hydropower, geothermal, landfill, and wind energy. Themes of publications were visually revised to ensure relevance to the topic and many articles were excluded based on the irrelevance of the journal's subject area.

Table 2.6: Patents and publication data and their sources

\begin{tabular}{|c|c|c|}
\hline Indicator & Description & Data source \\
\hline $\begin{array}{l}\text { Patents in climate } \\
\text { friendly } \\
\text { technologies }\end{array}$ & $\begin{array}{l}\text { Total number of patents in all } \\
\text { fields/technologies since } 1976 \text { in each } \\
\text { country } \\
\text { Total number of patents in renewable } \\
\text { and energy saving technologies since } \\
1976 \text { in each country }\end{array}$ & $\begin{array}{l}\text { USPTO database } \\
\text { Accessible on } \\
\text { http://patft.uspto.gov }\end{array}$ \\
\hline $\begin{array}{l}\text { Share of } \\
\text { Publications in } \\
\text { climate friendly } \\
\text { technologies }\end{array}$ & $\begin{array}{l}\text { Total number of publications in } \\
\text { scientific journals in each country for all } \\
\text { years } \\
\text { Percent of publications in scientific } \\
\text { journals in total pool of patents in each } \\
\text { country for all years. }\end{array}$ & $\begin{array}{l}\text { SCI-E database of the ISI } \\
\text { Web of Science was accesses } \\
\text { though the virtual library of } \\
\text { Maastricht University. } \\
\text { Access is limited to students } \\
\text { and employees of the } \\
\text { University }\end{array}$ \\
\hline
\end{tabular}

\subsection{Interviews with CDM experts}

Our research has also benefited from input and feedbacks from a number of CDM experts. We had formal and informal interviews with them in various stages of our research, including the research proposal formulation and exploration, the survey design and the testing and analysis of the research results. Below we name all the experts, with whom we discussed our study, and who thereby helped to improve the quality of our research. 
Geert-Jan Eenhoorn, a business development expert at World Wide Recycling BV, a company based in the Netherlands, advised us in earlier stages of the research design and survey design. The company he works for implemented several CDM projects in Latin America and Southeast Asia. Discussions with him were very insightful in understanding specificities of the CDM project life-cycle and his feedbacks on the questionnaire design helped to adjust several components.

Almaz Asipjanov is an expert at the Regional Environmental Centre for Central Asia. $\mathrm{He}$ is also a founder of the EnConsult company based in Kyrgyzstan, whose core business is to define potential CDM projects in Central Asian region, to provide methodological assessment, and to assist in the registration as CDM project. Contacts and discussions with $\mathrm{Mr}$ Asipjanov were maintained in many stages of our research including the theme exploration, the proposal design, the database building, the questionnaire development, and the discussion of results.

Experts at the UNDP based Climate Change Information Center of Armenia, Dr. Artem Kharazyan and Dr. Diana Harutyunyan were consulted during the field visit in Armenia. They tested the questionnaire and they informed us about the specificities of CDM project related experiences in Armenia, particularly in capacity building issues and technology transfer components. They also provided technical support in contacting project host companies and local stakeholders, and in the visiting the project sites.

Charles Brasor, an expert at the Climate Options Group, and Victor Ochoa, director of Granjas Carroll de Mexico who has an extensive experience with CDM projects in Mexico shared information on technological components of projects during our meetings in Mexico. The visit and interviews provided an insightful picture about biogas projects development and technological learning efforts of the Granjas Carroll company in biogas technology. 

PART II. MACRO LEVEL VIEW ON CDM AND TECHNOLOGICAL
KNOWLEDGE

\section{Chapter 3. TeChNOlOgY SOURCING IN CDM PROJECTS: THE OVERVIEW OF PROJECT DESIGN DOCUMENTS}

\subsection{Introduction}

Present chapter is of an exploratory nature and is based on the database compiled from the information extracted from the CDM project design documents. In previous chapter we described the process of building this database and in this chapter, which also serves as background for Chapter 4, we present an overview of the data in aggregated and disaggregated forms.

While the primary goal of CDM is to minimize the GHG mitigation cost, this mechanism is also seen by many as a promising facilitator of "north-to-south" transfer and diffusion of climate friendly technologies (Carraro, 1999; Grubb et al., 1999; Jepma and Van der Gaast, 1999; Oberthur et al., 1999). Empirical investigation of the actual scale of technology transfer, under the rapidly expanding CDM projects portfolio, has become an emerging agenda for researchers. As we discussed earlier, international technology transfer is mostly associated with sourcing technology from abroad. Technology itself is rather a complex phenomenon consisting not only of hardware in the form of machinery and equipment involved in the production process, but also of software elements in the form of expertise, knowledge, skills, and know-how. CDM project documents which we use as source of data often provided rather narrow information about technology and contained somewhat subjective claims of technology transfer. Therefore we were cautious about technology transfer information and focused on more objectively measurable statistics on technology origin. This chapter presents an overview of technology sourcing statistics in a population of 497 CDM project registered up to February 2007, thereby covering the first two years of the Kyoto Protocol enforcement. We also explore technology sourcing patterns and trends across projects, examine differences in patterns among countries, technology groups, and sectors, and explore the geographic origins of technology.

The chapter consists of four sections. In the section directly following we present an overview of the CDM projects in the database, including their geographical locations, types of technologies applied and sectors involved, project scale, and host 
organizations. In part 3.3 we present aggregated and disaggregated analyses on technology sourcing trends and patterns across countries, technology groups, and projects of different scales and sectors. The last section summarizes the analyses presented in the chapter.

\subsection{Description of the CDM projects database}

We reviewed project design documents of projects registered up to the beginning of 2007, a total number of 497. Figure 3.1 below shows that the cross-world distribution of projects is very uneven. Almost three quarter of projects is concentrated in four countries: Brazil, China, India and Mexico ${ }^{7}$. Twenty countries hosted just one to three projects. Continental distribution of project locations look as follows: $50.3 \%$ of all project sample is located in the Asian and Pacific region (250 projects); 45.3\% or 225 projects are located in Latin American countries; 13 projects $(2.6 \%)$ were initiated in Africa with the South African Republic hosting five of them; and the Middle East and Eastern Europe together count for $1.8 \%$ (or 9 projects). These statistics suggest that $\mathrm{CDM}$ projects are more actively initiated in larger countries.

\section{Figure 3.1 Geographical distribution of CDM projects in the database}

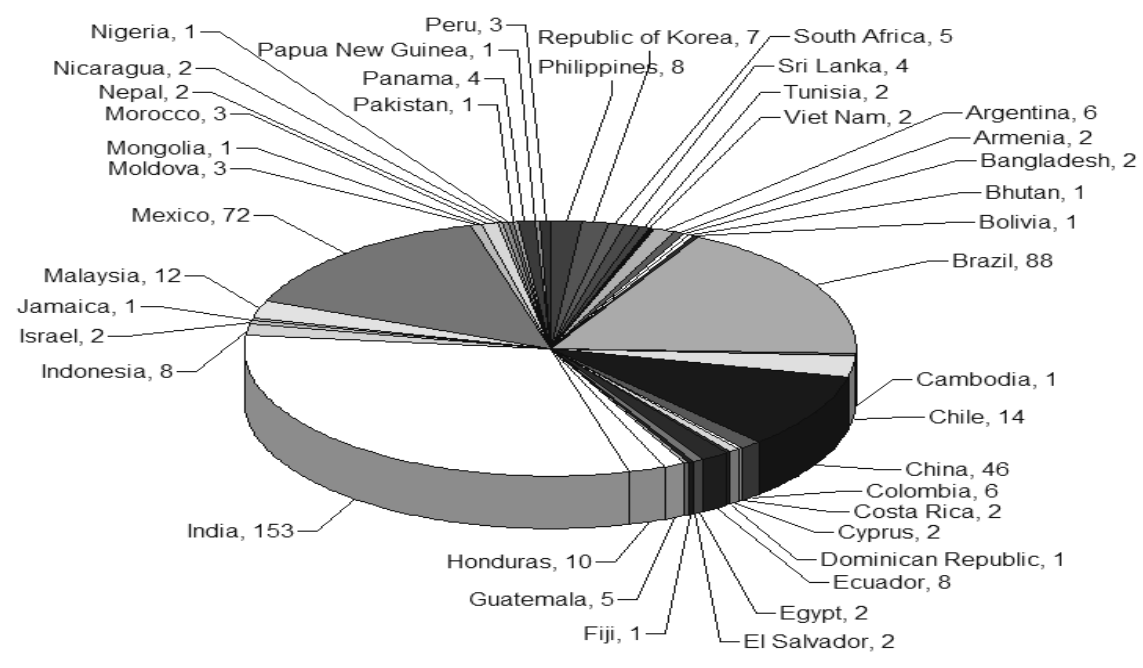

$N=497$

Source: author's database, built on information from project documents

\footnotetext{
${ }^{7}$ It is necessary to note that this trend continued in the following years too; however China became a leader in hosting new CDM projects. (reference source is http://cdmpipeline.org/cdm-projects-region.htm)
} 
The scope of technologies used in CDM projects includes a family of renewable energy generation technologies, such as reducing methane emissions from organic waste, and energy and fuel saving in various industries. The group of renewable energy projects appears to be the most numerous one. Table 3.1 shows that more than half of all projects are involved in renewable energy generation. Within this group, energy from biomass projects is the most frequent, followed by also rather large subgroups of small scale hydropower production projects and wind energy harvesting projects. Projects utilizing solar, geothermal, or tidal energy are still rare.

Table 3.1: Categories of technologies used in CDM projects

\begin{tabular}{|c|c|c|}
\hline Technology group and subgroup & number of projects & $\%$ \\
\hline I. Electricity from renewable energy: & 260 & $52.3 \%$ \\
\hline Energy from Biomass & 112 & $22.5 \%$ \\
\hline Hydropower & 81 & $16.3 \%$ \\
\hline Wind energy & 57 & $11.5 \%$ \\
\hline Solar energy & 4 & $0.8 \%$ \\
\hline Geothermal energy & 5 & $1 \%$ \\
\hline Tidal energy & 1 & $0.2 \%$ \\
\hline II. Methane capture in waste management: & 149 & $30.0 \%$ \\
\hline Biogas production & 105 & $21.1 \%$ \\
\hline Landfill gas & 44 & $8.9 \%$ \\
\hline III. Emission reduction in industry: & 88 & $17.7 \%$ \\
\hline Energy efficiency & 50 & $10.1 \%$ \\
\hline Cement production & 12 & $2.4 \%$ \\
\hline Fossil fuel switch & 10 & $2 \%$ \\
\hline HFCs destruction & 6 & $1.2 \%$ \\
\hline $\mathrm{N}_{2} \mathrm{O}$ destruction & 5 & $1 \%$ \\
\hline Fugitive emissions and coal mine methane & 4 & $0.8 \%$ \\
\hline Transport & 1 & $0.2 \%$ \\
\hline TOTAL & 497 & $100 \%$ \\
\hline
\end{tabular}

Source: author's database, build on information from project documents

The second largest group consists of waste management projects that aim to reduce methane emission generated from the decomposition of organic waste. Projects involved with the production of biogas from animal waste and sewage sludge are accountable for the greater share in this group; the landfill methane capture projects 
form a much smaller part., while they often also include utilization of biogas for energy generation.

Table 3.1 shows that the smallest (third) group of technologies involves a very diverse group of projects on reducing emission in various industries. Energy efficiency improvement is the largest subgroup and it includes energy saving measures in industries, the service sector, and in households. The next subgroup of projects in the cement industry is much smaller in size. This subgroup involves such technologies as substitution of fossil fuel for biomass, and reducing carbon dioxide in clinker process by blending cement with fly ash or slag. The subgroup of ten fossil fuel switch projects implements activities on substitution of coal with less carbon intensive fuels such as natural gas or briquettes. Projects involved in the destruction of emission of HFC and $\mathrm{N} 2 \mathrm{O}$, which are very strong and stable greenhouse gases, are projects in the chemical industry. Together they represent slightly above $2 \%$ of the sample. The following subgroup represents four projects on oilfield and coalmine associated gas recovery and utilization. And finally there is one project in the transport sector on dealing with the optimization of a city public bus transport system which helps to cut carbon emissions. Appendix A presents disaggregated cross-country statistics on the number of projects in each technology sector.

Based on the amount of carbon dioxide emission equivalents reduced, UNFCCC categorizes CDM projects into small and large scale projects. Small-scale projects include projects with renewable energy generation of up to $15 \mathrm{MW}$, energy efficiency with a reduction of consumption either on the supply or the demand side of up to 15 gigawatthours/yr, and other projects that both reduce emission and emit less than 15 kilotons of CO2 equivalent annually (UNFCCC, 2005). According to this categorization, our sample has 230 small scale and 267 large scale projects counting for $46.3 \%$ and $53.7 \%$ respectively. Figure 3.2 below shows the distribution of small and large scale projects across technology types. 
Figure 3.2 Distribution of small and large scale projects across technology types

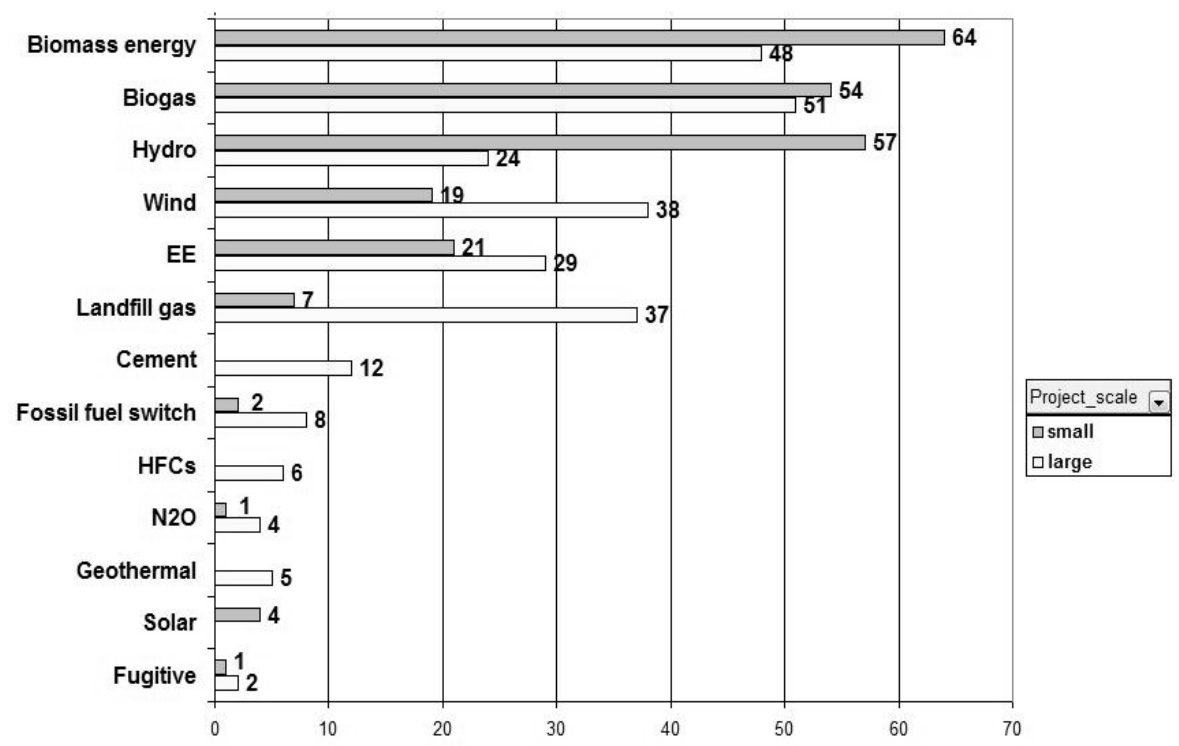

$N=497$

Sourc: author's database, built on information from project documents

\subsection{Technology sourcing in CDM projects: aggregated and disaggregated analysis}

While revising the description of CDM projects we checked for information on the country of origin of the technology. In categorizing the origin we adopted such categories as 'local', 'foreign', and 'combined', defining the origin of the technology in relation to the hosting-country, the country where the project is being implemented. The category 'foreign' standing for the technology developed in a country other than the hosting country, and 'combined' - when a project was involved in a combination of local and foreign technology and/or expertise. This categorization differs from the categorization used by other authors using binary variables to indicate technology transfer or absence of it (Dechezlepretre et al. 2008; Haites, 2006; Seres 2008). Technology transfer in their definition also included import of technology from abroad, but the complexity of the technology in terms of being a collaborative product and complex system of a number of subunits, was not considered. Examples of combined cases are when local engineers do the technical design of the facility, but the machines to equip the facility are bought abroad. Opposite cases often occur when foreign companies specialized in CDM projects bring their own design but involve local companies in supplying the parts for the technological lines. In some projects, 
technology is assembled out of local and foreign equipment blocks (e.g. imported automated control systems and a locally produced power generator, or local biogas digesters and an imported power cogeneration unit).

Inspection of the CDM project documents revealed the following trends in technology sourcing (see Figure 3.3): in about half of the projects (52\%) project implementers used only local technology and expertise; $19 \%$ of the projects were reported to have used only foreign technology and expertise; while $22 \%$ of the projects used various combinations of local and foreign expertise and technology. In 35 project documents ( $7 \%$ of the sample) the information about technology origin was not provided; neither could we find information from supplementary sources such as project monitoring reports and internet browsing.

Figure 3.4 shows cross tabulation estimates of technology sourcing statistics in projects of different scale. In the group of projects using purely local technology more than half are small-scale projects. The group using only foreign technology shows a different picture; three quarter being large-scale projects. In the groups of projects with combined technology, distribution of projects of different scale is more balanced, with a slightly higher number of large scale projects.. These observations suggest that projects having any degree of foreign participation in form of technology providers tend to be larger.. The graph also provides statistics for projects where sourcing statistics is missing. The number of large scale projects in this category is slightly higher than the number of small projects.

Figure 3.3.Technology sourcing in CDM projects: aggregated statistics

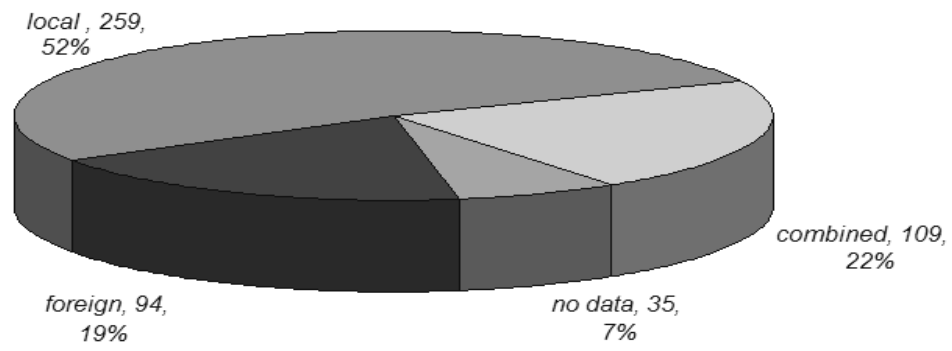

Source: author's database, built on information from project documents 
Figure 3.4 Technology sourcing in small and large scale projects

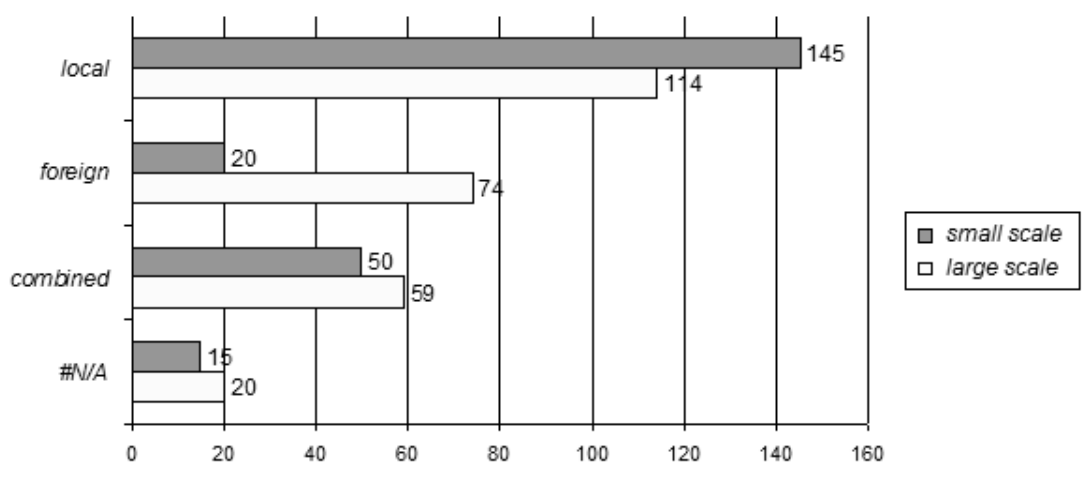

Source: author's database, built on information from project documents

Statistics on technology sourcing across various technology subgroups show very big variations (Table 3.2). Within the renewable energy group, projects on biomass energy show to be mostly inclined towards using local technology, rather than combined or imported. The number of biomass projects using local technology is almost four times higher than the total number of projects in two other two categories of this group. Hydropower generation projects are also similar in terms of larger use of local technology; but the trend for the number of combined technology applications (only three projects) differs. Roughly one fifth of all hydropower projects is based on foreign technology. It is also necessary to note missing data for a large number of hydropower projects. In wind energy projects, the use of foreign technology is somewhat higher than the use of local technology. Also taking in consideration the six other projects, that use combined technology, it is possible to suggest that wind energy project developers rely largely on foreign technologies and knowledge.

In the case of small subgroups of projects in geothermal, solar and tidal energy, small number statistics might give biased conclusions. In Table 3.2 one can see that projects in the geothermal industry seem to make more use of local technologies, while solar energy projects attracted foreign technology and knowledge to a larger extent in all projects. The one project on harvesting ocean energy used foreign technology. 
Table 3.2: Technology sourcing across technology groups

\begin{tabular}{|c|c|c|c|c|c|c|c|c|}
\hline \multirow{2}{*}{$\begin{array}{l}\text { I. Electricity from } \\
\text { renewable energy: } \\
\text { Biomass energy }\end{array}$} & \multicolumn{2}{|c|}{$\begin{array}{c}\text { Local } \\
\text { Nof project, } \%\end{array}$} & \multicolumn{2}{|c|}{$\begin{array}{c}\text { Foreign } \\
\text { Nofproject, } \%\end{array}$} & \multicolumn{2}{|c|}{$\begin{array}{c}\text { Combined } \\
\text { Nofproject, } \%\end{array}$} & \multicolumn{2}{|c|}{$\begin{array}{l}\text { Data non } \\
\text { available }\end{array}$} \\
\hline & 86 & $17.3 \%$ & 9 & $1.8 \%$ & 13 & $2.6 \%$ & 4 & $0.8 \%$ \\
\hline Hydro & 47 & $9.5 \%$ & 12 & $2.4 \%$ & 3 & $0.6 \%$ & 19 & $3.8 \%$ \\
\hline Wind & 21 & $4.2 \%$ & 29 & $5.8 \%$ & 6 & $1.2 \%$ & 1 & $0.2 \%$ \\
\hline Geothermal & 2 & $0.4 \%$ & 1 & $0.2 \%$ & & & 2 & $0.4 \%$ \\
\hline Solar & & & 2 & $0.4 \%$ & 2 & $0.4 \%$ & & \\
\hline Tidal & & & 1 & $0.2 \%$ & & & & \\
\hline $\begin{array}{l}\text { II. Methane capture in } \\
\text { waste management: } \\
\text { Biogas }\end{array}$ & 36 & $7.2 \%$ & 4 & $0.8 \%$ & 63 & $12.7 \%$ & 2 & $0.4 \%$ \\
\hline Landfill gas & 6 & $1.2 \%$ & 20 & $4 \%$ & 12 & $2.4 \%$ & 6 & $1.2 \%$ \\
\hline $\begin{array}{l}\text { III. Emission } \\
\text { reduction in industry: }\end{array}$ & & & & & & & & \\
\hline Energy efficiency & 39 & $7.8 \%$ & 3 & $0.6 \%$ & 7 & $1.4 \%$ & 1 & $0.2 \%$ \\
\hline Cement & 11 & $2.2 \%$ & 1 & $0.2 \%$ & & & & \\
\hline $\begin{array}{l}\text { Fugitive \& Coal } \\
\text { bed/mine methane }\end{array}$ & 2 & $0.4 \%$ & 2 & $0.4 \%$ & & & & \\
\hline Fossil fuel switch & 7 & $1.4 \%$ & 2 & $0.4 \%$ & 1 & $0.2 \%$ & & \\
\hline destruction of HFCs & 1 & $0.2 \%$ & 5 & $1 \%$ & & & & \\
\hline destruction of $\mathrm{N} 2 \mathrm{O}$ & 1 & $0.2 \%$ & 2 & $0.4 \%$ & 2 & $0.4 \%$ & & \\
\hline Transport & & & 1 & $0.2 \%$ & & & & \\
\hline Grand Total & 259 & $52.1 \%$ & 94 & $18.9 \%$ & 109 & $21.9 \%$ & 35 & $7.0 \%$ \\
\hline
\end{tabular}

Source: author's database, built on information from project documents

Projects in waste management related biogas capture also show different trends. Biogas projects largely involve combined technology and expertise (in almost two third of the cases), pure local technology (in one third of the cases) and very few of them use totally foreign technology. Contrastingly, in the case of landfill gas the largest share of projects used either foreign technology or combined technology, hereby showing the importance of foreign participation.

In the group of projects aimed at reducing emission in industry, the subgroups energy efficiency, cement, and fossil fuel switch showed strong preference for local technology. HFC destruction projects seem to prefer sourcing technology from abroad, while remaining technology subgroups did not show clear preferences for either source. 
Analysis of countries of technology origin showed interesting results (see Table 3.3). We divided the countries into two groups using the UNFCCC classification. One group consists of the Annex I countries, or countries that have emission reduction targets in accordance with the UNFCCC ${ }^{8}$. Another group is a list of countries defined as non-Annex countries; these countries do not have emission reduction targets and are considered as CDM projects recipient countries.

Examination of the country origin data revealed that technology from Annex I countries have been used in 175 projects of a sample of 497. This includes both cases of only foreign technology application, as cases in which foreign and local technology was used in combination. Table 3.3 shows that Irish technology was applied in 41 projects, the largest number in the group. The next largest counts are for technology from Germany, the USA and Denmark that were implemented in 21, 20 and 19 projects respectively. The then following large groups are the Japanese, Spanish, French and Dutch technologies, which together were used in over 45 projects

Table 3.3: Countries of technology origin and number of projects in which technology was used

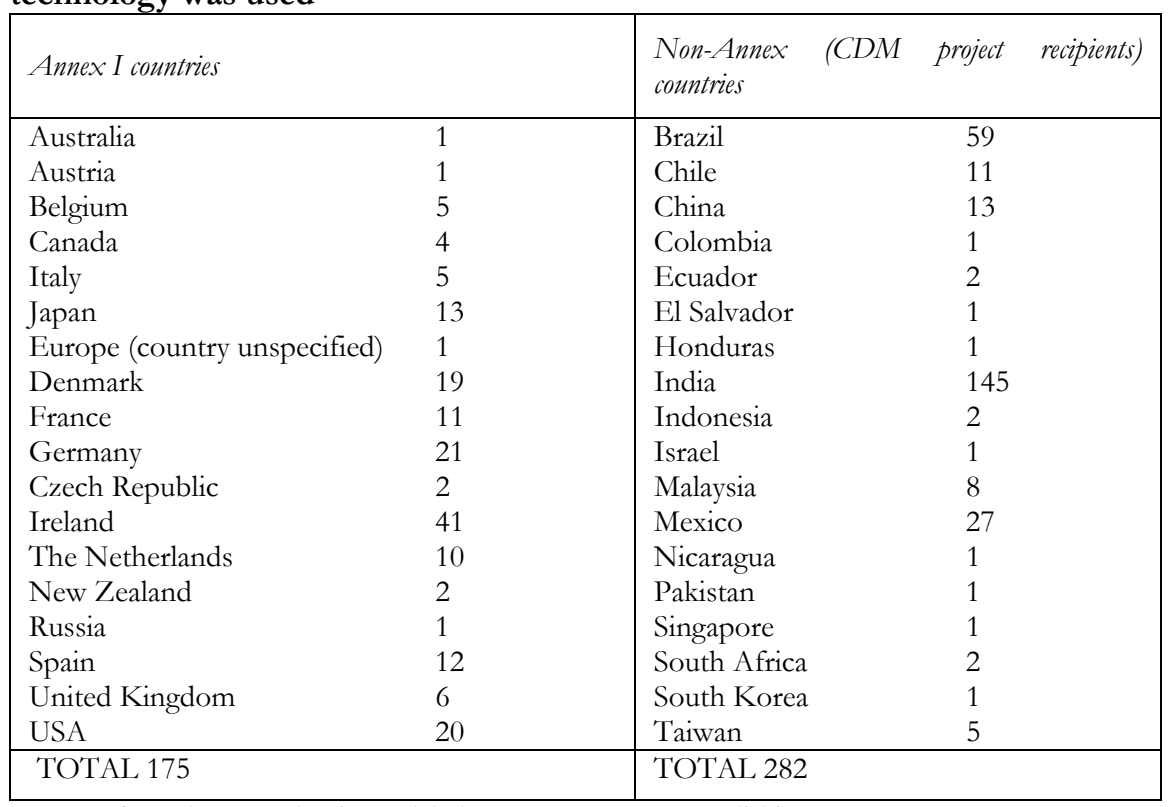

Note1: Information on technology origin in 68 projects was not available

Note2: In some projects, technology was sourced from two or more countries

Source: author's database, built on information from project documents

${ }^{8}$ We also included USA in this category, although it is not signatory to the Kyoto Protocol 
Statistics for technology sourcing from non-Annex countries show that India, with 145 projects using its technology, is the leading technology source country for CDM, followed by Brazil that supplied technologies in 59 projects, and Mexico (27 projects). Next in line are China, Chile and Malaysia, although the counts they have for technology provision are much more modest (13, 11, and 8 respectively). Taiwan and Singapore, while not hosting any CDM project, took part in totally six projects abroad.

The total number of cases when technology was sourced from non-Annex countries was 282, which is much higher than the case for Annex I countries. These findings indicate the important role of developing countries not just as initiators and hosts of CDM projects, but also as producers and suppliers of climate friendly technologies.

\subsection{Summary}

The purpose of this chapter was to present an overview of technology sourcing statistics in a database of $497 \mathrm{CDM}$ projects. We examined technology sourcing patterns and trends across projects, studied differences in patterns among countries, technology groups, and sectors, and explored the countries of origin of technology used in CDM projects. Our statistics showed that about three quarter of all CDM projects are implemented in just four countries, namely Brazil, India, China and Mexico. Most of the countries in the sample hosted only one to three projects by the beginning of 2007 .

Biogas and energy from biomass projects are the most numerous in the sample counting for about $44 \%$ of all projects. They are followed by hydropower, wind, and energy efficiency projects for which the number ranges between 50 and 88 .

Examination revealed that in about half of the projects $(52 \%)$ project implementers used only local technology and expertise; 19\% of projects were reported to have used only foreign technology and expertise; while $22 \%$ of projects used various combinations of local and foreign expertise and technology. The observations show that projects having any degree of foreign participation tend to be larger in scale. This might suggest that foreign partners prefer participation in projects that generate more carbon credits.

Our data also show that technology sourcing in different technology groups varies a great deal. Projects on biomass to energy, hydropower, energy efficiency, cement, and fossil fuels switch showed to be more based on local technology than on foreign or combined technology. Landfill gas recovery and HFC destruction projects seem to rely more on foreign technology. In over $60 \%$ of biogas projects, project implementers collaborate both with local and foreign technology providers. Other projects showed more balance among the three sources. 
Examination of countries of technology origin showed very interesting results. Technology was sourced from non-Annex countries, which are the developing countries in 282 cases, while developed countries, which are assumed to have a more advanced and larger scope of climate friendly technologies, supplied technology only in 175 cases. The largest technology origin country proved to be India, followed by Brazil, Ireland, Mexico, Germany, USA and Denmark. This analysis suggests that developing countries play an important role not only in hosting CDM projects but also in providing technological support in internationalizing climate change mitigation efforts. This role will be investigated more deeply in the following chapter of the thesis. 



\section{CHAPTER 4. KNOWLEDGE BASE DETERMINANTS OF TECHNOLOGY SOURCING IN THE CDM PROJECTS ${ }^{9}$}

\subsection{Introduction}

Under the sustainable development agenda, CDM projects, besides delivering various social and economic benefits, are expected to transfer climate friendly technologies (CFT's) and expertise to developing countries. Therefore, the CDM scheme has been viewed as an effective means of subsidizing technological advancement of developing economies and, consequently, bringing them towards a more climate friendly growth trajectory. Examples of $\mathrm{CDM}$ projects include the installation of various renewable energy producing facilities as well as projects geared towards the reduction of GHG emissions in chemical, cement, waste management and other industries by changing the processes or improving energy efficiency. Like many environmental technologies, GHG cutting technologies and related expertise are either not widely diffused, or even new to developing countries (Aslam, 2001; Forsyth, 1998). On the other hand, economical and technological frontrunner countries have big advantages in this aspect. Large amounts of $R \& D$ investment and special national programs such as promoting renewable energy and waste management practices, combined with stricter environmental standards have moved them to the technological frontier (Newell, 1997; Blackman, 1999). With the start of CDM large flows of technologies and expertise were expected to be observed spreading from the technologically developed North to the South. Hence from an international development perspective CDM has been alleged to be a new channel of international transfer and diffusion of green technologies (e.g. see Wilkins, 2002; Aslam, 2001).

However, real experience with CDM projects has not always supported this seemingly logical expectation. Studies harvesting technology transfer statistics from CDM projects report technology transfer happening for roughly one third of the projects only (Haites et al, 2006; Seres 2008, Dechezlepretre et al, 2008). Our examination of 497 projects presented in Chapter 3 showed that less than half of them involved various degrees of foreign technology participation. More specifically, 94 projects $(19 \%)$ fully relied on foreign technology; 109 projects (22\%) reported a combination of foreign and local technologies or joint effort of local and foreign engineers on the installation design. Given the high expectations of technology transfer, it is striking that in over half (or $56 \%$ ) of the projects reviewed by us the whole package of technology deployed was of local origin.

${ }_{9}^{9}$ This chapter is based on Doranova, A., Costa, I. and Duysters, G. 2007. Knowledge base determinants of technology sourcing in Clean Development Mechamism projects, forthcoming in Energy Policy journal 
Furthermore, companies from developing countries such as China, Malaysia, Taiwan and South Africa were identified as technology providers for projects in other developing countries (See Chapter 3 table 3.3). In 282 projects technology was supplied by companies from developing countries, while technology providers from developed countries, the so-called Annex 1 countries, took part in 175 projects $^{10}$. This development has been rather surprising especially in the light of the technology transfer promises stressed in the policy agenda. These figures might suggest that in the concept of the CDM based "North-to-South" technology transfer the capabilities of the "South" have been somewhat underestimated. Therefore it might be reasonable to put forward the argument to stress the importance of the local technological knowledge in developing countries in addressing goals of the Kyoto Protocol in general, and technology transfer in CDM projects in particular.

Talking about technology transfer, the countries that have experience with technologies are supposed to have accumulated knowledge in this technology which would make them less dependent on the acquisition of technology from abroad. In this study we distinguish two types of technological knowledge. First, the knowledge about how to produce and operate the technology; this involves skills of people dealing with this technology, knowledge embedded in the machines, and knowledge gained through optimization of these machines. Second, the scientific knowledge associated with formal $\mathrm{R} \& \mathrm{D}$ in certain technologies, which usually takes place either at companies developing these technologies, or at universities and public research labs. Both types of knowledge, practical and scientific, are building blocks of the country-level knowledge base. However they might have different effects when it comes to decision-making about where to acquire technology from for a new project.

We endeavoured to shed some light on this perspective by firstly investigating the available scientific and operational expertise of project host countries, which is appropriated by the 'technological knowledge base' concept. Secondly, we analysed the relationship of this knowledge base with the technology sourcing patterns in CDM projects. The aim of this study is exploratory and to the best of our knowledge this perspective has hardly been applied in CDM related research. The central research question addressed in this study is whether existing technological knowledge in the country can explain the technology sourcing patterns in CDM projects.

Because this study deals with the very specific case of climate friendly technologies, we had to focus on the technological knowledge base in a narrow technology group. Furthermore, in this paper we treat the concept of a knowledge base as a twodimensional concept representing practical and scientific knowledge in the CFT area of each country. Sub-questions addressed in this study refer to each of these dimensions

10 for 68 projects, information about the origin of technology providers was not available 
and are formulated as follows: What is the role of practical knowledge associated with the application of CFT's in the country in determining technology sources in CDM projects? What is the role of scientific knowledge in this process? How different are the roles of each knowledge type?

Technology sourcing statistics in CDM projects call first for theoretical grounding of the raised research questions, and second, for a more empirical setting in which macro level factors associated with a knowledge base can be operationalized. Our attempts to explain it through knowledge base indicators have a number of compelling reasons. First, in the current debate of the post Kyoto perspective there is a need for a better understanding of technological development aspects, especially with respect to developing nations (Kline et al, 2004). Second, despite high political interest in this area, CDM literature does not adequately address such perspectives as technological capabilities and learning, technological change, and catching-up. Our task is to fill this gap by bringing together and analyzing empirical data on technology sourcing in CDM projects and country level CFT specific technological capability and knowledge indicators.

The chapter is structured in the following way. The second part of the chapter provides more of the choice justification from the standpoint of the literature gap and discusses the theoretical concepts that ground the approach adopted in this study. The third part is methodological; it describes the data sources, construction of variables, provides descriptive statistics and econometric techniques. Econometric results are presented in the fourth part. Discussion, conclusions and implications appear in the last two sections of the chapter.

\subsection{Theoretical grounding and main arguments}

In order to understand why CDM project initiators in certain countries and/or technology sectors rely on local technologies and others on foreign ones, we tried to see what the concepts of a technological knowledge base and technological capabilities can offer us. The importance of the knowledge base of a country in its economic development and catching-up has been extensively highlighted in the economics literature. The idea of the knowledge economy has found imperative recognition in the policymaking domain and led to a paradigm shift in the whole concept of economic development (Foray and Lundvall, 1996; Abramowitz, 1989). It is now widely acknowledged that technological capabilities and a knowledge base are important strategic assets in boosting economic growth on national, sectoral, and firm levels. Besides, technological capabilities are a necessary prerequisite, both in the creation and diffusion of technologies. At the same time it would not be right to ignore the importance of technology transfer. Many studies have demonstrated that knowledge 
arrives with foreign direct investment. Therefore the idea of complementarity of foreign technology import with domestic technological effort as the most optimal recipe for promoting technical change and catching-up in developing countries has been repeatedly highlighted by development economists (Radosevic, 1999; Bell and Pavitt, 1993).

In the context of climate change mitigation the role of technology is acknowledged both by supporters and detractors of the Kyoto protocol. Early adoption and learning in climate friendly technologies have been suggested as the most efficient ways of combating climate change (Grubler et al., 1999; Thorn, 2008). Therefore it is very important to develop and diffuse this knowledge over the world, especially in developing countries whose rapid industrialization is threatening to outweigh all current efforts on mitigation of climate change. Being the largest framework of collaboration with developing countries under climate change initiatives, CDM has been seen as and hoped to be, a channel for the transfer of environmentally sound technologies (Philibert, 2005; Metz et al., 2000).

However, over the last years another perspective seems to be emerging: developing countries not as receivers of technology but as producers of it (see e.g. study by Brewer, 2008). Within this perspective there is a need to analyse the (current and future) active technological role of developing countries in mitigating climate change. Developments in the global renewable energy sector within the last few decades show the active positions of some developing countries in promoting renewable energy technologies. For example, favourable state policies made India the fourth and China the fifth global largest wind energy producers in 2007 (Lewis and Wiser, 2007). With the purpose of achieving energy independence, the Brazilian government pushed development of bioethanol production in the country, making Brazil the second largest producer and the global leader in export of biofuel (Lemos, 2007). Also, developing countries produce somewhat over $40 \%$ of the global renewable electric capacities without counting for large-scale hydropower (REN21, 2008). Certainly, these capacities are not spread equally across developing countries. Some countries are capable of implementing a full technology development cycle: starting from R\&D in green energy technologies up to and including the manufacturing and exploitation, while others do not even have generation capacities. With these perspectives as background, present study attempts to analyse the current state of the technological knowledge base of developing countries and its implications for CDM experience on the basis of empirical evidences and data.

We searched the literature on CDM to see if any attempt has been made to address this issue. There is a vast number of policy papers, ex-ante assessment studies, conceptual propositions, models and case studies building a dispersed discourse about the topic of CDM and technological development. This literature addresses such issues as 
technology selection, transfer barriers and potential, possible scenarios, etc. (e.g. see Schneider et al. 2008; Kaneko et al., 2006; Aslam, 2001; Millock, 2002). As yet the number of studies based on empirical data is still limited due to the rather short history of CDM implementation experience. However, it looks like more studies are on their way and preliminary results are fostering a new discourse. Recently there emerged a first wave of studies analyzing determinants of technology transfer patterns in CDM projects (Haites et al, 2006; De Conninck et al, 2007; Seres, 2008; Puyeo Velasco, 2007; Dechezlepretre et al, 2008). These authors used different sized datasets of CDM projects and built statistics on whether projects involved local or foreign technology and expertise, hence produced counts of technology transfer evidences. Then they analysed which factors were associated with technology transfer statistics. These studies highlight that technology transfer occurrence is positively associated with larger projects, availability of foreign partners and affiliation of project hosts with foreign companies, smaller countries, and those with larger GDP. Also, technology transfer seems to be associated with certain types of technologies only. ${ }^{11}$

With respect to the focus of our paper, interesting points have been revealed in studies by Puyeo Velasco (2007) and Dechezlepretre et al (2008). The first author investigated the impacts of renewable energy endowments and/or potential of host countries on technology transfer patterns in the CDM. One of the findings of the study was that large hydropower generation capacities are negatively associated with technology transfer occurrence in CDM projects. This was explained by the fact that in CDM host countries with hydro-electricity production capacities, the technology was already there, so that there was no need to transfer it from abroad. This was an appealing point for our study as it associates local availability of technology with practical experiencerelated knowledge.

Dechezlepretre et al (2008) included in their model the country-level technological capability index (also called ArCo) developed by Archibugi and Coco (2004) in order to identify its influence on technology transfer events in CDM projects. While it demonstrated that country level technological capability is positively associated with sourcing the technology from abroad, mixed results were obtained after controlling in different sectors, showing strong positive significance for energy and chemical industries and a negative influence in agriculture. These results are interesting, both in terms of getting insight, as well as in revealing potential challenges in the application of such a broad technological capability indicator as the ArCo index for this specific case. The ArCo index represents a country's overall technology and knowledge potential and is composed of country-level science, technology, education, and other indicators. The group of technologies applied under the CDM includes a number of environmental

11 According to the results of these studies technology transfer is more likely for agriculture, HFC, N2O projects and less likely for Biogas, Biomass energy, Cement, Coal bed/mine methane, Energy efficiency own 
technologies such as renewable energy, energy efficiency, waste management, etc. This group represents rather a narrow niche and its $\mathrm{R} \& \mathrm{D}$ related and diffusion dynamics differ from those of conventional technologies and products ${ }^{12}$. Therefore the country's capacity in these technologies could be different from the overall technological development level and aggregated S\&T capacities. In a few aspects our study builds on observations and the model of Dechezlepretre et al (2008). However we have tried to be more specific in defining the technological knowledge base indicators relevant to the $\mathrm{CDM}$ technologies and investigating their influence in technology sourcing statistics in CDM projects.

Another distinct feature in our study is the conceptual approach of the technology sourcing idea in CDM. The aforementioned studies focused on explaining the technology transfer occurrence (in other words foreign technology application) cases and investigated factors influencing the foreign technology choice. In contrast, the angle of our study is rather on projects using local technologies and factors influencing this alternative. We suggest that behind this choice there is a history of evolution and diffusion of the technology, and an accumulation of knowledge in this technology in the CDM project host country; this in turn is currently shaping CDM related developments in the country. Therefore our research questions call for understanding the knowledge base in the country in order to understand why in most of the cases project developers go for local technologies rather than foreign ones. In order to address the research questions we needed first to define the proxies that could serve as measures for applied and scientific knowledge; second, to identify data-sources and extract data constituting these proxies for each analysed country; third, to bridge these data to CDM projects statistics and carry out econometric analysis.

\subsection{Data and Methods}

\subsubsection{Data sources}

In this study we attempt to explain the technology sourcing patterns in a dataset of CDM projects registered during the first two years after the Kyoto Protocol enforcement. Chapters 2 and 3 provide details on extracting these data and some descriptive statistics. Information and data regarding each project were accessible through CDM Project design documents (PDD) which are available for download on the UNFCCC website. Although these documents do not have the explicit objective to present detailed information about the origin of technology deployed in the project, in

generation, Energy distribution, Fossil fuel switch, Fugitive, Hydro, Landfill gas, and Reforestation.

12 For example the literature on environmental innovations highlights the supremacy of a state inducement factor (special policies) over market forces (like demand or competition) in the success of environmental technologies. 
most cases we were able to extract information about the technology type, origin, and technology providers. In some cases it was necessary to supplement the revision of the project documents by checking additional documents from the UNFCCC, by consulting other internet resources, or through direct communication with experts involved in CDM projects. From the PDD's we acquired very detailed information about a project's location, its size in terms of annual reduction of carbon emission, the project operator, its affiliation status, partners, credit buyer information, etc. The project list itself and the time frame regarding registration were obtained from the online database of UNEP Risoe (2007).

The initial list of CDM projects included 497 projects located in 42 countries. During the analysis we had to exclude 37 observations due to missing data on project and/or country level. Thus the final dataset has 460 observations and covers 36 countries (see Appendix A). India, Brazil, Mexico and China are the largest project recipient countries hosting $76.3 \%$ of projects. Other countries have between one and fourteen projects. As for the technology origin, 257 projects $(55.9 \%)$ count application of purely local technology, 94 projects $(20.4 \%)$ involve a complete package of foreign technology, and 109 cases $(23.7 \%)$ report a combination of local and foreign technologies.

Various country-level data for constructing independent and control variables were acquired from the International Energy Agency (IEA), the United States patent and Trademark Office (USPTO), the United Nations Commodity Trade Statistics Database (COMTRADE), the Science Citation Index Expanded (ISI/SCI-E) of the Institute for Scientific Information, and the World Development Indicators (WDI) of the World Bank.

\subsubsection{Constructing variables}

\section{Dependent variable: Technology origin}

The present study has been designed to examine the origin of technology deployed in CDM projects. On the basis of the observations obtained through PDD documents we used three categories for technology sources: local, foreign, and combined, to indicate the 'Technology origin' variable. Our application of multi-categorical variables differs from approaches in other studies that use binary variables to indicate technology transfer evidence or absence of it (Dechezlepretre et al. 2008; Haites et al, 2006; Seres, 2008). Compatibility of their indicators with ours is in the definition of the technology transfer these authors apply. In their papers, technology transfer is allied with the import of equipment and/or knowledge from abroad. In our case we make a study of technology origin (local versus foreign) and in quite a large number of cases (109 projects) it was impossible to judge whether the technology and expertise applied in the project was entirely of either local or foreign origin. Therefore in addition to the categories local and 
foreign we introduced the category combined for the projects that involved a combination of local and foreign technology and/or expertise. Examples of combined cases are when local engineers do the technical design of the facility, but the machines to equip the facility are bought abroad. Opposite cases often occur when foreign companies specialized in CDM projects bring their design but involve local companies in supplying the parts for technological lines. In some projects, technology consists of local and foreign equipment blocks compiled and put together (e.g. imported automated control system and locally produced power generator, or local biogas digesters and imported power cogeneration unit).

\section{Independent variables:}

\section{Country's knowledge base indicators}

The country and sector specific technological knowledge base is a complex multidimensional concept. It includes such aspects as the diffusion level of the technology which reflects the knowledge in application of the technology, the availability of technology related $\mathrm{R} \& \mathrm{D}$, the production expertise in a country's specific sectors, the availability of educational institutions, and the technical potential in this area. Dealing with a CDM case requires looking into the indicators exclusively related to the generation and application of climate friendly technologies. Over $90 \%$ of CDM projects deal with renewable energy production, energy saving, and biogas recovery technologies. Therefore we focused on the collection of data on these specific subsectors. Table 4.1 below presents the constructs that we applied to indicate the CDM technologies specific knowledge base in each country.

The first factor, the diffusion level of climate friendly technologies, is associated with production capacities and practical experience in climate friendly technologies. The assumption here is that the higher diffusion level of the technology represents better practical knowledge in this technology in a country. We suggest two proxies to measure it: the production of electricity from renewable energy sources and the share of export of these technologies.

The amount of electricity produced by renewable sources, and its share in the total energy mix of the country are fairly good indicators of the country's experience and hence knowledge in the application of renewable energy technologies. Evidently, larger renewable energy generation capacities are associated with a higher diffusion level of renewable energy technologies in a country which in turn is associated with larger operational knowledge in these technologies.

The logic behind using the "Export" performance indicators is somewhat similar. Countries with higher shares of export in certain technologies are the ones that 
produce these technologies. Production requires strong and sophisticated knowledge that is constituted by engineering knowledge, knowledge embedded in machines, and often R\&D. Therefore we argue that a country's performance in export of climate friendly technologies is a good indicator of the local knowledge in these technologies.

Table 4.1: Indicators proposed to measure the knowledge base specific to CDM technologies

\begin{tabular}{|l|l|l|}
\hline $\begin{array}{l}\text { Constructs for CDM } \\
\text { technologies knowledge base }\end{array}$ & Data and measurements & Source of data \\
\hline $\begin{array}{l}\text { Diffusion level of } \\
\text { climate friendly } \\
\text { technologies }\end{array}$ & $\bullet \begin{array}{l}\text { Share of energy from hydro, wind, } \\
\text { solar, geothermal, biomass in total } \\
\text { primary energy supply } \\
\text { Share of climate friendly } \\
\text { technologies in the flow of total } \\
\text { export of goods }\end{array}$ & $\begin{array}{l}\text { International Energy } \\
\text { Agency }\end{array}$ \\
\hline $\begin{array}{l}\text { Scientific effort in } \\
\text { climate friendly } \\
\text { technologies }\end{array}$ & $\begin{array}{l}\text { Share of scientific articles in } \\
\text { climate friendly technologies in } \\
\text { total pool of scientific articles } \\
\text { Number of patents in climate } \\
\text { friendly technologies by inventor }\end{array}$ & $\begin{array}{l}\text { Science Citation Index } \\
\text { expanded }\end{array}$ \\
\hline
\end{tabular}

Source: Author

From the International Energy Agency (IEA) database we obtained the data on electricity generated from renewable energy sources and calculated its share in the total national energy production mix (Total primary energy supply, TPES) for 2005. This gave us our first independent variable 'Renewable energy share'. Similarly we calculated the share of climate friendly technologies in the total value of exported goods ('Export of (F''). The source for the export data was the UN Commodity Trade Statistics Database that uses the Harmonized Commodity Description and Coding System (HS1996). The OECD has well-defined typologies of technologies and specifying codes for environmental technologies in various sectors (Steenblik, 2005a, b). We restricted our search to codes covering the energy sector, such as energy production and saving (see Appendix III for codes used). Our methodological choice is again based on the dominance of energy technologies in overall CDM projects' portfolio.

The second group of variables represents the purely scientific or R\&D-related knowledge base of the countries, which can be measured through the number of patents filed and scientific articles published in the fields of climate friendly technologies. Although many inventions are never patented in developing countries, patents can represent a valid proxy for a form of codified knowledge generated by profit-seeking firms and organizations (Archibugi and Coco, 2004). Patent count is a 
widely applied indicator for measuring innovativeness of a country, company or industry. And no one would argue that innovation is a result of intensive knowledge application, while a patent is a document for codification of scientific knowledge.

We used the USPTO database to search for data on each country because this office receives a greater number of foreign patent applications than any other patent office (Archibugi and Coco, 2004). The patent IPC codes for specific renewable energy technologies have been sourced from Johnstone et al (2008). Others covering such technologies as landfill gas recovery and energy efficiency were identified by us. The complete list of IPC codes used in the search is presented in Appendix II. As was expected, patent counts demonstrated a significant difference in performance between such countries as Israel and South Korea and the rest of the group. Roughly one third of the countries counted zero patens in climate friendly technologies. Due to this problem we had to convert the continuous variable into a dummy by introducing two new categories: "zero and low performers" and "medium and high-performers". The grouping approach was based on using the median as a threshold for splitting the whole group of countries. Thus the variable 'Patent in CFT' indicates if a particular country belongs to the medium and high performers group (=1).

\footnotetext{
Armenia, Bangladesh, Bolivia, Cambodia, Guatemala, Honduras,

Moldova, Mongolia, Morocco, Nepal, Nicaragua, Pakistan, Chile, Costa

Rica, Dominican Republic, Ecuador, El Salvador

Zero and low performers

(below median group)

South Africa, Argentina, Philippines, Mexico, China, Cyprus, India, Sri

Lanka, Colombia, Peru, Brazil, Jamaica, Nigeria, Egypt, Indonesia, Malaysia, Viet Nam, Israel, Republic of Korea

Medium and high performers

(above median group)
}

Another important source of codified knowledge is scientific literature (Archibugi and Coco, 2004). Scientific publications represent the knowledge generated in universities, research centres, and other publicly, as well as privately funded research organizations. Therefore the number of publications is another definite proxy for scientific knowledge in a country and/or in a particular field. Narrowing down to a field of climate friendly technologies we could evaluate the knowledge base of each country in these technologies.

The variable indicating the share of scientific articles on climate friendly technology studies in the total number of scientific articles ('Publications in CFT') was obtained from publication counts from the Science Citation Index Expanded (SCI-E) database in ISI Web of Science. This database is known to be the most comprehensive and validated, and believed not to be heavily discriminating against developing countries 
(Archibugi and Coco, 2004). For the search strategy we employed a lexical query consisting of a small set of keywords. Themes of publications were visually revised to ensure relevance to the topic. Several articles were excluded based on the irrelevance of the journal's subject area.

\section{Control variables}

Additional variables we took into consideration in the econometric analysis are project specific characteristics and country specific variables. In selecting them we referred to suggestions by other studies on CDM driven technology transfer.

Project specific variables such as the size, ownership status of the project operator company, i.e. subsidiary or foreign partner, and existence of similar projects in a host country have been taken into consideration. Previous quantitative studies have established that there are economies of scale in technology transfer: All other things being equal, transfers in large projects are more likely (Dechezlepretre et al 2008; Haites, 2006; Seres, 2008). Following this we included a project size variable ('Project size') in the model. It is necessary to note that the project size is measured by annual amount of $\mathrm{CO} 2$ equivalent emission reduction. Furthermore, these studies established that the probability of transfer is $50 \%$ higher when the project is developed in a subsidiary of a company from an Annex 1 country (Dechezlepretre et al. 2008). We have recorded the information about the evidence of host projects being a subsidiary of a foreign partner and subsequently introduced the subsidiary dummy indicator ('Subsidiary'). Besides this, the previous study also established that the probability of involvement of any sort of foreign technology decreases with the number of projects using the same type of technology in the country (Dechezlepretre et al, 2008). Following this finding we controlled for these factors by introducing the variable 'Similar projects', which indicates the number of CDM projects in the same technology for each country.

Country specific variables included in our econometric model are country size, income level, trade and local renewable energy resource endowment. Country size is treated in our model through Log of population ('Population' variable). It captures the effect of a country's size on the propensity to import technology. Theoretically, large countries have a more diversified industrial base, which means a greater chance of having technology domestically available. A similar argument goes for the GDP per capita ('GDP/cap') indicator. Countries with a higher level of wealth production tend to have a better technological base, and are likely to have technologies in their domestic market. However the observations on these variables in other studies based on varied size samples of projects showed mixed results (Seres, 2008; Haites et al, 2006; Dechezlepretre et al, 2008). 
Previous studies on technology transfer in CDM were in line with general economic literature in providing empirical evidence that transfer of technology is associated with higher FDI and international trade activities (Pueyo Velasco, 2007; Dechezlepretre et al, 2008). To capture this effect we introduced the variable 'Trade', which is the sum of the trade value of exports and imports of all commodities during the years 2002-2005 divided by the country's GDP. The control variable related to FDI was avoided for the following reasons: first, participation of the foreign capital is already captured by the subsidiary dummy variable; second, the FDI/GDP indicator showed a high correlation with other variables, which may distort the regression results.

Table 4.2 summarizes the information on variables that we have applied, their descriptive statistics, and expected effect on the outcome. Table 4.3 presents the correlation coefficients among all variables. A correlation test helps to detect a possible problem of multicollinearity in the regression and to select the control variables to be included in the final model. This test resulted in omitting some of the control variables that we initially planned to have in the model ${ }^{13}$. The independent variables essential for our study were deliberately kept. Nevertheless, the results of the correlation test did not show a high correlation among the independent and control variables and there was thus no multicollinearity problem.

\footnotetext{
${ }^{13}$ FDI inflow, availability of credit buyer, and GDP growth that were suggested by other studies appeared to have high correlation with the rest of the variables risking possible multicollinearity problems. Therefore we excluded them in the econometric analysis.
} 
Table 4.2: Definition of variables and summary statistics

\begin{tabular}{|c|c|c|c|c|}
\hline Variables & Description & Mean & $\begin{array}{l}\text { Std. } \\
\text { Dev. }\end{array}$ & $\begin{array}{l}\text { Exp } \\
\text { outcome }\end{array}$ \\
\hline Technology origin & $\begin{array}{l}\text { Dependent variable technology origin; } \\
\text { Categorical variable containing \{Local, } \\
\text { Foreign, Combined\}. }\end{array}$ & - & - & - \\
\hline Project size & $\begin{array}{l}\text { Log of the size of the project (expected } \\
\text { annual reductions in ktCO2eq) }\end{array}$ & 3.709 & 1.507 & - \\
\hline Subsidiary & $\begin{array}{l}=1 \text { if the project host company is the } \\
\text { subsidiary of a foreign partner, } 0 \\
\text { otherwise }\end{array}$ & 0.220 & 0.414 & - \\
\hline Similar projects & $\begin{array}{l}\text { Natural Log of the number of projects } \\
\text { already using the same type of } \\
\text { technology within a host country }\end{array}$ & 2.613 & 1.325 & + \\
\hline Trade & $\begin{array}{l}\text { sum of annual values of exports and } \\
\text { imports of all commodities divided by } \\
\text { the value of GDP (average for 2002- } \\
\text { 2005) }\end{array}$ & 0.489 & 0.320 & - \\
\hline Population & $\begin{array}{l}\text { Natural Log of total population in } \\
\text { millions (2005) }\end{array}$ & 5.449 & 1.672 & + \\
\hline$G D P / c a p$ & $\begin{array}{l}\text { GDP per capita (2005) in thousand } \\
\text { USD }\end{array}$ & 3.418 & 3.346 & + \\
\hline Publications in CFT & $\begin{array}{l}\text { Share }(\%) \text { of scientific articles in climate } \\
\text { friendly technologies in a national pool } \\
\text { of scientific publications }\end{array}$ & 0.515 & 0.276 & + \\
\hline Patents in CFT & $\begin{array}{l}=1 \text {, if country has more than } 1 \text { patent in } \\
\text { climate friendly technologies, } \\
=0 \text {, if country has zero or } 1 \text { patents }\end{array}$ & 0.893 & 0.308 & + \\
\hline Export of CFT & $\begin{array}{l}\text { Share }(\%) \text { of climate friendly } \\
\text { technologies in total value of exported } \\
\text { goods, average of } 2002-2005\end{array}$ & 1.402 & 0.826 & + \\
\hline $\begin{array}{l}\text { Renewable energy } \\
\text { share }\end{array}$ & $\begin{array}{l}\text { Share }(\%) \text { of renewable energy in the } \\
\text { national total primary energy supply for } \\
2005 \text {. }\end{array}$ & 0.543 & 0.567 & + \\
\hline
\end{tabular}




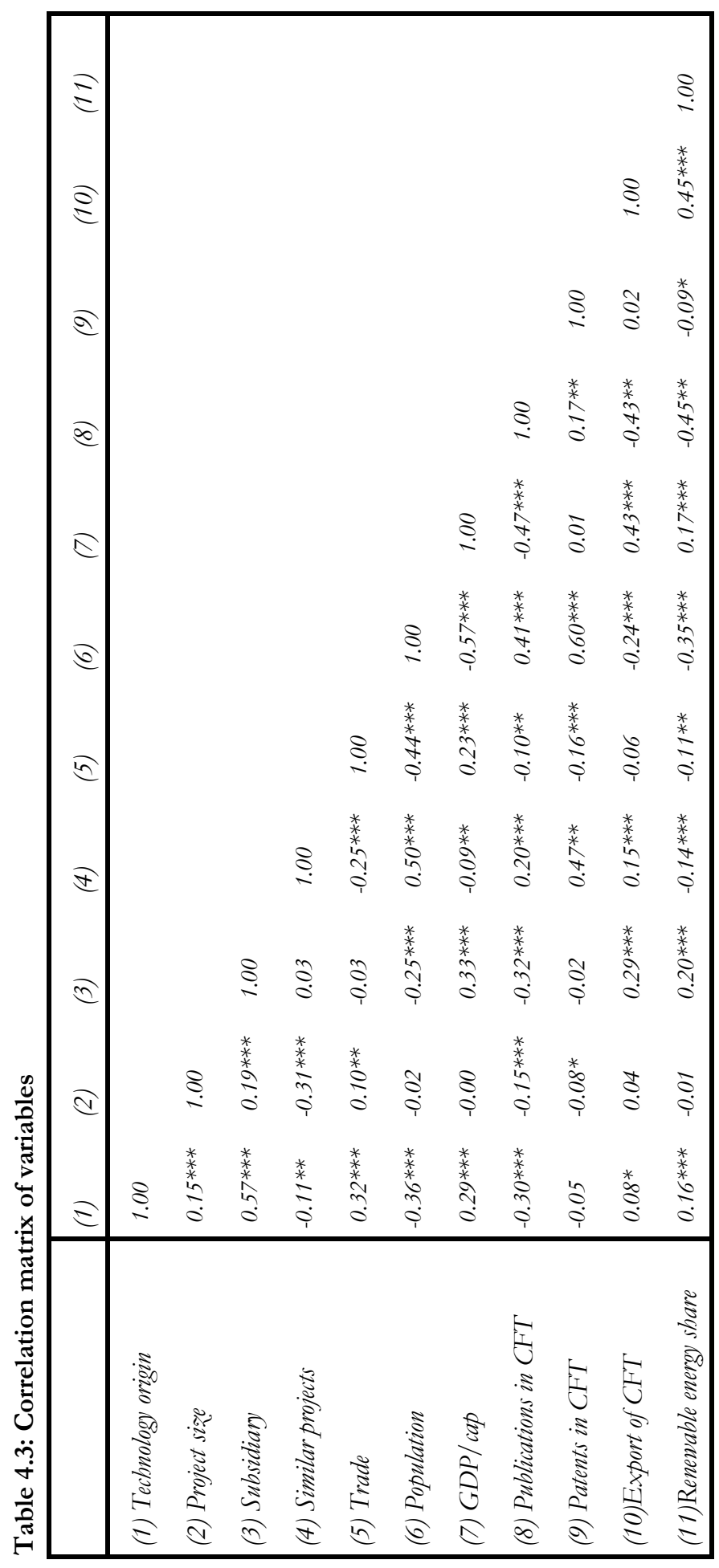




\subsubsection{Multinomial Logit Model estimation}

The dependent variable indicating technology origin in each project is a categorical variable with three possible outcomes: local, foreign and combined (Table 4.4).

Table 4.4: Distribution among outcome categories of the dependent variable "Technology origin"

\begin{tabular}{|l|ccc|}
\hline Outcome categories & Frequency & Percent & Cumulative \\
\hline Local & 257 & 55.87 & 55.87 \\
Foreign & 94 & 20.43 & 76.3 \\
Combined & 109 & 23.7 & 100 \\
\hline Total & 460 & 100 & \\
\hline
\end{tabular}

In the cases of the categories of non-ordered nature like this it is appropriate to use multinomial logistic regression model (Greene, 2003; Long and Freese, 2006). The multinomial logit essentially works as a simultaneous estimator of separate binary logits for each pair of outcome categories. When using this model, one category of the dependent variable is chosen as the comparison, or reference category. In general for $J$ alternatives, only $J-1$ binary logits need to be estimated.

In the multinomial logit model we assume that the log-odds of each response follow a linear model:

$$
\underset{\log }{\eta_{i j}}=\frac{\operatorname{Pr}_{i j}}{\operatorname{Pr}_{i j}}=\alpha_{j}+\beta_{j} \mathbf{x}_{i},
$$

where $\alpha_{j}$ is a constant and $\beta_{j}$ is a vector of regression coefficients, for $j=1,2, \ldots, J-1$. This model is analogous to a logistic regression model, except that the probability distribution of the response is multinomial instead of binomial and we have $J-1$ equations instead of one. The $J-1$ multinomial logit equations contrast each of categories $1,2, \ldots, J-1$ with category $J$, whereas the single logistic regression equation is a contrast between successes and failures.

We need $J$-1 equations to describe a variable with $J$ response categories and it makes no difference which category we pick as the reference cell, because we can always convert from one formulation to another. In our case with $J=3$ categories, 'foreign' was assigned to be the reference category, thus we contrast categories $1=$ 'local' versus 
$3=$ 'foreign', and $2=$ 'combined' versus $3=$ 'foreign'. The missing contrast between categories 'local' and 'combined' can be obtained in terms of the other two, since

$$
\log \left(\operatorname{Pr}_{\mathrm{i} 1} / \operatorname{Pr}_{\mathrm{i} 2}\right)=\log \left(\operatorname{Pr}_{\mathrm{i} 1} / \operatorname{Pr}_{\mathrm{i} 3}\right)-\log \left(\operatorname{Pr}_{\mathrm{i} 2} / \operatorname{Pr}_{\mathrm{i} 3}\right)
$$

The multinomial logit model may also be written in terms of the original probabilities $\mathrm{Pr}_{\mathrm{ij}}$ rather than the log-odds. Starting from equation (1) and adopting the convention that $\mathrm{y}_{\mathrm{ij}}=0$, we can write

$$
\operatorname{Pr}_{\mathrm{ij}}=\frac{\exp \left\{\eta_{\mathrm{ij}}\right\}}{\sum_{\mathrm{k}=1}^{J} \exp \left\{\quad \eta_{\mathrm{ik}}\right.}
$$

for $\mathrm{j}=1, \ldots, J$. To verify this result we exponentiate equation (1) to obtain $\operatorname{Pr}_{\mathrm{ij}}=\operatorname{Pr}_{\mathrm{ij}}$ $\exp \left\{\mathrm{y}_{\mathrm{ij}}\right\}$. Note that the convention $\mathrm{y}_{\mathrm{j} j}=0$ makes this formula valid for all $\mathrm{j}$. Next sum over $j$ and use the fact that $\sum_{j} \operatorname{Pr}_{i j}=1$ to obtain $\operatorname{Pr}_{i j}=1 / \sum_{j} \exp \left\{\eta_{i j}\right\}$. Finally, use this result on the formula for $\operatorname{Pr}_{\mathrm{ij}}$. Note that Equation (3) will automatically yield probabilities that add up to one for each i.

\subsection{Results}

The multinomial logit model was estimated using Stata version 10. The results of the regression are presented in table 4.5. Both models show the estimates of the choice of local technology and combined technology sources over the default category of foreign technology. Model 1 includes the results for the control variables only, whereas Model 2 also incorporates the independent variables. This table shows only the estimates for each category against the default category (foreign origin). To check whether there is a different effect of the independent variables on the different choice of technology origin, we can use odds ratios $\left(e^{\wedge} b\right.$ and $\left.e^{\wedge} b S t d X\right)$ presented in table 4.6. This table decomposes the effect of the independent variables on the technology source into binary choice models. If the value of the binary choice is greater than 1 , it indicates an effect of the independent variable on selecting one technology source over another; a value smaller than 1 indicates an effect in the opposite direction. Statistical significance of the result can be judged by the significance of the associated coefficients $(B)$ presented in the same table. 
Table 4.5: Multinomial logit estimates of preference of technology source

(Std. Err. adjusted for 36 country clusters)

\begin{tabular}{|c|c|c|c|c|}
\hline & \multicolumn{2}{|c|}{ Model 1} & \multicolumn{2}{|c|}{ Model 2} \\
\hline & Local & Combined & Local & Combined \\
\hline Project size & $\begin{array}{l}-0.388^{* *} \\
(0.127)\end{array}$ & $\begin{array}{l}-0.419^{* *} \\
(0.148)\end{array}$ & $\begin{array}{l}-0.529 * * * \\
(0.131)\end{array}$ & $\begin{array}{l}-0.453^{* *} \\
(0.168)\end{array}$ \\
\hline Subsidiary & $\begin{array}{l}-1.976^{* *} \\
(0.833)\end{array}$ & $\begin{array}{l}1.978^{* *} \\
(0.661)\end{array}$ & $\begin{array}{l}-2.210^{*} \\
(1.032)\end{array}$ & $\begin{array}{l}1.759 * \\
(0.693)\end{array}$ \\
\hline Similar projects & $\begin{array}{l}0.579 * \\
(0.268)\end{array}$ & $\begin{array}{l}0.695^{* *} \\
(0.221)\end{array}$ & $\begin{array}{l}0.362 \\
(0.299)\end{array}$ & $\begin{array}{l}0.546^{*} \\
(0.275)\end{array}$ \\
\hline Trade & $\begin{array}{l}-2.774 * * \\
(1.249)\end{array}$ & $\begin{array}{l}0.873^{*} \\
(0.527)\end{array}$ & $\begin{array}{l}-1.610 \\
(1.226)\end{array}$ & $\begin{array}{l}0.898 \\
(0.678)\end{array}$ \\
\hline Population & $\begin{array}{l}0.121 \\
(0.184)\end{array}$ & $\begin{array}{l}-0.089 \\
(0.205)\end{array}$ & $\begin{array}{l}0.722 * * \\
(0.228)\end{array}$ & $\begin{array}{l}-0.123 \\
(0.335)\end{array}$ \\
\hline$G D P / c a p$ & $\begin{array}{l}0.030 \\
(0.059)\end{array}$ & $\begin{array}{l}-0.032 \\
(0.064)\end{array}$ & $\begin{array}{l}0.114 \\
(0.078)\end{array}$ & $\begin{array}{l}-0.087 \\
(0.094)\end{array}$ \\
\hline Publications in CFT & & & $\begin{array}{l}1.726 \\
(1.486)\end{array}$ & $\begin{array}{l}0.162 \\
(1.46)\end{array}$ \\
\hline Patents in CFT & & & $\begin{array}{l}-2.287^{* *} \\
(0.759)\end{array}$ & $\begin{array}{l}0.629 \\
(1.235)\end{array}$ \\
\hline Export of CFT & & & $\begin{array}{l}1.031 * * * \\
(0.288)\end{array}$ & $\begin{array}{l}0.365 \\
(0.372)\end{array}$ \\
\hline $\begin{array}{l}\text { Renewable energy } \\
\text { share }\end{array}$ & & & $\begin{array}{l}0.056^{*} \\
(0.031)\end{array}$ & $\begin{array}{l}0.047 \\
(0.045)\end{array}$ \\
\hline _cons & $\begin{array}{l}2.078 \\
(1.448)\end{array}$ & $\begin{array}{l}-0.418 \\
(0.911)\end{array}$ & $\begin{array}{l}-1.507 \\
(1.425)\end{array}$ & $\begin{array}{l}-0.894 \\
(1.838)\end{array}$ \\
\hline Log likelihood & & 6.46 & & 3.99 \\
\hline Prob $>$ chi 2 & & 0000 & & 000 \\
\hline Pseudo R2 & & 3496 & & \\
\hline
\end{tabular}




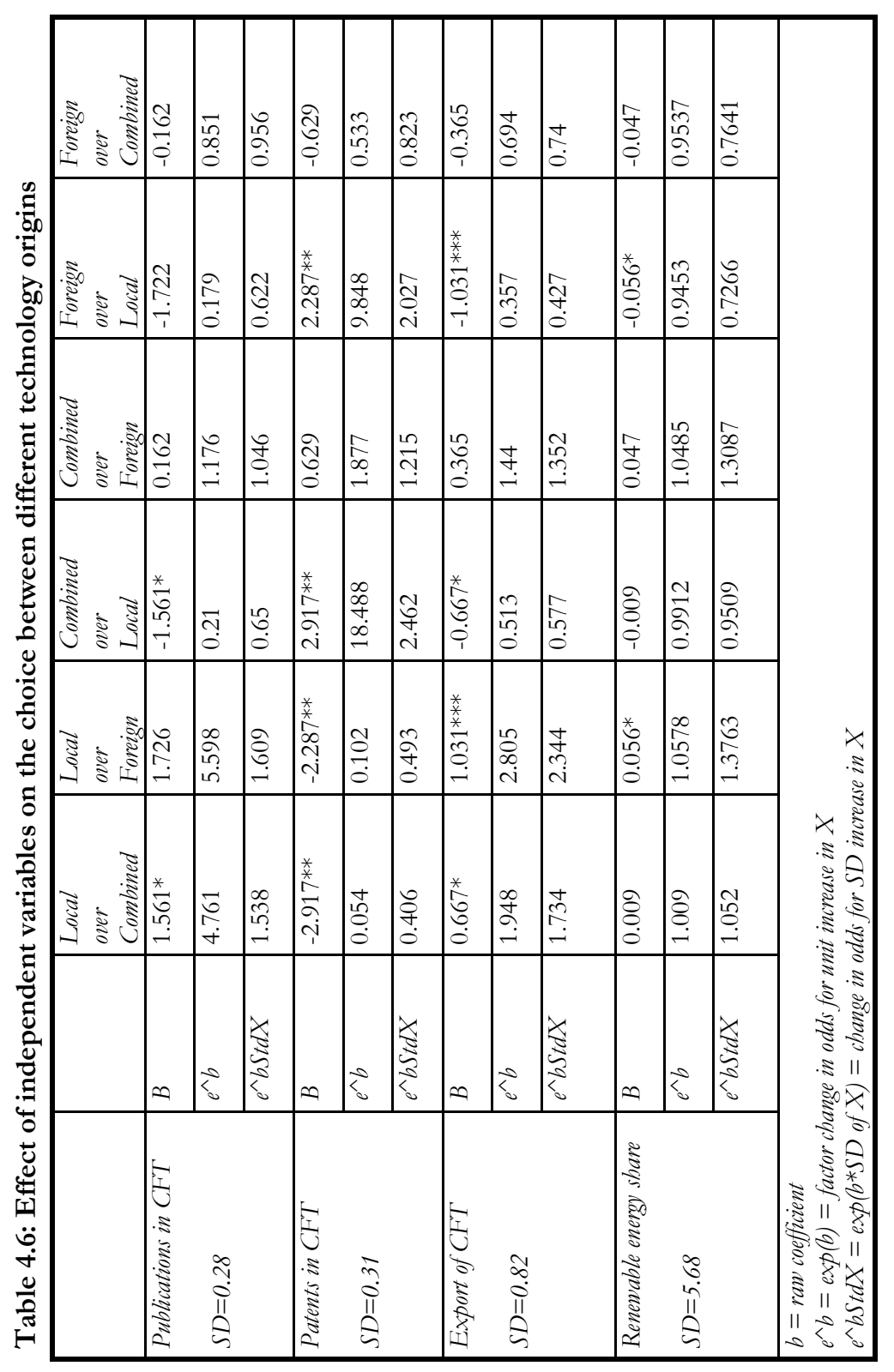


The results in tables 4.5 and 4.6 show that the scientific contribution in terms of publications in climate friendly technologies in a country is expected to have a positive effect on the preference for local over combined technologies (10\% significance) in $\mathrm{CDM}$ projects. Results for the comparison between preferences of local and combined over foreign technologies do not show statistical significance; therefore we are not able to draw conclusions.

The results for the influence of patenting activities show a negative effect on using purely local technology and to the contrary seem to be associated with a preference for combined technology over local. A positive association is also observed for "Foreign over Local". We note that the magnitude of the coefficients make it clear that countries with high patenting activities give slightly higher preference to combined sourcing over foreign. The results on local and foreign technology sourcing show the opposite of our expectations and require careful interpretation.

Results on the effect of a country's export of renewable energy and CFT's on the preference of local technology over imported ones show a positive, stable, and strong significance in the regression model. A slightly smaller but still positive coefficient is associated with preference of local over combined technologies (10\% significance). This logically supports the idea that availability of the technology on the local market decreases the propensity of bringing in similar technology from abroad.

Countries' renewable energy production data showed a rather modest but positive effect towards a preference of local over imported technologies. This can be stated with an acceptable confidence level (10\% significance). The result for combined vs. imported, as well as for local vs. combined technologies didn't show results with sufficient statistical significance level.

It would also be informative to present the results for control variables. Project size the first micro (project) level variable- showed consistency in negative influence on choice of both local and combined over imported technologies. This confirms findings of previous studies saying that larger CDM projects mostly rely on foreign technology and smaller projects source local technology (Seres, 2008; Haites et al, 2006; Dechezlepretre et al, 2008). We would add that smaller projects rely almost equally on local or combined sources of technology (though with very tiny preference for the combined option) rather than exclusively on foreign technologies.

Results for subsidiary effects show that project implementers who have an affiliation with a foreign company prefer combined technologies over purely local and purely foreign technologies. This effect is also strong in the choice of foreign technologies over local ones. This observation is also in line with findings of previous studies. 
The existence of other, similar projects increases the propensity of using local and combined technologies over foreign ones. This is probably due to the local availability of technologies which leads to a higher number of projects in the same technological sector. However we note that in the model 2 we did not obtain statistically significant coefficients for preference of local over foreign technology. We also note that the coefficient for combined technologies (in Model 1) is slightly higher, meaning that project developers have a slightly higher preference for combined over purely local sourcing.

Talking about the effect of macro level economic indicators, our model 2 showed a statistically significant positive effect of the country size and no evidence of influence of income level on the preference for local over foreign and combined technologies. Results for other categories are not statistically significant and the effect of the country size on the choice between combined and imported technologies can not be predicted with certainty. Thus our results regarding the role of the size and economic performance of the country seem to be in contrast with previous studies (Seres, 2008; Haites et al, 2006; Dechezlepretre et al, 2008) proposing a peripheral nature of these indicators in explanation of technology transfer statistics.

The result of Model 1 on the role of trade openness of the country is consistent with previous studies, while in Model 2 results can not be stated with high confidence. In the base model Trade indicators show a rather strong association with the application of combined technologies (to more extent) and foreign technologies (to lesser extent) and have a negative association with the application of purely local technologies. Hence, this result seems to confirm the argument that trade openness makes the import of technologies for CDM projects easier.

\subsection{Discussion}

In this study we examined whether the technological knowledge base of a host country determines the technology sourcing patterns in the CDM projects. Since the initiation of the CDM scheme, trends in CDM projects have been showing reliance mostly on local sources of technology. This was in contrast with the expected large technology transfer from developed economies that possess far superior expertise in environmental technologies. Thus our task was to investigate factors that can explain these developments. A logical line that was pursued in this study suggested that the developing countries already have climate friendly technologies locally available, and CDM became another enabler for their commercialization. We investigated macro-level data indicating locally available expertise in these technologies and tried to use these data in explanation of technology sourcing trends in CDM project. Distinction was 
made between applied and scientific expertise and the role of each was investigated in technology origin preferences in CDM projects. It is always a challenge to explain micro level developments through macro level factors, so in this study we tried to justify the choice and made arguments as plausible as possible.

With our empirical results we can declare that countries with more experience in applying and producing climate friendly technologies have a higher probability in using local and combined technologies in CDM projects. This is certainly established through the export indicator, which represents a country's capacity to manufacture equipment, machines, and trade them abroad. This implies that if the country produces and exports technologies there is rarely a need to import technologies for CDM projects. The results for renewable energy generation data also suggest the importance of practical experience and availability of local expertise in making the choice for local technologies in new projects. Thus our results show a positive influence of local knowledge associated with CFT application in selecting a local source of technology in CDM projects.

However, the results for scientific knowledge are quite intricate, which gives room to a range of speculations. While scientific effort in terms of publications seems to associate positively with local and mixed technology sourcing, patenting activities show a positive association with mixed and foreign technologies, but a negative one with local technologies. It is quite a challenge to give a complete explanation. The reason behind a high preference for combined technology could possibly be that countries with high patenting statistics like Israel, South Korea and Cyprus implement more joint projects with overseas partners who bring foreign technology along. However, these countries seem to have frequent cases of import of a complete set of technology for the CDM project. This factor could be associated with more active trade activities and sometimes the smaller size of these countries.

If we take the perspective of the countries where CDM projects rely mostly on local technology, there might be a few explanations related to how the patent institute functions there. One argument could be that the patent institute possibly is not very well established in a number of developing countries (Correa, 2005) In the countries where it is established it might not be fully enforced, or the local technology developers rely on other mechanisms to protect their technology (Lesser, 1991) which might cause the large occurrence of zero- and one-patent countries in our dataset. However there might be additional explanations and we would suggest further investigation of this issue.

Another important point that has to be considered in our analysis lies in the difference between applied and scientific knowledge. This difference has direct implication from a technology lifecycle perspective. Applied or experience related knowledge is the one associated with diffused, economically proven and mature technologies, while patents 
and publications basically represent new technologies that still need to prove their economical viability and often these new technologies never reach their adoption and diffusion stage. It is necessary to bear in mind that here we analyse the application of technology in CDM projects which represent the commercialization stage of the technology lifecycle. In this stage a technology that has already proven its cost effectiveness and marketability in the local market, would be deployed in a project. Therefore it is fairly reasonable to observe clear and strong positive results for applied knowledge data, and to obtain mixed results for patents and publication data. The latter may suggest that availability of theoretical knowledge and scientific developments may not always translate into their practical deployment.

\subsection{Conclusion and implications}

This study has demonstrated that technological knowledge in climate friendly technologies can, to a certain degree, explain the technology sourcing pattern in CDM; consistent results were obtained with three out of four proxies for the knowledge base. Thus with reference to the research questions we can argue that the present technological knowledge base, to a certain extent determines technology sourcing patterns in CDM projects, and more specifically the better knowledge base seems to positively associate with preference for local technologies. The role of practical knowledge has proved to be more significant than the scientific knowledge. The general conclusion is that countries with greater experience in development and application of technologies tend to rely more on their own technology or collaborate with foreign partners in compiling the technological facility, rather than to rely solely on imported technology.

It is also necessary to mention that this study showed clear indications of a methodological contribution in measuring the knowledge base of the country in the specific niche of climate friendly technologies. Results of the study demonstrated that the knowledge base indicators proposed by us could be used to explain to a certain extent the technology transfer patterns in CDM projects, although their application might need some cautiousness ${ }^{14}$.

Along the methodological input, this study contributes to the literature on transfer and diffusion of environmental technologies in developing countries. The novelty of the study is in bringing the case of CDM project related technology transfer, which has not received its deserved attention in the literature stream. Second, and more importantly, it merges the perspective of knowledge base national technological capabilities with a focus on environmental technologies in this literature stream. We stress the importance

\footnotetext{
${ }^{14}$ This is especially true in the case of patent data, which presented two difficulties to us: first in terms of availability, and second in the correct interpretation of their impact in the model.
} 
to investigate the role of environmental and renewable energy policies in building the technological and knowledge base of a country. It is well established that for development, innovation and diffusion of environmental technologies the role of the right state policies is of great importance (Lewis and Wiser, 2007, Lanjouw and Mody, 1993; Jaffe and Stavins, 1995). In the context of technology transfer under CDM, studying renewable and energy policies of developing countries and their role in CDM associated sourcing technologies from abroad or developing them locally, might give interesting perspectives.

Results of the study suggest implications both for developing countries striving to address economic problems, as well as for developed countries which are interested in reaching emission reduction targets. Developing countries with better technical and scientific expertise would not need to depend on foreign technology to initiate CDM projects, which allows avoiding transaction costs associated with importing technology from abroad and decreases the overall investment cost of the project. Furthermore, local production of the technology is allied with other socio-economic benefits such as employment of local people in manufacturing and other stages of the production chain. Sourcing the local technology or cooperating with foreign technology providers spurs the economic base of the local producers.

What are the implications of the study results for the international policy agenda? First of all, they call for changing the paradigm of technology transfer in the climate change mitigation agenda and consider developing countries not as passive receivers of technology, but as producers and innovators. In line of the sustainable development perspective the importance of building effective national innovation systems need to be highlighted rather than the just narrow technology transfer activities. Second, the interest of the developed countries -the purchasers of carbon emission credits generated by CDM projects- is in the economic cost-effectiveness of the project. In the short and long-run, reliance on the developing countries' expertise and technology would allow to secure higher cost-effectiveness of the investment in projects and to reduce the overall cost of climate change mitigation.

Nonetheless, we see a number of points that represent limitations of the present study. First, in the knowledge base concept and the collection of indicators that have been applied in our study we missed the indicator capturing human capital. A country's human capital, represented by the pool of scientists, engineers, graduates of technical schools and universities, is an important component of the national- level technological capabilities (Achibugi and Coco, 2004; Lall, 1992). However the country-level data on engineers, graduates, scientist in energy and environmental technologies were hardly available restraining us from involvement of human capital related factors in our study. Another, albeit less favourable option is to use data on total scientists and engineers 
provided by UNESCO, National Science Foundation, UNDP Human Development Report, though these sources also lack data on many developing countries ${ }^{15}$.

Another limitation of the study emerges from the fact that we used aggregated data on different technologies. First of all they concern publications, patents, production and export data. In our study we tried to be more specific by focusing on extracting data on the climate friendly technologies' group. What would be even more interesting to do is to break our focus further down and to carry a separate analysis for each technology type. This would require fracturing the sample as well as each variables group according to technology type, but this exercise would envisage more accurate and challenging results.

Despite the limitation, as well as in line with addressing them, the study opens new avenues for further research which may also allow us to understand and explain the trends in CDM based technology transfer in a more comprehensive way. The importance of the study is that it builds a stepping stone for further research and discussion of the role of developing countries in global climate change mitigation.

${ }^{15}$ In regards to our study, data were not available for over half of the countries represented in our sample. 


\section{PART III. MICRO LEVEL VIEW ON CDM AND TECHNOLOGICAL LEARNING}

\section{CHAPTER 5. TECHNOLOGICAL LEARNING PATTERNS AND INTENSITY IN CDM PROJECTS: OVERVIEW OF THE SURVEY RESULTS}

\subsection{Introduction}

In chapter 2 we described the process of data collection through survey of companies implementing CDM projects in China, Brazil, India and Mexico. This chapter's purpose is to present the survey outcomes. On the basis of descriptive statistics we analyse technological learning patterns and trends at the aggregate level (i.e. all sample) and a disaggregated level (i.e. for each country and subgroup). The latter is necessary in order to see if there are any cross country and subgroup level differences in the observed patterns. However before presenting the survey results we shall explain how we measured learning outcome of CDM projects.

\subsection{Framework for measuring learning outcomes of CDM projects}

The line of the analysis in part 5.3 of this dissertation is built on the idea that the realization of $\mathrm{CDM}$ projects is expected to have an impact in the form of learning, or of accumulation of technological capabilities of the project host companies. To be able to assess the learning impact we needed to define types of technological capabilities to be used as proxies for measuring learning progress. In defining our classifications we base ourselves on the taxonomies of technological capabilities suggested by Lall (1992), Biggs et al. (1995), Bell and Pavitt (1993); Amdsen (2001); Figueiredo (2001); Bell (2007). These taxonomies generally distinguish between routine production capabilities and innovative technological capabilities. Variations in many cases also include such capability types as adaptive, duplicative, linkage, investment (Lall, 1992; Biggs et al, 1995), project execution (Amdsen, 2001; Bell, 2007), design, and engineering capabilities (Bell, 2007). Application of different frameworks of technological capabilities depends on the scope and focus of study, or industry, or sectors being analyzed. Often frameworks are applied to investigate the life-time evolution of a certain company or sector (e.g. Figueredo, 2001, 2003; Ariffin 2000).

In our case we studied a relatively short-term progress in the technological capabilities level of companies implementing CDM projects. Because there are a number of diverse technologies applied in CDM projects we made use of a framework that includes technological capabilities common for the whole group. Our framework distinguishes 3 categories, the process operation capabilities, the most basic ones, the process improvement capabilities, or intermediary ones, and the innovative capabilities, 
which are categorized as advanced. Operation capabilities involve the skills, knowledge, and resources needed to use the technology, plant, and processes efficiently to make established outcomes. These capabilities enable firms to deal with day-to-day activities (and problems), such as monitoring of raw material input, scheduling production, controlling process quality, maintaining machinery, etc. Process improvement capabilities consist of the skills, knowledge, and resources which enable firms to assimilate, change, and improve technology through such activities as capital stretching, adapting or modifying processes, improving efficiency, etc. The category of innovative or advanced capabilities includes design and engineering skills and resources. Table 5.1 presents constructs for each category of capabilities, and an explanation for each construct. The framework was also discussed with experts dealing with CDM project implementation and then adjusted according their recommendations.

Table 5.1: Technological Capabilities taxonomy applied in the research

\begin{tabular}{|c|c|c|}
\hline category & construct & Explanation \\
\hline $\begin{array}{l}\text { Process operation } \\
\text { capabilities } \\
\text { (basic) }\end{array}$ & $\begin{array}{l}\text { Preventive maintenance } \\
\text { Process quality control } \\
\text { Debugging } \\
\text { Equipment adjustment }\end{array}$ & $\begin{array}{l}\text { Revealing possible defects/Maintenance of } \\
\text { machines/equipment on a regular basis } \\
\text { Systematic independent control of the quality } \\
\text { of the technological process } \\
\text { Removing defects, mistakes, breakages in the } \\
\text { equipment } \\
\text { Adjustment of the equipment(s) to the local } \\
\text { conditions, or to the particular technological } \\
\text { lines/system }\end{array}$ \\
\hline $\begin{array}{c}\text { Process } \\
\text { improvement } \\
\text { capabilities } \\
\text { (intermediary) }\end{array}$ & $\begin{array}{l}\text { Equipment stretching } \\
\text { Efficiency improvement } \\
\text { and cost saving } \\
\text { Process adaptation }\end{array}$ & $\begin{array}{l}\text { Increase the scope of functions or } \\
\text { productivity of the equipment. } \\
\text { Reducing cost, energy consumption of the } \\
\text { equipment by keeping high production level } \\
\text { Adaptation of the technological process to } \\
\text { local circumstances/ conditions/ changes }\end{array}$ \\
\hline $\begin{array}{l}\text { Innovative } \\
\text { capabilities } \\
\text { (advanced) }\end{array}$ & $\begin{array}{l}\text { Equipment design } \\
\text { Development of } \\
\text { turnkey project/ facility }\end{array}$ & $\begin{array}{l}\text { Engineering design of the technological } \\
\text { process / technological line, inventions, with } \\
\text { possible patenting } \\
\text { Detailed design of the single equipment/ } \\
\text { machine, inventions, with possible patenting } \\
\text { Detailed design of a complete technological } \\
\text { facility/ unit/ plant }\end{array}$ \\
\hline
\end{tabular}

Source: elaborated by author, based on technological capabilities literature and discussion with project specialists 


\subsection{Patterns in technological learning in CDM projects}

As was described above technological learning was measured by assessing the progress in technological capabilities. Respondents were asked to assess the progress in each of these capabilities using a scale from 0 (no increase) to 6 (very high progress).

Aggregated results of the survey presented in Figure 5.1 show that the progress in technological capability levels did occur as a result of CDM project experience. The reported progress in technological capabilities ranges, on the average, between 2.16 and 3.41 (on the $0-6$ point scale) for all ten types of capabilities. It is clearly visible that progress in advanced capabilities group associated with development and innovative performance, is smaller than in the basic and intermediate capability groups. The mean estimate for each subgroup is 2.99 for the basic capabilities, 2.85 for the intermediary, and 2.47 for the advanced capabilities, which generally supports the assumption that development of more advanced capabilities is a much more complex process, which requires more time and more efforts (Bell and Pavitt, 1993; Ernst et al, 1998; Hobday, 1995; Kim, 1997; Lall, 1992). The disaggregated results on each type of capability show variations in comparison to aggregated statistics. For example, two of three intermediary level capabilities, namely 'process adaptation' and 'efficiency improvement and cost saving' were reported to have an average progress of 3.03 and 3.10, which is comparatively higher than in the three out of four categories of basic capabilities (ranging between 2.78 and 2.94). In overall statistics, the most progress was achieved in capabilities in process quality control (3.41) and the least in equipment design (2.16). These results show rather large standard deviation numbers indicating a larger spread of the values across the sample. This can also be seen from the web-diagrams in figure 5.2 which shows more details on technological capability building performance in each subgroup.

Figure 5.1 A progress in technological capabilities as reported by survey respondents: mean values and standard deviations (scores 0-6)

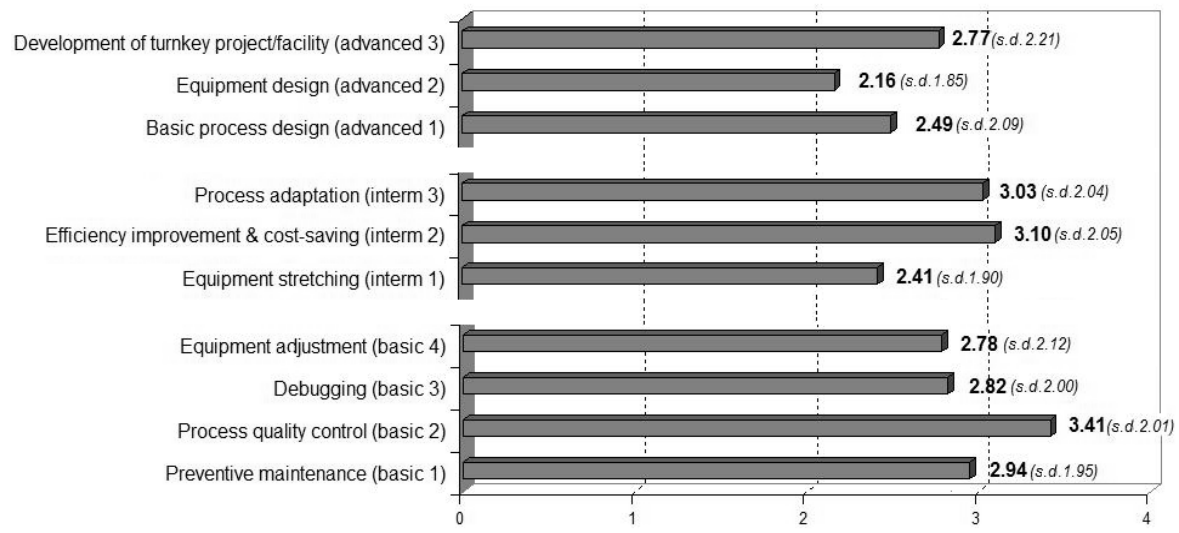

$(N$ observations $=104)$ Source: own calculation based on survey data 
Table 5.2: T-test results comparing differences among Basic, Intermediate and Advanced TC groups

\begin{tabular}{|l|c|c|c|}
\hline & $\begin{array}{c}\text { Basic TC } \\
\text { versus } \\
\text { Intermediate TC }\end{array}$ & $\begin{array}{c}\text { Basic TC } \\
\text { versus } \\
\text { Advanced TC }\end{array}$ & $\begin{array}{c}\text { Intermediate TC } \\
\text { versus } \\
\text { Advanced }\end{array}$ \\
\hline Mean & Basic TC & Basic TC & Advanced \\
Standard deviation & 2.99 & 2.99 & 2.47 \\
Mean & 1.89 & 1.89 & 1.77 \\
Standard deviation & Intermediate TC & Advanced & Intermediate TC \\
Mean difference & 2.85 & 2.47 & 2.85 \\
T-value & 1.86 & 1.77 & 1.86 \\
Sig. (2-Tailed) & 0.14 & & \\
\end{tabular}

Source: own calculation based on survey data

Table 5.2 shows the results of T-test comparing differences in mean values in Basic, Intermediate and Advanced TC groups. Difference between Basic and Advanced groups while having largest is also statistically significant at $10 \%$ level. Difference between mean values of Basic and Intermediate, as well as between Intermediate and Basic TC groups is not statistically significant. The fact is that the most differences are not statistically significant is probably due to small size of the sample.

The diagrams in figure 5.2 disaggregate the survey results by presenting counts of scores in each subgroup. It shows that the respondents in general reported low progress (2-score) more often than any other score in every capability category., especially in comparison with the two lowest and the highest impact categories. Relatively more frequent zero progress was reported for capabilities associated with equipment design, efficiency improvement, and equipment stretching. Overall zero impact counts ranged between 5 and 23, showing smaller counts for basic capabilities and larger for intermediary and advanced categories.

Combination of small counts and higher ranges among counts are also observed for the very low progress category (1-score). Here we see more frequent counts for advanced capabilities group and less frequent counts for all intermediate and most of the basic capabilities groups. It is interesting to note that combining these 'no impact' and 'very low impact' groups might supplementary result in more equally distributed counts for each type of capability. 
Figure 5.2 Impact of CDM experience on technological capabilities: counts of cases in each score group

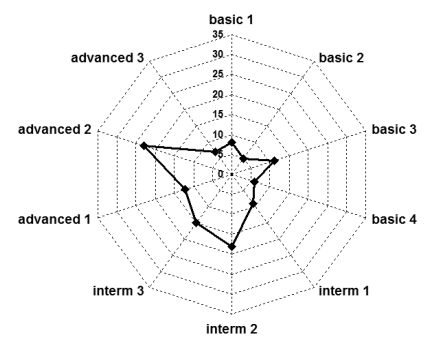

no impact (0-scores)

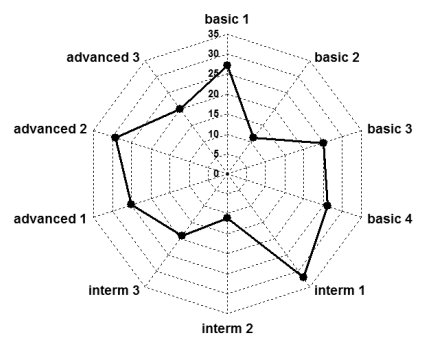

low impact (2-score)

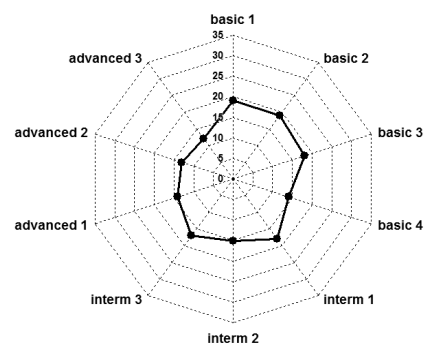

medium impact (4-score)

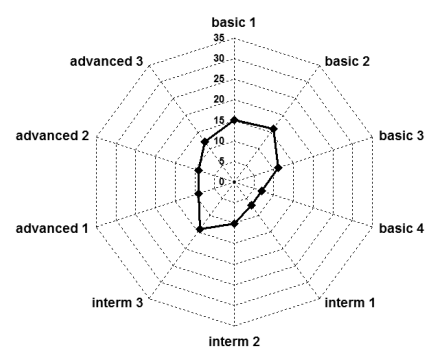

high impact (6-score)

Source: own calculation based on survey data

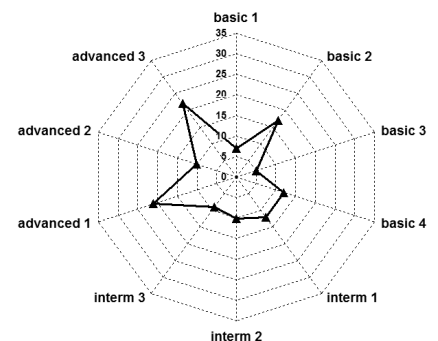

very low impact (1-score)

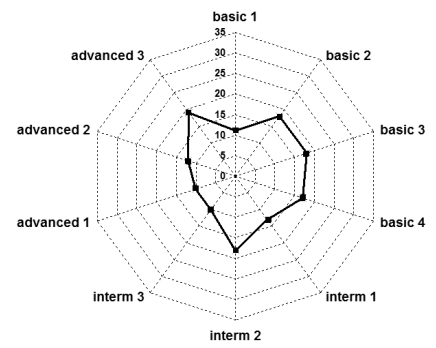

medium-low impact (3-score)

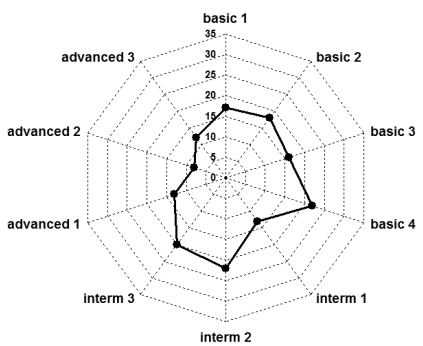

medium high impact (5-score) 
As noted above the largest counts seem to be in the 2-score group. However this diagram also shows the large divergence among counts for progress in different types of capabilities (between 11 and 33). Although this layout seems to point to the dominance of the lower learning impact of CDM projects, three other diagrams must be considered; the 3-score, 4-score, and 5-score diagrams. These diagrams show more consistencies among types of capabilities, as well as among themselves in terms of having a smoother shape characterizing smaller divergence in count numbers for each capability type and having fairly close ranges (between 10-20). A closer look at the diagrams shows that counts for advanced level capabilities are slightly fewer than for basic and intermediary capabilities. A combination of these three score sub-groups will produce a relatively large group having 'about medium' level learning impact from $\mathrm{CDM}$ project. The last web-diagram demonstrates that the highest score for progress in technological capabilities was reported relatively less frequent; basic capabilities counting for the most, and the advanced capabilities for the least number of cases.

This disaggregation analyses and singled out statistics on each score group show a very diverse progress in technological capabilities of project host companies. Nevertheless, it is rather clear that most of them experienced progress between low impact (score 2) and medium high (5 score) levels, confirming convergence towards the estimated earlier mean values of the reported scores for technological capabilities (Figure 5.2). Very little evidence for high progress suggests that just a few project-host companies managed to perfect their technological capabilities as a result of CDM projects and that it is a rather difficult task to achieve this level.

\subsection{Differences across technology groups}

This section contains an analysis of technological learning patterns in different technology groups. CDM projects cover very diverse greenhouse gas emission cutting technologies. For the ease of understanding and also for the purpose of delineating differences in learning patterns across projects, the technologies have been aggregated into three categories - each category having some characteristics in common. The first category, being the largest, includes renewable energy technologies, namely wind energy, hydro power and energy from biomass production. Although these technologies could conceptually be different, they are all electricity producing technologies. The second category is the most diverse one and consists of greenhouse gas emission reduction in various industries and service sectors. While some of them involve end-of-pipe emission cutting (fugitive emissions capturing and HFC destruction), others reduce emissions by improving the technological process, using less carbon intensive fuel and introducing energy saving measures. The third group is formed by the technologies for the capturing and utilization of methane emissions from organic waste. Methane is a very strong greenhouse gas, released during the 
decomposition of organic compounds in anaerobic condition. On the landfill sites this gas is collected and burned. In animal farms and waste water treatment plans, special digesters, along with biogas storage tanks, are installed. In some cases collected biogas is used in the production of hot water and/or electricity. We note that this group is quite large, with biogas production technologies counting for about one third of the whole sample.

Table 5.3: TC building progress estimates for each technology group

(0-6 scale, average for each technology)

\begin{tabular}{|r|c|ccc|}
\hline & $\begin{array}{c}\text { Size of } \\
\text { group }\end{array}$ & $\begin{array}{c}\text { basic } \\
\text { TC }\end{array}$ & $\begin{array}{c}\text { intermediate } \\
\text { TC }\end{array}$ & Advanced TC \\
\hline Hydropower & 17 & 2.65 & 2.53 & 1.58 \\
Electricity from renewable energy & & & & \\
Energy from biomass & 17 & 4.6 & 2.55 & 2.49 \\
Emission reduction in industry & & & 4.08 & 3.12 \\
Cement production & 2 & 1.75 & 2.5 & \\
Energy efficiency & 7 & 4.96 & 4.9 & 4.5 \\
Fuel switch & 1 & 0 & 0 & 0 \\
Fugitive emission & 1 & 5 & 5.33 & 3.33 \\
HFC gases destruction & 2 & 4.75 & 3 & 3.5 \\
Methane capture/waste management & & & & \\
Biogas production & 34 & 1.63 & 1.82 & 1.82 \\
Landfill gas capture & 7 & 4.54 & 4.52 & 3.67 \\
\hline
\end{tabular}

Source: own calculation based on survey data

Table 5.3 presents average outcomes in technological capability building for each technology group within each category. It depicts quite substantial heterogeneity among some groups. For example, technological learning from biomass-to-energy projects, energy efficiency activities, HFC gases destruction, fugitive emissions and landfill gas capture projects generated good progress in all levels of technological capabilities (between 3 and 5.3), which is well above the mean values for overall sample. Activities on installation of wind and small hydropower plants generated average level learning and show higher progress in basic capabilities and decreasing patterns for intermediate and advanced capabilities. The biogas technology hosts' group (the largest group) showed relatively small progress (between 1.62 and 1.82), suggesting smaller learning impact from CDM experience. However it is interesting to note that they reported slightly higher progress in their process improvement (intermediary) and innovative (advanced) capabilities compared with progress in basic process operation capabilities. Noticeably, cement producers show a very distinct trend in their technological capabilities accumulation; while having small improvement in basic capabilities (1.75) and slightly larger progress in intermediary level skills (2.5), they reported very great progress in innovative competences (4.5). These scores suggest very 
active involvement in research and development activities by cement companies. In this respect WBCSD (2008) reports the growing interest and involvement of cement producers in the development of new ways of producing cement so that, as well as through overall reduced energy consumption, $\mathrm{CO}_{2}$ emission reduction can also be achieved in the process of calcinations. Fuel switch technology cases are reported to have zero progress in all ranges of technological capabilities. Because it is the only observation in this technology category it is unclear whether it is the general trend in this type of project, or that this is just the case of this specific project host.

\subsection{Cross country differences}

Disaggregated country level statistics on each type and subgroup of technological capability building progress is presented in Table 5.4. The Indian project operators reported, on the average, higher progress (3.66), followed by the Chinese (3.25) and Brazilian (2.35) companies. The Mexican companies being the least learning subgroups, showed only half of the progress of the Indian project operators (1.63). The composition of Mexican CDM project portfolio suggests that country-level modes learning performance comes from the fact that the dominant majority of projects implements there are in biogas technology, and this technology group showed considerably lower learning impact than other technology group.

Table 5.4: CDM related technological learning: Country level estimates (0-6 scale, average for each country)

\begin{tabular}{|l|ccccc|}
\hline & Brazil & China & India & Mexico & total sample \\
\hline Size of the sample & $N=40$ & $N=13$ & $N=35$ & $N=16$ & $N=104$ \\
\hline Preventive maintenance & 2.15 & 4.08 & 4.0 & 1.69 & 2.94 \\
Process quality control & 3.20 & 4.31 & 3.97 & 2.0 & 3.41 \\
Debugging & 2.30 & 3.69 & 3.71 & 1.44 & 2.82 \\
Equipment adjustment & 2.28 & 2.77 & 3.83 & 1.75 & 2.78 \\
Average basic TC's & $\mathbf{2 . 4 8}$ & $\mathbf{3 . 7 1}$ & $\mathbf{3 . 8 8}$ & $\mathbf{1 . 7 2}$ & $\mathbf{2 . 9 9}$ \\
& 1.83 & 2.31 & 3.37 & 1.88 & 2.41 \\
\hline Equipment stretching & 2.63 & 4.23 & 3.86 & 1.69 & 3.10 \\
Efficiency improvement \& cost-saving & 2.40 & 4.0 & 4.03 & 1.63 & 3.03 \\
Process adaptation & $\mathbf{2 . 2 8}$ & $\mathbf{3 . 5 1}$ & $\mathbf{3 . 7 5}$ & $\mathbf{1 . 7 3}$ & $\mathbf{2 . 8 5}$ \\
Average intermediate TC's & & & & & \\
\hline Basic process design & 2.25 & 2.15 & 3.34 & 1.50 & 2.49 \\
Equipment design & 1.70 & 2.38 & 2.89 & 1.56 & 2.16 \\
Development of turnkey project/facility & 2.78 & 2.54 & 3.60 & 1.13 & 2.77 \\
Average advanced TC's & $\mathbf{2 . 2 4}$ & $\mathbf{2 . 3 6}$ & $\mathbf{3 . 2 8}$ & $\mathbf{1 . 4 0}$ & $\mathbf{2 . 4 7}$ \\
\hline \multicolumn{1}{|c|}{ Total Average } & $\mathbf{2 . 3 5}$ & $\mathbf{3 . 2 5}$ & $\mathbf{3 . 6 6}$ & $\mathbf{1 . 6 3}$ & $\mathbf{2 . 7 9}$ \\
\hline
\end{tabular}

Source: own calculation based on survey data 
In mastering advanced technological capabilities Indian companies showed on the average the highest progress by reporting considerably higher score than the rest of countries. This country level performance generally follows the trend showing the highest increase in basic operation capabilities, and the lowest in innovative and design expertise, with intermediate capabilities ranging in between. A small deviation appears though in the Mexican trend: project hosts in this countries scored almost equal average progress in basic and intermediary capabilities (1.72 and 1.73)

\subsection{Project host companies characteristics and technological learning}

Innovation and technical change literature highlight relevance of firm specific features such as age, size, human capital, experience, etc. in their learning, technology adoption and assimilation performances. Therefore in the survey we collected a wide scope of data about CDM project host organizations. Table 5.5 presents data on characteristics of project hosts in a cross country comparison perspective.

Average age of project host companies varies between 6.7 years in China to 18.5 years in Brazil. One can see though, that the average age statistics is rather close for Brazil, India and Mexico (between 14 and 18.5), in comparison to the Chinese companies, which appear to be at least twice as young. The actual age statistic ranges from one to 83 years, evidencing very large variations form the average values. In order to inspect any trends in technological learning related to age differences we split the sample in two groups having median ( $=10$ years) as a cutting point. This gives us two subgroups of 52 observations each. Figure 5.3 demonstrates differences between two subgroups in their average progress in all levels of technological capabilities. One can observe that younger companies achieved significantly higher progress than older companies, particularly in basic and intermediary capabilities. The increase in advanced capabilities does not differ very much between the two gropes. It is interesting to see that older companies sustained practically equal progress in each of three levels of technological capabilities, while the impact diminished for younger companies in the more advanced categories of capabilities.

One of the measurements for company size is the number of employees. In this respect Indian companies show, on the average to be the biggest and, almost double the Brazilian, triple the Chinese, and quadruple the Mexican average size of companies (see table 5.5). The actual size of companies in the total sample varies between 8 and 5000 employees showing large heterogeneity. Using median $=50$ employees as a cutting point we split the sample into two groups to see possible differences in learning progress. Figure 5.4 shows that in comparison with smaller companies, larger sized entities achieved, on the average, smaller progress in improving their capabilities after experience with CDM projects. This holds for all three levels of capabilities, with the gap being largest in basic capabilities and a further reduction in intermediary and advanced levels. 
Table 5.5: Characteristics of CDM project host companies

\begin{tabular}{|c|c|c|c|c|}
\hline & Brazil & China & India & Mexico \\
\hline Size of the sample & $N=40$ & $N=13$ & $N=35$ & $N=16$ \\
\hline Average age of company, years & 18.5 & 6.7 & 17.3 & 14.0 \\
\hline \multicolumn{5}{|l|}{ Number of employees: } \\
\hline Average number of employees & 366.5 & 208.5 & 644.6 & 151.8 \\
\hline $\begin{array}{l}\text { Average number of employees with } \\
\text { university degree (\% from total) }\end{array}$ & $\begin{array}{c}84.7 \\
(16.9 \%)\end{array}$ & $\begin{array}{c}55.6 \\
(41.8 \%)\end{array}$ & $\begin{array}{c}290.2 \\
(28.9 \%)\end{array}$ & $\begin{array}{c}16.0 \\
(12.4 \%)\end{array}$ \\
\hline $\begin{array}{l}\text { Average Number of employees with } \\
\text { technical school degree (\%from total) }\end{array}$ & $\begin{array}{r}155.23 \\
(22 \%)\end{array}$ & $\begin{array}{c}89.85 \\
(42.7 \%)\end{array}$ & $\begin{array}{l}140.94 \\
(34 \%)\end{array}$ & $\begin{array}{c}27.69 \\
(19.1 \%)\end{array}$ \\
\hline Average \% of highly skilled employees & $39 \%$ & $84.6 \%$ & $63 \%$ & $31.5 \%$ \\
\hline \multicolumn{5}{|l|}{$\mathrm{N}$ of companies with prior experience: } \\
\hline in technology application (\% from total) & $18(45 \%)$ & $7(53.8 \%)$ & $26(74.3 \%)$ & 0 \\
\hline in technology development (\% from total) & $18(45 \%)$ & $8(61.5 \%)$ & $25(71.4 \%)$ & $2(12.5 \%)$ \\
\hline $\begin{array}{l}\mathrm{N} \text { of companies hosting more than } \\
\text { one CDM projects (\% from total) }\end{array}$ & $13(32.5 \%)$ & $2(15.4 \%)$ & $16(45.7 \%)$ & $4(25 \%)$ \\
\hline \multicolumn{5}{|l|}{ Ownership status: } \\
\hline Number of state companies (\%from total) & 0 & $4(30.8 \%)$ & $7(20 \%)$ & 0 \\
\hline $\begin{array}{r}\text { Number of domestic private companies } \\
\text { (\%from total) }\end{array}$ & $31(77.5 \%)$ & $9(69.2 \%)$ & $26(74.3 \%)$ & $13(81.3 \%)$ \\
\hline $\begin{array}{r}\text { Number of foreign private companies } \\
\text { (\%from total) }\end{array}$ & $8(20.0 \%)$ & 0 & $2(5.7 \%)$ & 0 \\
\hline Number of joint-ventures (\% rom total) & $1(2.5 \%)$ & 0 & 0 & $3(18.8 \%)$ \\
\hline
\end{tabular}

Source: own calculation based on survey data 
Figure 5.3 TC building differences in younger and older companies (average values on 0-6 scale)

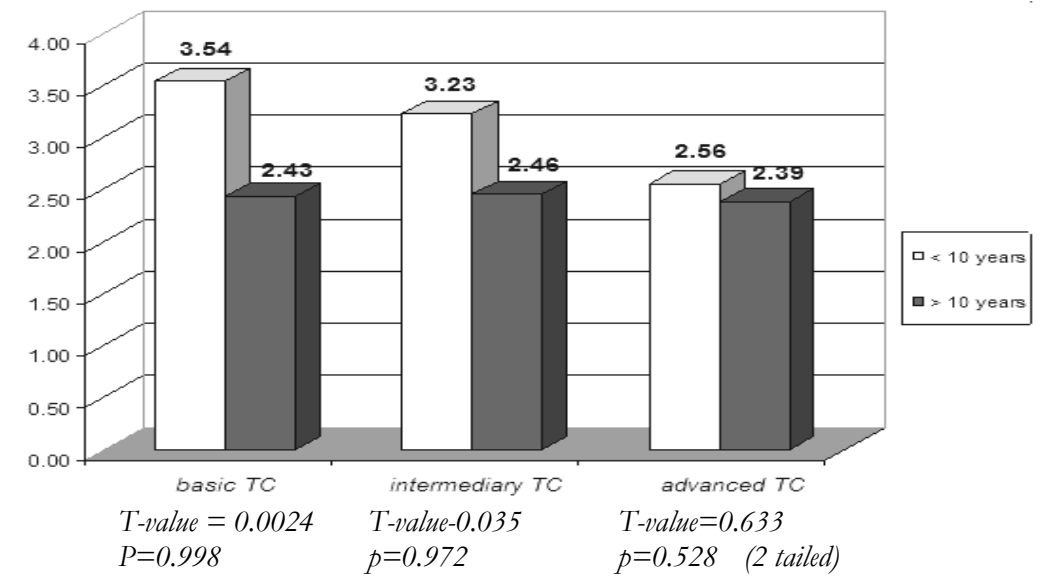

Source: own calculation based on survey data

Figure 5.4 TC building in larger and smaller scale companies (average values on 0-6 scale)

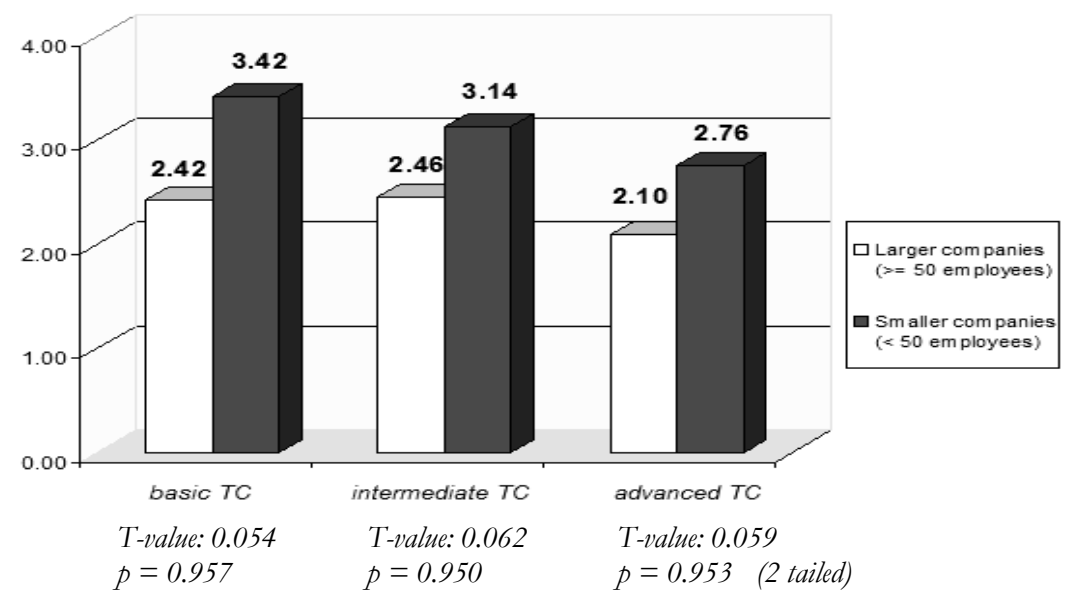

Source: own calculation based on survey data

In terms of employees' staff composition, Chinese and Indian companies reported to have a very high share of highly qualified technical personnel: $84.6 \%$ and $63 \%$ respectively (see table 5.5). This includes employees with university and technical school degrees. In contrast, in Brazilian and Mexican project host companies, 39\% and $31.5 \%$ of human resources consist of highly qualified employees. 
From table 5.5 we see that many companies reported to have experience with the technology used in CDM projects before the CDM project opportunity came into view. For example over $70 \%$ of the Indian sample, more than half of the Chinese respondents and $45 \%$ of Brazilian project operators worked on development of technology and/or applied it in practice. This is a quite obvious matter for companies working in the renewable energy generation industry. However this might also point to evidence of companies attempts to introduce clean technologies induced by other than CDM incentives. Another suggestion is that some of the technologies used in CDM projects are not totally new to the host countries. The Mexican case is, however, very contrasting in this regard; it demonstrates no earlier experience in application and has only two cases of technology development efforts by the project operators. This could be probable as CDM regime was the most important factor in the promotion of new carbon reduction technologies in Mexico.

In order to trace any differences in learning outcomes we cross-tabulated relevant average learning scores against subgroups of companies with and without prior technological capabilities relevant to the technology used in CDM projects (see Table 5.6). The general picture demonstrates a clear advantage of the companies having earlier competences in all range of capabilities. They maintained much better progress in all levels of technological capabilities. These data also show a slight diminishing effect in learning progress with every next higher level capability group.

Table 5.6: TC building progress in companies with and without prior relevant competences (0-6 scale)

\begin{tabular}{|c|c|c|}
\hline & without prior $T C$ & hadprior TC \\
\hline Preventive maintenance & 1.89 & 3.81 \\
\hline Process quality control & 2.63 & 4.11 \\
\hline Debugging & 1.78 & 3.75 \\
\hline Equipment adjustment & 1.90 & 3.65 \\
\hline Average basic TCs & 2.05 & 3.83 \\
\hline Equipment stretching & 1.89 & 3.25 \\
\hline Efficiency improvement \& cost-saving & 2.15 & 4.08 \\
\hline Process adaptation & 2.04 & 3.91 \\
\hline Average intermeditae TCs & 2.03 & 3.75 \\
\hline Basic process design & 1.98 & 3.21 \\
\hline Equipment design & 1.75 & 3.13 \\
\hline Development of turnkey project/facility & 2.10 & 3.68 \\
\hline Average advanced TCs & 1.95 & 3.34 \\
\hline
\end{tabular}

Source: own calculation based on survey data 
There are also cases that a company initiates and implements more than one CDM project. The survey results indicated that one third of all surveyed companies run more than one CDM projects (see table 5.5). This factor can potentially intensify the learning by project host companies and we will consider this factor in the econometric analysis in the following chapter.

Table 5.7: TC building estimates for each group of organizations with different ownership status (0-6 scale)

\begin{tabular}{|c|c|c|c|c|}
\hline & \multicolumn{2}{|c|}{ Local } & \multicolumn{2}{|c|}{ Foreign } \\
\hline & State company & $\begin{array}{c}\text { Domestic private } \\
\text { company }\end{array}$ & $\begin{array}{l}\text { Foreign private } \\
\text { company }\end{array}$ & Joint-venture \\
\hline Size of subsample & $N=11$ & $N=79$ & $N=10$ & $N=4$ \\
\hline Preventive maintenance & 3.27 & 3.03 & 1.10 & 4.50 \\
\hline Process quality control & 3.09 & 3.47 & 2.70 & 4.50 \\
\hline Debugging & 2.55 & 2.83 & 2.30 & 4.25 \\
\hline Equipment adjustment & 2.64 & 2.85 & 1.80 & 4.00 \\
\hline Average basic TC's & 2.89 & 3.04 & 1.98 & 4.31 \\
\hline Equipment stretching & 2.09 & 2.44 & 1.60 & 4.50 \\
\hline $\begin{array}{l}\text { Efficiency improvement \& } \\
\text { cost-saving }\end{array}$ & 3.18 & 3.10 & 2.60 & 3.50 \\
\hline Process adaptation & 2.82 & 3.03 & 2.00 & 5.50 \\
\hline Average intermeditae TC's & 2.70 & 2.85 & 2.07 & 4.50 \\
\hline Basic process design & 2.82 & 2.40 & 1.80 & 4.25 \\
\hline Equipment design & 2.18 & 1.99 & 1.90 & 5.25 \\
\hline $\begin{array}{l}\text { Development of turnkey } \\
\text { project/facility }\end{array}$ & 2.45 & 2.69 & 3.00 & 3.75 \\
\hline Average advanced TC's & 2.48 & 2.36 & 2.23 & 4.42 \\
\hline
\end{tabular}

Source: own calculation based on survey data

Another factor that is frequently considered in the literature on technological spillovers and learning is ownership status of the company. It is often argued that foreign ownership gives firms in developing countries an advantage in terms of better access to advanced technologies and knowledge (Aitiken and Harrison, 1990; Djankov and Hoekman, 2000). In our survey we also collected the information about ownership status of the project host companies. Besides local and foreign ownership, we also define whether the local companies are privately or publicly owned. And in the group of foreign ownership companies we distinguish between 100\% foreign companies and joint ventures involving just partial foreign ownership. Table 5.7 shows that domestic companies have a very dominant presence in the whole sample (14 foreign against 90 domestic companies). The Chinese sample consists of only domestic companies, of which four are public companies and nine are private companies. Similarly, the Indian 
sample is mostly represented by domestic private firms (74\%) and domestic state companies $(20 \%)$, with only two companies being of foreign origin. The samples of Mexican and Brazilian project hosts have no state owned companies, have a higher presence of firms with foreign ownership (19\% and $23 \%$ respectively), and also dominantly consist of local private companies.

Average learning performance in different ownership groups shows substantial variations (see table 5.7). Joint-ventures reported the highest progress, on the average, which was possibly a benefit from collaboration with foreign counterparts. In contrast, companies with $100 \%$ foreign ownership had, on the average, the least progress. Also note a slightly higher progress in innovative capabilities, in comparison to basic ones, which is contrary to the common trend of diminishing progress in more sophisticated expertise. The local private and state companies group showed, on the average, rather close progress, with average scores in the middle of those for joint ventures and foreign companies.

\subsection{Involvement of project hosts and technology provider in CDM project activities}

CDM project initiation and implementation often requires involvement of several organizations. This is not always the case when the project host company plays an active role in every stage of the project. Sometimes project host companies contract other companies to develop the project and install the facility, in which case their involvement project activities, is small. Often, running a CDM project requires the creation of a new company that eventually becomes a permanent operator of the newly installed CDM facility. In such an arrangement, involvement of the project host company can vary a lot.

In the survey we asked about involvement of the CDM project host company in each stage of the project realization. It was designed to obtain answers in "yes/no" format. We could thus calculate how many project hosts were involved in each stage of project. Figure 5.5 demonstrates the aggregated statistics of involvement. There we can see that over $85 \%$ of the project host companies took part in equipment installation, and adjustment and testing stages. $77.88 \%$ of all project hosts were involved in the initial stage when the project idea was discussed and developed. Almost two thirds reported their involvement in design of the technological facility to be installed under the CDM project, and only $47 \%$ took part in design of the equipments. The last one is perhaps due to the fact that often the standard equipment set was purchased elsewhere, rather than developed internally. 
Figure 5.5 Involvement of CDM project host companies in various stages of project realisation (in percent)

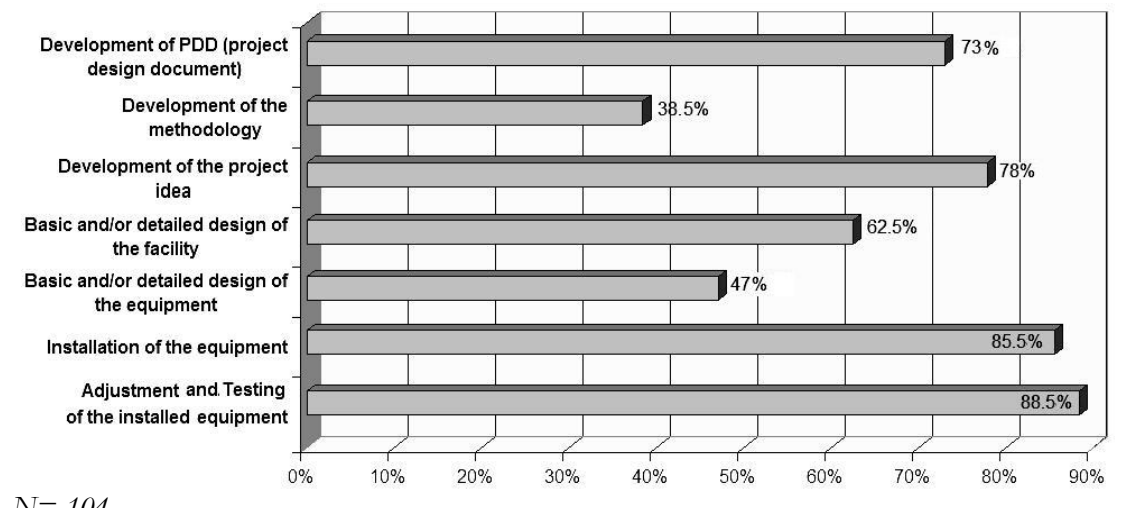

$N=104$

Source: own calculation based on survey data

The core of the PDD (project design document) preparation is a calculation of the amount of carbon emission reduction that can be achieved by the project (which are further converted into emission credits that can be traded). These calculations are based on special methodologies which can be unique not only for each project type or technology, but also for technology sub-types, location, climatic condition, or a combination of all or some of these. Sometimes project implementers develop new methodology appropriate for the project they are planning to implement; but mostly they apply existing methodologies. PDD and methodology development require a certain expertise in emission calculation, and often project developers invite external consultants to help them with calculations and PDD design; or just totally outsource this task to these consultants. In our sample, $73 \%$ of project hosts took part in PDD preparation while only $38.4 \%$ took part in methodology development.

It was also our task to see how active the involvement of technology providers was throughout the CDM project cycle. Technology providers are considered to be an important source of knowledge and expertise provided together with the hardware technology. Specialized training and coaching activities that they provide for their clients are specifically aimed at developing certain skills and abilities for further use in operating and maintaining the delivered technology. Project host companies can also get spillover from technology providers' participation in various stages of project implementation. Thus we asked respondents to report the participation of technology provider in various stages of the project, as well as whether or not they provided special training activities for the recipients. 
Figure 5.6 Involvement of technology providers in various stages of project realisation (in percent)

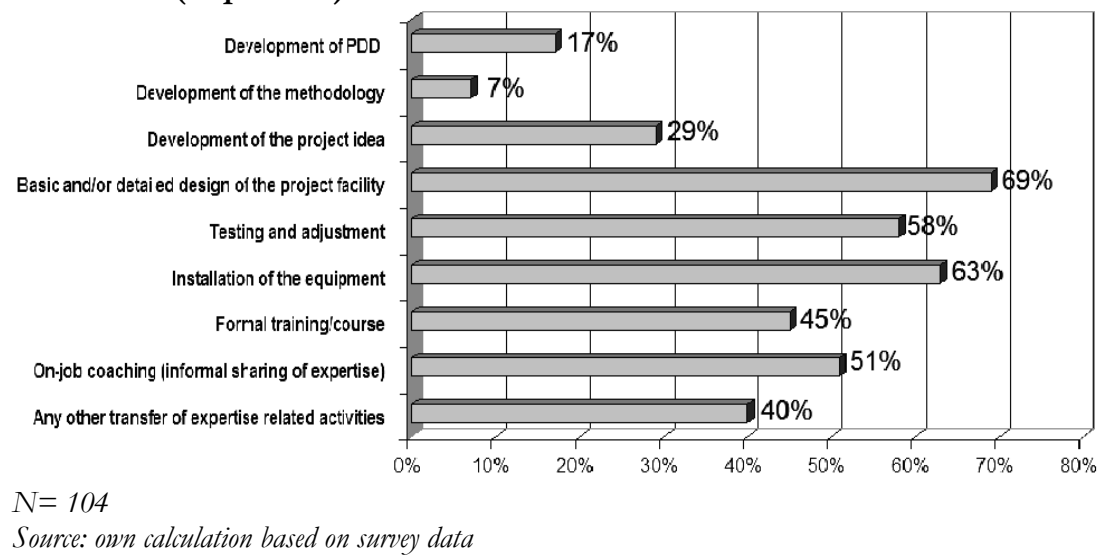

Figure 5.6 presents statistics on the involvement of technology suppliers in different activities during CDM project implementation. High participation was reported for the facility design stage (69\%), technology installation $(63 \%)$ and testing and adjustment stages (58\%). This says that in about more than half of the 104 project cases technology providers took part in the above mentioned activities. However special training activities were provided in fewer cases (40-51\% of all projects). Involvement of technology providers in project idea development was in less than a third of the projects $(29 \%)$. They took part in PDD preparation only in $17 \%$ of all project cases, and in methodology development only for $7 \%$ of cases. In general we can see that overall involvement of technology providers is less than that of project host companies.

\subsection{Summary}

In this chapter we had a closer look at the sample characteristics and studied the technological learning patterns on aggregated and disaggregated levels. On the aggregate level we could see that the highest progress was achieved building basic technological capabilities that are necessary in day to day process operation, quality control, technology maintenance, small adjustments, and debugging. This is rather logical as these capabilities are comparatively easy to develop. Slightly smaller progress was achieved in building intermediary level capabilities including activities on process improvement (equipment stretching, process adaptation, efficiency and improvement and cost-saving). The least progress was reported for advanced level technological capabilities which are associated with design, development, and innovative activities (process, equipment and turnkey facility design). These skills proved to be more 
difficult to obtain during $\mathrm{CDM}$ project experience, which is also a common observation for conventional project cases.

In our analysis we used a 0-6 scale for assessment of the learning impact. Singled out statistics for each score group showed that most of the project hosts scored between 2 and 5 , with fewer cases in the minimum and maximum extremes.

Disaggregation according to technology groups showed very large heterogeneities among them. The highest level of learning was achieved in biomass-to-energy projects, energy efficiency activities, HFC gases destruction, fugitive emissions and landfill gas capture projects. The lowest learning was reported for the biogas technology group and no progress for fuel switch project, which is the only project of this technology type.

In the cross country comparison we could see that the Indian project operators on average reported the higher progress, followed by the Chinese and Brazilian companies. The Mexican companies being the least learning subgroup scored, on the average, only half of that of the Indian companies.

Further we analysed company specific features and their relevance in the technological capability building progress in CDM projects. We focused on company's age, size, prior experience, and ownership status. The following key features emerged from these analyses:

Splitting the sample into two groups with companies younger than and companies older than 10 years showed that younger companies achieved on the average higher progress than older companies. This is particularly visible in the statistics for basic and intermediary level capabilities. Comparison of performances according to company size showed that companies with a smaller number of employees $(<51)$ on the average achieved higher learning progress than companies with larges number of people. Higher progress in technological capability building was also observed in the case of companies having prior experience with technology used in CDM projects (both, in technology application and technology design). This finding indicates the importance of having prior knowledge in order to absorb new knowledge. Analysis of the possible role of ownership structure on companies' learning abilities showed that project hosts in joint venture arrangement benefited highly from the CDM project experience. Average-level progress in technological capabilities building was achieved by domestic companies with private and public ownership status. The poorest progress was reported by project host companies with $100 \%$ foreign ownership.

The last section of the chapter analysed the level of involvement of project host company and technology providers in various stages of CDM project implementation. It was revealed that project host operators had a more active involvement in projects than technology providers, which may point to the fact that only some project hosts sourced new knowledge from the technology providers, and those who did not so, 
possibly learned through their own efforts and experience.

The analysis in this chapter provides a first picture on trends in learning progress by the survey respondents. This analysis serves as a helpful background for further investigation of determinants of technological capability building in CDM projects using econometric techniques in the following chapters. 


\section{CHAPTER 6: ABSORPTIVE CAPACITY AND TECHNOLOGICAL LEARNING IN CDM PROJECTS ${ }^{16}$}

\subsection{Introduction}

The foremost concern of a technology transfer initiative is building technological capabilities and a knowledge base which is crucial for sustainability of results of the project comprising this transfer. The success of a project and particularly of its technology transfer component depends to a large extent on various internal resources and capabilities of a company implementing the project. Knowledge resources being the major contributor to the organization's ability to assimilate new technology and knowledge, are therefore a key aspect in successful technology transfer.

$\mathrm{CDM}$ projects are a relatively new phenomenon in traditional markets; they have rather unusual incentives for their initiation (carbon credits), involve only certain industrial sectors, and involve "green" technologies that are often nor widely diffused. While having certain specificities, CDM projects from the view of technical implementation, follow similar stages as many other new projects initiated by a company. Therefore the technology transfer and associated learning processes in these projects also are expected to follow common patterns of traditional processes. In addition, it is necessary to note that the focus of our analysis is the organization hosting CDM projects. In this regard in our attempt to explain the technological learning process under the CDM project experience we can benefit from organizational theory, particularly from the sub-area on organizational learning. Moreover, the combination of organizational learning literature with the literature on international technology transfer can give perspectives that would be interesting both for policy makers as well as for business managers (Cusumano and Elenkov, 1994). Nevertheless we have to bear in mind the specificities of the CDM project case in the interpretation of the study results and drawing theoretical and policy implication.

The technology transfer process is essentially considered as a knowledge accumulation process. Gupta and Govindarajan (2000) disaggregate this process into knowledge creation, acquisition, and retention, while Davenport and Prusak (2000) suggested that the knowledge transfer process consists of transmission and absorption, culminating in a behavioural change by the recipient. Many authors recognize the lack of absorptive capacity in the recipient as a friction, which slows or prevents transfer (Whangthomkum et al, 2006; Lin et al., 2002; Davenport and Prusak, 2000; Kim, 1997; Wong et al., 1999). Cohen and Levinthal $(1989,1990)$ in their seminal work highlighted

\footnotetext{
${ }^{16}$ This chapter is based on Doranova. A. 2009 Absorptive capacity and technological learning in CDM projects" in International Journal of Technology and Globalisation, special issue on Sustainability innovations in newly industrializing countries.
} 
the fact that organizations cannot benefit from external knowledge flows just by being exposed to them; instead, they must develop absorptive capacity, which authors define as the ability to recognize the value of new external knowledge, and then assimilate and utilise such knowledge for commercial ends. A firm's absorptive capacity builds on its existing stock of knowledge, much of which is embedded in its products, processes and people (Cohen and Levinthal, 1989), and it has become a key driver of a firm's competitive advantage because of the increased importance of external knowledge sourcing (Cockburn and Henderson, 1998; Zahra and George, 2002; Escribano et al. 2009).

An organization's technological knowledge can be represented by a bundle of technological capabilities indicating its competence in implementing certain functions and activities. Thus we interpret organizational technological learning as a technological capability building process and use these terms as synonyms in this study. The literature has offered a number of taxonomies of firm-level technological capabilities (e.g. Lall, 1992; Bell and Pavitt, 1993; Figueiredo, 2003) that were adopted by us in the survey of CDM project host organizations. In this survey we assessed technological learning outcomes of CDM project experiences and collected a range of data about these organizations. The present chapter applies these data in addressing the following research question: how does the project host organization's absorptive capacity represented by its prior knowledge, human resources, and training efforts- explain technological learning dynamics resulting from CDM projects? Furthermore we considered factors, such as characteristics of a technology acquirer organization, that may determine learning outcomes. We also investigated the exogenous effect of institutional factors working as an enabling environment for building organizational absorptive capacity and technological learning.

The academic contributions of this study are the following. The existing literature on technology transfer in CDM has a rather limited number of empirical studies ${ }^{17}$ which have not managed to address technological learning issues deeply. Hence, the present study is a contribution in filling this gap, by applying unique and more comprehensive data collected through the survey of CDM project hosting companies. It is also necessary to note that in the family of studies focused on CDM, the present work is rather novel in its approach in studying the technology transfer issue by application of organizational theory and technological learning perspectives. By bringing concepts of technological capabilities and absorptive capacity, it enriches the CDM related literature conceptually and methodologically. On the other hand by bringing the example of $\mathrm{CDM}$ project implementation, it contributes to the empirical literature linking

${ }_{17}$ To the best of our knowledge there is only one case-study that investigated knowledge transfer processes, technological capability building and spillover impacts in four CDM projects based in Malaysia (Hansen, 2008). 
absorptive capacity phenomena with organizational learning and investigates in what manner this relationship works.

The chapter is organized as follows. The next section presents a theoretical background in discussing the position of organizational learning literature towards technology and knowledge transfer, and elements of absorptive capacity as the determinants and develops a relevant hypothesis. The methodological part presents definitions of variables, data, and econometric methods. Further we present results of econometric analysis. The chapter concludes with a discussion of results and implications for further research.

\subsection{Theory and hypotheses}

\subsubsection{The role of absorptive capacity in technological learning}

Ever since the introduction of the absorptive capacity concept by Cohen and Levinthal (1989; 1990) the literature stream on absorptive capacity has been growing. The concept has been used in studies of national innovation systems, economics growth, and international technology transfer (e.g. Mowery and Oxley, 1996; Keller, 1996; Liu and White 1997); though it found much wider application in the organizational learning literature, studying this phenomenon in firms, as well as in the interorganizational (dyadic and networks) contexts (e.g. Szulanski, 1996; Lane and Lubatkin, 1998; Kim, 1997).

The definition of absorptive capacity operationalized in the organizational theory was proposed by Cohen and Levinthal (1990) and further augmented by Lane et al., 2001; Zahra and George, 2002; Van Den Bosch et al., 2005. It refers to the firm's ability to recognize the value of external technology, knowledge, and information; to identify and acquire the new technology; to assimilate it, and to apply or exploit the new technology for commercial ends. There is a large number of studies showing the importance of absorptive capacity in improving firm's performance (e.g. Levinson and Asahi, 1995; Mowery et al., 1996). Many authors have proposed that absorptive capacity is the foundation for technological learning and eventually for innovation within an organization (Kedia and Bhagat, 1988; Fu and Shi, 1995; Veugelers and Cassiman, 1999) as well as in technological alliances (e.g. Lane and Lubatkin, 1998; Simonin, 1999; Ahuja and Katilla, 2001). A quite commonly accepted assumption in many studies has been that learning and absorptive capacity co-evolve by influencing each other. This would appear applicable also for the case of technology transfer projects as learning is its crucial component. 
Few authors who have done empirical studies on technology transfer projects in various industries, addressed the role of absorptive capacity in effectiveness of technology transfer (e.g. Lin et al., 2002; Dahgfous, 2004; Whangthhomkum, 2006). Although these authors had diversified definitions of technology transfer outcomes, each definition largely captured elements of knowledge transfer and learning. This makes them comparable among each other, as well as makes relevant references for our study. The general agreement in these studies has been that successful technology transfer entails much more than the mere acquisition of physical assets, and the recipient's lack of absorptive capacity can result in a poor transfer. Lin et al (2002) established that such factors as the type of technology, the transfer channels and the R\&D processes will not be able to successfully support a firm without strong absorptive capacity, in its technology transfer performance. The study by Whangthhomkum (2006) was focused on investigating relationships between dimensions of technology transfer performance and elements of absorptive capacity, thus excluding other internal and external factors from their analytical model. The finding was that effectiveness of technology transfer is related to all elements of absorptive capacity positively, but not all to the same degree. For example Daghfouse (2004) studied the influence of prior knowledge and learning efforts (which are important components of absorptive capacity) on effectiveness of technology transfer projects and found a positive effect in both cases, however the effect of prior knowledge was weaker in comparison with factors associated with learning efforts.

Furthermore, few conceptual papers from the technology transfer stream have discussed the absorptive capacity as one of the determinants of successful technology and knowledge transfer (e.g. Cusumano and Elenkov, 1994; Dunning, 1994). Among the critical remarks from these papers is that absorptive capacity is a necessary condition to a successful technology transfer but not an alternative to it.

Thus in the literature the positive influence of absorptive capacity on technological learning outcomes has been well established. However, the singled out impacts of its dimensions has been rather underinvestigated. Absorptive capacity, being a complex factor, represents company's knowledge accumulated through its experience and training, and residing in its employees (Cohen and Levinthal, 1990; Zahra and George, 2002; Van Den Bosch et al., 2005). In our study we acknowledge this multidimensional feature of absorptive capacity. We consider its dimensions such as prior knowledge, human capital, and training efforts, and investigated their individual influence on technological learning results of CDM projects. Previously, the independent impact of each of these components has not been investigated. Often authors use just one of the above mentioned components as a proxy of absorptive capacity, although in survey based studies the measurement of it was done through multiple indicators which were further put into one factor (e.g. Daghfous, 2004; Whangthomkum et. al, 2006; Bohn, 1994). 
In this chapter we also follow the insights from the studies discussing the role of knowledge resources heterogeneity in knowledge transfer between two units or organizations (Szulanski, 1996; Lane and Lubatkin, 1998; Ahuja and Katilla, 2001), as well as technological distance (Noteboom, 1992, 1999) and technological overlap (Mowery et al. 1996; Kim and Inkpen, 2005). These studies address learning and innovations in dyads of technological partners and argue that the relationship between technological distance/overlap and learning outcomes is non-linear, or of inverted Ushape character. Following these studies one can expect that the highest learning results, and the best appropriation of the technology is achieved in cases where the technology recipient companies already have some prior knowledge about the technology, rather than having no knowledge or being completely familiar with the technology. Furthermore we also distinguish between prior knowledge related to earlier experience with technology application and/or development, and those related to prior experience with CDM projects. The last aspect is conditioned by the fact that it is a study based on a CDM project case.

\subsubsection{Hypotheses}

\section{Prior knowledge and technological distance}

Innovation and technological change literature frequently has noted that the technological process can not be improved if it is not well understood (Yeung and Ulrich, 1994) and that it is crucial that the company possesses relevant and knowable information before starting to address uncertainty in production and innovation activities (Daghfous, 2004; Daghfous and White, 1994). A similar argument holds for technology transfer projects. The technology can not be successfully transferred if the recipient is not able to understand the processes it is based on. Having the knowledge based on training or acquisition of codified knowledge is usually not enough, therefore experience with a similar technology leads to a faster and more efficient transfer and appropriation of it.

In this regard, Cohen and Levinthal (1990) referred to memory development, in which accumulated prior knowledge enables the ability to store new knowledge into one's memory and to recall and use it. This process grounds the key notion of absorptive capacity which stipulates that prior related knowledge facilitates the learning or absorption of new related knowledge. Correspondingly, Cohen and Levinthal (1990) argued that the ability to evaluate and utilise outside knowledge is largely a function of the level of prior related knowledge.

Inkpen (2002) summarised that the acquisition of knowledge is a cumulative process, meaning knowledge builds only on the knowledge that is already there. Similarly Powell et al (1996) argued that knowledge facilitates the use of other knowledge and what can 
be learned is crucially affected by what is already known. Grant (1996) and Dyer and Singh (1998) also showed in their studies that learning performance is enhanced when the object of learning is related to what is already known and when there is a common language as the basis for interpreting experience. While studying internal knowledge transfers, Szulanski (1996) found that the ability of the recipient unit to value and apply new knowledge was critical for successful transfers. Lane and Lubatkin (1998) introduced a dyad-level construct which they called 'relative absorptive capacity' and empirically proved its positive effect on inter-organizational learning. In their approach they added the similarities in compensation practices and organizational structures, as well as the knowledge/technology recipient or buyer firm's familiarity with the technology seller firm's set of organizational problems, to prior related knowledge. Prior knowledge has also been explored in such contexts as entrepreneurship and technological innovation. For instance, Shane (2000) found that prior knowledge of entrepreneurs plays a significant role in the number of opportunities that they discover following a technological change.

Based on the theoretical findings described above, one would expect that companies having experience with the technologies applied in CDM project before initiating the actual project, would be more progressive in their technological capability building. Similarly it is expected that companies that are implementing more CDM projects would have better experience and knowledge in project related activities, including the technology component. Therefore we hypothesize that:

(H1a) The recipient's prior level of knowledge about relevant technology positively influences technological learning outcomes of CDM projects

However, studies emerged in the 1990's on technological distance and technological overlap suggested that the relationship between learning results and prior knowledge in dyadic technological contracts is more complex than just linear (Noteboom, 1992, 1999; Mowery et. al 1996, 1998). They argue that a small difference in the technological knowledge bases of two companies (in other words small technological distance or large technological overlap) does not result in a great deal of learning, as there is not much to learn from each other. In a technology provider-recipient dyad this would translate into a case in which the recipient is largely familiar with the technology delivered by the provider and therefore no big dynamics in learning is expected. Furthermore, knowledge transfer has been found to occur to a lesser extent also in the case of a very large difference (or dissimilarity) in levels of knowledge of two partner companies. This recalls the main idea of the absorptive capacity concept explaining why a company that has very small or no prior knowledge in a certain area would not be able to absorb more sophisticated knowledge in this area. The most fruitful learning takes place in the case of a certain level of difference in knowledge base that allows companies to understand and absorb the knowledge from each other. This difference is 
referred to as the optimal technological (or cognitive) distance. Thus the relationship between the technological distance and technological learning results can be graphically shown as an inverted U-shaped function. In similar vein several studies have found that for effective knowledge transfer, partners need to have a balance of similarity and dissimilarity in their knowledge bases (Szulanski, 1996; Lane and Lubatkin, 1998; Ahuja and Katilla, 2001).

These observations have the following implication for the case of technological learning in CDM projects: the company's prior knowledge, being a determinant of technological distance between technology recipient and supplier companies would also have an inverted U-shaped relationship with learning outcomes of CDM project related technology acquisition processes. In other words we can expect that technology recipients with no or very small prior knowledge would not be able to efficiently benefit in terms of learning as they would miss absorptive capacity, while the ones having very extensive prior knowledge in technology and CDM projects would not gain much new knowledge. The group in the middle, with a balanced (optimal) level of prior knowledge, would have the largest gain in learning.

Thus we hypothesize that:

(H1b) In CDM projects technological learning is an inverted U-shaped function of a recipient organization's prior knowledge level

Another distinction has to be made in the quality of prior knowledge, which would have an implication on absorptive capacity of the learner and consequently on the learning outcomes of the CDM project. The technological capabilities literature distinguishes between innovative and production capabilities (Lall, 1992; Bell and Pavitt, 1993), assigning the quality of 'advanced' to the prior and 'basic' to the latter. Technological learning (which is also defined as a capability building process) is an evolutionary self reinforcing, path-dependent process, in which the level of learning or technological capability building results, depends on the level or quality of pre-learning technological capabilities (Figueiredo 2003).

\section{Qualification of personnel}

An organization's absorptive capacity is related to the ability of its individual employees to assimilate, process and transform external knowledge flows. Therefore the human capital definition of absorptive capacity has found frequent application in empirical studies. The definition of absorptive capacity proposed by Mowery and Oxley (1995:70) is the one having the human capital in its focus '.... broad array of skills, reflecting the need to deal with the tacit component of transferred technology, as well as the frequent need to modify a foreign-sourced technology for domestic application'. 
Among measurements of the human capital dimension of absorptive capacity are investment in scientific and technical training and the number of scientists and engineers (Mowery and Oxley, 1995; Keller, 1996), and the number of doctorates within the R\&D department (Veugelers, 1997).

Zahra and George (2002) who provided a comprehensive review of key dimensions of the absorptive capacity construct noted that its human capital dimension received recognition in studies on firm level, as well as in studies addressing national level technology transfer deliberates (Glass and Saggi, 1998; Keller, 1996; Kim and Dahlman, 1992; Luo, 1997; Veugelers, 1997). The assumption applied in these studies is that companies and countries with a higher number of technical and managerial experts would be able to absorb, utilize and improve an acquired technology faster and more effectively because qualification of these personnel allows them to understand the principles behind the functioning of this technology. In organizational knowledge management literature a noteworthy consideration is given to tacit knowledge as an important supplement to codified knowledge in maintaining an effective knowledge base of a company (Jensen et al, 2007). The central point is that tacit knowledge is a form of knowledge that is highly personal and deeply rooted in individual experiences, ideas, values and emotions (Gourlay, 2006).

In regards to technological knowledge, engineers and technical personnel form the core of the company's technological knowledge base, and are carriers of the organization's tacit knowledge. While acquiring new technology, as is in the case of CDM projects, it is particularly important to have employees with engineering and technical qualification and experience, as they are carriers of tacit knowledge allowing them to understand the technology, adjust and improve it, and to utilize it to full efficiency. Hence, they are an important element in a company's overall absorptive capacity. Thus for the CDM related knowledge transfer and competence building the role of human resources is expected to be important:

(H2) A bigher representation of human resources such as engineers and technical personnel in an organization is positively associated with more dynamic technological learning in CDM projects

\section{Training efforts}

Kim (1998) identified that the intensity of effort to increase prior knowledge is one of the essential determinants of a firm's absorptive capacity. Training of employees is a crucial element of learning activities aimed at improving the technological and managerial knowledge of employees, which in turn contributes to better absorptive capacity of the whole company. As a general practice most successful companies develop individual and group skills and knowledge by promoting learning at every level 
and making the competency acquisition a part of the company's business strategy (Nevis et al., 1995). The acquirement of cutting-edge and relevant knowledge accelerates teams' and individuals' capability to assimilate more new knowledge and subsequently develop innovative products and processes (Cohen and Levinthal, 1990).

The acquisition of new technology is often complemented with training, on job coaching, and instructing by the technology supplier which is usually aimed at teaching about how to operate the acquired technology. In this way it assures acquisition of new knowledge related to completely new or renewed functions. Training, being the interactive form of knowledge delivery has a big advantage over delivery of paper manuals or guidelines, because during the interactive training a lot of tacit knowledge and information is made available to the knowledge recipient (Leonard-Barton, 1995; Jensen et al., 2007).

It is important to distinguish purpose and scope of the training activity, as this can define its learning impact. As a common case the knowledge delivered through training, complementing new technology, contributes to the formation of basic technological capabilities, such as the capability to operate a technological/production process, assure quality control, do preventive maintenance, debugging and adjustments of the equipment to the local conditions or to the technological line (Lall, 1992). Training can help not only in proper utilization of the technology, but also to gain a better understanding of processes on which the technology is based, which might give possibilities for further improvement and efficiency increase. Hence, there are chances that more profound technological capabilities make incremental innovation possible (e.g. equipment stretching, efficiency improvement and cost saving, adaptation of process by introducing changes). However the training delivered along with new machinery is usually rather narrow in its scope, as it is specifically aimed at teaching how to operate the technology, therefore its contribution to the building of advanced innovative skills, such as design of facility or/and equipment or turnkey project design might be weaker in comparison to basic and intermediary capabilities. Based on these considerations we hypothesize that:

(H3a) Training delivered by the technology provider contributes to general technological capabilities of the CDM project recipient

(H3b)Training delivered by the technology provider contributes more to the building of basic technological capabilities and less to the advanced capabilities of the CDM project recipient organizations. 


\subsection{Methods}

\subsubsection{Data}

The present study is based on data collected through the survey of CDM project host companies which are the unit of analysis. The final dataset consists of data from 104 companies, located in Brazil, China, India and Mexico. Both, dependent and independent variables used in the econometric analysis in this chapter are based on the data collected during the survey. Description of the data is presented in Chapter 5. Details about survey design and implementation are presented in Chapter 2.

\subsubsection{Definition of variables}

In our study we describe the technological learning or capability building level as a discrete outcome typical of a qualitative dependent variable model. We model the probability of increase in a certain level of technological capability as a function of a set of explanatory factors measured via independent and control variables described below.

\section{Dependent Variable: Technological Capability Building}

Our study aims to measure the impact of the experience with CDM projects on companies' technological capabilities level, and further to investigate determinants of it. The technological capability building level is the dependent variable in our econometric model. As we discussed in Chapter 5 in defining and examining the technological capabilities we distinguish between companies' abilities to use and operate technologies (day-to-day operation, or basic capabilities), abilities to implement more creative work such as stretching equipment, improving efficiency and cost-cuts by introducing novelties in the production process (process improvement, or intermediate capabilities), and abilities to implement designing machines, production technologies, and turnkey facilities which require more sophisticated R\&D expertise (innovation or advanced capabilities). The complete list includes ten types of technological capabilities, four of which belong to the group of operational capabilities, three to the process improvement capabilities, and the other three to innovation capabilities.

To capture the technological capability building impact of experience with CDM projects, the respondent was asked to assess this impact on each of ten capabilities using a Likert-type scale ranging from 0 (zero impact) to 6 (very high impact). It was important for us to capture the technological capability building dynamics for each of the three groups as we wanted to see how CDM related experience influences building of simpler and more sophisticated groups of capabilities. Therefore the final dependent variables basicTC, intermediate $T C$ and advanced $T C$ were constructed by taking a simple 
arithmetic mean for each of the three groups. This is also justified by high correlation $(>0.85)$ among variables within each of the three groups and by the factor analysis which showed that variables within each of these groups fall into one factor.

\section{Independent Variables:}

\section{Prior experience proxies}

Following the hypothesis about the relevance of a company's absorptive capacity for technological capability building under the CDM project we defined the independent variables that refer to absorptive capacity. The first is the relevant prior experience that we tried to measure by asking if the company had certain technological capabilities before CDM experience. Most studies following Cohen and Levinthal (1990), have considered the level of prior related knowledge as the determinant of absorptive capacity. In our study we determined relevant prior knowledge by asking if the CDM host companies already had any of the ten described above capabilities prior to CDM experience. Existence of the capabilities would obviously be associated with prior experience. Thus the variable will be the indicator of one of the dimensions of absorptive capacity. By taking the average of all ten capabilities we obtained the unified variable previous $T C$ which is a continuous variable ranging between 0 and 1 . Given the prediction for an inverted U-shaped relationship between prior knowledge and learning outcomes, in our regression model we include both prior knowledge variable and its squared term as a second order measure. However these two variables showed a high correlation between each other. Therefore to reduce the possible multicollinearity between the single term and squared term, we used the squared term of a deviation from the mean and obtained the variable previous $T C^{2}$.

Another indicator that captures the prior experience component of absorptive capacity is a CDM host company's involvement in other CDM projects. Naturally the companies with more CDM projects would have more experience in the application of technology and hence a better understanding of this technology. Thus we introduce the binary variable Other_projects indicating if the CDM project host company has implemented more than one projects $(=1)$ or not $(=0)$.

\section{Human resources related proxies}

One of the most popular indicators of absorptive capacity is related to the human resources of a company. It has been widely accepted that a skilled and educated work force enhances the firm's absorptive capacity (Cohen and Levinthal, 1990). This is because the endowment of human and knowledge capital within a company determines its overall ability to appropriate the acquired technology as well as opportunities related to it. The endowment of human capital can be proxied by the share of the trained staff 
having university degrees/engineering qualifications and technical school education among the total pool of employees. We expect that the higher the proportion of trained personnel in the organization is, the greater the organization's ability to absorb the knowledge will be. Thus we adopt the Qualification variable (qualification of employees) and expect it to be positively related to technological capability building scores.

Training is another important factor that is directly associated with human resource quality and absorptive capacity. Since technology transfer involves technology and the entire scope of embodied and disembodied knowledge associated with it, it relies on human resource input, which is considerably more difficult to transfer than equipment. Moreover, it has been recognized that human resource development should be at the very heart of any technology transfer endeavour because it is the personnel that needs to be taught how to use the equipment. One of the evaluation measures for human resource capability in technology transfer is the training offered by the technology provider (Chen, 1997; Lyles and Salk, 1996; Lyles et al., 1997; Lane et al., 2001). In our case the provision of training, the on-job coaching and the other capacity building activities by technology provider was captured by the Training variable calculated as an average of binary variables associated with these three types of activities.

Table 6.1 below summarises the references used in defining measurements for the components of absorptive capacity.

Table 6.1: Measurements of absorptive capacity components and references

\begin{tabular}{|l|l|}
\hline \multicolumn{1}{|l|}{ Measurement } & References \\
\hline Prior relevant experience: & Dagfous (2004) \\
- $\quad$ Previous technological capabilities & Inkpen (2002) \\
& Dyer and Singh (1998) \\
& Grant (1996) \\
& Shane (2000) \\
& Lofstrom (2000) \\
& Whangthomkum (2006) \\
& Expert in-depth interviews \\
- Human resources: & \\
- Share of highly qualified personnel & Chen (1997) \\
Training from technology supplier & Lyles and Salk (1996) \\
& Lyles et al. (1997) \\
& Wang et al. (2001) \\
& Whangthomkum (2006) \\
& Expert in-depth interviews \\
\hline
\end{tabular}




\section{Control Variables}

A set of variables was used to control for other factors which could influence technological learning by CDM project host companies. We categorized them as micro or project host company characteristics related variables and macro factors that capture country related differences.

\section{CDM project host company characteristics related variables}

Size of company. In the literature, firm size has been traditionally regarded as a crude measure of the extent to which a firm may be said to be resource-rich. This may suggest that larger firms would have advantages in accessing, and also possessing, better and more diversified knowledge. However, some authors also suggest that sometimes the size of an organization may contribute to its inertia and thus inhibit learning (Lane et al, 2001). In CDM project related learning the project host company's size may have either of the above effects.

We define the size of a company by the number of employees.. Other measurement options used as a size indicator in many studies, such as financial resources and range of activities, have been considered to be less relevant especially in the context of diversified technology industries that CDM projects comprise. Size variable showed a very large variance across firms constituting our sample. For further analysis the group was divided into two groups: the group small-size including companies with 10-50 employees and the group larger-size counting for 51 employees and more (Table 6.2).

Table 6.2: Distribution of project host companies according to size

\begin{tabular}{|l|l|l|}
\hline Size (N employees) & Freq. & Percent \\
\hline Small(10-50 employees) & 59 & 56.7 \\
Larger (>=51 employees) & 45 & 43.3 \\
Total & 104 & 100 \\
\hline
\end{tabular}

Age of company This is another company specific variable that can be used as a determinant factor of technological learning. However the impact of age on technological learning is difficult to predict. It may generate a positive effect for older companies who have more experience hence better prior knowledge, but contrarily, the company may not learn anything new from the project. Company age was calculated as the number of years since the company was established. The age variable ranges from 1 to 83 , with mean $=15.94$. $50 \%$ of the companies are ten years old or less. In order to standardize the variable for further regression analysis we transformed it by taking its natural logarithm. 
Ownership status of company. Foreign equity participation often increases chances for the company to acquire more advanced knowledge and technologies. This fact may also diversify the channels of knowledge flow by involving a greater number of technology providers and imposing the technology recipient to more interaction. In our sample we categorized companies in two groups: one with 100 percent local ownership and the other with foreign (which includes joint ventures and 100 percent foreign companies). We may expect that companies with foreign equity would be associated with higher technological learning. To capture the ownership effect we introduced the dummy variable indicating domestic technology as 1 and foreign technology as 0 .

Table 6.3: Distribution of CDM project host companies according to their ownership status

\begin{tabular}{|l|c|c|}
\hline Ownership & Freq. & Percent \\
\hline Foreign & 14 & 13.46 \\
Local & 90 & 86.54 \\
Total & 104 & 100 \\
\hline
\end{tabular}

\section{Country related control variables}

Country related differences have been captured by introducing country dummies India, China, Mexico and Brazil .

The importance of the national institutions (or policies) in promotion of technological capability building and learning have been largely acknowledged in the literature (Biggs et al. 1995; Bell, 1984; Lall, 1992). Respondents have been asked to evaluate the quality of a number of policies presumably relevant for CDM and to associate them with technological learning. The list of policies included the ones on CDM capacity promotion, such as capacity building and finance schemes, renewable energy stimulation, general environmental policies, education related to clean and renewable energy technologies, increasing awareness about CDM among companies and local municipalities, incentives for foreign companies to invest in CDM projects and active involvement of civil society organizations in CDM activities. Each policy was evaluated by respondents using Likert-type scale from 0-6; 0 (absence of policy), 1 (poor)... 6 (very good). By taking the average score for all listed institutions we calculated the unified variable Policy for measuring quality of the institutions as perceived by the respondents. 
Table 6.4: Quality of policies relevant to $\mathrm{CDM}$ (based on evaluation of respondents)

\begin{tabular}{|l|l|l|}
\hline Policies & Mean & St.Dev. \\
\hline CDM promotion (e.g. capacity building, financing schemes, etc) & 3.35 & 1.72 \\
Renewable energy technologies promotion & 3.70 & 1.50 \\
Environmental policies & 3.67 & 1.48 \\
Education related to clean and renewable technologies & 3.33 & 1.60 \\
Increasing awareness of companies about CDM & 3.39 & 1.59 \\
Increasing awareness of local municipal authorities about CDM & 3.08 & 1.64 \\
Incentives for foreign companies to be involved in CDM projects & 2.84 & 1.77 \\
Active cooperation with civil society organizations & 2.80 & 1.54 \\
\hline
\end{tabular}

\subsubsection{Regression model}

Table 6.5 summarizes the information on all variables, their descriptive statistics and hypothesized effect on the outcome. For the econometric analysis we applied the Ordinary Least Squares (OLS) regression technique. Being the simplest, OLS method is the most frequently used approach to regression analysis (Greene, 2003). We used this technique because dependent variables BasicTC, IntermediateTC, and AdvancedTC consist of continuous data ranging between values of 0 and 6 .

This classical multivariate linear regression model stipulates a linear relationship between dependent variables and a set of independent variables and can be described as

$$
y_{i}=\sum_{b=1}^{K} x_{i h} \beta_{b}+\varepsilon_{i}
$$

Formally for each observation $i$, the value of the dependent variable, $y_{i}$ is related to a sum of $\mathrm{K}$ explanatory variables, $x_{i} b$, with $h=1, \ldots, K$, each multiplied with a regression coefficient, $\beta_{b}$, and the random error term, $\mathcal{E}_{i}$. Typically, the first explanatory variable is set equal to one, thus its coefficient is referred to as the intercept.

Within the constraints of the OLS model there are several assumptions. One of them is an independence of covariates which otherwise causes multicollinearity problem in the regression. Table 6.6 presents the results of the correlation test for all independent and control variables included in the regression analysis. No high correlation between dependent and independent variables are observed indicating that the results of the regression are robust. Other assumptions of OLS concern the hypothesis about normal distribution and homoskedasticity of the residuals. Examination of the Q-Q plot of Studentized residuals for dependent variables confirmed normal distribution assumption $(\mathrm{p}<0.001)$ thus allowing us to avoid bias in parameters estimation in the regression. Therefore we think that OLS technique proves to be appropriate for our analysis. 
Table 6.5: Definition of variables and summary statistics

\begin{tabular}{|c|c|c|c|c|c|c|}
\hline Variables & Description & Mean & $\begin{array}{l}\text { Std. } \\
\text { Dev. }\end{array}$ & Min & $\operatorname{Max}$ & $\begin{array}{l}\text { Expec. } \\
\text { outcom }\end{array}$ \\
\hline $\begin{array}{l}\text { basicTC } \\
\text { intermediateTC } \\
\text { advancedTC }\end{array}$ & $\begin{array}{l}\text { Dependent variables, indicating the } \\
\text { accumulation of basic, intermediary and } \\
\text { advanced technological capabilities (TC) } \\
\text { after CDM project experience }\end{array}$ & $\begin{array}{l}2.99 \\
2.85 \\
2.47\end{array}$ & $\begin{array}{l}1.90 \\
1.87 \\
1.77\end{array}$ & $\begin{array}{l}0 \\
0 \\
0\end{array}$ & $\begin{array}{l}6 \\
6 \\
6\end{array}$ & \\
\hline previousTC & $\begin{array}{l}\text { TC level prior to CDM project } \\
\text { experience, estimated as simple mean of } \\
\text { ten previous TCs. }\end{array}$ & 0.46 & 0.40 & 0 & 1 & + \\
\hline previousTC ${ }^{2}$ & Squared term of previous TC & 0.16 & 0.10 & 0.001 & 0.287 & - \\
\hline Other_projects & $\begin{array}{l}=1 \text { if the project host company had } \\
\text { another project, } 0 \text { otherwise }\end{array}$ & 0.34 & 0.47 & 0 & 1 & + \\
\hline Qualification & $\begin{array}{l}\text { Share of personnel with higher } \\
\text { qualification }\end{array}$ & 0.23 & 0.20 & 0 & 0.8 & + \\
\hline Training & $\begin{array}{l}\text { average of binary variables associated } \\
\text { with training, on-job coaching and other } \\
\text { capacity building efforts }\end{array}$ & 0.46 & 0.50 & 0 & 1 & + \\
\hline Size & $\begin{array}{l}=1 \text { if company is larger scale and }=0 \text { if } \\
\text { it is small scale }\end{array}$ & 0.43 & 0.50 & 0 & 1 & $+/-$ \\
\hline Age & Natural log of the age of company & 2.43 & 0.84 & 0 & 4.42 & $+/-$ \\
\hline Local_ownership & $\begin{array}{l}=1 \text { if company has local ownership } \\
\text { status, } 0 \text { if foreign }\end{array}$ & 0.87 & 0.34 & 0 & 1 & $+/-$ \\
\hline Local_technology & $\begin{array}{l}=1 \text { if the technology of local origin, } 0 \text { if } \\
\text { it is partially or fully imported }\end{array}$ & 0.55 & 0.50 & 0 & 1 & $+/-$ \\
\hline India & $\begin{array}{l}=1 \text { if project is implemented in India, } 0 \\
\text { otherwise }\end{array}$ & 0.34 & 0.47 & 0 & 1 & \\
\hline China & $\begin{array}{l}=1 \text { if project is implemented in China, } 0 \\
\text { otherwise }\end{array}$ & 0.13 & 0.33 & 0 & 1 & \\
\hline Brazil & $\begin{array}{l}=1 \text { if project is implemented in Brazil, } 0 \\
\text { otherwise }\end{array}$ & 0.38 & 0.49 & 0 & 1 & \\
\hline Policy & $\begin{array}{l}\text { Simple mean of perceived quality of } \\
\text { institutions evaluated on } 0-6 \text { scale }\end{array}$ & 3.23 & 1.35 & 0.33 & 6 & + \\
\hline
\end{tabular}




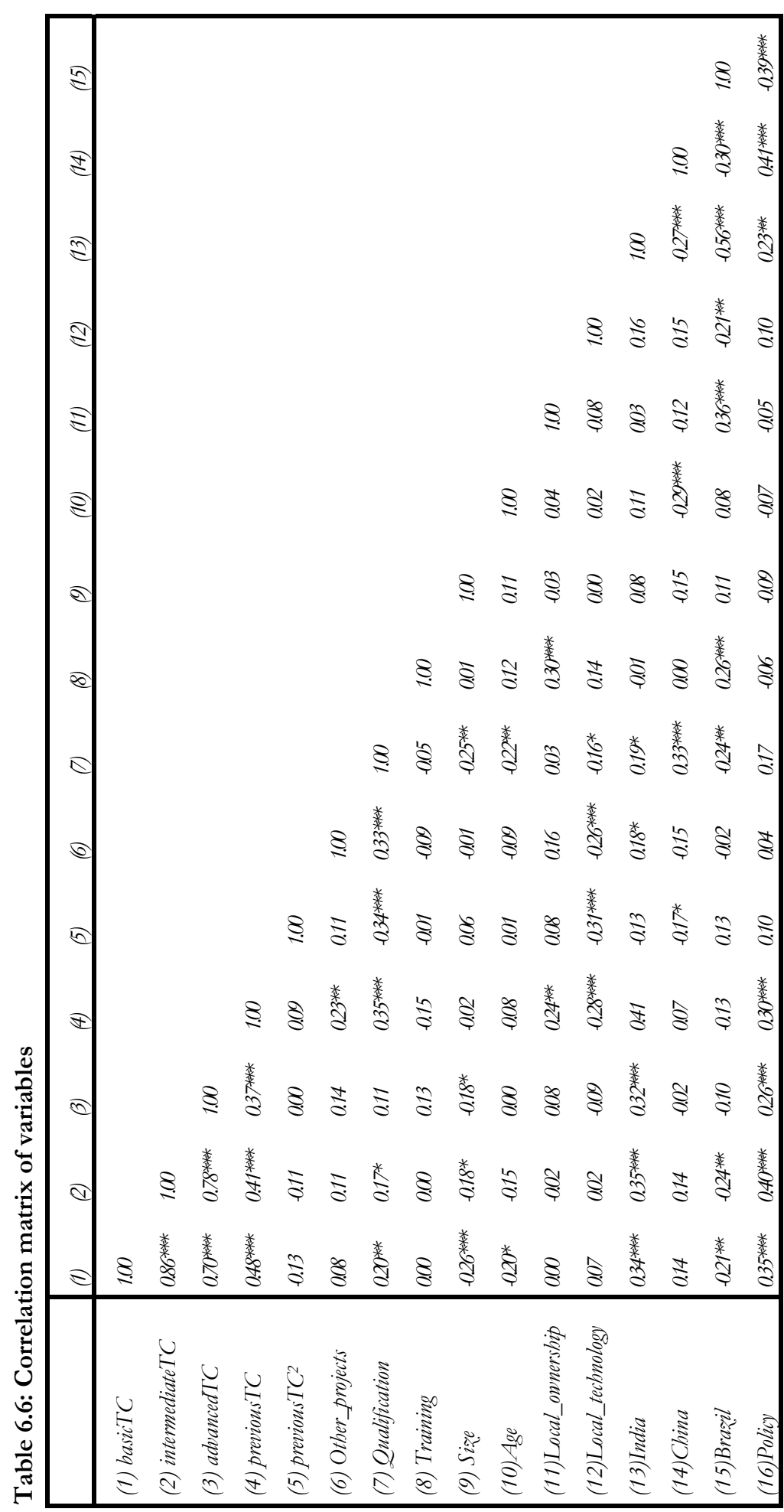




\subsection{Results}

Table 6.7 displays the estimation results of the OLS model. As a base to compare our results against, we first ran a regression with only control variables. Models 1.1, 2.1, and 3.1 in Table 6.6 represent the impact of the control variables on increase in basic, intermediate, and advanced technological capabilities. Models 1.2, 2.2, and 3.2 present the results for the model that also include independent variables.

Hypothesis 1a argues that a CDM projects recipient's prior level of knowledge about relevant technology positively influences technological learning outcomes of CDM project. The regression results on the effect of prior knowledge level measured by previous TC, on post-project TC building outcomes show a positive sign in all three basic, intermediary and advanced TC building cases. Statistical significance of the results are on a $1 \%$ level in case of basic TC, and on a $10 \%$ level for intermediary and advanced TC building. Thus these results confirm the hypothesis 1a. Results for the magnitude of the effect (the coefficients) demonstrate that prior TC have higher effect on increase of basic TC, less on intermediate TC, and even less effect on advanced TC.

Results on quadratic term of the prior knowledge level (previousTC2) seek to test the hypothesis $1 \mathrm{~b}$ which, in contrast to hypothesis $1 \mathrm{a}$, argues for a parabolic, inverted Ushaped relationship between prior and post project TC levels of the project host company. This hypothesis implies that technology recipients with no or very small prior knowledge would not be able to benefit efficiently in terms of learning as they would miss absorptive capacity, while for the ones having very extensive prior knowledge in technology and CDM projects would not acquire much new knowledge; and the recipients with close to optimal (not too high and not too low) level of prior knowledge would be the nearest to achieving highest learning outcomes. The regression results for squared term of previous TC show negative and statistically significant (10\% level) coefficients for models 1.2 and 2.2. The result for model 3.2 is not statistically significant. Considering significant and positive coefficient in case of previous TC and negative significant effect for its squared term we found support for Hypothesis $1 \mathrm{~b}$ in the case of basic and intermediary TC building, though not for advanced TC. The magnitude for the coefficients in both bases slightly differs, showing stronger effect in intermediate TC case.

The test for the relevance of experience with other projects (Other_project) to learning outcomes did not show statistical significance. But we note that the coefficients obtained a positive sign in the regression results. 
Table 6.7: OLS regression estimates of impact of dependent and control variables on basic, intermediate, and advanced technological capabilities

\begin{tabular}{|c|c|c|c|c|c|c|}
\hline & \multicolumn{2}{|c|}{ BasicTC } & \multicolumn{2}{|c|}{ Intermediate TC } & \multicolumn{2}{|c|}{ AdvancedTC } \\
\hline & Model 1.1 & Model 1.2 & Model. 2.1 & Model 2.2 & Model 3.1 & Model 3.2 \\
\hline previousTC & & $\begin{array}{l}2.206^{* * *} \\
(0.542)\end{array}$ & & $\begin{array}{l}1.415^{*} \\
(0.567)\end{array}$ & & $\begin{array}{c}1.137^{*} \\
(0.573)\end{array}$ \\
\hline previous $T C^{2}$ & & $\begin{array}{l}-3.195^{*} \\
(1.819)\end{array}$ & & $\begin{array}{l}-3.555^{*} \\
(1.902)\end{array}$ & & $\begin{array}{l}-1.428 \\
(1.920)\end{array}$ \\
\hline Other_projects & & $\begin{array}{l}0.109 \\
(0.360)\end{array}$ & & $\begin{array}{l}0.322 \\
(0.377)\end{array}$ & & $\begin{array}{l}0.254 \\
(0.380)\end{array}$ \\
\hline Qualification & & $\begin{array}{l}1.438 \\
(1.111)\end{array}$ & & $\begin{array}{l}2.082^{*} \\
(1.162)\end{array}$ & & $\begin{array}{l}0.992 \\
(1.172)\end{array}$ \\
\hline Training & & $\begin{array}{l}0.394 \\
(0.353)\end{array}$ & & $\begin{array}{l}0.412 \\
(0.370)\end{array}$ & & $\begin{array}{c}0.711 * \\
(0.373)\end{array}$ \\
\hline Size & $\begin{array}{l}-1.036^{* *} \\
(0.329)\end{array}$ & $\begin{array}{l}-1.027 * * \\
(0.318)\end{array}$ & $\begin{array}{l}-0.696^{*} \\
(0.330)\end{array}$ & $\begin{array}{c}-0.743 * \\
(0.333)\end{array}$ & $\begin{array}{c}-0.785^{*} \\
(0.328)\end{array}$ & $\begin{array}{c}-0.783^{*} \\
(0.336)\end{array}$ \\
\hline Age & $\begin{array}{l}-0.406^{*} \\
(0.199)\end{array}$ & $\begin{array}{c}-0.405^{*} \\
(0.191)\end{array}$ & $\begin{array}{l}-0.301 \\
(0.199)\end{array}$ & $\begin{array}{l}-0.325 \\
(0.199)\end{array}$ & $\begin{array}{l}-0.014 \\
(0.198)\end{array}$ & $\begin{array}{l}-0.038 \\
(0.201)\end{array}$ \\
\hline Local_ownership & $\begin{array}{l}-0.391 \\
(0.368)\end{array}$ & $\begin{array}{c}-0.631 * \\
(0.360)\end{array}$ & $\begin{array}{l}-0.402 \\
(0.369)\end{array}$ & $\begin{array}{l}-0.584 \\
(0.377)\end{array}$ & $\begin{array}{l}-0.140 \\
(0.366)\end{array}$ & $\begin{array}{c}-0.378 \\
(0.380)\end{array}$ \\
\hline Local_technology & $\begin{array}{l}-0.021 \\
(0.482)\end{array}$ & $\begin{array}{c}-0.389 \\
(0.566)\end{array}$ & $\begin{array}{l}-0.361 \\
(0.484)\end{array}$ & $\begin{array}{c}-0.378 \\
(0.592)\end{array}$ & $\begin{array}{c}-0.732 \\
(0.480)\end{array}$ & $\begin{array}{c}-0.602 \\
(0.597)\end{array}$ \\
\hline India & $\begin{array}{l}2.291 * * * \\
(0.546)\end{array}$ & $\begin{array}{l}0.928 \\
(0.666)\end{array}$ & $\begin{array}{l}2.063^{* * *} \\
(0.548)\end{array}$ & $\begin{array}{l}1.239 * \\
(0.696)\end{array}$ & $\begin{array}{l}1.930 * * \\
(0.543)\end{array}$ & $\begin{array}{l}1.114 \\
(0.703)\end{array}$ \\
\hline China & $\begin{array}{l}1.144 \\
(0.695)\end{array}$ & $\begin{array}{l}0.232 \\
(0.807)\end{array}$ & $\begin{array}{l}0.943 \\
(0.697)\end{array}$ & $\begin{array}{l}0.563 \\
(0.844)\end{array}$ & $\begin{array}{l}0.521 \\
(0.692)\end{array}$ & $\begin{array}{l}0.020 \\
(0.852)\end{array}$ \\
\hline Brazil & $\begin{array}{l}1.319 * \\
(0.552)\end{array}$ & $\begin{array}{l}0.527 \\
(0.575)\end{array}$ & $\begin{array}{l}1.053^{*} \\
(0.554)\end{array}$ & $\begin{array}{l}0.457 \\
(0.602)\end{array}$ & $\begin{array}{l}1.123^{*} \\
(0.550)\end{array}$ & $\begin{array}{l}0.503 \\
(0.607)\end{array}$ \\
\hline Policy & $\begin{array}{l}0.320^{*} \\
(0.141)\end{array}$ & $\begin{array}{l}0.272^{*} \\
(0.140)\end{array}$ & $\begin{array}{l}0.401 * * \\
(0.141)\end{array}$ & $\begin{array}{l}0.378^{*} \\
(0.147)\end{array}$ & $\begin{array}{l}0.284^{*} \\
(0.140)\end{array}$ & $\begin{array}{c}0.255^{*} \\
(0.148)\end{array}$ \\
\hline _cons & $\begin{array}{l}2.200 * * \\
(0.825)\end{array}$ & $\begin{array}{l}2.579 * \\
(1.016)\end{array}$ & $\begin{array}{l}1.897 * \\
(0.828)\end{array}$ & $\begin{array}{l}2.786^{*} \\
(1.063)\end{array}$ & $\begin{array}{l}1.494^{*} \\
(0.821)\end{array}$ & $\begin{array}{l}1.745 \\
(1.073)\end{array}$ \\
\hline Number of obs & 104 & 104 & 104 & 104 & 104 & 104 \\
\hline Prob $>F$ & 0.0000 & 0.0000 & 0.0000 & 0.0000 & 0.0007 & 0.0020 \\
\hline R-squared & 0.3352 & 0.4465 & 0.3087 & 0.3754 & 0.2401 & 0.2888 \\
\hline Adj R-squared & 0.2792 & 0.3665 & 0.2505 & 0.2852 & 0.1761 & 0.1860 \\
\hline
\end{tabular}


Hypothesis 2 states that a higher representation of human resources such as engineers and technical personnel is positively associated with more dynamic technological learning in CDM project. The coefficient for the variable is indeed positive in all three models, but statistically significant (on 10\% level) only in model 2.2, thereby providing support for the hypothesis 2 in case of intermediate TC and no conclusion in the other two cases. We also note that the magnitude of the coefficient is higher in model 2.2, smaller in model 1.2 and considerably smaller in model 3.2.

Hypothesis $3 \mathrm{a}$ argues that training activities provided by the technology providers under CDM projects would have positive effect on building TCs. Coefficients for the training variable shows a positive sign in all three models, however the results are statistically significant $(10 \%)$ only in model 3.2. Therefore the hypothesis was supported only for the case of advanced TCs. However these results did not acquire a sufficient support for hypothesis $3 \mathrm{~b}$ because we expected to see larger effect in basic capabilities and smaller effect in advanced. Rather the magnitude of the coefficient shows opposite trend suggesting the higher influence of training activities on building advanced TCs.

Results for the control variables demonstrate the following: size variable, which is a large firm dummy, shows negative and statistically significant (5\% and 10\% level) association with learning outcomes. This implies that experience with CDM projects does not result in higher technological learning in larger companies. This supports the argument of Lane et. al (2001) saying that large companies tend to be more inert which inhibits their learning. Another explanation could be that larger companies are too large or too experienced to be influenced by the experience with CDM projects. From the other point of view, it can also be interpreted that small sized companies implementing CDM projects tend to benefit more in terms of TC building, which might be due to their flexibility or lack of experience.

Our prediction for the Age related variable was either of opposite outcomes. The results showed negative effect of age on technological learning outcomes of CDM projects. This is perhaps because older companies have more experience and knowledge and CDM does not increase their base of skills and knowledge. Coefficients of the dummy specifying local ownership status have a negative effect on technological capability building which is statistically significant on the $10 \%$ level only in model 1.2 (basic TC's). This proves that companies with foreign ownership participation have a higher probability to get their basic technological capability increased.

The results for technology origin did not show statistical significance, thus we do not interpret them. Country dummies show positive and statistically significant effect (in most of the cases for India and half of the cases for Brazil). This means that Indian and Brazilian companies tend to achieve progress in technological learning as a result of CDM project implementation. Results for China are also positive, but statistically not 
significant. The indicator for quality of polices relevant to CDM implementation and technological development demonstrate a positive, stable and statistically significant (on $5-10 \%$ level) effect in all models.

Additionally, in order to check whether there are interaction effects among variables, we tried introducing in the regression models several interaction variables capturing various combination between previousTC, Other_projects, Qualification, Training, Size, Age, Local_ownership and Local_technology. This exercise did not render statistically significant results for interaction variables in any of the models, thus declining possibility of strong interaction effect in the regression models.

\subsection{Discussion}

In this chapter we have tested the effect of various dimensions of absorptive capacity on technological capability building of CDM project host companies. We based our results on a sample of 104 companies in Brazil, China, India and Mexico; countries which are most active in initiating these projects. Several hypotheses about the impact of absorptive capacity in technological learning were tested and the results provided varying levels of support for these hypotheses.

In the discussion leading up to the first hypothesis we argued that there is a positive relationship between prior knowledge and technological capability building as a result of CDM project implementation. Results of our study largely support the prediction that prior knowledge being an important element of organizational absorptive capacity eases further learning. This result is consistent with widely recognized results of studies on absorptive capacity (Cohen and Levinthal, 1990; Lane and Lubatkin, 1998; Kim, 1998).

Hypothesis $1 \mathrm{~b}$ is a complement to the first hypothesis. It seeks to investigate the relationship between prior knowledge and learning results in more detail by studying patterns of the learning function. We followed the suggestions by the literature that learning outcome is not just positive, but also curvilinear function of the organization's prior knowledge (Noteboom, 1992, 1999; Mowery et. al 1996, 1998). Our findings confirm that the learning opportunity is greater when there are some differences between the knowledge base of the organization and the knowledge that is embedded in the new technology arriving along with the CDM project. The learning outcomes are rather limited in the case of very poor and very rich prior knowledge bases. Thus our results established an inverted U-shape relationship between prior knowledge and learning outcomes. In reality CDM project host companies drastically vary in their knowledge base, which is determined first of all by their experience in CDM specific technologies. For some companies (e.g. ones specialized in wind or hydropower generation) CDM experience does not produce any value-added in their technological 
capabilities, while in many cases a CDM project is a mean of introducing a new technology in the company's production cycle, which also requires fostering new expertise and capabilities. Our survey and supplementary in-depth interviews also revealed that some companies had prior experience in introducing CDM related technologies long before this mechanism was put into work (e.g. experiments with biogas utilization in animal farms), which allowed them to accumulate some expertise and build absorptive capacity for larger and more sophisticated projects.

However it is necessary to note that while a positive relationship has been proved for prior TCs and all three types of TC building outcomes, the inverted curvilinear relationship were obtained only for the cases of basic and intermediate level skills appropriation, but not for advanced/innovative capability building. The (simple) explanation we suggest is that the relationship between prior knowledge and learning of advanced knowledge is not curvilinear, but linear and positive. This suggests that when it comes to learning of advanced technological expertise companies still learn a lot independently from richness of their prior knowledge base, in other words they don't reach their knowledge saturation level. However further investigation would be helpful in finding out if this is the case only specifically for CDM project experience or this can apply to other practices of new technology acquisition.

Another indicator for prior knowledge which we included in the regression analysis was the experience with other CDM projects. The fact of having more than one project did not prove to contribute to technological learning in CDM projects. This might be because in our sample we included companies that implemented projects in 2005-2006, meaning a rather short time span between projects which does not allow the building of more solid knowledge based on earlier project experience.

The third hypothesis addresses the human resource dimension of an organization's absorptive capacity. It predicts that companies with a larger share of highly qualified personnel such as engineers and technical experts would benefit from more extensive technological learning during CDM project implementation. The hypothesis found statistically significant confirmation only in the case of intermediate TC building thus finding partial support and consistency with earlier studies (e.g. Glass and Saggi, 1998; Kim and Dahlman, 1992; Luo, 1997; Veugelers, 1997). Besides, we note that the magnitude of the coefficient is larger in the intermediate TC group related model in comparison to the other two. These results might be related to the scope of capabilities covered in the intermediate TC group such as process improvement and incremental innovation. If the company has a pool of engineers, an increase in basic capabilities during the project experience might not happen as they already possess them, while improvement in intermediate capabilities benefits from the CDM experience. In the same way higher qualifications could influence advanced technological competences building, however this was not proved in our results. Earlier studies investigating the 
human capital dimension of absorptive capacity draw on learning in innovative activities (e.g. Glass and Saggi, 1998; Keller, 1996), therefore it is puzzling that in our study we did not find statistically strong results. Possibly this has to do with the fact that in CDM projects design and development activities are often implemented by the technology providers, rather than by the recipient. However this finding needs to be kept open for further investigation.

Testing the hypotheses $3 \mathrm{a}$ and $3 \mathrm{~b}$ addressing the relevance of training activities in TC building impact of CDM project showed not very conclusive results. Statistically strong coefficient is associated with role of training in building advanced technological capabilities, while results for basic and intermediary TC groups were not proved with sufficient confidence level. Positive sign of the coefficients imply positive association between qualification factor and technological learning, which in its turn allows for an argument about the relevance of training in an absorptive capacity concept and its role in technological learning. Our initial concern was that these results might be caused by narrow presentation of the training data because we used a dummy variable for capturing the training effect. We have tried running regression with disaggregated variables capturing various training activities. These variable are dummies training, onjob_coaching, and other_training each indicating if any of these activities took place or not. We did not achieve much improvements: statistically significant $(10 \%)$ results were obtained only for training variable in models for intermediary TC (2.2) and advanced TC (3.2). "onjob_coaching" and "other_training" have rendered no strong results in all three models.

We think there is a serous problem related with measurement of the training effect. As we noted above the problems might be in a narrow presentation of the training data and using a dummy variable for capturing the training effect. Considering that even disaggregated data didn't show much statistically strong results, we suspect that having them as binary variables do not help to study their effect on TCs. The qualitative information about the training, on-job coaching and other activities such as content, duration, intensity, etc. was not addressed in the survey. We believe that the quality of training activities provided by the technology provider very much varied across the projects which may have caused rather diverse effect on knowledge transfer.

Furthermore we think that the way we framed training related question in the questionnaire could be with assessment elements. In other words instead of asking whether there was a training by technology providers it is probably better to ask how effective and educative were the training activities and to use a Likert-type scale to rank the effect.

As an overall observation of the regression results it is necessary to highlight the singled out effect of each variable. Prior technological knowledge captured by the previous technological capabilities proxy showed the strongest effect on learning 
outcomes in comparison with other components. The dynamics of the coefficient across the three models shows that prior knowledge has higher effect building basic TCs, while this effect diminishes with raise of complexity of TCs. Qualification of personnel also obtained a larger coefficient indicating its stronger effect. This suggests that absorptive capacity of the project host organization is represented to a larger extent by a combination of prior knowledge and the presence of highly qualified employees, and to a lesser extent by experience with CDM projects and training efforts.

\subsection{Conclusion and implications}

Overall we feel that our chapter contributed to answering the research question in the following way: we have highlighted an important but previously unstudied topic of absorptive capacity in technological learning in CDM projects. Our study demonstrated the methodological suitability of combining various indicators for absorptive capacity and considering them as dimensions of an organization's absorptive capacity. Authors who introduced the concept of absorptive capacity defined it as a complex factor, representing a company's knowledge, accumulated through its experience and formal and informal learning, and residing in its employees (Cohen and Levinthal, 1990; Zahra and George, 2002; Van Den Bosch et. al, 2005). Unlike approaches in earlier studies which compiled a single factor for absorptive capacity compiled out of several measurements (e.g. Daghfouse, 2004; Whangthhomkum, 2006), in our study we tried the opposite by singling out effects of different dimensions of absorptive capacity on technological capability building dynamic. By doing this we revealed the strong role of prior knowledge and skills in relevant technology in further learning and appropriation of the technology. Also the importance of availability of highly qualified personnel for more effective learning was partially assured. While these findings do not bring big news in organizational learning literature, they can have implications for the CDM and technology transfer related discourse and policies. Thus based on our results we argue that promotion of the domestic knowledge base in climate friendly technologies and fostering human resources would create a fruitful ground for more effective technological learning and spillovers from further CDM project experience.

The important goal of CDM is contributing to sustainable development in project host countries. Technology and knowledge transfer is considered as part of the sustainable development agenda. An increasing segment of CDM literature discusses the possibility of measuring the sustainable development impact of CDM. The approach we used in our study is based on the technological capability taxonomy widely acknowledged in technical change and innovation studies (Lall, 1992; Bell, 2007; Figueiredo, 2003). Assessing the range of technological capabilities allowed us to measure the technological learning impact of CDM project. This framework showed its viability and 
reliability and can potentially be used in studying technological development aspects of CDM.

Considering the impact of CDM projects in terms of technological learning and capability building from the sustainable development angle we can suggest the following implications: once companies in developing countries take part in CDM projects they accumulate a range of technological capabilities and competences which may have spillover effects on the country's economy and facilitate diffusion of clean technologies. Although these effects might hardly be traced at the current moment, future prospects and research avenues are there.

As a policy implication we suggest governments and company leaders to steer and invest in building local absorptive capacity which would further ensure better appropriation of new knowledge and technologies. This is particularly becoming important for the clean technologies niche as the trend in demand for these technologies is lately increasing along with globalization of environmental governance and strengthening of environmental standards. In this regard we found our result on the effect of policies promoting CDM and renewable energy expertise and technologies to be very relevant. All our results show strong positive association of policies with technological learning and capability building, which suggests that institutional environment matter also for micro level technological learning.

Talking about limitations of the study, we have noted in the discussion above the possible misspecifications and limitations of certain data we have collected. As we discussed in the case of training data, the problems seem to be caused by missing data on quality of training.

Other limitations of our study are related with our sample. Despite showing sufficient statistical representativeness of our sample (discussed in chapter 2, section 2.3.4) limited number of observations can still be considered as one of the major weaknesses of the study. Conducting survey is a very time and effort consuming exercise, and ensuring high response rate can be a matter of deploying larger resources. For future similar studies, it is recommended to attract considerable resources for surveys and use techniques enhancing motivation of respondents.

Furthermore, in our study we covered only four countries, though as the largest recipients of CDM projects these covered around three quarters of the global CDM projects pool. Many countries were not covered by our survey, among them countries which are small and economically less developed. Thus results we acquired in this chapter despite being insightful might not be relevant for these countries.

Second, the statistics of CDM projects have somewhat changed since 2007. Recent developments in the CDM market show growing leadership of China in initiating CDM projects. In contrary to our sample which was based on statistics of 2007, the share of 
China is rather modest, which implied a small sample representing this country. Resampling and new similar research may have different observations for this country.

Above mentioned limitation may translate into opportunities for further research with improved questionnaire and enlarged sample covering larger range of countries. Besides, the interesting and promising results obtained with policy variables may give a motivating ground for deeper investigation of the role of policies in technology and knowledge transfer in CDM projects.

In conclusion it is necessary to note that in the literature strand addressing technology and knowledge transfer in CDM projects this study is believed to be unique in terms of obtaining company level data and pioneering in terms of applying the organizational learning approach. Our most important lesson that follows through this experience is that well established and conceptually and methodologically rich organizational learning literature can provide a solid ground for studying technology transfer and learning issues in CDM projects and suggest a good opportunities for further research. 


\section{CHAPTER 7. LEARNING BY DOING AND LEARNING THROUGH INTERACTION IN CDM PROJECTS}

\subsection{Introduction}

Technological capability building in CDM projects is a complex process in which many endogenous and exogenous factors play their roles. In the previous chapter we investigated the factors intrinsic to the technology recipient organizations, such as their internal knowledge resources and absorptive capacity, which determine technological learning outcomes in $\mathrm{CDM}$ project experience. Thus the perspective of the technology recipient and their knowledge base was the major focus of the analysis. However, it is obvious that learning is not only determined by internal features of the learning organization. System approach always suggests examination of the external environment and the interaction with other agents, because usually learning and innovation are generally interactive processes. Correspondingly Dougherty (1999:262) states "knowledge transfer is about connection, not collection", and connection ultimately depends on the choice made by individuals. Knowledge transfer, as a component of a larger technology transfer process in particular may well be a 'two-way process' between the transferor and the transferee (Li-Hua, 2003). Furthermore, the ability of a firm to learn from another firm is jointly determined by the relative characteristics of the two firms (Lane and Lubatkin, 1998).

Therefore, in this chapter we propose to use a more inclusive analytical framework by also considering the perspective of technology providers and the interaction with them. In CDM projects, as well as in any new industrial activity involving acquisition of new technology, the role of the technology provider can be important in further operation of a new facility (Schneider et al., 2008; Metz et al., 2000). Being a supplier of the technology they carry not only an explicit knowledge about how to operate it, but also substantial elements of tacit knowledge that can be transferred in interactive communication (Odigie and Li-Hua, 2008). In the case of CDM the activity implemented and technology used in the project are often new to a host company. Our survey showed that roughly half of the project host companies had no prior experience in CDM related technology application and development (see Chapter 5). This suggests the great importance of two factors in the process of acquisition and assimilation of the new technology: first, the recipient's own efforts and, second, the efficiency of knowledge delivery by the technology provider.

The role of technology providers, especially in micro-level perspective,, has largely been overlooked in the literature on technology transfer in CDM projects. The paper that is worth noticing is the study of Malaysian CDM projects by Hansen (2008) which 
provides a detailed picture on knowledge and expertise transfer dynamics and the role played by European technology providers in this process. However the narrow scope of the study does not provide a conclusive picture and has limited relevance to overall CDM projects experience, thus proposes further investigation. Supplementary literature that provides more insights on the perspectives we analyse in this chapter, is the organizational learning literature discussing various modes of learning as by doing, using and interaction (e.g. von Hippel and Tyre, 1995; Jensen et al., 2007; Lundvall, 1988), and its sub-section on joint ventures and alliances, which is more developed in terms of analysing knowledge transfer in technology recipient-supplier dyads (e.g. Inkpen 2002; Mowery et al., 1996).

This chapter aims to study the roles of technology providers and recipients in technological learning in CDM projects. One set of issues we address here is the technology providers' characteristics and involvement in the project. Another set covers factors that are associated with technology recipients' active position, namely their involvement in the project and in overcoming challenges in technology acquisition and assimilation. The analytical framework in this chapter captures two perspectives of learning/technological capability building: "learning through interaction" with technology provider and "learning by doing" the project and adopting the technology. The following research question induces the analysis: Which of these two modes of learning prevail in building technological capabilities of CDM project host organizations? We also investigate if the technology provider's familiarity with the country context and ownership ties with the technology recipient, influence the learning results.

This study is based on the survey of $104 \mathrm{CDM}$ project host companies located in Brazil, China, India and Mexico.

The chapter is constructed in the following order: section 7.2 presents the theoretical background and a set of hypotheses to be tested. Section 7.3 describes the methodological setting including data and construction of variables used in the regression analysis. Econometric results are described in the section 7.4 and discussed against the proposed hypothesis and theories in section 7.5. We conclude and discuss implications in the last section of the chapter.

\subsection{Theory and hypotheses}

\subsubsection{Learning modes in CDM projects: analytical framework}

Conceptual and empirical researches of various factors that influence the technology acquisition performance of firms have been rapidly expanding during the last two decades. The streams of literature which are particularly focused on identifying a larger 
scope of factors relevant for this field are technology management and transfer, technological alliances, organizational learning, and innovation studies.

In developing the framework for the analysis in this chapter, we built upon the perspective that technological learning under CDM is a combination of several modes of learning such as learning by doing, learning by training and learning by interaction (Jensen et al, 2007; Lundvall 1988). Since we are here analysing technological knowledge and capabilities, the technology provider, who is a potential source of this knowledge, is an important part of the framework. It is rather logical to assume that the technology provider is the one that knows most about the technology it is offering. In the context of a new project, the technology recipient has to undergo a time-consuming process of mastering the new technology. In this process the help of the technology provider can be essential. At the same time many empirical evidences suggest that technology mastery is largely a result of the individual experience with technology, and confronting day-to-day changes and challenges (Hatch and Mowery, 1987; Tyre and von Hippel, 1997). Overall learning/ technological capability building under the CDM project can be induced by any of these modes. Therefore, the analytical framework suggested in this chapter considers each of these modes. It assumes that learning by doing is represented to a large extent by the overall involvement and active positions of the technology recipient company in the project and accumulation knowledge from own experience, problems solving, etc., Learning through interaction and training, on the other hand, is built around the cooperation with technology provider throughout project stages, and concerns knowledge sourced from the technology provider. In our study, therefore, we attempt to investigate if any of these modes play a prevailing role in technological learning in CDM projects. Additionally factors such as the technology provider's familiarity with local country context and the organizational ties with the project host, were included in the analysis, because they were considered to be directly or indirectly influential on the effectiveness of the knowledge transfer process.

Innovation literature emphasizes that innovation and technological learning are interactive processes not only among customers and suppliers, but also with knowledge institutions (Freeman, 1987; Kline and Rosenberg, 1986; Lundvall, 1988). The survey preceding this paper revealed that knowledge institutions, such as research institutes, laboratories and universities were not involved in the CDM project related activities in the dominant majority of cases. For this reason, interaction with knowledge institutions is out of the scope of the framework considered in this paper. As was mentioned above, the major focus is on the interaction between technology providers and technology recipients, or the CDM project host companies. 


\subsubsection{Hypotheses}

Learning through interaction with technology providers

In contrast to information, knowledge is often 'sticky', difficult to codify and difficult to transfer (von Hippel, 1994). Its stickiness is in the fact that 'we can know more than we can tell' (Polanyi, 1967:4). Therefore, possession of codified knowledge such as instructions on application, guidelines, etc., does not deliver the full range of knowledge and skill associated with certain equipment or production line. Moreover, the documented instructions, as a general practice, provide information on technology application, and rarely information allowing understanding the technology and process that it is based on. This understanding of technology is crucial for its further improvement, stretching, or upgrading, that are associated with development and application of higher levels of technological capabilities.

Knowledge is generally known to consist of two significant components: namely explicit and tacit. However, 'the greater the extent to which a technology exists in the form of the softer, less physical resources, the greater the proportion of tacit knowledge it contains' (Li-Hua, 2003:2). Tacit knowledge, due to its non-codifiable nature has to be transferred through intimate human interactions (Tsang, 1997).

Many studies on organizational and technological learning argue for social or interpersonal nature of the learning process. They highlight the importance of interaction processes, such as discussion, debating and persuasion, and significance of relationship like trust and antagonism to overcome uncertainty and ambiguity of activities (March and Olsen, 1975). Whether it is an inter-organizational collaborative arrangement as a joint-venture, a technological alliance or a technology transfer collaboration between companies, or indigenous efforts within organization, close interaction is an important way to communicate implicit knowledge that may not have only a technical nature, but also a socio-cultural. A successful transfer is achieved when it bridges the gap between two parties clarifying, for the user, the potential of the technology, and facilitating the supplier's ability to provide the necessary cultural skills for operating it (Levin, 1993). Furthermore, technology is transferred through several channels and formal or informal organizational modes and ample evidence establishes a strong link between the amount of capabilities transferred and the modes of transfer (Contractor, 1985; Dunning, 1981; Mansfield and Romeo, 1980; Reddy and Zhao, 1990). The interactive component, in the form of more or less integrated collaboration, varies in each type of mode. Although the studies did not aim to address the role of interaction, the more interaction intensive modes like join ventures and direct investments proved to be better in promoting technological capability building than for example technical agreement which is less integrative for technology supplier and recipient parties. 
In case of a technology acquisition, building tacit knowledge around this technology also requires close and intensive communication with technology provider (Kathuria, 2002). Considering the case of CDM project implementation, the amount of knowledge transferred might depend on the intensity of interaction between technology recipient and provider. Because the project has many stages, each of them may involve different ways of interaction which depend on the degree of involvement of each two parties in a particular stage of the project. Hansen (2008) and Doranova et al., (2009) describe that in some cases the participation of technology provider in the CDM project implementation is very limited and basically may represent simple shipping, while in other cases they are involved in a complete cycle of project design, implementation, and monitoring of a CDM project. In many cases technology providers took part only in the stages of equipment delivery and installation, but not in the project initiation stage when the project and facility were designed. What is important for us here is to understand whether the collaboration and interaction between technology recipient and provider took place in each phase of CDM project and whether this made any implications on the knowledge transfer outcomes.

The project preparation phase is rich in design activities, at which technology providers are supposed to be far better than the recipients. Close collaboration at this stage is a good opportunity to acquire design and development related knowledge and skill, as well as deeper a understanding of the technology and the processes which it is based on. Analogously, the collaboration and interaction during the project implementation phase might be important. The essential periods are in the early stages of equipment exploitation and adjustment because these might be the most learning intensive parts of the project. Technology recipient, before being left alone with the new machine has to try to benefit from advice and instructions from the technology provider. Therefore, close interaction is important at this stage. Moreover, formal training and coaching activities are often a part of the technology providers service (Kathuria, 2002). These are by definition, interactive activities, with the deliberate purpose to provide knowledge about dealing with the new equipment.

Following the argument above, we draw the following hypotheses:

H1a: Collaboration with the technology provider in the initial stages of a project (preparation and design) positively contributes to technological learning/ capability building by the CDM project host company

H1b: Collaboration with technology provider in the stages of project implementation (installation, adaptation) positively contributes to technological learning/ capability building by the CDM project host company

H1c: Interaction with technology provider though training/coaching activities positively contributes to technological learning/ capability building by the CDM project host company 
Ties between technology provider and recipient

Levin (1993) describes the transfer of technology as a process consisting of two opposing sub-processes. Seen by the supplier, it encompasses both the shipment of merchandise and the transfer of necessary knowledge to operate the equipment. From the position of the receiver, the process involves acquiring material artifacts and managing the learning process necessary to operate the equipment. The author suggests that transfer of knowledge as seen by the provider can have a very different meaning from learning how to operate the equipment as seen from the user side. The implication is that the gap in cultural, technological and other differences is less in case these two actors had previous formal or informal ties between them. Trust, established channels of knowledge flow, routines of information exchange are usually there if the partners have had long-lasting ties (Levin, 1993; Inkpen 2000).

The literature provides many evidences of effective technology transfer between organizations maintaining formal or informal ties. For example, Inkpen (2000) argues that joint ventures and other foreign equity party companies proved to benefit more from technology transfer and spillovers because throughout the history of partnership, firms learn about each others' ways of doing business, and interpret each others' acts from experiences. In the same line Heide and Miner (1992) argue that firms that have worked together in the past will have basic understandings about partner skills and capabilities, which should provide an impetus for learning. As a result, experienced partners, or parent and subsidiary can forgo the relationship building processes that will be necessary for partners working together for the first time, which speeds up the learning process. On the contrary, inexperienced partners must go through a relationship building period that is often associated with trust building (Gulati, 1995), which may intervene with the technological learning process and slow it down. This is a process of developing the relational routines that are necessary to create a successful partnership leading to successful knowledge transfer.

There are also a number of examples described in case studies by Hansen (2008), Doranova et al (2009) where in landfill methane capture and biomass projects the parent company is the main technology provider in CDM project. This fact proved to ensure close joint effort during the project's initiation, implementation and maintenance, which further resulted in effective strengthening of expertise of the daughter company that is the main and long-term implementer of the CDM project. Otherwise in other modes of organizational arrangements in CDM projects establishment of closer cooperation and trustful relationship between project partners is expected to take time and efforts. This might have an implication on the knowledge exchange process between them, first of all on intensity of it, as well as on content and quality of it. The important factor here is an incentive of a technology provider to share knowledge with the recipient. In parent-subsidiary relationships, the trust building 
process is not necessary, because it should already be there along with the interest of the technology provider in the success of the joint initiative. Therefore, we can expect that if the technology provider is a parent organization of the project host organization, then the long-term interaction and monitoring is guaranteed, and commitment from technology supplier's side makes knowledge transfer more effective. Thus, we can hypothesis that:

H2: Existence of parent-subsidiary ties between technology provider and the CDM project host is positively associated with technological learning by the latter

\section{Familiarity of the technology provider with the host country context}

The profiles of technology providers in CDM projects is diverse, including both local and foreign affiliation, structure, and experience in the country. While it is the first experience in the host country for some, for others the country is a permanent field for their activities. Clearly that the performance of the foreign companies with larger experience in the country might be better due to familiarity with the local environment, understanding the local conditions, needs and culture (Child et al., 2005). This familiarity with local context is an attribute of local companies, joint ventures and foreign companies that have been present in the country before. In this respect, they have obvious advantage over companies that are new in the country. Familiarity with local setting, culture, market, regulations, as well as knowing the network of local organizations and institutions is the type of advantage that allows them to be more efficient, responsive and adaptive in new collaborations and projects.

This issue has been adequately addressed in the studies about influence of organizational and national cultures on performance of cooperative agreements, such as alliances, and joint ventures, between organizations from different countries (e.g. Harrington, 1988; Pothukuchi et al., 2002; Lu, 2006). Although the outcomes are not absolutely straightforward and point to a larger scope of factors and their interaction, there is generally a strong position about the significance of cultural background and the importance of the role of cultural and national differences in cooperative strategy and the success or failures in technological cooperation. Nevertheless, it is widely assumed that distance between the culture to which the firm is accustomed and that of the new geographical or organizational location where it is supposed to work defines the scale of barriers the organization has to overcome and efforts it has to invest in order to establish good collaboration.

However, local context concerns not only cultural and institutional factors. Knowledge about peculiarity of geophysical, climatic, as well as infrastructural conditions is also an important asset if one wants to build a plant in a foreign country. A lot has been discussed about technologies parachuted from other countries that never happen to be 
appropriate or compatible in the new location (Stewart, 1987). Appropriateness and compatibility of machines can be ensured if the technology provider is aware of the local circumstances of weather, infrastructure, and input of raw materials. They also may need to draw on the experience of other local firms (Kathuria, 2001).

Countries where CDM project are implemented vary a lot in terms of their social, political, cultural settings, market structure, ties among business actors and geophysical and climatic conditions. They may differ among each other as much as they differ from most developed economies. Therefore knowing the local context including culture, regulation, market, geophysical and climatic conditions of this country is important for the technology provider to be more efficient in delivering the technology and knowledge associated with it. This is especially important for foreign companies bringing their technology in the developing countries. Therefore, we expect knowledge transfer and technology absorption to be more effective in projects having a local technology provider, or foreign ones with prior experience in the country of the project implementation. Thus the hypothesis is that:

H3: Technology provider's familiarity with the context of the country where CDM project is implemented increases their efficiency in knowledge transfer and is in this way positively associated with higher technological learning

\section{Experience based learning}

Since the seminal studies by Wright (1936) and Arrow (1962) 'learning by doing' concept has drawn attention of technology management and innovation researchers. They have attempted to explain not just the relevance of the idea of building a knowledge base as experience with certain operation is gained, but also underpinnings of learning process and its influence on firms innovativeness (e.g. Hatch and Mowery, 1998; Tyre and von Hippel, 1997). The idea behind the concept is that knowledge is accumulated through day-to-day operation as employees face on-going changes that confront them with new problems, regardless of the extent to which the knowledge is ultimately codified. Finding solutions to problems enhances and extends the scope of employees' skills and know-how, which in turn add up to company's aggregate competence level. Some of the problems are specific, while others are generic, therefore learning may result in both specific and general competencies (Jensen et al., 2008). When the process is complex it will involve more interaction within the team of the company and this strengthens the internal information and knowledge exchange that may become regular practice. Thus, internal interaction contributes to the overall learning on the organization's level. As the organization gets more insight in the actual operating of technology it starts revealing more efficient ways to organize work and solve problems, as they appear (Dutton and Thomas, 1984). 
Dahlman and Westphal (1981:14) in their work on technology mastery emphasized that in the technology acquisition process "although knowledge (associated with the technology, disembodies) can be transferred, the ability to make effective use of it cannot be. This ability can only be acquired through indigenous technological effort, leading to technological mastery through human capital formation". They broke down the application of technological knowledge into four broadly defined categories of activities in the order in which technological mastery is typically achieved, such as: product engineering (relates to operation of existing facilities), project execution (pertains to the establishment new capacities), capital goods manufacture (embodies knowledge in facilities and equipment, and R\&D (as an activity to generate new knowledge). Dahlman and Westphal (1981) argue that in the process of undertaking the first three activities, those carrying them out often find themselves involved in the solution of technical products not previously encountered. Such problem solving represents an exercise of technological efforts which may lead to a higher level of technology mastery.

We apply the similar line of thought in the case of project implementation experience. A CDM project, being a heavily technical initiative, consists of a set of technical actions requiring extensive knowledge on planning, design, compilation, operation, adjustment, troubleshooting, repair, etc. It is known that a CDM project often is a new activity for either existing, or the newly established organization, implying the necessity of the acquisition of knowledge and skills in above-mentioned functions. While a large share of knowledge arrives in codified and explicit forms along with instructions, guidelines, training and coaching, one can expect that actual practice of dealing with technology is also full of learning merits. This learning might largely be associated with tacit and implicit knowledge, one that is particular to certain geographic and climatic conditions, or conditions of raw material input. Sometimes this knowledge might earlier not have been available to technology developers and providers, who also can benefit from the situation in terms of 'learning by using' ${ }^{18}$. However, the focus of our study being on learning by the technology recipient we concentrate on their involvement in 'doings' and 'usings' during the project implementation.

Based on the discussion above and our preliminary observations we can expect that the actual involvement in the project is important for knowledge acquired through learning by doing. Project operator companies that are more actively involved in project implementation achieve higher level of learning and technological capability building. Alternatively, the companies with minimum involvement in project related activities

\footnotetext{
${ }^{18}$ Rosenberg (1982) in discussion of 'learning by using' refers to this kind of knowledge accumulation. It is facilitated by feed-backing the information about behaving the technology in the actual long-term practice. This learning mode concerns to more extent the technology developers and providers who use can use this feed backed information for further improvement of the technology design. Thus while this is interesting phenomena, our focus in this study is learning by technology recipients or users.
} 
expected to benefit less in terms of knowledge accumulation. Stating this we hypothesize the direct relationship between learning outcomes and involvement in the project:

H4a: The amount of knowledge and skills acquired by the project host is positively associated with the degree of overall involvement in the CDM project activities

In most cases of CDM projects, companies purchase the technology elsewhere rather than develop it internally. In many cases, the technology is a standard unit designed to operate in certain physical and climatic condition. It is also often developed and manufactured abroad which implies differences in social dimension in addition to just environmental dissimilarities. Therefore once installed, it is often necessary to adapt acquired equipment or procedures to local conditions (Kathuria, 2002). The adaptation is required not only because of physical or climatic factors (e.g., in agriculture), it may also arise when plant and equipment are sensitive to local raw materials (e.g., biogas production in animal farms) or to inputs of local origin, or if the inputs are sourced from different suppliers than those who serve the manufacturers of the equipment. Adaptation and adjustment is also done to match to standards of local technical infrastructure in order to ensure input and output processes (e.g. electricity consumption or feed-in). Managerial procedures may also need to be adjusted because, for example, quality circles or quality assurance originated from developed countries, are very much different from that prevailing in many developing countries (Kathuria, 2002).

Adaptation proved to require rather sophisticated inputs of skills or information, drawing on the experience of other local firms. Various empirical studies in developing/newly industrializing countries demonstrate that the most important source of technological change within firms occurred not from formal R\&D activities but from these relatively trivial trouble-shooting efforts to adapt equipment and procedures to local conditions (Kathuria, 1999; Katz, 1987; Fransman, 1986).

In the words of Tyre and von Hippel (1997: 71) '... errors encountered in the process of trying new policies, technologies, or behaviour are a major source of learning and improvement in organizations'. In their study about adaptive learning, they explored the process of problem solving around new manufacturing equipment following the field test and early factory use. They argue that the adaptive learning in response to machine problems does not always involve collaborative interaction. Instead, they observed that routines, technical systems, events embedded in their physical settings determine what actors can do, what they know, and what they can learn. Although the organizational, technical as well as cultural contexts in which CDM projects are implemented might differ from case to case, adaptive learning (either independently or 
in collaboration) through solution of problems encountered in early stage of technology exploitation could be a significant source of knowledge accumulation. Thus we hypothesize that:

H4b. The CDM project host companies that encountered major challenges in the early stage of technology exploitation manage to build stronger technological capabilities

\subsection{Methods}

\subsubsection{Data}

As in previous chapters the analysis in this chapter is based on data collected though survey of $104 \mathrm{CDM}$ project host companies located in Brazil (40), China (13), India (35) and Mexico (16). The designs of the survey and the non-response analysis are presented in the Chapter 2 and description of the data is presented in Chapter 5.

\subsubsection{Definition of variables}

Similar to the analysis in Chapter 6 we define the technological learning or capability building level as a discrete outcome that is typical of the qualitative dependent variable model. The probability of an increase in the technological capability level was modelled as a function of a set of explanatory factors measured via independent and control variables described below.

\section{Dependent Variable: Technological Capability Building}

In present study we follow the logic set out in the previous chapter and study the determinant of technological learning or capability building by the CDP project host organization. The technological capability building level is the dependent variable in our regression model. In the survey we assessed the progress of project host companies' in a group of technological capabilities, four of which belong to the group of operational capabilities (also defined as basic capabilities), three to the process improvement capabilities (intermediary capabilities), and the other three to the innovation capabilities (advanced capabilities) ${ }^{19}$. Respondents were asked to assess this progress in each capability using a Likert-type scale ranging from 0 (zero impact) to 6 (very high impact). It was important for us to capture the technological capability building dynamics for each of the three groups, as we wanted to see how CDM related

${ }^{19}$ See chapter 5; sections 5.2 and 5.3 present details on taxonomy of technological capabilities and survey results. 
experience influences building of simpler and more sophisticated groups of capabilities. Therefore, the final dependent variables basicTC, intermediate $T C$ and advancedTC were constructed by taking the simple arithmetic mean for each of the three groups.

\section{Independent Variables}

\section{Interaction with technology provider}

Learning through interaction is among important modes of knowledge acquisition (Kline and Rosenberg, 1986; Lundvall, 1988; Vinding, 2002). In the context of technological learning in CDM projects a substantial knowledge is expected to be sourced from technology provider. Thus, more active interaction with technology provider might lead to better technological knowledge transfer. In the survey conducted within the framework of this research there was no direct question asking whether interaction with technology provider took place. Instead, we asked to indicate in which of the activities of the project implementation cycle the technology provider and the project host took part. These measures allow us to know the overall degree of involvement of each of the project participants in the project. Activities in the project were grouped into two phases: first, the project and facility design and preparation stage; and second, the project implementation stage involving activities on facility installation, adaptation, adjustment and operation. By matching involvement in each of the activities by project host and technology providers we judged the possible interaction. For example, in activities in which one of the participants took part but another did not, we can assume that interaction did not take place. Contrarily we assume interaction if both of the participants took part in a certain activity (see table 7.1 below). Mathematically it is possible to derive the interaction variables for each activity by multiplication of variables indicating involvement of project host and technology provider in this activity.

Table 7.1 Explanation on deriving Interaction variable for each activity

\begin{tabular}{|l|c|c|c|}
\hline & \multicolumn{2}{|c|}{ Involvement } & \multirow{2}{*}{ Interaction evidences } \\
\cline { 2 - 3 } & of project host & of technology provider & No \\
\hline Activity 1 & Yes & No & No \\
Activity 2 & No & Yes & Yes \\
Activity 3 & Yes & Yes & . \\
\hline
\end{tabular}

After deriving the interaction variable for each activity we grouped them according to project initiation and project implementation related activities. Further, by taking the simple arithmetic average of variables belonging to each group, we calculated two variables representing the degree of interaction during the project design phase (Interaction design) and the interaction during the project implementation phase (Interaction implementation). It is also necessary to mention that the activities related variables in each 
group had a high correlation to each other, which gives additional justification for grouping them and deriving a joint variable.

\section{Training}

This variable captures such activities as training, on-job coaching, and other types of capacity building activities provided by the technology providers during the CDM project implementation. This is basically another form of technology provider recipient interaction mode. Training activities, being interactive in their nature and having a deliberate purpose to transfer the knowledge, are expected to contribute to a large extent to the learning and technological capability building by the project host organization. Beside this, the interactive nature of training and on-job coaching allows to transfer some tacit knowledge too. In our survey the respondents were asked to indicate if their technology provider provided training, on-job coaching and/or other capacity building efforts. Having this data, we estimated the Training variable as an average of binary variables associated with these types of activities.

\section{Parent company}

In order to test hypothesis 2 proposing effect of parent-subsidiary link between technology provider and project host on learning by the latter, we introduced the variable Parent. It is a binary variable indicating whether there is an ownership link between the two or not. It is logical to expect much more efficient knowledge transfer between parent and subsidiary companies, due to the stronger link, motivation, and long-term perspectives.

\section{Experience in the host country}

Hypothesis 3 argues that knowing the context of developing countries and especially the country where the CDM project is implemented is important for the technology provider to be more efficient in delivering the technology and knowledge associated with it. In the survey we asked whether the technology provider has previously worked in the particular country which gave us the binary variable Experience.

\section{Degree of technology recipient's involvement in project cycle}

In our preliminary analysis we also suggest that knowledge can be sourced not only from the technology provider or other external sources, it can also be accumulated via one's own intensive experience and learning efforts. Notions of learning by doing and using reflect to a large extent this mode of learning. In the CDM project implementation context one's own learning efforts through a more active involvement in each stage of the project, expect to lead to better learning results. This is assumed because involvement of the project host organization in certain types of activities might be minimal due to outsourcing the activity either to technology provider or other agents. Intensity of project host company's involvement in the project cycle is captured 
by the variable Involvement which was estimated as a principle component of binary variables indicating project host's participation in such activities as project idea development and design, facility design, equipment design, installation of the equipment, testing, adjustment and preparation of project design document for CDM status acquisition.

\section{Efforts in technology adaptation}

While the variable above measures involvement of the project host companies in the overall project cycle, the variable presented here captures the effect of difficulties encountered by project hosts during technology acquisition and adjustment. Particular attention is paid to the project adjustment and adaptation stage as at this stage companies receiving new technologies encounter the highest absorption rate though intensive learning by using, as well as revealing important and large elements of tacit knowledge associated with technology application (Kathuria, 2002). In our survey we addressed this issue by asking whether project host overcame any problems and challenges related to technology acquisition, installation and adaptation. The variable Challenges, which is a binary variable, captures this effect. In our survey, 31.7\% of project hosts reported to have faced and overcome challenges associated with technology acquisition, installation and adaptation stages. 
Table 7.3 below summarises the references used in defining measurements for the independent variables used in the regression model.

Table 7.2: Measurements of independent variables and references

\begin{tabular}{|c|c|}
\hline Measurement & References \\
\hline $\begin{array}{l}\text { - Learning through interaction with technology } \\
\text { provider }\end{array}$ & $\begin{array}{l}\text { Levin (1993) } \\
\text { Kathuria (2002) } \\
\text { Hansen (2008) } \\
\text { Whangthomkum (2006) } \\
\text { Experts in-depth interviews }\end{array}$ \\
\hline $\begin{array}{l}\text { - Learning through training provide by technology } \\
\text { provider }\end{array}$ & $\begin{array}{l}\text { Kathuria (2002) } \\
\text { Whangthomkum (2006) } \\
\text { Experts in-depth interviews }\end{array}$ \\
\hline - $\quad$ Parent company (parent-subsidiary link) & $\begin{array}{l}\text { Levin (1993) } \\
\text { Inkpen (2000) } \\
\text { Hansen (2008) } \\
\text { Experts in-depth interviews }\end{array}$ \\
\hline $\begin{array}{l}\text { - Technology providers experience in and } \\
\text { knowledge of the host country }\end{array}$ & $\begin{array}{l}\text { Child et al. (2005) } \\
\text { Pothukuchi et al. (2002) } \\
\text { Lu (2006) } \\
\text { Kathuria (2002) } \\
\text { Experts in-depth interviews }\end{array}$ \\
\hline $\begin{array}{l}\text { - Degree of technology recipient's involvement in } \\
\text { project cycle }\end{array}$ & $\begin{array}{l}\text { Dutton and Thomas (1984) } \\
\text { Jensen } \text { et al. (2008) } \\
\text { Experts in-depth interviews }\end{array}$ \\
\hline - Efforts in technology adaptation & $\begin{array}{l}\text { Kathuria (2002) } \\
\text { Experts in-depth interviews }\end{array}$ \\
\hline
\end{tabular}

\section{Control variables}

The group of control variables used in the regression analysis in this chapter is the same as in Chapter 6, except for the variables capturing ownership and technology origin, due to their weak statistical relevance in explaining technological capabilities' building.

Size of company is defined by the number of employees. Other measurement options such as financial resources, and range of activities, used as a size indicator in many 
studies, have been considered to be less relevant especially in the context of diversified technology industries that $\mathrm{CDM}$ projects comprise. The size variable showed a very large variance across firms constituting our sample. For further analysis, the group was divided into two groups: a small-size group including companies with 10-50 employees and a larger-size group counting for more than 50 employees. The literature does not have conclusive observation on the effect of a company's size. Some authors suggest that larger companies have advantages in accessing and absorbing knowledge. In contradiction, there are arguments that sometimes the large size may contribute to company's inertia and inhibit learning.

Age of company was calculated as the number of years since the company was established. The Age variable ranges from 1 to 83, with the mean $=15.94 .50 \%$ of the companies are ten years old or less. In order to standardize the variable for further regression analysis we transformed it by taking its natural log. The impact of age on technological learning is difficult to predict. It may generate a positive effect for older companies who have more experience, hence better prior knowledge, but to the opposite, the company may not learn anything new from a project.

Country dummies The sample includes project host companies from Brazil, China, India and Mexico. In the regression analysis in order to capture country differences, we included a country related dummy variable for three out of four countries, namely India, China and Brazil.

Policy The importance of the national institutions in promotion of technological capability building and learning has been largely acknowledged in the literature. Respondents have been asked to evaluate the quality of the range of policies related to $\mathrm{CDM}$ and clean and renewable technologies in their country on the Likert-type scale from 0 (absence of policy) to 1 (poor) to 6 (very good). By taking the average score for all listed institutions, we calculated the unified variable Policy for measuring quality of the institutions as perceived by the respondents.

\subsubsection{Regression model}

Table 7.3 summarizes the information on all variables, their descriptive statistics and hypothesized effect on the outcome. For the econometric analysis, we applied the Ordinary Least Squares (OLS) regression technique. Being the simplest, OLS method is the most frequently used approach to regression analysis (Greene, 2003). As in the previous chapter, we opted to use this technique because the dependent variables BasicTC, IntermediateTC, and AdvancedTC consist of continuous data ranging between values of 0 and 6 . 
This classical multivariate linear regression model stipulates a linear relationship between dependent variables and a set of independent variables. Within the constraints of the OLS model, there are several assumptions. One of them is an independence of covariates which otherwise causes multicollinearity problem in the regression. Table 7.4 presents the results of correlation test for all independent and control variables included in the regression analysis. A high correlation index (0.71) between Training and Interaction implementation variable is a sing of a potential threat of multicollinearity. Further in the regression analysis we tried running regression by omitting Training variable. This did not cause much variation in regression outcomes, indicating that the results of the regression are robust. Other assumptions of OLS concern the hypothesis about normal distribution and homoskedasticity of the residuals. Examination of the Q-Q plot of Studentized residuals for dependent variables confirmed a normal distribution assumption $(\mathrm{p}<0.001)$ thus allowing us to avoid bias in parameters estimation in the regression. Therefore, we can assure that OLS technique proves to be appropriate for our analysis. 
Table 7.3: Definition of variables and summary statistics

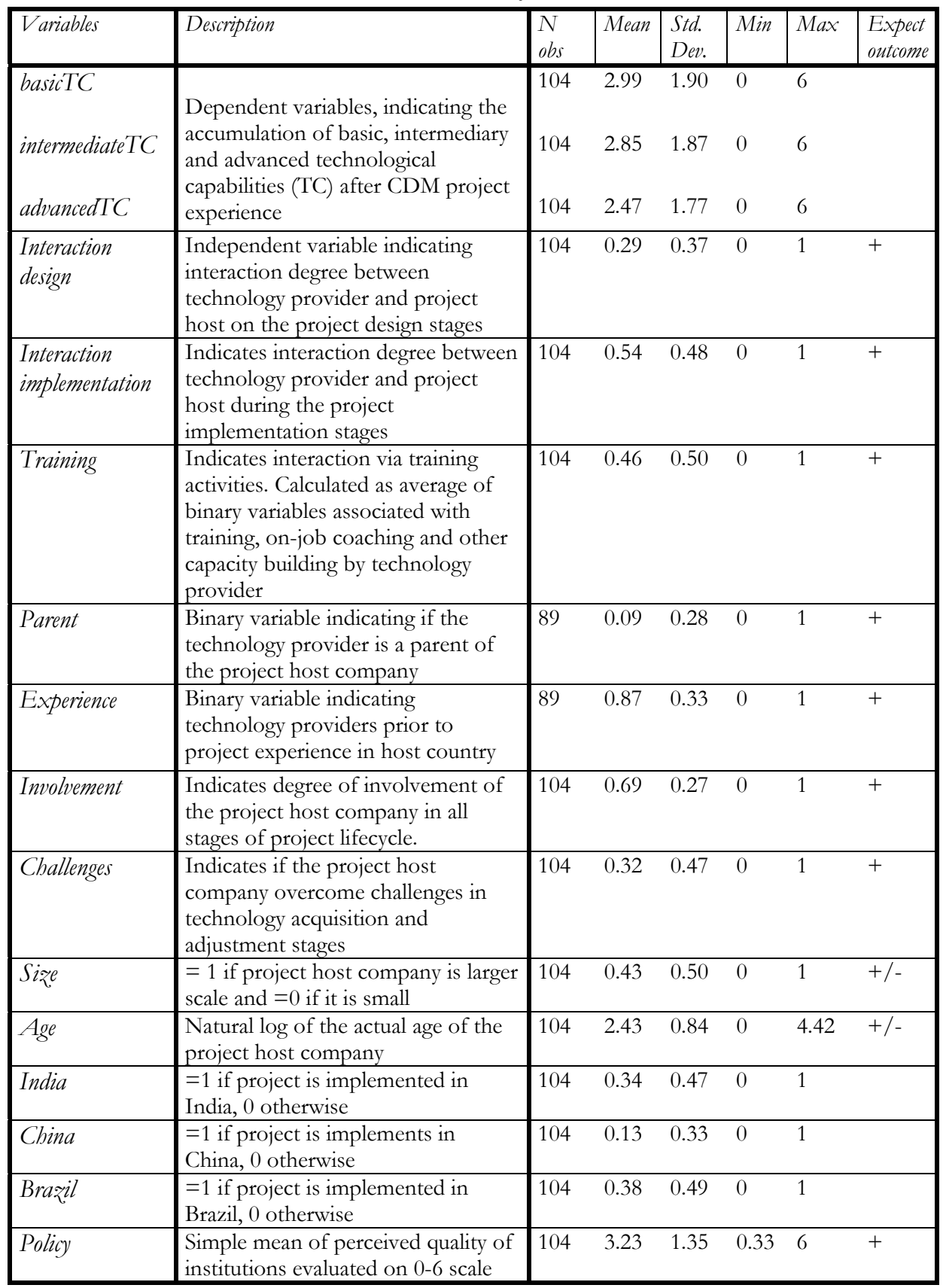




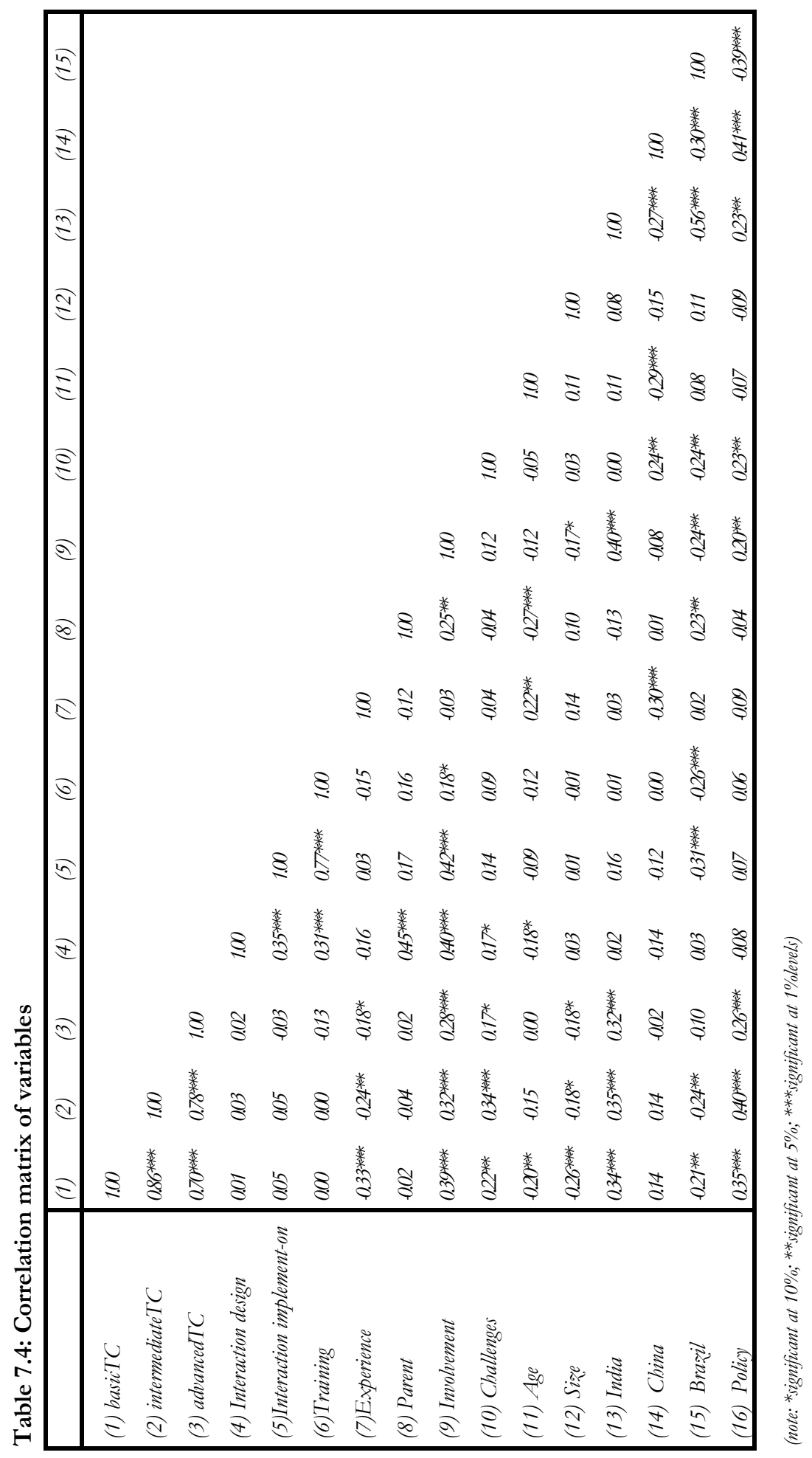




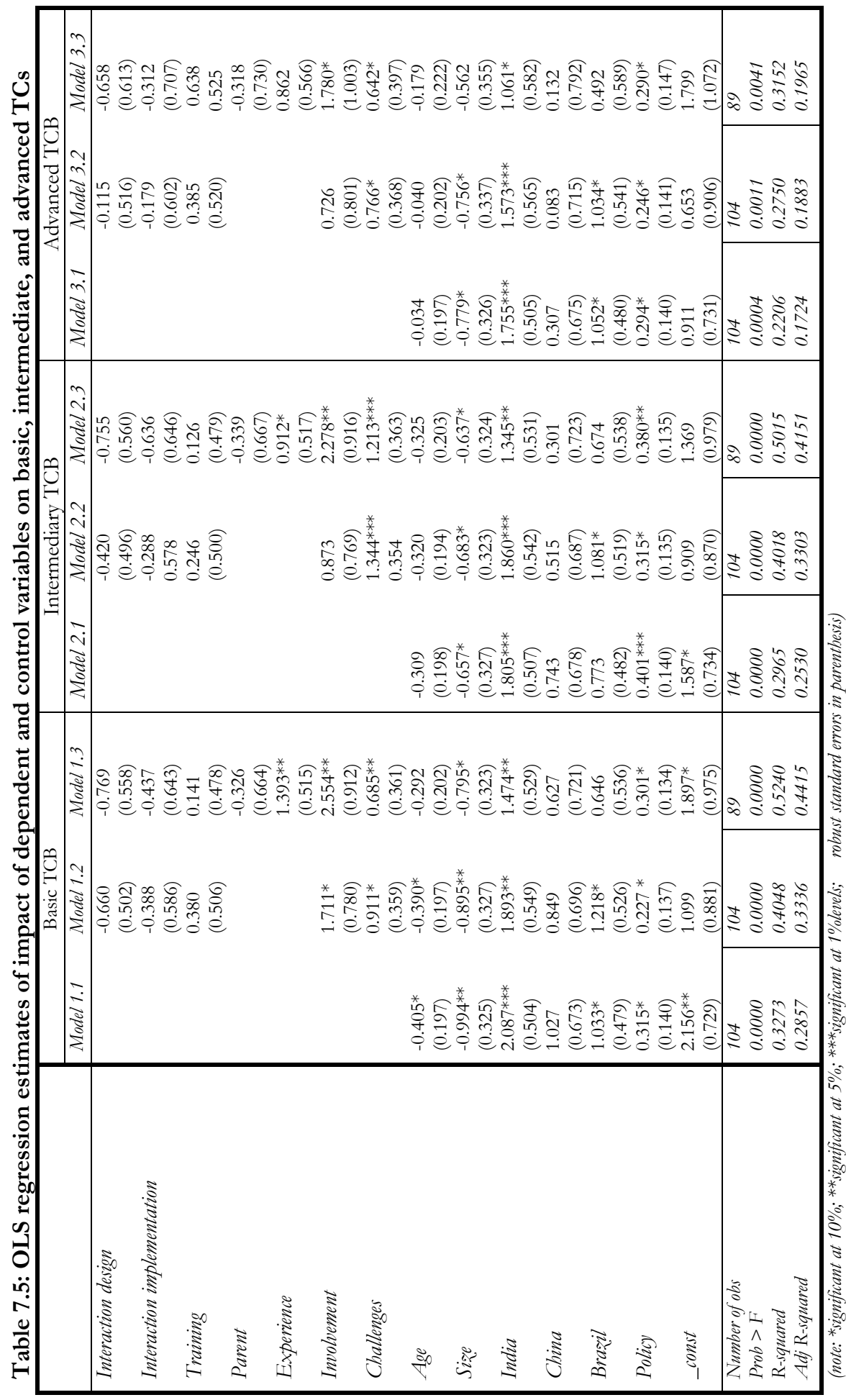




\subsection{Results}

Regression results presented in Table 7.5 indicate that in the models 1.3, 2.3, 3.3, when taken together, the variables explain 52, 50, and 31 per cent of the variation in the building of respectively basic, intermediate and advanced technological capability $\left(\mathrm{R}^{2}\right.$ statistics being $0.524,0.501$ and 0.351$)$. Models $1.1-2.3$ are statistically significant at 0.0000 level and models $3.1-3.3$, at $0.001-0.004$ level (F-test).

In the regression models the independent variables are entered sequentially. In table 7.5 models 1.1, 2.1, and 3.1 are the baseline models including only control variables. Models 1.2, 2.2, and 2.3 add independent variables capturing effects of 'learning by doing' and 'learning by interaction'. Models 1.3, 2.3, and 3.3 include the attributes of technology providers such as their ties with project host and their familiarity with the country context. It is necessary to point to the fact that the number of observation for these variables is 89 , while the full number of observations is 104 . Therefore these last three models are based on a smaller number of observations; however, closer observation in variations of other variables did not show big changes in their magnitude and signs. Overall, the coefficients and their significance are stable and robust across the models and the models are statistically significant. The improvement of the $\mathrm{R}$ squared and adjusted $\mathrm{R}$ squared statistics suggest better fitting models once independent variables are included. It is necessary though, to point out that the overall performance of the first two models, explaining the variations in building basic and intermediate technological capabilities, is comparatively better than the last model.

Hypotheses 1a, 1b, and 1c predict a positive effect of interaction on technological learning outcomes. Results on the variables Interaction design, Interaction implementation and Training, indicating joint work and interaction between technology recipient and provider in various stages of project implementation, did not show statistically significant results in either of the models. The small magnitude of the coefficients also points to the negligible role the variables might have in predicting learning outcomes. Therefore we can state that the regression results do not find support for the hypotheses 1a, 1b, and 1c.

Hypothesis 2 predicts that the existence of ties between technology provider and recipient positively influences the learning experience by the latter during CDM project experience. This is captured by the variable Parent indicating a parent-subsidiary relationship between technology provider and recipient. Regression results do not show any statistically significant results for this relationship. Closer examination of the data indicates that only 8 project host organizations are reported being daughter companies of the technology provider. This kind of small representation in the sample might be a cause for not obtaining strong results. 
Hypothesis 3 suggests a positive effect of technology provider's familiarity with country context with more effective learning outcomes in CDM projects. This hypothesis obtains support in the models 1.3 and 2.3 explaining variations in basic and intermediate technological capabilities building at respectively five and ten percent statistical significance levels. Results of Model 3.3 are not statistically strong, pointing to the possible irrelevant prior experience in the country concerning abilities of technology providers to deliver more advanced expertise and knowledge.

The last two hypotheses test the factors associated with technology recipient's experience in CDM projects and its effect on further learning outcomes. Hypothesis $4 \mathrm{a}$ predicts that project host companies that were more actively involved in every stage of the CDM project cycle are expected to achieve higher mastering in technological capability building. This hypothesis is supported in all three models with statistical significance at five (models 1.3 and 2.3) and ten percent (model 3.3.) levels. We also note that the comparatively larger magnitude of the coefficients suggest the big importance of a more intensive involvement in project in order to acquire stronger technological capabilities.

The effect of confronting difficulties associated with technology adaptation is tested by the hypothesis 4b. Regression analysis shows support for this hypothesis. Statistical significance of the results at five, one, and ten percent level in models 1.3, 2.3, and 3.3 respectively show that the results are robust. It is interesting to observe that the coefficient is higher in the model explaining intermediate technological capability building which is represented by shop-floor level process improvement and incremental innovativeness.

The control variables included in the model, capture the project host characteristics: Age and Size, country differences (country dummies) and the institutional factor (Policy). In general, results for control variables do not differ much in comparison with the results in Chapter 6. The size variable, being a dummy variable for larger firms, shows negative and statistically significant association with learning outcomes. This means that experience with CDM projects does not result in higher technological learning in larger companies. This supports the argument of Lane et. al (2001) saying that large companies tend to be more inert which inhibits their learning. Another explanation could be that larger companies are too large or too experienced to be influenced by the experience with CDM projects. From another point of view, it can also be interpreted that small sized companies implementing CDM projects tend to benefit more in terms of TC building, which might be due to either their flexibility and/or their lack of experience.

Our prediction for the Age related variable was either of opposite outcomes. The results showed a negative effect of age on technological learning outcomes of CDM 
projects. This suggests that older companies have more experience and knowledge and CDM does not add to their base of skills and knowledge.

Country dummies show a positive and a statistically significant effect (in most of the cases for India and in some of the cases for Brazil). This means that both Indian and Brazilian companies tend to achieve progress in technological learning as a result of CDM project implementation. Results for China are also positive, but statistically not significant. This might be because of the small sample (13) of Chinese project host organizations in the overall sample.

Results for the perception of quality of political institutions relevant to CDM and clean technologies promotion demonstrate a positive effect in all three models. Results are statistically significant, stating the importance of the institutional framework for technological capability building in the CDM projects.

\subsection{Discussion}

In this chapter we based our analysis on a sample of 104 companies in Brazil, China, India and Mexico, countries which are the most active in initiating these projects counting for about $75 \%$ of global CDM projects portfolio. We have tested the effect of various modes of learning taking place during implementation of CDM projects on the technological capabilities level of the project host companies. By introducing the technology provider in the general analytical framework of this chapter, we studied factors associated with these actors and their impact on technological learning on technology recipient party.

We built the discussion by confronting the first and the last hypothesis because our findings for either of them might be relevant for the other. The study allowed us to assess the effect of learning sourced from technology providers through interaction during project design (hypothesis 1a), implementation (hypothesis 1b), and training (hypothesis 1c) by setting it against the effect of learning accumulated through independent experience reflected through the overall degree of project host's involvement in the project (hypothesis $4 \mathrm{a}$ ) and ability to confront problems arisen during technology adaption (hypothesis 4b). The hypotheses predict a positive influence of both modes on the technological capabilities level of the project recipient. However, the study results established clearly the importance of "learning by doing", but found no relevance in "learning through interaction" in technological capabilities building in CDM projects. These results suggest that the more successful project hosts learn dominantly from their own experience in dealing with problems they faced during the early stages of technology exploitation. Whether a technology provider was involved throughout the project implementation or not, did not prove to be of 
significant matter. While the first finding about relevance of indigenous effort is supported by the literature (e.g. Dahlman and Westphal, 1981; Tyre and von Hippel, 1997), lack of results on interaction requires careful interpretation.

Learning is known to be a cumulative process, which is cumulative not only in the sense of building on existing knowledge, but also through experiences the company undergoes. Our results, showing the positive impact of more active involvement in project activities on learning outcomes are in line with the literature highlighting the significance of experience (Dutton and Thomas, 1984). Furthermore, our finding supports the idea of adaptive learning and errors being a major source of learning in new activities discussed by Tyre and von Hippel (1997). Yet we have to specify here that this adaptive learning through addressing challenges contributes more to development of intermediate technological capabilities, reflecting the abilities to introduce incremental innovations and improvement in the existing technology. This is a rather logical outcome proving that difficulties and errors during operation of the new machines require users first to understand the mechanics on which the machine is based, which defines how it works. Only after understanding this "black box" the user is able to fix problems, eliminate errors and make the machine or facility to function consistently. This comprehension of the machine is much more than knowing how to run it; it allows the user to be able to improve it by adjusting

On the other hand, the role of technology providers' involvement neither in design, nor in implementation of the project activities did not seem to generate knowledge spillovers. Here we also recall the results from Chapter 6 demonstrating the importance of prior knowledge on further technological learning in CDM projects. The implication is that the project host companies that already had some experience relied more on their own knowledge and expertise rather than working closely with technology provider in every activity. As Hansen (2008:108) suggests that CDM project companies '...seem do not engage in 'technology transfer' activities as such, but instead in technology procurement, contracts, license, royalty, and fee agreement....' which provide less possibilities for interaction with technology provider.

Our survey of project host companies demonstrated that not all of them equally participated in every stage of the project implementation (see Chapter 5). Our preliminary interviews with CDM project implementers also showed that in some cases like small hydro power production, wind energy, the company was in full control over all the project phases. However, in a number of cases of biogas projects implemented at animal farms, most of activities were outsourced to a company specializing in biogas digesters. This company then took full care of the installation, operation and maintenance of the biogas installation, while the project host companies were involved in a very limited scope of activities, the ones mostly related to monitoring of the digesters functions and management of input and output materials. While this 
arrangement showed efficiencies in terms of labour division, it prevented the project hosts from a deeper understanding of the technology ${ }^{20}$.

In addition, field visits and on-site interviews ${ }^{21}$ revealed that a large amount of understanding of technology and accumulation of knowledge about technology takes place during the stage of technology acquisition and adjustment when the technology users face the highest number of problems and challenges. It is interesting that the one Mexican animal farming company, chose to avoid the extensive services of intermediary agents on technology provision. It took up the burden of tackling with numerous technology adjustment challenges itself, rather then delegating it to the technology provider. In the end it developed very strong knowledge in biogas digestion technology and established its own unit consisting of several engineers dealing only with biogas production processes. These kind of efforts on overcoming various problems in the technology adjustment stage led to intensive learning and understanding of the technology, and the processes on which it is based, as well as the conditions under which the technology performs better and why.

These two cases, showing lack of interaction between technology provider and active efforts in adaptive learning, provide case evidence to confirm our regression results and support our hypotheses.

The training, another way of interaction, also did not prove to be helpful in building technological capabilities. This might be because it is not the fact of having training that is important, but the quality and intensity training and coaching activities, purpose and scope of issues covered, degree of interactive exchange channelling not only explicit, but also tacit knowledge (Jensen et al., 2007; Tsang, 1995). It is therefore advisable to further investigate and capture various qualitative aspects of training activities that technology recipients acquire.

In the discussion leading up to hypothesis 2, we argued that there is a positive relationship in ties between technology recipient and provider and technological capability building as a result of CDM project implementation. We captured these ties by a dummy variable indicating whether the technology provider is a parent company or not. Regression analysis did not prove the hypothesized relationship. This finding is largely in conflict with the known literature (Hansen, 2008; Doranova et al, 2009; Levin, 1993; Inkpen, 2000; Coughlin, 1983), as well as with the information received from interviews on the few projects in which technology provider and recipient maintain a formal parent-subsidiary relationship. As we mentioned earlier this lack of statistical support was perhaps due to a very low number of cases reporting a parent-subsidiary relationship. Another explanation could be that the parent company took care of most

\footnotetext{
20 interview with Charles Brasor, Climate Options Group, former experts of AgCert,

21 interviews with experts operating CDM projects in Bangladesh, Brazil, Argentina, Armenia and Mexico
} 
of the stages, which prevented its subsidiary company from learning from the CDM experience. However, we tend to consider this result as rather inconclusive, therefore we urge for further investigation, either via case studies or by applying larger samples in the statistical analysis.

Hypothesis 3 predicts a positive effect of technology provider's familiarity with the country context on the technological learning by the recipient. Arguments to support this were that companies that have larger experience in developing countries, especially in the one in which they are implementing new activities, increases chances of success of their activity. Underlying this success is a composite of factors such as familiarity with local culture and national specificities (Child et al, 2005) and consideration of geophysical, climatic and infrastructural conditions (Kathuria, 2001). While the first factors can helps technology providers to be more flexible in the socio-cultural environment, the second set helps them to design technology more appropriate to the local natural and infrastructural environment.

We obtained support for hypothesis 3 for the cases of basic and intermediary levels learning, stating that technology providers' familiarity with the country positively associated with building basic and intermediary technological capability. In general, it is in agreement with the existing literature (e.g. Lu, 2006; Harrington, 1988, Kathuria, 2001) featuring the importance of familiarity with cultural and national specificities, as well as with physical and climatic conditions. But, if we consider the results (or lack of them) for other hypotheses related to technology providers, we have to be careful in interpretation of this result. We cannot say that technology providers' familiarity allowed them to be efficient in knowledge delivery and cooperation with a project host company because we did not obtain results pointing to the importance of interaction. What we can speculate is that technology providers, knowing the local conditions and settings, delivered the technology in such a package that made it easier to assimilate, even without intensive interaction. Such locally oriented technologies might be more clear and accessible for project host companies, which make them easier to master and apply (Kathuria, 2001).

\subsection{Conclusions and implications}

In our framework examining the determinant of technological learning in CDM projects along with the technology recipient perspective we included factors associated with technology providers and the interaction with them. Dynamism of learning was captured by viewing this process as a complex of modes such as learning by doing, and learning by interaction with technology provider. The research questions urged to define which of these two modes of learning prevail in building technological capabilities of CDM project host organizations and how the technology provider's 
familiarity with the country context and ownership ties in with recipient's influence on the learning outcomes.

Our results did not show a big role for the technology provider in the technological capability building process in CDM projects. It proved that neither formal ties, nor interaction between technology provider and recipients during the project implementation boost learning by the latter. It did show though, the relevance of technology provider's familiarity with the country where project is implemented.

We established that learning outcomes instead, mostly depend on factors associated with the technology recipient. The important conclusion is that in general learning and technological capability building is an outcome of project implementing company's active position in the project implementation. Learning is once more proved to be an indigenous proactive process (von Hippel and Tyre, 1995; Tyre and von Hippel 1997). This brings up the following implication within the climate change mitigation and technology transfer agenda: in the facilitation of technological learning, technology acquisition, and transfer in CDM projects as well as in any other activities on adoption and promotion of environmental technologies, serious attention has to be paid to the involvement and active position of local organizations implementing this project and adopting the technology. Their individual learning by doing and adapting makes them stronger in further sustaining the project, as well as their organization.

This study makes theoretical contributions in several ways. First, it expands the pool of CDM based technology transfer literature, which otherwise lacks empirical evidence on the technological impact of CDM projects in developing countries; the application of indigenous survey data makes it unique in the CDM studies family. Second, by introducing organizational learning concepts to study the technology acquisition process in CDM projects it diversifies the theoretical approaches in studying CDM projects. Third, being a pioneer in the study on technology providers' role in CDM related technological learning it opens up new path for further investigation of this issue.

Along with the positive highlights mentioned above, the study has several limitations. As was demonstrated earlier, the results on interaction did not show statistically significant results. One of the reasons could be the not appropriate measurement of interaction, especially of its qualitative dimensions. One can imagine that interaction and cooperation in project activities can be less active or more active, which defines the information exchange between technology recipient and provider. This variable was obtained by matching interaction variables for each activity by multiplication of variables indicating the involvement of project host and technology provider in this activity. The initial involvement variable was of a binary nature, which does not allow to judge on the qualitative side on how intensive the involvement was. Therefore, 
future research has to consider the qualitative aspect in the measurement of interaction, possible through introduction of a scaled evaluation of interaction intensity. This chapter shares the limitations related to our sample mentioned in Chapter 6, where we mentioned that only four countries, Brazil, China, India and Mexico where covered. In spite of that fact they host around three quarter of all CDM projects; our findings might be only relevant to these four countries, and not to the rest group of countries also hosting a smaller number of projects. Thus results we acquired in our study even though being insightful, might have little relevance to these countries. Moreover, the statistics on these four leading countries also have changed since 2007 and show the growing leadership of China. Re-sampling and a new similar research may have different observations for this country. Another important limitation, which we discussed earlier, is related with a small size of our sample. Although the sample correctly represent the population we targeted in the survey (discussed in chapter 2, section 2.3.4), its small size may not reflect the developments in CDM related capability building. Larger scale surveys with insurance of sufficient resources and incentive schemes would be needed if similar studies are initiated in future.

These above stated limitations, however, present possibilities for further research in the study of learning under CDM projects. Studying a larger sample of countries and projects would be an interesting and useful step further in understanding the technological impact of CDM projects in different contexts. In this regard, deeper investigation of each country's policies and government institutions, and their role in promoting knowledge accumulation and collaboration in CDM projects would be one of the recommended areas for further research. Overall, this study provided very interesting perspectives on dynamics of technological learning under CDM projects which are insightful for technology transfer topics acquiring popularity under the current Kyoto regime. This topic has largely been under-investigated, thus our study not only contributed to filling the gap by using organizational learning concepts, but also showed the road for further research. 


\section{CHAPTER 8. CONCLUSIONS AND IMPLICATIONS}

\subsection{Introduction}

This final chapter provides an overview of the most important conclusions of this dissertation. We will seek to answer our general research question and to reflect on the findings of our analyses. Furthermore, we will elaborate on the theoretical, methodological, empirical, and policy implications of our study. Finally, we will discuss the limitations of this thesis and provide suggestions for future research.

The main purpose of this thesis was to gain a better insight into the technology transfer and learning processes under CDM projects of the Kyoto Protocol. The CDM framework, designed to implement carbon emission cutting projects in developing countries, has been widely associated with sustainable development benefits, one of the dimensions being the transfer of new climate friendly technologies. CDM is commonly seen as a promising channel for sourcing and diffusion of modern clean technologies in developing countries and in this way putting them in a carbon friendly growth trajectory (Grubb et al., 1999; Jepma and Van der Gaast, 1999; Aslam, 2001). The main argument put forward in the present research is that international technology transfer is not straightforward and costless, but requires recipients to have a scope of capabilities enabling them to assess their needs, and to select, import, assimilate, adapt, and develop the appropriate technologies. Technology being a complex construct, includes not only machinery or hardware, but even more important, knowledge, expertise, competence, skills, know-how, procedures, services, organizational and operational measures, and other tacit and codified elements (Rosenberg, 1982; Ernst et al., 1998; Kranzberg, 1986). Therefore transfer of technology requires transfer of all these intangible but important elements, which can take place only through an extensive learning process.

Despite wide recognition of the importance of technology and knowledge transfer in the climate change mitigation policy agenda, as well as in academic discourse, this issue has not received adequate attention in academic research. In this regard, especially the technological learning and capability building related aspects have been hardly investigated. Therefore this thesis had an aim to contribute in bridging the gap and in enriching the CDM and technology transfer related literature with unique empirical case. The main question guiding the research in this dissertation was "How do technology transfer and learning take place in CDM projects and what are the causes and outcomes of these processes?”

In studying technology transfer and learning under CDM projects, we approached it from macro and micro level perspectives. Macro perspective allowed us to assess the knowledge base in climate change mitigation technologies available in the CDM project 
recipient countries. This assessment was important to understand the local technological conditions in which CDM initiatives emerge and the role of technological knowledge in the CDM framework. Research sub-questions, addressing this perspective, were posed to investigate whether local technological knowledge existing in CDM recipient country can explain technology sourcing in CDM projects. A micro level perspective was applied to study the localized impact of CDM projects and to understand how and under what conditions technological learning takes place in companies implementing CDM projects. Research sub-questions addressed a range of micro level factors, including internal knowledge resources, the role of technology providers, and the actual CDM experience, which can influence technological learning outcomes.

The dissertation was written in eight chapters segregated into three complementary parts, the first having an introductory purpose and the second and third containing empirical chapters containing macro and micro level analyses respectively. Each chapter had specific objectives but, by addressing the main research question, they altogether contribute in the understanding of technology transfer and learning under CDM projects, and the causes and outcomes of these processes. Although the results have been discussed in each empirical chapter, in the sections below we present the broader overview of the research findings and their implications for academic research and policy making.

\subsection{Major findings}

In studying technology transfer and technological learning under CDM projects we based ourselves on several settings. First, we proposed that the current technology transfer trends in CDM projects might be explained by the availability or lack of a relevant technological knowledge base in the recipient country. Second, we resided on the argument that technology transfer is largely a learning process, in which acquiring expertise, knowledge, and technological capabilities is far more important that just the simple purchasing of hardware. We assumed that successful learning depends on a number of internal and external factors associated with characteristics and internal resources of project host companies, their behaviour and their interaction with partners, and tried to investigate the actual role of these factors. Following this logical sequence the main findings and conclusions are summarised under the following headings.

- $\quad C D M$ projects host countries largely rely on local technology rather than foreign ones 
The research began with the investigation of technology transfer related information available from project description documents. CDM project based technology sourcing statistics showed that over half of the projects use local technology. Incidents using combined technology are far less, but are still slightly more than the number of cases in which purely foreign technology was applied. Further examination showed that in a number of cases technology was imported from other developing countries. This finding is not completely new; some other studies using different samples of CDM projects also obtained similar results. However, these observations have not yet been sufficiently highlighted and analysed in respect to challenging the idea and expectations of North-South technology transfer promoted under the CDM framework. This challenge became an important provision in directing our further analysis of CDM related technology transfer. It made us draw our attention to studying the role of developing countries not only as project recipients but also as technology suppliers. Thus in Chapter 4 we investigated the availability of local knowledge and expertise in developing countries and its implication in technology sourcing under CDM projects.

\section{- $\quad$ The local knowledge base is an important factor in technology sourcing in CDM projects}

Following the analysis of technology sourcing in CDM projects we examined whether the technological knowledge base of a host country determines these sourcing patterns in the CDM projects. The line of logic that was followed in this study, suggested that developing countries already have climate friendly technologies locally available, and CDM became another enabler for their commercialization. We investigated macro level data indicating locally available expertise and knowledge in these technologies and used these data in the explanation of technology sourcing trends in CDM project. A distinction was made between applied (or practical) and scientific knowledge. The first comprised the knowledge associated with technology application, which was measured through renewable energy generation capacities and exports volumes in technologies relevant to CDM. The second, was measured traditionally by the number of patented inventions and scientific publication in climate friendly technologies. Results of the study showed strong association of richer practical knowledge with a higher preference for local technology. Availability of scientific knowledge also showed a similar pattern, though in case of patent data local technology was the second preference after the combined one. In other words, countries that have their own technologies do not rely on imported technology in CDM project implementation. Therefore, an important finding of this study was, that local knowledge availability does determine the decision of CDM project implementers in choosing their technology sourcing..

- $\quad C D M$ project experience creates diverse learning impact across different projects and countries 
This finding was one of the important results of survey conducted among CDM project host companies in Brazil, China, India, and Mexico. The companies were asked to indicate how much they had learned from the CDM project related experience. Using a Likert type scale they assessed their progress in a range of technological capabilities, such as basic (operational), intermediary (process improvement) and advanced (design and development) capabilities. Aggregated results showed that the average progress in basic capabilities was higher than in intermediary capabilities, and the smallest progress was achieved in more sophisticated (advanced) capabilities. Besides, learning outcomes differ across countries with the Indian project hosts having reported the highest progress, followed by the Chinese, Brazilian, and finally Mexican companies. In technology group comparison the largest improvements were observed in projects on energy efficiency improvement, landfill methane utilization and converting biomass into energy. The lowest progress was reported for fuel switch and biogas production projects.

Overall the important finding was that CDM projects induced learning in the majority of CDM project host companies; however, the magnitude of the learning progress varied significantly. In explaining learning differences, we referred to the theories in organizational learning and technology transfer and achieved support for some of the hypotheses.

- Prior knowledge and experience are important in appropriation of incoming new knowledge; but, too much of prior knowledge diminishes the learning impact.

These results were established in our analysis of the role of absorptive capacity, in other words, internal knowledge resources of the organization in the further efficient appropriation of external knowledge and understanding of new technologies. In the analysis we defined several indicators which represent various dimensions of a company's absorptive capacity. Among them, prior knowledge proved to have the strongest, statistically confirmed, effect on learning outcomes. However the results also showed that this effect diminished with an increase in the level of prior knowledge, proving the inverted U-shaped curve of the learning function.

Therefore, the important finding of the analysis is, is that availability of prior knowledge about the technology used in CDM project allows companies to learn even more through CDM project experience; however, at the same time this effect declines if the level of prior knowledge is very high and companies will not benefit much from the project in term of learning as the knowledge would not be new for them. 
- More active involvement in all stages of CDM project and overcoming challenges in technology adaptation secure higher learning outcomes

The finding regarding more active involvement by project hosts has fairly straightforward logic, which supports the importance of learning by doing and using. In the analysis it was held in comparison with learning by interaction, which basically represented interaction or cooperation with technology providers in various stages of the project. Econometric analysis results proved the strong effect of the learning by doing mode in CDM project based knowledge acquisition, and did not find evidences supporting the learning by interaction mode; hence declining the importance of technology providers' role. It was also proven that a larger component of learning and technology mastering, is facilitated through finding solutions to challenges arising during the technology adaptation and adjustment stages. Thus the finding suggests that the more successful project operators learn predominantly through their own experience, acquired in their dealing with problems faced during the early stages of technology exploitation.

- Increasing role of policies in promotion of technology transfer and learning for climate change mitigation

Though the role of policies in technology and knowledge transfer was not the core issue investigated in our study, a possible importance of this aspect was counted in the analysis. Assessing the quality of national CDM, renewable energy and environmental policies were suggested in the survey. The judgment was mainly left to the survey respondents, yet the outcome of their responses integrated in the econometric models showed a strong association between policy provisions in technological learning. This result found a positive reflection in the interviews and informal discussions with experts that we had during the different stages of the research. This has invisible, nevertheless important implications for the national knowledge base, which is to a large extent a product of national policies.

To summarize the general research outcomes, we discovered the important contributory role of scientific and practical knowledge in CDM related development, and restated the confidence that developing countries are able to play a more active role as knowledge and technology experts in global climate change reduction, rather than being just passive receivers of technology. These findings were echoed by micro level results, which similarly established importance of company level knowledge and internal efforts in gaining better technological learning in CDM project. Overall, we think that our research finding provided deep insight in the technological learning and technology sourcing processes taking place on micro and macro levels. 


\subsection{Contributions and Implications}

Detailed discussion of contributions and implications of the research has been presented in each empirical chapter. Here we provide a more generalized overview of theoretical, empirical, methodological and policy implications of the research finding of the dissertation.

\section{Theoretical and empirical}

As we discussed in earlier chapters the group of the literature covering issues of technology transfer in CDM is still immature, lacks theoretical grounding and rigorous empirical evidences. This dissertation intended to contribute in filling this gap by undertaking in-depth study and applying concepts of learning and technological capability building in a new context.

Considering the vast under-investigated background of the issue of technological development under CDM regime, our research turned out to be pioneering in many aspects and can be considered to be of explorative mission. In the literature strand addressing technology and knowledge transfer in CDM projects, this study is believed to be novel in terms of applying the organizational learning approach. One of the important implications that evolved from our work is that well-established and conceptually and methodologically rich organizational learning literature can provide a solid ground for studying technology transfer and learning issues in CDM projects and suggest promising prospects for further application in this area.

Our study is also unique in terms of obtaining and using empirical data from the survey of CDM projects operator companies. Thus far, to our knowledge, it is the only survey of this scale and rigor, implemented in studying aspects of CDM projects host companies. It is also distinctive in its objective to assess the impact of CDM projects in terms of technological development on a local level. The survey allowed us to collect data that were not otherwise available in the CDM project documents and reports, which proved to be of assistance in studying factors barely addressed in CDM literature previously such as company level characteristics and their interaction with technology providers (Chapters 6 and 7). On other hand, by bringing the example of $\mathrm{CDM}$ projects, it contributed to the empirical literature on organizational learning, technology transfer and knowledge base.

Our study also introduced a new set of factors that can explain why CDM project recipient countries rely on local or imported technologies in implementing projects (Chapter 4). While knowledge base related determinants proved to be appropriate in explaining technology sourcing statistics in CDM project, the overall implication of the study is in highlighting and reassuring the academic discourse on the importance of 
knowledge and the fostering of national technological capabilities in achieving sustainable and environmentally sound economic progress in the developing world.

\section{Methodological}

Possibilities and methodologies of measuring the sustainable development impact of CDM have been receiving larger recognition both in the CDM literature as well as in the policy agenda under the Kyoto Protocol. In this respect, our study is believed to be important input. In studying technological learning we used an approach based on the technological capability taxonomy widely acknowledged in technical change and innovation studies (Lall, 1992; Bell, 2007; Figueiredo, 2003). Assessing the range of technological capabilities allowed us to measure the technological learning impact of CDM projects. This framework showed its viability and reliability and can potentially be used in studying the technological development aspects of CDM, it is, however, necessary to note that it is a time-consuming and effort-intensive survey exercise.

Within the discourse of relevant studies investigating patterns of technology transfer and determinants of it, our study stands out by presenting new group of factors explaining technology sourcing in CDM projects (Chapter 4). This study proved to have a clear methodological contribution in measuring the scientific and practical knowledge in the specific niche of climate friendly technologies for each CDM host country. Results of the study demonstrated that the knowledge base indicators that we proposed, could be a good instrument in analysis of the technology transfer patterns in CDM projects.

\section{Policy}

The findings of the study have a number of implications for policies on the promotion of technological solution of climate change problems and the involvement of developing countries in the international effort on climate change mitigation

There are implications both for developing countries whose current priorities are more on economic development, rather than on addressing environmental problems, as well as for developed countries who are currently urged to reduce their carbon emissions. There is a clear need for changing the paradigm of technology transfer in the climate change mitigation agenda and to consider developing countries not as passive receivers of technology, but also to promote their potential as producers and innovators. Under the sustainable development agenda of the Kyoto Protocol, the importance of building effective national knowledge and innovation systems in clean technologies need to be highlighted, rather than just the narrow technology transfer activities. CDM cases are already proving market and economic efficiencies in using local technologies. 
Therefore, developing local capacities in clean technologies in developing countries has a big potential in reducing the cost of global climate change mitigation under the international emission trading regime. Developing countries with better technical and scientific expertise would not need to depend on foreign technology to initiate CDM projects, which allows avoiding transaction costs associated with importing technology from abroad, and decreases the overall investment cost of clean projects. Additionally, local production of the technology is allied with other socio-economic benefits such as employment of local people in manufacturing and other stages of the technological process, and involvement of other supplier companies in the productions chain, which can spur development of local industries and enhance the economic base of the country in general.

The climate change problem is becoming more and more alarming and its importance in the political agenda is constantly growing. The international community is advocating for a more active position of developing countries in solving this problem. Therefore building the technological capacities of developing countries should become a priority issue for national and international development programmes. The findings of our research propose governments and company leaders to steer and invest in building local absorptive capacity which would further ensure better appropriation of new knowledge and technologies. This is particularly becoming important for the clean technologies niche as the trend in demand for these technologies is lately increasing along with globalization of environmental governance and strengthening of environmental standards.

In line with this, our research outcomes on the importance of policies promoting CDM and renewable energy expertise and technologies proved to be very relevant. By showing the strong positive association with technological learning and capability building, they call attention to the fact that the institutional environment matters not only for macro level technological growth, but also for micro level technological learning.

\subsection{Limitations and future research}

Along with contributions and interesting findings, the study covered in this dissertation has a number of limitations. In each empirical chapter, the limitation concerning the object of analysis, were presented. Here we would like to briefly summarise the most substantial ones, in our view, and supplement them with a discussion on how to address them in future research.

One of the noticeable limitations (which is relevant to both macro and micro-level studies) is associated with the limited coverage of the countries and possibly the time span. While the macro study had a relatively good country coverage for the targeted 
time span up to 2007, it possibly missed out further developments in CDM projects that took place after the indicated year. Recent statistics showed rapid growth in the CDM projects pool and a change of leadership in CDM attractiveness among the largest hosts. China that earlier had a comparatively modest performance in terms of initiating CDM projects (which is why its share in our sample was not very big) has later become a global leader in the number of CDM projects it runs. In addition, the number of countries that host CDM projects also increased. Therefore results obtained in our study might be less representative for the current status of CDM development. In this regards we see a necessity to expand the research by including a larger sample of countries and projects which, consequently, also means a wider time coverage.

Similarly, in the micro level study, we covered only four countries Brazil, China, India, and Mexico, which were the largest recipients of CDM projects hosting about $75 \%$ of the global CDM projects portfolio in 2007. As we discussed in the chapters 6 and 7 the study results might be biased towards the selected four countries. Business models selected in different countries for CDM projects might be dictated by the conditions of investment environment established in the country, by the knowledge base (e.g. availability of technology and expertise which we discussed in chapter 4), by the national policy regulations working either pro or against CDM promotion and by other circumstances. Furthermore a large number of countries that were not covered by our survey are smaller and economically less advanced. Therefore the results obtained in our study, despite being insightful, might have partial relevance to these countries.

Another considerable weakness of the study, which has al been mentioned in the chapter 6 and 7, is the limited number of observations in the survey based analysis. Despite showing sufficient statistical representativeness of our sample, its small size may have caused less strong results in our regression. Yet this sample related limitation may translate into opportunities for new research with a survey population including larger range of countries and larger coverage of CDM host companies. However, one needs to bear in mind that conducting larger surveys and ensuring higher response rate requires large resources and bigger and possibly international teams of researchers.

It is also necessary to point out the methodological limitation which was encountered in our research. While appropriating the knowledge base concept and the building indicators were applied in our macro level study, we missed the indicator capturing human capital. This indicator can be represented by the number or share of scientists, engineers, graduates of technical schools and universities and it is an important component of the national level technological capabilities. In our study we had a need for country-level data on engineers, graduates, and scientist in energy and environmental technologies, which were not possible to obtain because these data are very specific and many developing countries have a very poor data provision. This restrained us from using human capital related factors in our study on the relevance of 
local knowledge in technology sourcing in CDM. Although using these data would be very much useful for the new extended research, we, however, still have our doubts about the availability of such data.

Finally, while working with data from the survey, although they were very comprehensive and useful, we felt that future surveys should have better specifications of the data, measuring not only quantitative elements but also qualitative aspects, e.g. quality and extent of training, degree of interaction with technology providers.

For further research we see an appealing opportunity in investigation of policies' impact on technological learning in clean technologies niches. Although it was not the core focus of our study we obtained interesting and promising results suggesting an important role of policy provisions in technological learning in CDM projects. This finding gives a motivating ground for future research with deeper investigation of the intertwined effect of national energy, environmental, technology and CDM policies in technology, and knowledge transfer under the Kyoto Protocol.

We end this dissertation by concluding that despite the limitations, as well as in line with addressing them, the study opens new avenues for further research which may also allow us to understand and explain the trends in CDM based technology transfer and learning in a more comprehensive way. The importance of the study is that it builds a stepping stone for further research and discussion of the role of developing countries in global climate change mitigation. 


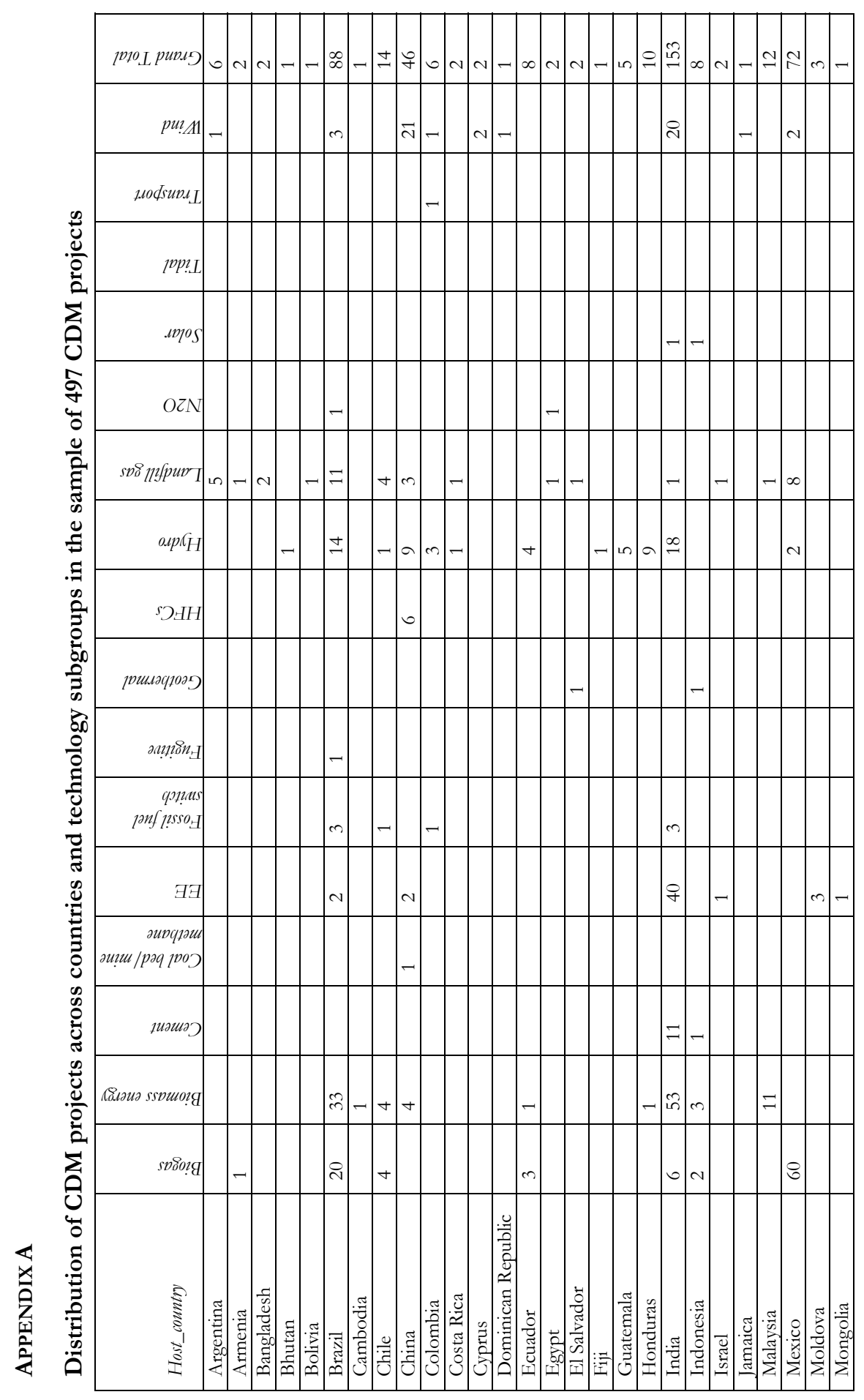




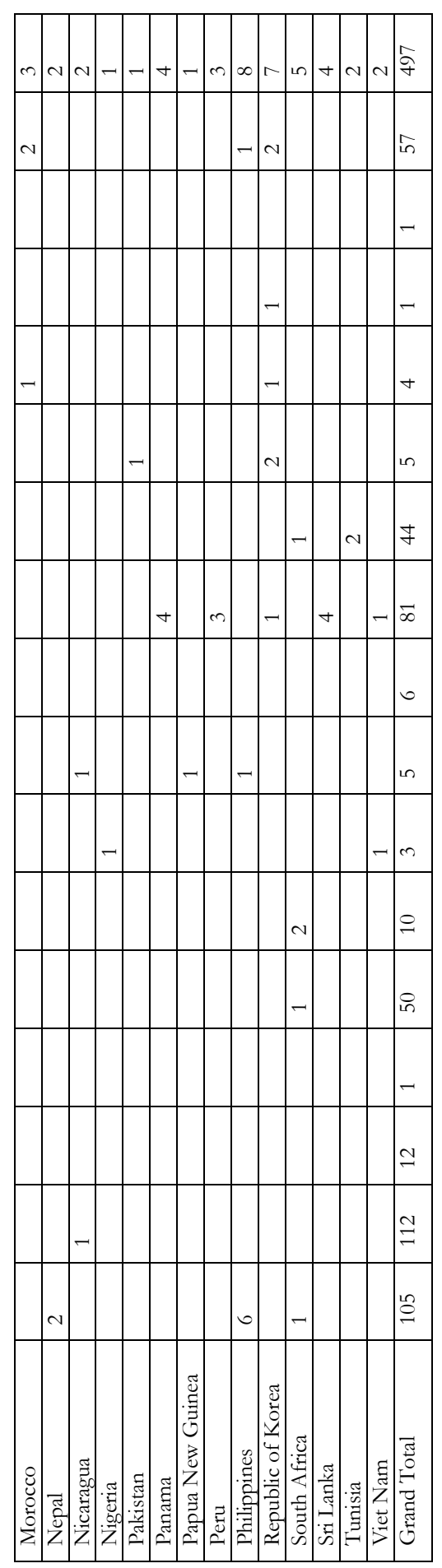




\section{APPENDIX B}

\section{Statistics of technology origin in CDM projects (sample of 460 projects)}

\begin{tabular}{|c|c|c|c|c|}
\hline host country name & local & imported & combined & Total \\
\hline India & 141 & 3 & 9 & 153 \\
\hline Brazil & 43 & 7 & 30 & 80 \\
\hline Mexico & 27 & 3 & 42 & 72 \\
\hline China & 18 & 26 & 2 & 46 \\
\hline Chile & 11 & 3 & 0 & 14 \\
\hline Malaysia & 1 & 3 & 7 & 11 \\
\hline Ecuador & 2 & 6 & 0 & 8 \\
\hline Philippines & 1 & 1 & 6 & 8 \\
\hline Republic of Korea & 1 & 5 & 1 & 7 \\
\hline Colombia & 2 & 4 & 0 & 6 \\
\hline Indonesia & 2 & 4 & 0 & 6 \\
\hline Argentina & 0 & 5 & 0 & 5 \\
\hline South Africa & 1 & 0 & 3 & 4 \\
\hline Honduras & 1 & 2 & 0 & 3 \\
\hline Moldova & 0 & 0 & 3 & 3 \\
\hline Armenia & 0 & 2 & 0 & 2 \\
\hline Bangladesh & 0 & 2 & 0 & 2 \\
\hline Costa Rica & 1 & 1 & 0 & 2 \\
\hline Cyprus & 0 & 2 & 0 & 2 \\
\hline Egypt & 0 & 2 & 0 & 2 \\
\hline El Salvador & 2 & 0 & 0 & 2 \\
\hline Guatemala & 1 & 1 & 0 & 2 \\
\hline Israel & 1 & 1 & 0 & 2 \\
\hline Morocco & 0 & 1 & 1 & 2 \\
\hline Nepal & 0 & 0 & 2 & 2 \\
\hline Nicaragua & 1 & 1 & 0 & 2 \\
\hline Peru & 0 & 2 & 0 & 2 \\
\hline Viet Nam & 0 & 2 & 0 & 2 \\
\hline Bolivia & 0 & 0 & 1 & 1 \\
\hline Cambodia & 0 & 1 & 0 & 1 \\
\hline Dominican Republic & 0 & 1 & 0 & 1 \\
\hline Jamaica & 0 & 1 & 0 & 1 \\
\hline Mongolia & 0 & 0 & 1 & 1 \\
\hline Nigeria & 0 & 1 & 0 & 1 \\
\hline Pakistan & 0 & 0 & 1 & 1 \\
\hline Sri Lanka & 0 & 1 & 0 & 1 \\
\hline Total & 257 & 94 & 109 & 460 \\
\hline
\end{tabular}

Notes: initial sample was 497 projects. Due to the missing data 37 observations had to be dropped out of the analysis. 


\section{APPENDIX C}

\section{Survey Questionnaire}

\section{Questionnaire for company operating CDM project \# XXX}

This survey is part of a scientific research project undertaken by UNU-MERIT in collaboration with UNFCCC. The purpose of this survey is to investigate the learning impact of CDM projects in terms of technological expertise, skills, knowledge transfer as well as supporting factors and conditions for successful capability building by the CDM project operator. This questionnaire aims to gather information related to the CDM project \# XXX

Your answers are completely confidential and will be released only as summaries in which no individual's answers can be identified. This survey is voluntary. However, you can help us very much by taking a few minutes to share your experiences and opinions about CDM projects. If for some reason you prefer not to respond, please let us know by ...

If you would like to receive a copy of the final survey analysis report please contact Asel Doranova at doranova@merit.unu.edu.

\section{Definitions used in this survey:}

CDM project operator is the company operating the project facility, for example operating a renewable energy power plant built under CDM project.

Technology provider is the company that developed and/ or supplied with the technology/ equipment for the CDM project facility.

\section{Information about the progress of the project \# XXX}

1. What is the status of the technical implementation of the project?

() day-to-day exploitation of the facility is ongoing

() the facility has not started operating yet

\section{Who was the initiator of the project idea?}

(If it was a joint effort of two or more partners, please indicate all these partners)

[] project operator company

[] technology provider

[] PDD (project design document) consultant company

[] credit buyer

[] local NGO

[] public/state agency

[] other please specify ........... 


\section{Information about the $\mathrm{CDM}$ project operator ${ }^{22}$}

This section aims to gather information about the CDM project operator, its background and experience

3. Please provide the name of the CDM project operator company:

4. Is the company operating and managing other CDM projects registered before January 2007?

() No, this is the only project

() Yes please specify the registration number of these projects: ...........

5. The Year of establishment of the CDM project operator company:

6. Please specify the total number of employees:

(if you don't have exact numbers, you can provide approximate numbers)

Please specify the number of employees with the following qualification

With university degree:

Technical school degree/diploma:

No special degree: ............

7. Which one of the following ownership statuses applies to the CDM project operator?

() State owned company/ state organization

() Domestic privately owned company

() Foreign privately owned company country:

() Joint venture please specify the name and the country of the companies that are part of this

Joint venture:

\begin{tabular}{|ll|}
\hline Country (required) & Company name (optional) \\
\hline $1 . \ldots \ldots \ldots \ldots$ & $\ldots \ldots \ldots \ldots$ \\
\hline $2 . \ldots \ldots \ldots \ldots$ & $\ldots \ldots \ldots \ldots$ \\
\hline $3 . \ldots \ldots \ldots \ldots$ & $\ldots \ldots \ldots \ldots$ \\
\hline
\end{tabular}

\footnotetext{
${ }^{22}$ CDM project operator is the company operating the project facility, for example operating a renewable energy power plant built under CDM project.
} 
8. Please specify which one of the following applies to the CDM project operator company:

() the company was established only with the purpose to operate one specific $\boldsymbol{C D M}$ project

() the company was established with the purpose to do CDM business (e.g. develop CDM projects, CER generation, CDM and emission trading related consultancy, etc)

() CDM is not its core business; rather the company implemented CDM project to improve environmental performance of its main industrial process

() other, namely:

III. Information about knowledge transfer, skills and capability building related to $\mathrm{CDM}$ project activities

9. Please indicate if the project operator company was involved in the...

(Multiple answers are possible)

[] Development of the project idea

[] Basic and/or detailed design of the facility

[] Basic and/or detailed design of the equipment/machine

[] Installation of the equipment

[] Testing and Adjustment of the installed equipment

[] Development of the methodology

[] Development of PDD (project design document) 
10. Did the CDM project operator company have competence in the following functions before starting the CDM project?

\begin{tabular}{|c|c|c|c|}
\hline Functions & Explanation & Yes & $\begin{array}{l}\text { No or not } \\
\text { applicable }\end{array}$ \\
\hline $\begin{array}{r}\text { Preventive } \\
\text { maintenance }\end{array}$ & $\begin{array}{l}\text { Revealing possible defects/Maintenance of } \\
\text { machines/equipment on a regular basis }\end{array}$ & () & () \\
\hline Process quality control & $\begin{array}{l}\text { Systematic independent control of the quality of the } \\
\text { technological process }\end{array}$ & $($ ) & $($ ) \\
\hline Debugging & Removing defects, mistakes, breakages in the equipment & () & () \\
\hline Equipment adjustment & $\begin{array}{l}\text { Adjustment of the equipment(s) to the local conditions, } \\
\text { or to the particular technological lines/system }\end{array}$ & $($ ) & () \\
\hline Equipment stretching & $\begin{array}{l}\text { Increase the scope of functions or productivity of the } \\
\text { equipment. }\end{array}$ & () & () \\
\hline $\begin{array}{r}\text { Efficiency } \\
\text { improvement and } \\
\text { cost saving }\end{array}$ & $\begin{array}{l}\text { Reducing cost, energy consumption of the equipment by } \\
\text { keeping bigh production level }\end{array}$ & () & $($ ) \\
\hline Process adaptation & $\begin{array}{l}\text { Adaptation of the technological process to local } \\
\text { circumstances/ conditions/ changes }\end{array}$ & $($ ) & () \\
\hline Basic process design & $\begin{array}{l}\text { Engineering design of the technological process } \\
\text { / technological line, inventions, with possible patenting }\end{array}$ & $($ ) & () \\
\hline Equipment design & $\begin{array}{l}\text { Detailed design of the single equipment/ machine, } \\
\text { inventions, with possible patenting }\end{array}$ & $($ ) & () \\
\hline $\begin{array}{l}\text { Development of } \\
\text { turnkey project/facility }\end{array}$ & $\begin{array}{l}\text { Detailed design of a complete technological facility/ } \\
\text { unit/ plant }\end{array}$ & $($ ) & () \\
\hline
\end{tabular}

11. To what extent the experience with this CDM project contributed to improving and/or building competence of the CDM project operator company in the following functions

\begin{tabular}{|c|c|c|c|c|c|c|c|}
\hline & \multicolumn{7}{|c|}{$\begin{array}{c}\text { Please rank contribution } \\
\text { from } 0 \text { (NO or Not applicable) to } 6 \text { (Very } \\
\text { STRONG) }\end{array}$} \\
\hline & 0 & 1 & 2 & 3 & 4 & 5 & 6 \\
\hline Preventive maintenance & () & () & () & () & () & () & () \\
\hline Process quality control & () & () & () & () & () & () & () \\
\hline Debugging & () & () & () & () & () & () & () \\
\hline Equipment adjustment & () & () & () & () & () & () & () \\
\hline Equipment stretching & () & () & () & () & () & () & () \\
\hline $\begin{array}{r}\text { Efficiency improvement and cost } \\
\text { saving }\end{array}$ & () & () & () & () & () & () & () \\
\hline Process adaptation & () & () & () & () & () & () & () \\
\hline Basic process design & () & () & () & () & () & () & () \\
\hline Equipment design & () & () & () & () & () & () & () \\
\hline $\begin{array}{r}\text { Development of turnkey } \\
\text { project/facility }\end{array}$ & () & () & () & () & () & () & () \\
\hline
\end{tabular}


12. To what extent has the experience with this CDM project contributed to improving competence of the project operator company in the following areas?

\begin{tabular}{|c|c|c|c|c|c|c|c|}
\hline & \multicolumn{7}{|c|}{$\begin{array}{c}\text { Please rank contribution } \\
\text { from } 0 \text { (NO or Not applicable) to } 6 \text { (Very } \\
\text { STRONG) }\end{array}$} \\
\hline & $\mathbf{0}$ & 1 & 2 & 3 & 4 & 5 & 6 \\
\hline $\begin{array}{r}\text { Acquisition of better managerial } \\
\text { practices }\end{array}$ & () & () & () & () & () & () & () \\
\hline Introduction of organizational change & () & () & () & () & () & () & () \\
\hline $\begin{array}{r}\text { Cooperation and interaction } \\
\text { with } \underline{\text { domestic partner-companies }}\end{array}$ & () & $($ ) & $($ ) & () & $($ ) & $($ ) & $($ ) \\
\hline $\begin{array}{r}\text { Cooperation and interaction } \\
\text { with international partner-companies }\end{array}$ & () & () & () & $($ ) & () & $($ ) & () \\
\hline $\begin{array}{r}\text { Cooperation with governmental } \\
\text { agencies } \\
\end{array}$ & () & () & () & $($ ) & $($ ) & () & $($ ) \\
\hline $\begin{array}{r}\text { Cooperation with international } \\
\text { organizations and donors }\end{array}$ & () & () & $($ ) & () & () & $($ ) & $($ ) \\
\hline $\mathrm{CDM} /$ emission trading business & () & () & () & () & () & () & () \\
\hline $\begin{array}{r}\text { PDD development } \\
\text { (project design documentation) }\end{array}$ & () & $($ ) & $($ ) & $($ ) & $($ ) & $($ ) & $($ ) \\
\hline Development of the methodologies & () & () & () & () & () & () & () \\
\hline
\end{tabular}

\section{Technology supply side in CDM projects}

This section aims to gather information about the technology used in this project, technology providers and their role

$$
\text { in the project }
$$

\section{IV. (A) Technology}

13. Please specify the origin of the technology involved in the project:

() Domestically assembled

() Assembled by the foreign firm(s)

Please specify the country/countries:

( ) Mixed: Some parts are from local suppliers, some part from foreign suppliers

Please specify the country/countries:

14. Has this technology existed/been used in your country before the project?

()Yes ()No

If yes, please specify where it was applied:

(Multiple answers are possible)

[] in other CDM projects

[] in non-CDM projects 
15. Does the technology/equipment applied in the project include high-tech elements? ()Yes ()No

16. Is the technology applied in this project the most sophisticated in its group? ()Yes ()No

17. Did the company face any difficulties in technology adjustment and application? ()Yes ()No

If yes, please provide more information (optional)

IV. (B) Technology provider(s) ${ }^{23}$

18. Please provide the name of the company (ies) that was technology provider for this project:

19. Please indicate if any of the following statuses apply to technology provider(s):

() Multinational company with presence in your country

() Large domestic company

() Large foreign company (not multinational)

() Domestic small or medium scale company

() Foreign small or medium scale company

If foreign company please provide country name......

20. If the technology provider is a foreign company or MNC, does it have earlier experience of working in your country?

()Yes ()No

\footnotetext{
${ }^{23}$ Technology provider is the company that developed and/or supplied with the technology/equipment for the CDM project facility.
} 
21. Does the technology provider(s) have experience of working with other CDM projects?

$$
\text { ()Yes ()No }
$$

22. Please indicate if the technology provider(s) is a parent company of the project operator:

$$
\text { ( ) Yes ( ) No }
$$

23 Approximately how many years has the technology provider been in this technology area:

$$
\text { (number of years) }
$$

24. Please indicate if any of the technology providers is a holder of the licence/patent for the technology implemented in this project

$$
\text { ( ) Yes ( ) No }
$$

\begin{tabular}{|c|c|}
\hline Development of the project idea & [] \\
\hline $\begin{array}{r}\text { Basic and/or detailed design of the project } \\
\text { facility }\end{array}$ & \\
\hline Installation of the equipment & \\
\hline Testing of the installed equipment & \\
\hline Adjustment of the installed equipment & [] \\
\hline Formal training/course & \\
\hline $\begin{array}{r}\text { On-job coaching (informal sharing of } \\
\text { expertise) }\end{array}$ & [] \\
\hline $\begin{array}{r}\text { Any other transfer of expertise related } \\
\text { activities }\end{array}$ & [] \\
\hline Development of the methodology & [] \\
\hline $\begin{array}{r}\text { Development of PDD (project design } \\
\text { document })\end{array}$ & [] \\
\hline
\end{tabular}

25. Please indicate in which of the following activities each of the technology providers has been involved:

(Multiple answers are possible)

\section{Local environment and interaction with other partners}


26. Please indicate if any of the mentioned below types of partner were involved in various stages of the CDM project related activities:

(Multiple answers are possible)

\begin{tabular}{|c|c|c|c|c|c|c|c|}
\hline & $\begin{array}{c}\text { Researc } \\
b \\
\text { organiza } \\
\text { tions }\end{array}$ & $\begin{array}{l}\text { Local } \\
\text { NGOs }\end{array}$ & $\begin{array}{c}\text { Internat } \\
\text { ional } \\
\text { develop } \\
\text { ment } \\
\text { agency }\end{array}$ & $\begin{array}{l}\text { CER } \\
\text { buyer }\end{array}$ & $\begin{array}{l}\text { Local } \\
\text { investor }\end{array}$ & $\begin{array}{l}\text { Foreign } \\
\text { investor }\end{array}$ & $\begin{array}{c}P D D \\
\text { consulta } \\
n t s\end{array}$ \\
\hline $\begin{array}{r}\text { Development of the project } \\
\text { idea }\end{array}$ & [] & [] & [] & [] & [] & [] & [] \\
\hline $\begin{array}{l}\text { Basic design of the } \\
\text { facility/technology }\end{array}$ & [] & [] & [] & [] & [] & [] & [] \\
\hline $\begin{array}{r}\text { Initial stages of the equipment } \\
\text { exploitation and adjustment }\end{array}$ & [] & [] & [] & [] & [] & [] & [] \\
\hline $\begin{array}{r}\begin{array}{r}\text { Development of the } \\
\text { methodology }\end{array} \\
\end{array}$ & [] & [] & [] & [] & [] & [] & [] \\
\hline $\begin{array}{r}\text { development of the PDD } \\
\text { (project design document) }\end{array}$ & [] & [] & [] & [] & [] & [] & [] \\
\hline $\begin{array}{r}\text { Monitoring of the CDM } \\
\text { project }\end{array}$ & [] & [] & [] & [] & [] & [] & [] \\
\hline
\end{tabular}

27. How do you rate your country policies and support in the following fields?

\begin{tabular}{|c|c|c|c|c|c|c|c|}
\hline & \multicolumn{7}{|c|}{ Please rank contribution } \\
\hline & \multicolumn{7}{|c|}{ from 0 (NO or Not applicable) to 6 (Very effective) } \\
\hline Fields & 0 & 1 & 2 & 3 & 4 & 5 & 6 \\
\hline $\begin{array}{r}\text { CDM promotion (e.g. capacity } \\
\text { building activities, special } \\
\text { financing schemes, etc) }\end{array}$ & () & ( ) & $($ ) & () & $($ ) & () & () \\
\hline $\begin{array}{r}\text { Renewable energy } \\
\text { technologies promotion }\end{array}$ & () & () & $($ ) & $($ ) & $($ ) & $($ ) & () \\
\hline Environmental policies & () & () & () & () & () & () & () \\
\hline $\begin{array}{l}\text { Education related to clean } \\
\text { and renewable technologies }\end{array}$ & () & $($ ) & $($ ) & () & () & () & () \\
\hline $\begin{array}{l}\text { Increasing awareness of } \\
\text { companies about CDM }\end{array}$ & () & $($ ) & $($ ) & () & $($ ) & $($ ) & () \\
\hline $\begin{array}{r}\text { Increasing awareness of local } \\
\text { municipal authorities about } \\
\text { CDM }\end{array}$ & () & () & $($ ) & () & () & () & () \\
\hline $\begin{array}{r}\text { Incentives for foreign } \\
\text { companies to be involved in } \\
\text { CDM projects }\end{array}$ & () & () & () & () & () & () & () \\
\hline $\begin{array}{r}\text { Active cooperation with civil } \\
\text { society organizations }\end{array}$ & () & () & () & () & () & () & () \\
\hline
\end{tabular}


APPENDIX D

COMTRADE Export data: Code Description

\begin{tabular}{|c|c|}
\hline \multicolumn{2}{|c|}{ Renewable energies } \\
\hline 2207.10 & Ethanol \\
\hline 2905.11 & Methanol \\
\hline 4401.10 & Fuel wood, in logs, in billets, twigs, faggots or similar forms \\
\hline 4401.30 & $\begin{array}{l}\text { Sawdust and wood waste and scrap, whether or not agglomerated } \\
\text { in logs, riquettes, pellets or similar forms }\end{array}$ \\
\hline 7321.13 & Cooking appliances and plate warmers for solid fuel, iron or steel \\
\hline 7321.83 & Non electrical domestic appliances for liquid fuel \\
\hline 8410.11 & Of a power not exceeding $1,000 \mathrm{~kW}$ \\
\hline 8410.12 & Of a power exceeding $1,000 \mathrm{~kW}$ but not exceeding $10,000 \mathrm{~kW}$ \\
\hline 8410.13 & $\begin{array}{l}\text { Of a power exceeding } 10,000 \mathrm{~kW} .8410 .90 \text { — Parts including } \\
\text { regulators }\end{array}$ \\
\hline 8410.90 & Hydraulic turbines and water wheels; parts including regulators \\
\hline 8413.81 & $\begin{array}{l}\text { Pumps for liquids, whether fitted with a measuring device or not; } \\
\text { [Wind turbine pump] }\end{array}$ \\
\hline 8419.11 & Instantaneous gas water heaters \\
\hline 8419.19 & $\begin{array}{l}\text { Instantaneous or storage water heaters, non-electric - other [solar } \\
\text { water heaters] }\end{array}$ \\
\hline 8502.31 & Electric generating sets and rotary converters - Wind powered \\
\hline 8502.40 & $\begin{array}{l}\text { Electric generating sets and rotary converters [a generating set } \\
\text { combining an electric generator and either a hydraulic turbine or a } \\
\text { Sterling engine] }\end{array}$ \\
\hline 8541.40 & $\begin{array}{l}\text { Photosensitive semiconductor devices, including photovoltaic } \\
\text { cells whether sssembled in modules or made up into panels; } \\
\text { lightemitting diodes }\end{array}$ \\
\hline \multicolumn{2}{|c|}{ Energy savings and management } \\
\hline 3815.00 & Catalysts \\
\hline 7008.00 & Multiple-walled insulating units of glass \\
\hline 7019.90 & Other glass fibre products \\
\hline 8404.20 & Condensers for steam or other vapour power units \\
\hline 8409.99 & $\begin{array}{l}\text { Parts suitable for use solely or principally with the engines of HS } \\
8407 \text { or } 8408 \text {; other }\end{array}$ \\
\hline 8418.69 & Heat pumps \\
\hline 8419.50 & Heat exchange units \\
\hline 8419.90 & Parts for heat exchange equipment \\
\hline 8539.31 & Fluorescent lamps, hot cathode \\
\hline 8543.19 & Fuel cells \\
\hline 9028.10 & Gas supply, production and calibrating metres \\
\hline 9028.20 & Liquid supply, production and calibrating metres \\
\hline 9032.10 & Thermostats \\
\hline
\end{tabular}

Source: Steenblik (2005a, b) 


\section{APpendix E}

\section{Patent data: USPTO}

Date of extraction: July 15, 2008

Source: http://patft1.uspto.gov/netahtml/PTO/search-adv.htm

US Patent \& Trademark Office, Patent Full Text and Image Database

Searching 1976 to present

\begin{tabular}{|c|c|}
\hline BIOGAS & $\begin{array}{l}\mathrm{icl} / \mathrm{A} 01 \mathrm{C} 3 / 02 \mathrm{OR} \mathrm{icl} / \mathrm{A} 01 \mathrm{C} 3 / 04 \mathrm{OR} \mathrm{icl} / \mathrm{A} 01 \mathrm{C} 3 / 06 \mathrm{OR} \\
\mathrm{icl} / \mathrm{A} 01 \mathrm{C} 3 / 08\end{array}$ \\
\hline BIOMASS & $\begin{array}{l}\mathrm{icl} / \mathrm{B} 01 \mathrm{~J} 41 / 16 \text { OR } \mathrm{icl} / \mathrm{C} 10 \mathrm{~L} 5 / 42 \mathrm{OR} \mathrm{icl} / \mathrm{C} 10 \mathrm{~L} 5 / 44 \mathrm{OR} \\
\mathrm{icl} / \mathrm{C} 10 \mathrm{~L} 1 / 14 \mathrm{OR} \mathrm{icl} / \mathrm{F} 02 \mathrm{~B} 43 / 08\end{array}$ \\
\hline GEOTHERMAL & icl/F24J3\$ OR icl/F03G4\$ OR icl/H02N10/00 \\
\hline HYDROPOWER & $\mathrm{icl} / \mathrm{F} 03 \mathrm{~B} 13 / 06 \mathrm{OR}$ icl/F03B13/08 OR icl/F03B13/10' \\
\hline LANDFILL & $\mathrm{icl} / \mathrm{B} 09 \mathrm{~B} 1 / 00 \mathrm{OR}$ icl/B09C1/00 \\
\hline OCEAN & $\begin{array}{l}\mathrm{icl} / \mathrm{F} 03 \mathrm{~B} 13 / 12 \mathrm{OR} \mathrm{icl/F03B13/14} \mathrm{OR} \mathrm{icl/F03B13/16} \mathrm{OR} \\
\mathrm{icl} / \mathrm{F} 03 \mathrm{~B} 13 / 18 \mathrm{OR} \mathrm{icl/F03B13/20} \mathrm{OR} \mathrm{icl/F03B13/22} \mathrm{OR} \\
\mathrm{icl} / \mathrm{F} 03 \mathrm{~B} 13 / 24 \mathrm{OR} \mathrm{icl/F03G7/04} \mathrm{OR} \mathrm{icl/F03G7/05} \mathrm{OR} \\
\mathrm{icl} / \mathrm{F} 03 \mathrm{~B} 7 / 00\end{array}$ \\
\hline SOLAR & $\begin{array}{l}\mathrm{icl} / \mathrm{F} 03 \mathrm{G} 6 \$ \text { OR } \mathrm{icl} / \mathrm{F} 24 J 2 \$ \text { OR } \mathrm{icl} / \mathrm{F} 25 \mathrm{~B} 27 / 00 \mathrm{OR} \\
\mathrm{icl} / \mathrm{F} 26 \mathrm{~B} 3 / 28 \mathrm{OR} \mathrm{icl} / \mathrm{H} 01 \mathrm{~L} 31 / 042 \mathrm{OR} \mathrm{icl} / \mathrm{H} 02 \mathrm{~N} 6 / 00 \mathrm{OR} \\
\mathrm{icl} / \mathrm{E} 04 \mathrm{D} 13 / 18 \mathrm{OR} \mathrm{icl} / \mathrm{B} 60 \mathrm{~L} 8 / 00\end{array}$ \\
\hline WIND & $\begin{array}{lccccc}\mathrm{icl} / \mathrm{F} 03 \mathrm{D} 1 \$ & \text { OR } & \mathrm{icl} / \mathrm{F} 03 \mathrm{D} 3 \$ & \text { OR } & \mathrm{icl} / \mathrm{F} 03 \mathrm{D} 5 \$ & \text { OR } \\
\mathrm{icl} / \mathrm{F} 03 \mathrm{D} 7 \$ & \text { OR } & \mathrm{icl} / \mathrm{F} 03 \mathrm{D} 9 \$ & \text { OR } & \mathrm{icl} / \mathrm{F} 03 \mathrm{D} 11 \$ & \text { OR } \\
\mathrm{icl} / \mathrm{B} 60 \mathrm{~L} 8 / 00 & \mathrm{OR} \mathrm{icl} / \mathrm{B} 63 \mathrm{H} 13 / 00 & & & \\
\end{array}$ \\
\hline
\end{tabular}

Example 1: "Query all wind patents, German inventor":

$\mathrm{icn} / \mathrm{DE}$ AND (icl/F03D1\$ OR icl/F03D3\$ OR icl/F03D5\$ OR icl/F03D7\$ OR $\mathrm{icl} / \mathrm{F} 03 \mathrm{D} 9$ \$ OR icl/F03D11\$ OR icl/B60L8/00 OR icl/B63H13/00)

Example 2: "Query all landfill patent, Indian assignee":

acn/IN AND (icl/B09B1/00 OR icl/B09C1/00)

Note: As we did not have full access to a (current) offline version of the USPTO patent database, we used a php/cURL script to automatically extract the numbers from the USPTO website. This method is not recommended for bulk downloads, as you "may be denied access to the server without notice".

Note: We are well aware of the fact that IPC codes in the USPTO database have not been cleaned. E.g., A01C3/02 also appears as A01C003/02. However, due to restrictions placed on the search interface, we could not use both variants in one query. Taking the union of the two might result in double counts. 


\section{REFERENCES}

\section{A}

Abramowitz, M., 1989. Thinking about Growth, Cambridge University Press, Cambridge.

Acharya, R., 1999. Bio-Pharmaceuticals in Chinese Taipei and India, in: Mytelka, L.K (Ed.), Competition, Innovation and Competitiveness in Developing Countries. OECD Development Centre, Paris.

Ahuja, G., Katila, R., 2001. Technological acquisitions and the innovation performance of acquiring firms: A longitudinal study. Strategic Management Journal, 22, 197-220.

Aitiken, B.J., Harrison, A. E., 1999. Do domestic firms benefit from direct foreign investment? Evidence from Venezuela. The American Economic Review, 89(3), 605-618.

Amsden, A. H., 2001. The rise of 'the rest': Challenges to the West from late-industrializing economies. Oxford University Press, Oxford

Archibugi, D., Coco, A., 2004. A new indicator of technological capabilities for developed and developing countries (ArCo). World Development 32 (4), 629-654.

Ariffin, N., 2000. The internationalisation of innovative activities: The Malaysian electronics industry. DPhil Thesis. SPRU, University of Sussex, Brighton.

Arrow, K., 1962. The economic implications of learning by doing. Review of Economic Studies, 29(1), 155-173.

Aslam, M.A., 2001. Technology transfer under the CDM: Materializing the myth in the Japanese context? Climate Policy 1, 451-464.

\section{B}

Bell, M., 2007. Technological Learning and the Development of Production and Innovative Capacities in the Industry and Infrastructure Sectors of the Least Developed Countries: What Roles for ODA? Background paper No 10, prepared for UNCTAD's Least Developed Countries Report: Knowledge, Technological Learning and Innovation for Development. Sussex.

Bell, M., Pavitt, K., 1993. Technological Accumulation and Industrial Growth: Contrasts between Developed and Developing Countries. Industrial and Corporate Change, 2(2), 157-210.

Bell. M., 1984. Learning and the accumulation of industrial technological capability in developing countries, in: King, K., Fransman, M. (Eds.), Technological capacity in the Third World. Macmillian, London,

Biggs, T., Shah, M., Srivastava, P., 1995. Technological Capabilities and Learning in African Enterprises. World Bank Technical Paper No 288.

Blackman, A., 1999. The economics of technology diffusion: implications for climate policy in developing countries. Discussion Paper 99-42, Resources For the Future, Washington, DC. 
Blaikie, N., 2003. Analysing Quantitative Data: From Description to Explanation. London Sage Publication Inc., London.

Bohn, R.E., 1994. Measuring and technological knowledge. Sloan Management Review, Fall, 6173.

Brewer, T., 2008. Climate change technology transfer: a new paradigm and policy agenda. Climate Policy 8, 516-526.

\section{C}

Carraro, C. (ed.), 1999: International Environmental Agreements on Climate Change. Kluwer, Dordrecht, The Netherlands.

Chen, E.Y., 1997. Research on issues in Cross-Cultural Technology Transfer CCTT: a fact finding research focused on Japanese invested owned Taiwanese companies. Institute for International Studies and Training, Japan.

Child, J., Faulkner, D., Tallman, S.B., 2005. Cooperative strategy, second edition. Oxford University Press.

Chudnovsky, D., Lopez, A., 2007. Transitions and institutional change: the case of the Dutch waste subsystem, in: Parto and Herbert-Copley (Eds.), Industrial innovation and environmental regulation: developing workable solutions. UNU-Press.

Clark, W., Paolucci, E., 1997. An Industrial Model for Technology Commercialisation: Fuel Cells into Vehicle Process and Design Manufacturing. Paper presented at the International Conference on Product Design and Manufacturing, Stockholm, Sweden.

Cockburn, I.M., Henderson, R.M., 1998. Absorptive capacity, coauthoring behavior, and the organization of research in drug discovery. The Journal of Industrial Economics, 46(2), 157-182.

Cohen, W.M., Levinthal, D.A., 1989. Innovation and learning: the two faces of R\&D. The Economic Journal, 99, 569-596.

Cohen, W.M., Levinthal, D.A., 1990. Absorptive capacity: A new perspective on learning and innovation. Administrative Science Quarterly, 35, 128-152.

Contractor, F., 1985. Licensing versus Foreign Direct Investment in U.S. Corporate Strategy: An Analysis of Aggregate U.S. Data, in: Rosenberg, N., Firschtak, C. (Eds.), International Technology Transfer: Concepts, Measures and Comparisons. Praeger: New York.

Correa, C., 2003. Managing Provision of Knowledge: The design of Intellectual Property Laws, in Kaul, I., Conceicao, P., Le Goulven, K., Mendoza, R. (Eds.), Providing Global Public Goods, Oxford University Press.

Coughlin, C. C., 1983. The Relationship between Foreign Ownership and Technology Transfer. Journal of Comparative Economics, 7, 400-414.

Cusumano, A., Elenkov, D., 1994. Linking international technology transfer with strategy and management: a literature commentary. Research Policy, 23(2), 195-215. 
Daghfous, A., 2004. An empirical investigation of the roles of prior knowledge and learning activities in technology transfer. Technovation, 24, 939-953.

Daghfous, A., White, G.R., 1994. Information and innovation: a comprehensive representation. Research Policy 23 (3), 267-280.

Dahlman, C. J., Westphal, L. E., 1981. The Meaning of Technological Mastery in Relation to Transfer of Technology. The Annals of the American Academy of Political and Social Science, 458(1), 12-26.

Davenport, T. H., Prusak, L., 2000. Working knowledge: How organizations manage what they know. Harvard Business School Press, Boston.

de Coninck, H., Haake, F., van der Linden, N., 2007. Technology transfer in the Clean Development Mechanism. Climate Policy, 7, 444-456.

Dechezlepretre, A., Glachant, M., Menierea, Y., 2008. The Clean Development Mechanism and the international diffusion of technologies: an empirical study. Energy Policy, 36, 1273-1283.

Dillman, D. A. 2007. Mail and internet surveys: the tailored design method, second edition. John Wiley and Sons

Djankov, S., Hoekman, B., 2000. Foreign investment and productivity growth in Czech enterprises. World Bank Economic Review, 14 (1), $49-64$.

Doranova, A., Costa, I., Eenhoorn, G-J., 2009. Beyond the Emissions Market: Kyoto and the Internationalization of the Waste Recycling Industry, in: Dolfsma, W., Duysters, G. \& Costa, I. (Eds.), Multinationals and Emerging Economies: The Quest for Innovation and Sustainability. Edward Elgar, Cheltenham, UK

Dougherty, V., 1999. Knowledge is about people, not databases. Industrial and Commercial Training, 31(7), 262-266

Dunning, J. H., 1981. Alternative Channels and Modes of International Resource Transmission', in: Sagafi-Nejad, T., Perlmutter, H., Moxon, R. (Eds.), Controlling International Technology Transfer: Issues, Perspectives and Implications. Permagon, New York.

Dunning., J., 1994. Consequences of the international transfer if technology by MNEs: a home country perspectives, in: Chen, E., Dunning, J. (Eds.), Technology transfer to developing countries. United Nations Conference on Trade and Development Programme on Transnational Corporations, Taylor \& Francis.

Dutton, J.M., Thomas, A., 1984. Treating Progress Functions as a Managerial Opportunity. The Academy of Management Review, 9(2), 235-247.

Dyer, J.H., Singh, H., 1998. The relational view: cooperative strategy and sources of interorganizational competitive advantage. Academy of Management Review 23, 660-679. 
EC, 2008. World Energy Technology Outlook - 2050: WETO-H2. European Commission Directorate-General for Research.

Ernst, D., Mytelka, L., Ganiatsos, T., 1998. Technological capabilities in the context of export-led growth: A conceptual framework, in: Ernst, D., Ganiatsos, T., Mytelka, L. (Eds.), Technological Capabilities and Export Success in Asia. Routledge Taylor \& Francis group.

Escribano, A., Forsfuri, A., Tribo, J., 2009. Managing external knowledge flows: The moderating role of absorptive capacity. Research Policy, 38(1), 96-105.

\section{$\mathbf{F}$}

Figueiredo, P. N., 2001. Technological learning and competitive performance. Edward Elgar, Cheltenham.

Figueiredo, P.N., 2003. Learning, capability accumulation and firms differences: evidence from latecomer steel. Industrial and Corporate Change, Oxford University Press, 123, 607-643.

Figueiredo, P.N., Vedovello, C., 2005. Firms' creative capabilities, the supporting innovation systems, and globalization in Southern Latin America: a bleak technological outlook or a myopic standpoint? Evidence from a developing region in Brazil. UNU-INTECH Discussion Papers Series, ISSN 1564-8370, August.

Foray, D., Lundvall, B.-A., 1996. The knowledge-based economy: from the economics of knowledge to the learning economy, in: Foray, D., Lundvall, B.-A. (Eds.), Employment and Growth in the Knowledge-based Economy, OECD Documents, Paris.

Forsyth, T., 2003. Climate change investment and technology transfer in Southeast Asia, in: Harris, P. (Ed.), Climate Change and East Asia: The politics of global warming in China and East Asia. Routledge, London and New York.

Forsyth, T., 1998. Technology transfer and the climate change debate, Environment, 40(9) 1620, 39-43.

Fransman, M., 1986. Machinery in economic development, in: M. Fransman (Ed.), Machinery and Economic Development. Macmillan, London, 1-53.

Freeman, C., 1987. Technology Policy and Economic Performance - Lessons from Japan. Pinter, London.

Fu, J., Shi, P., 1995. Technological accumulation versus technology innovation: an approach of Chinese firms' technological innovation from technological accumulation dimension. Sun YatSen Management Review, 3(4), 112-121. 


\section{G}

Glass, A.J., Saggi, K., 1998. International technology transfer and the technology gap. Journal of Development Economics, 55, 369-398.

Goldemberg, J., 1998. Leapfrog Energy Technologies. Energy Policy, 26(10), 729-741.

Gourlay, S. N., 2006. Towards conceptual clarity concerning 'tacit knowledge': a review of empirical studies, Knowledge Management Research and Practice 41, 60-69.

Grant, R. M., 1996. Prospering in dynamically-competitive environments: Organization capability as knowledge integration. Organization Science, 7(4), 375-387.

Greene, W.H., 2003. Econometric Analysis, fifth edition. Prentice-Hall, Upper Saddle River, NJ.

Grubb, M., Vrolijk, C. and Brack, D., 1999. The Kyoto Protocol: A Guide and Assessment.

Royal Institute of International Affairs, London.

Grubler, A., Nakicenovic, N., Victor, D.G., 1999. Dynamics of Energy Technologies and Global Change. International Institute for Applied Systems Analysis, Austria.

Gulati, R., 1995. Does familiarity breed trust? The implications of repeated ties for contractual choice in alliances. Academy of Management Journal, 38, 85-112.

Gupta, A.K., Govindarajan, V., 2000. Knowledge flows within multinational corporations. Strategic Management Journal, 21, 473-496.

\section{$\mathbf{H}$}

Haites, E., Duan, M., Seres, S., 2006. Technology Transfer by CDM Projects. Margaree Consultants and Tsinghua University. Basic Project.

Hansen, U., 2008. Technology and knowledge transfer from Annex 1 countries to Non Annex 1 countries under the Kyoto Protocol's Clean Development Mechanism (CDM) - An empirical case study of CDM projects implemented in Malaysia. CD4CDM Working Paper Series, No 5, UNEP Risoe Center, Roskilde.

Harrington, K., 1988. Strategic alliances and partner asymmetries, in: Contractor, F., Larange, P. (Eds.), Cooperative strategies in international business, MA, Lexington.

Hatch N. W., Mowery D. C., 1998. Process Innovation and Learning by Doing in Semiconductor Manufacturing. Management Science, 44 (11), Part 1 of 2, 1461-1477.

Heide, J., Miner, A., 1992. The shadow of the future: Effects if anticipated interaction and frequency of contract on buyer-seller cooperation. Academy of Management Journal, 35 (2), 265291.

Hobday, M., 1995. East Asian Latecomer Firms: Learning the Technology of Electronics, World Development, 23 (7), 1172-1193 
IEA, 2007. World Energy Outlook 2007 - China and India Insights. International Energy Agency, Paris.

Inkpen, A.C., 2002. Learning, knowledge management, and strategic alliances: so many studies, so many unanswered questions, in: Contractor, F.J., Lorange, P. (Eds.), Cooperative Strategies and Alliances. Pergamon, Oxford, 267- 289

IPCC, 1996. Technologies, Policies, and Measures for Mitigating Climate Change. IPCC

Technical Paper 1, by R. T. Watson, M. C. Zinyowera, R. H. Moss, Intergovernmental Panel on Climate Change.

IPCC, 2007. Climate change 2007: the physical science basis (summary for policy makers), Intergovernmental Panel on Climate Change.

\section{J}

Jaffe Adam B., Stavins Robert N., 1995. Dynamic Incentives of Environmental Regulations: The Effects of Alternative Policy Instruments on Technology Diffusion. Journal of Environmental Economics and Management, 29(3), S43-S63.

Jensen, M.B., Johnson, B., Lorenz, E., Lundvall, B.Å., 2007. Forms of Knowledge, Modes of Innovation and Innovation Systems, Research Policy, 36 (5), 680-693.

Jepma, C. J., van der Gaast, W., 1999. On the Compatability of Flexible Instruments. Kluwer, Dordrecht, The Netherlands.

Johnstone, N., Hascic, I., Popp, D. C., 2008. Renewable Energy Policies and Technological Innovation: Evidence Based on Patent Counts. NBER Working Paper, No. W13760.

\section{$\mathbf{K}$}

Kaneko, Sh., Yonamine, A, Yong Jung, T., 2006. Technology choice and CDM projects in China: case study of a small steel company in Shandong Province. Energy Policy, 34 (10) , 1139-1151.

Kathuria, V. 1999. Role of externalities in inducing technical change: A case study of the Indian machine tool industry, Technological Forecasting and Social Change 61 (1), 25-44.

Kathuria, V., 2002. Technology transfer for GHG reduction: A framework with application to India. Technological Forecasting and Social Change, 69 (4), 405-430.

Katz, J. (Ed.), 1987. Technology Generation in Latin American Manufacturing Industries, Macmillan, London.

Katz, J., Gutkowski, M., Rodrigues, M., Goity, G., 1987. Productivity and Domestic Technological Search Efforts: The Growth Path of a Rayon Plant in Argentine, in: Katz, J. (Ed.), Technology Generation in Latin American Manufacturing Industries. Macmillan, London.

Kedia, B.L., Bhagat, R.S., 1988. Cultural Constraints on transfer of technology across nations: implications for research in international and comparative management, The Academy of Management Review, 13 (4), 559-73. 
Keller, W., 1996. Absorptive capacity: on the creation and acquisition of technology in development. Journal of Development Economics, 49, 199-227.

Kim, C-S, Inkpen A., 2005. Cross-border R\&D alliances, absorptive capacity and technology learning. Journal of International Management, 11, 313- 329.

Kim, L., 2004. The multifaceted evolution of Korean technological capabilities and its implications for contemporary policy. Oxford Development Studies 32 (3), 341-36.

Kim, L., Dahlman, C., 1992. Technology policy for industrialization: An integrative framework and Korea's experience. Research Policy, 21, 437-453.

Kim, L., 1997. The dynamics of Samsung's technological learning in semiconductors. California Management Review, 39 (3), 86-100.

Kim, L., 1998. Crisis construction and organizational learning: Capability building and catching up at Hunday Motor. Organizational Science, 9, 506-529.

Kline, D. M., Vimmerstedt, L., Benioff, R., 2004. Clean energy technology transfer: A review of programs under the UNFCCC, Mitigation and Adaptation Strategies for Global Change, 9, 1-35.

Kline, S.J., Rosenberg, N., 1986. An overview of innovation, in: Landau, R. and Rosenberg, N. (Eds.), The Positive Sum Strategy: Harnessing Technology for Economic Growth. National Academy Press, Washington, D.C., 275-305.

Kranzberg, M., 1986. The Technical Elements in International Technology Transfer: Historical Perspectives, in: McIntyre, J. R., Papp, D.S. (Eds.), The Political Economy of International Technology Transfer. Quorum Books, New York, 31-46.

\section{$\mathbf{L}$}

Lall, S., 1992. Technological capabilities and industrialization. World Development, 20 (2), 165186.

Lane, P.J., Lubatkin, M., 1998. Relative absorptive capacity and inter organizational learning. Strategic Management Journal, 19: 461-477.

Lane, P.J., Salk, J.E., Lyles, M.A., 2001. Absorptive capacity, learning, and performance in international joint ventures. Strategic Management Journal, 22, 1139-1161.

Lanjouw, J. O., Mody, A., 1993. Stimulating Innovation and the International Diffusion of Environmentally Responsive Technology: The Role of Expenditures and Institutions, mimeo.

Lemos, W., 2007. The Brazilian Ethanol Model. ICIS, available on http://www.icis.com/Articles/2007/02/12/4500680/the-brazilian-ethanol-model.html, accessed on September 10, 2008.

Leonard-Barton, D., 1995. Wellsprings of Knowledge: Building and Sustaining the Sources of Innovation. Harvard Business School Press, Boston, MA.

Lesser, W., 1991. Forms of Patent Protection, in: Lesser, W. (Ed.), Equitable Patent Protection in the Developing World: Issues and Approaches. Eubios Ethics Institute. 
Levin, M., 1993. Technology transfer as a learning and developmental process: an analysis of Norwegian programmes on technology transfer. Technovation, 13 (8), 497-518.

Levinson, N., Asahi, M., 1995. Strategic Alliances and Inter-organizational Learning. Organizational Dynamics, Autumn, 50-63.

Lewis, J.I., Wiser R.H., 2007. Fostering a renewable energy technology industry: An international comparison of wind industry policy support mechanisms. Energy Policy, 35, 1844-1857.

Li-Hua, R., 2003. From Technology Transfer to Knowledge Transfer: a Study of International Joint Venture Projects in China. IAMOT Paper Archive. June 13, Newcastle Business School, University of Northumbria at Newcastle, UK.

Lin, C., Tan, B., Change, S., 2002. The critical factors for absorptive capacity. Industrial Management and Data Systems, 102 (6), 300-308.

Liu, X., White, R.S., 1997. The relative contributions of foreign technology and domestic inputs to innovation in Chinese manufacturing industries. Technovation, 17 (3), 119-125.

Lofstrom, S.M., 2000. Absorptive capacity in strategic alliances: investigating the effects of individuals' social human capital on internal-firm learning', Organization Science, Winter Conference, Keystone, Colorado

Long, J.S, Freese, J., 2003. Regression Models for Categorical Dependent Variables Using Stata, revised edition. College Station, TX: Stata Press.

Lu, L. T., 2006. The relationship between cultural distance and performance in International Joint Ventures; a critique and ideas for further research. International Journal of Management, 23 (3), 436-447.

Lundvall, B.-A., 1988. Innovation as an Interactive Process - from User-Producer Interaction to National Systems of Innovation, in Dosi, G., Freeman, C., Nelson, R., Silverberg, G., Soete, L. (Eds.), Technical Change and Economic Theory, Pinter Publishers, London.

Luo, Y., 1997. Partner selection and venturing success: The case of join ventures with firms in People's Republic of China. Organizational Science, 8, 684-662.

Lyles, M.A., Salk, J.E., 1996. Knowledge acquisition from foreign parents in international joint ventures: an empirical examination in the Hungarian context. Journal of International Business Studies, Special Issue, 27 (5), 877-903.

Lyles, M.A., Salk, J.E., Lane, P.J., 1997. A longitudinal study of learning and performance in transitional economy international joint ventures. For the Carnegie-Bosch Institute Working Paper Series, Available online http://cbi.gsia.cmu.edu/papers/cbi_workingpaper-1998_06.html Downloaded July 22, 2004.

\section{$\mathbf{M}$}

Mansfield, E., Romeo, A., 1980. Technology Transfer to Overseas Subsidiaries by U.S.-Based Firms, Quarterly Journal of Economics, 95, 737-750. 
March, J. G., Olsen, J. P., 1975. The Uncertainty of the Past: Organizational Learning Under Ambiguity. European Journal of Political Research, 3, 147-171.

Metz, B., Davidson, O.R., Martens, J.W., van Rooijen, S.N.M, McGrory, L. van W. (Eds.) 2000, Methodological and technological issues in technology transfer. A special report of the IPCC Working Group III. Cambridge University Press, Cambridge.

Millock, K., 2002. Technology transfers in the Clean Development Mechanism: an incentives issue. Environment and Development Economics 7, 449-466.

Mowery, D. C., Oxley, J. E., Silverman, B. S., 1996. Strategic alliances and interfirm knowledge transfer. Strategic Management Journal, 17, 77-91.

Mowery, D. C., Oxley, J. E., Silverman, B. S., 1998. Technological overlap and interfirm cooperation: implications for the resource-based view of the firm. Research Policy, 27, 507-523.

Mowery, D.C., Oxley, J.E., 1995. Inward technology transfer and competitiveness: The role of national innovation systems. Cambridge Journal of Economics, 19, 67-93.

Mytelka, L. K., 2007. Technology Transfer Issues in Environmental Goods and Services: An Illustrative Analysis of Sectors Relevant to Air-pollution and Renewable Energy. Research Report, International Centre for Trade and Sustainable Development (ICTSD)

\section{$\mathbf{N}$}

Nevis, E.C., Dibella, A.J., Gould, J.M., 1995. Understanding organizations as learning systems. Sloan Management Review, 36 (2), 73-85.

Newell, R. G., 1997. Environmental policy and technological change: the effects of economic incentives and direct regulation on energy-saving innovation. Ph.D. Thesis. Harvard University, Cambridge, MA.

Nooteboom, B., 1992. Towards a dynamic theory of transactions. Journal of Evolutionary Economics, 2, 281-299.

Nooteboom, B., 1999. Inter-Firm Alliances: Analysis and Design. Routledge, London.

\section{$\mathbf{O}$}

Oberthur, S., Ott, H.E., Yamin, F., 1999. The Kyoto Protocol: International Climate Change Policy for the New Millenium. Cambridge University Press, Cambridge

Odigie, H and Li-Hua, R., 2008. Unlocking the Channel of Tacit Knowledge Transfer, Working Papers of Management of Technology Study Centre. University of International Business and Economics, Beijing, China.

Olsen, K.H., 2007. The clean development mechanism's contribution to sustainable development: a review of the literature. Climatic Change, 84 (1), 59-73. 


\section{$\mathbf{P}$}

Parto, S., Loorbach, D., Lansink, A., Kemp, R., 2007. Transitions and institutional change: the case of the Dutch waste subsystem, in: Parto S., Herbert-Copley (Eds.), Industrial innovation and environmental regulation: developing workable solutions. UNU-Press.

Philibert, C., 2005. The role of technological development and policies in a post-Kyoto climate regime. Climate Policy, 5, 291-308.

Polanyi, M., 1967. The Tacit Dimension. Routledge \& Kegan Paul Ltd, London

Pothukuchi, V., Damanpour, F., Choi, J., Chen, C.C. Park, S.H., 2002. National and organizational culture differences and international joint venture performance. Journal of International Business Studies, 33 (2), 243-256.

Powell, W.W., Koput, K.W., Smith-Doerr, L., 1996. Interorganizational collaboration and the locus of innovation: networks of learning in biotechnology. Administrative Science Quarterly, 41, 116-145.

Pueyo Velasco, A., 2007. Variable Underpinning technology transfer through CDM projects Join Implementation Quarterly, 13 (3), 5-7.

\section{$\mathbf{R}$}

Radosevic, S., 1999. International Technology Transfer and Catch-up in Economic Development. Edward Elgar, Cheltenham.

Reddy, N. and Zhao, L., 1990. International Technology Transfer: A Review. Research Policy, 19, 285-307.

REN21, 2008. Renewables 2007 - Global Status Report. REN21 Secretariat and Worldwatch Institute, Paris and Washington, D.C.

Rosenberg, N., 1982. Inside the Black Box: Technology and Economics. Cambridge University Press, New York.

\section{S}

Schneider, M., Holzer, A., Hoffmann, V., 2008. Understanding the CDM’s contribution to technology transfer. Energy Policy, 36 (8), 3862-3871.

Sercovich, F., 1987. Design Engineering and Endogenous Technical Change, in: Katz, J. (Ed.), Technology Generation in Latin American Manufacturing Industries. Macmillan, London.

Seres, S., 2008. Analysis of technology transfer in CDM Projects. Prepared for UNFCCC Registration \& Issuance Unit CDM/SDM.

Shane, S., 2000. Prior knowledge and the discovery of entrepreneurial opportunities. Organizational Science, 11 (4), 448-469. 
Simonin, B. L., 1999. Ambiguity and the process of knowledge transfer in strategic alliances. Strategic Management Journal, 20, 595-623.

Steenblik, R., 2005a. Environmental Goods: A Comparison of the APEC and the OECD lists, OECD Trade and Environment Working Paper No. 2005-04. OECD, Paris.

Steenblik, R., 2005b. Liberalisation of Trade in Renewable-energy Products and Associated Goods: Charcoal, Solar Photovoltaic Systems, and Wind Pumps and Turbines, OECD Trade and Environment Working Paper No. 2005-07. OECD, Paris.

Steensma, H.K., Corley, K.G., 2000. On the performance of technology sourcing partnerships: the interaction between partner interdependence and technology. Academy of Management Journal, 43, 1045-1067.

Stewart, F. 1987. Macro policies for appropriate technology in developing countries. Boulder, Colo. (EUA), Westview.

Szulanski, G., 1996. Exploring internal stickiness: Impediments to the transfer of best practice within the firm. Strategic Management Journal, 17, 27-43.

\section{$\mathbf{T}$}

TERI, 1997. Capacity building for technology transfer in the context of climate change. Tata Energy Research Institute, New Delhi.

Thorne, S., 2008. Towards a framework of clean energy technology receptivity. Energy Policy, 36 (8), 2831-2838.

Tsang, E.W.K., 1995. The Implementation of Technology Transfer in Sino-foreign Joint Ventures. International Journal of Technology Management, 10, (7/8), 757-766.

Tyre, M. J., von Hippel, E., 1997. The Situated Nature of Adaptive Learning in Organizations. Organization Science, 8 (1), 71-83.

\section{$\mathbf{U}$}

UN, 2003. Implementation of the Clean Development Mechanism in Asia and the Pacific. Issues, challenges and opportunities. Economic and Social Commission for Asia and Pacific, United Nations, New York. http://www.unescap.org/esd/publications/CDM.pdf

UNEP Risoe, 2007. CDM/JI Pipeline Analysis and Database, available at /http://cdmpipeline.org .

UNEP, 2004. Introduction to the Clean Development Mechanism. UNEP Collaborating Center on Energy and Environment, Risoe National Laboratory, Roskilde, Denmark

UNFCCC, 2003. Capacity-building in the development and transfer of technologies. Technical paper. United Nations Framework Convention on Climate Change, FCCC/TP/2003/1, Bonn. 
UNFCCC, 2005. Simplified modalities and procedures for small-scale clean development mechanism project activities, decision 4/CMP.1, Annex II. Available on http://cdm.unfccc.int/Projects/pac/pac_ssc.html

UNFCCC, 1992. United Nations Framework Convention on Climate Change. United Nations.

UNFCCC, 2002. Report of the Conference of the Parties on its seventh session, held at Marrakech from 29 October to 10 November 2001. Addendum to part Two: Action taken by the conference of the parties, Volume two. The Marrakesh Accords. UNFCCC, Climate Change Secretariat, Bonn. Available on http://unfccc.int/resource/docs/cop7/13a02.pdf\#page $=2$ UNFCCC, 1997. Kyoto Protocol to United Nations Framework Convention on Climate Change. UNFCCC Secretariat, Bonn.

\section{V}

Van den Bosch, F., Van Wijk, R., Volberda. H., 2005. Absorptive Capacity: Antecendents, Models, and Outcomes, in: Easterby-Smith, M., Lyles, M. (Eds.), The Blackwell Handbook of Organizational Learning and Knowledge Management. Wiley-Blackwell.

Van der Gaast, W., Begg, K., Flamos, A., 2009. Promoting sustainable energy technology transfers to developing countries through the CDM. Applied Energy, 86 (2), 230-236.

Veugelers, R., 1997. Internal R\&D expenditures and external technology sourcing. Research Policy, 26, 303-315

Veugelers, R., Cassiman, B., 1999. Make and buy in innovation strategies: evidence from Belgian manufacturing firms. Research Policy, 28 (1), 63-80.

Vinding, A. L., 2002. Inter-organizational Diffusion and Transformation of Knowledge in the Process of Product Innovation, Ph.D. Thesis, Aalborg University.

von Hippel, E., 1994. "Sticky Information" and the Locus of Problem Solving: Implications for Innovation. Management Science, 40 (4), 429-439.

von Hippel, E., Tyre, M. J., 1995. How learning by doing is done: problem identification in novel process equipment. Research Policy, 24 (1), 1-12.

\section{W}

Werner, S., Praxedes, M., Kim, H-G., 2007. The Reporting of Nonresponse Analyses in Survey Research. Organizational Research Methods. 10 (2), 287-295.

Westphal, L.E., Kim, Linsu, Dahlman, C.J., 1985. Reflections on the Republic of Korea's Acquisition of Technological Capability, in: Rosenberg, N. and Frischtak, C., International Technology Transfer Concepts, Measures, and Comparisons. Praeger, New York.

Whangthomkum, N., Igel, B., Speece, M., 2006. An empirical study of the relationship between absorptive capacity and technology transfer effectiveness, International Journal of Technology Transfer and Commercialisation, 5 (1/2), 31-55. 
Wilkins, G., 2002. Technology transfer for renewable energy: overcoming barriers in developing countries. Earthscan, London.

Wong, V., Shaw, V., Sher, P., 1999. Intra-firm learning in the technology transfer a study of

Taiwanese information technology firms. International Journal of Innovation Management, 3 (4), $427-458$.

WBCSD, 2008. Cement Sustainability Initiative Progress Report. World Business Council on Sustainable Development. Available on http://www.csiprogress2007.org

Wright, T., 1936. Factors affecting the cost of airplanes. Journal of Aeronautical Science, 3(4), 122-128.

\section{$\mathbf{Y}$}

Yeung, A. K., Ulrich, D., 1994. How organizations learn: an exploratory study on antecedents and consequences of organizational learning styles. Presented to the Organizational Learning Symposium in OMT Division and Organizational Development and Change Division, National Academy of Management.

Z

Zahra, S., George, G., 2002. Absorptive capacity: a review, re-conceptualization and extension. Academy of Management Review, 27 (2), 185-203. 


\section{Summary of the dissertation}

\section{TECHNOLOGY TRANSFER AND LEARNING UNDER THE KYOTO REGIME: Exploring the technological impact of CDM projects in developing countries}

Climate change mitigation is currently one of the most important issues on the international political agenda and the foremost concern is about further economic growth and impact of these processes on global warming. While the most economically advanced countries are held responsible for triggering global climate change, international economic forecasts point at the rapid economic growth of developing countries, which will increase overall energy consumption and associated carbon emissions in the next decades. Therefore the debate has been increasingly focusing on designating an active role to developing countries in the post Kyoto regime and directing them towards a more climate friendly growth trajectory by stimulating adoption and diffusion of cleaner technologies.

The dissertation sheds light on perspectives related to sustainable and technological development opportunities of developing countries under the climate change mitigation agenda. Central in the present research is the Clean Development Mechanism (CDM), one of the mechanisms of the Kyoto Protocol facilitating generation of tradable emission credits by implementing carbon emission reduction projects in developing countries. In addition to the primary goal of reducing greenhouse gases (GHG), CDM is also expected to simultaneously assist developing countries by promoting transfer of modern GHG abatement technologies. Despite being frequently claimed the potential of technology transfer via CDM projects has been under-investigated in the academic area.

The thesis is an effort to filling this gap by studying the technology-sustainable development aspects of the CDM projects, with a particular focus on technological learning and capability building. We base our approach on the argument that technology cannot be transferred easily and costless among countries, and more important, a successful technology adoption requires recipients to have capabilities to assess the need for, select, import, assimilate, adapt, and develop the appropriate technologies. Therefore, the sustainability of technological development is ensured only if these capabilities are in place.

In our research we have considered the complexity of the issue and in order to avoid a one sided perspective we have studied it from macro and micro level angles. The macro view allows assessing climate change mitigation relevant technological knowledge available in the developing countries, which is important in order to understand the local technological conditions in which CDM initiatives emerge, as well as to understand the role of technological knowledge in CDM framework. The micro 
level perspective is very helpful in understanding the impact of CDM projects on knowledge and expertise building within the context of organizations and companies dealing with these projects. Targeting to study very specific outcomes on the level of concrete companies is an advantage of the micro level approach. In the end it is the companies which are the final users of technology, and who channel its final environmental, societal and economical impact into society.

The body of this dissertation consists of three parts, the first being introductory, second and third parts being empirical that contain analysis on macro and micro level. In part one consisting of Chapters 1 and 2 we give an introductory overview of the CDM framework of the Kyoto Protocol and technological development issues debated in relevance to it, presented the analytical framework used in studying the technological development dimension of CDM, along with research questions leading our study. Chapter 2 introduces sources of data used in the research founding this dissertation. In fact we used two major sources which allowed us to build two databases: one based on CDM project design documents and another based on a survey of CDM project host companies. In Chapter 2 we describe the ways the data were collected and check the representativeness of the survey sample.

Part two of the dissertation, consisting of Chapters 3 and 4, presents a macro level view on interplay between country level knowledge base and technology flows in CDM projects. Analysis in these chapters is of an exploratory nature. It is based on the database of 497 projects implemented in 41 developing countries collected through careful revision of $\mathrm{CDM}$ project design documents. A description of the data is presented in Chapter 3. The data shows an interesting trend in CDM related technology sourcing: despite the extensively highlighted north-south technology transfer potential, the majority of CDM projects appear to rely on domestic technology sources. In Chapter 4 we attempt to explain this trend. We introduced country knowledge base related indicators for measuring CDM recipient countries' existing scientific and applied knowledge in climate friendly technologies and investigated their relevance in the CDM case. Thus the central research question in that context is whether existing technological knowledge in the country shapes the technology sourcing patterns in CDM projects. Results of the econometric analysis showed that the countries' technological knowledge base to a certain extent determines technology sourcing patterns in CDM projects, and more specifically a better knowledge base seems to be positively associated with a preference for local technologies. The role of practical knowledge has proved to be more significant than scientific knowledge. The conclusion is that countries with a higher experience in the development and application of technologies tend to rely more on their own technology or collaborate with foreign partners in compiling the technological facility, rather than to purely rely on imported technology. 
Part three includes Chapters 5, 6 and 7, and presents a micro level view on technological learning taking place under CDM projects. The focus here is on CDM project host companies and their learning. Technological learning impact is measured through progress in a range of technological capabilities. The analysis is based on data collected through a survey of $104 \mathrm{CDM}$ project host companies. Chapter 5 describes the data collected through the survey and analyzes technological learning patterns and trends at aggregated and disaggregated levels, and for each country and subgroups. The following Chapters 6 and 7 try to explain technological learning performances of project host companies. In pursuing the analysis we benefited extensively from the organizational learning literature which has proven to be a very enriching complement to the international technology transfer literature.

Chapter 6 aims to investigate how the project host organization's absorptive capacity can explain technological learning dynamics resulting from CDM projects. Because the absorptive capacity of a company is a complex multidimensional phenomenon, we attempt to capture a few elements of it, namely the company's prior knowledge in technology applied in CDM project, human resources, and training efforts leading to building the internal knowledge of an organization. Besides we consider factors such as characteristics of a technology acquirer organization that may determine learning outcomes. We also investigate the exogenous effect of institutional factors working as an enabling environment for building organizational absorptive capacity and technological learning as an end result. The important result of the study is that the prior knowledge about the technology proves to be the most important element of the CDM project host's absorptive capacity. Thus prior knowledge proved to have the strongest, statistically confirmed effect on learning outcomes. However the results also showed that this effect has diminished with increase in level of prior knowledge, proving an inverted U-shaped curve of learning function.

In Chapter 7 we also study determinants of technological learning by CDM project hosts, but propose a more inclusive framework by considering also the perspective of technology providers and interaction with them. One set of issues we attempt to address concerns technology providers' characteristics and involvement in the project. Another set covers factors associated with the project host company's active position in initiation and implementation of the project and overcoming challenges in technology acquisition and assimilation. Thus the approach in this chapter captures two perspectives of technological learning: "learning through interaction" with a technology provider and "learning by doing" the project and adopting the technology. Results of the study showed a strong effect of learning by doing mode in CDM project based knowledge acquisition, and did not find evidence supporting learning by interaction mode, hence declined the importance of the technology provider's role. It was also proven that a larger component of learning and technology mastering is facilitated through finding solutions to challenges arising during the technology adaptation and 
adjustment phase. Thus the finding suggests that more successful project operators learn dominantly through their own experience and dealing with problems they faced during the early stages of technology exploitation.

Overall the thesis has a number of theoretical, empirical, methodological, and policy contributions. In the literature on technology transfer in CDM projects it is novel in using technological capability concepts and organizational learning theories. Originality is also in presenting a new set of factors that can explain why CDM project recipient countries rely on local or imported technologies in implementing projects. The study is unique in terms of obtaining and using empirical data from a survey of CDM project operator companies. It also shows a clear methodological contribution in measuring the scientific and practical knowledge in the specific niche of climate friendly technologies for each CDM host country. The overall implication of the study is in highlighting and reassuring the academic discourse on the importance of knowledge and fostering technological capabilities both on national and company level in achieving sustainable and environmentally sound economic progress in the developing world. 


\section{Samenvatting van het proefschrift}

\section{TECHNOLOGIE-OVERDRACHT EN LEREN IN HET KADER VAN HET KYOTO- PROTOCOL: Verkenning van de technologische impact van CDM-projecten in ontwikkelingslanden}

De beperking van klimaatverandering staat momenteel hoog op de internationale politieke agenda en een grote zorg is het effect van economische groei op de opwarming van de aarde. De wereldwijde klimaatverandering is in gang gezet door de economisch meest ontwikkelde landen, maar sommige ontwikkelingslanden maken nu een snelle economische groei door. Hierdoor zal volgens internationale economische prognoses hun energieverbruik en de uitstoot van broeikasgassen in de komende decennia toenemen. Juist daarom richt het debat zich in toenemende mate op het toekennen van een actievere rol aan deze ontwikkelingslanden in het post-Kyoto tijdperk, en wil men hen stimuleren in het gebruik van duurzame energie en de adoptie en overdracht van schone technologieën.

Dit proefschrift belicht de kansen van ontwikkelingslanden op het gebied van duurzame- en technologische ontwikkelingen in het kader van de klimaatverandering agenda. Centraal in dit onderzoek staat het clean development mechanism (CDM), één van de drie instrumenten uit het Kyoto-protocol. Via CDM worden emissiereducties gerealiseerd in ontwikkelingslanden, en het draagt bij tot een vermindering van de uitstoot van broeikasgassen (BKG) o.a. door de overdracht van moderne technologie. Het potentieel van technologie overdracht wordt algemeen onderkend, maar is op academisch gebied onvoldoende onderzocht.

Dit proefschrift tracht deze leemte op te vullen door aspecten van technologischduurzame ontwikkeling van CDM-projecten te bestuderen, met een bijzondere aandacht voor leren en capaciteitsopbouw op technologisch gebied. We baseren onze aanpak op het argument dat technologie niet eenvoudig en kosteloos kan worden overgedragen tussen landen; de succesvolle adoptie van technologie vereist dat de ontvanger de capaciteiten heeft om te beoordelen aan welke technologieën men behoefte heeft, en om deze te importeren, assimileren, aan te passen, en te ontwikkelen. In dit oogpunt kan de duurzaamheid van technologische ontwikkeling alleen worden gewaarborgd in de aanwezigheid van deze capaciteiten.

In ons onderzoek hebben we de complexiteit van de problematiek overwogen, en bekijken we het geheel vanuit een macro- en micro niveau om een eenzijdig perspectief te vermijden. Op macro niveau beoordelen we de technologische kennis van ontwikkelingslanden op het gebied van de beperking van klimaatverandering, wat inzicht geeft in de lokale technologische omstandigheden waarin CDM-initiatieven tot stand komen en in de rol van technologische kennis in het CDM-raamwerk. Het micro 
niveau geeft een beter beeld van de impact van CDM-projecten op de opbouw van kennis en expertise in de context van organisaties en bedrijven die betrokken zijn bij deze projecten. Op dit niveau kunnen we zeer specifieke resultaten van bedrijven bestuderen; uiteindelijk zijn de bedrijven de eindgebruikers van de technologie, en zijn zij degene die de resultaten voor het milieu en op sociaal-economisch gebied verspreiden in de samenleving.

Het proefschrift bestaat uit een inleiding gevolgd door empirische analyses op macroen micro niveau. In deel I -bestaande uit hoofdstuk 1 en 2- gaven we een inleidend overzicht van het CDM-framework en het Kyoto-protocol, en het gerelateerde debat over technologische ontwikkeling. Verder presenteerden we het analytische raamwerk met de technologische ontwikkeling dimensie van CDM, en de onderzoeksvragen die onze studie leiden. Hoofdstuk 2 introduceert de gebruikte data bronnen, waarvan twee als invoer hebben gediend voor de constructie van onze eigen databases: CDM project documentatie, en een enquête onder de zogenaamde CDM "gastheer" bedrijven (zij die de projecten uitvoeren). Verder beschrijven we de wijze waarop de data werd verzameld en controleren we de representativiteit van de doelgroep benaderd in de enquête.

Hoofdstuk 3 en 4 maken deel uit van deel II van het proefschrift, welke de wisselwerking tussen de knowledge base op nationaal niveau en technologie flows in CDM-projecten bekijkt vanuit het macro niveau. De analyse in deze hoofdstukken is van verkennende aard en is gebaseerd op een database van 497 projecten in 41 (ontwikkelings)landen. Deze database is tot stand gekomen d.m.v. een zorgvuldige inspectie van CDM-project documentatie. Hoofdstuk 3 geeft een gedetailleerde beschrijving van de data. Deze toont een interessante trend voor de sourcing van CDM-gelerateerde technologie: ondanks het veelgeprezen potentieel van Noord-Zuid technologie overdracht lijkt de meerderheid van de CDM-projecten te vertrouwen op binnenlandse bronnen. In hoofdstuk 4 proberen we deze trend te verklaren a.d.h.v. indicatoren voor wetenschappelijke en toegepaste kennis in klimaatvriendelijke technologieën en hun relevantie m.b.t. CDM. De centrale onderzoeksvraag in dit verband is of bestaande technologische kennis vorm geeft aan de technologie sourcing patronen in CDM-projecten. Resultaten van de econometrische analyse toonde aan dat de technologische knowledge base van een land in bepaalde mate deze patronen bepaalt, en dat een sterkere knowledge base positief is geassocieerd met een voorkeur voor binnenlandse technologie. Praktische kennis blijkt belangrijker dan wetenschappelijke kennis. De conclusie is dat landen met meer ervaring in de ontwikkeling en toepassing van technologieën eerder geneigd zijn om op hun eigen technologie te vertrouwen, of om samen te werken met buitenlandse partners bij de constructie van de technische installatie, i.p.v. de technologie in zijn geheel te importeren. 
Deel III behandelt op micro niveau het concept van leren in technologisch oogpunt dat gebeurt in CDM-project in de hoofdstukken 5, 6, en 7. De nadruk ligt hier op de CDM gastheer bedrijven en hun leertraject. Het effect van leren wordt gemeten a.d.h.v. vooruitgang in een reeks van technologische vaardigheden. De analyse is gebaseerd op de gegevens verzameld via een enquête onder 104 CDM gastheer bedrijven.

Hoofdstuk 5 beschrijft de enquête data, en analyseert trends en patronen van "technologisch leren" op een geaggregeerd en gedesaggregeerd niveau, en per land en subgroep. De hoofdstukken 6 en 7 proberen de leerprestaties van gastheer bedrijven te verklaren. In onze analyse hebben we uitvoerig gebruik gemaakt van de literatuur op het gebeid van organisatorisch leren, welke heeft bewezen een uiterst verrijkende aanvulling te zijn op de internationale technologie overdracht literatuur.

Hoofdstuk 6 onderzoekt hoe de absorptie capaciteit van de gastheer de dynamiek van technologisch leren voortvloeiend uit CDM-projecten kan verklaren. Omdat de absorptiecapaciteit van een onderneming een complex multidimensioneel verschijnsel is, proberen we om enkele elementen ervan vast te leggen, namelijk de bestaande kennis m.b.t. technologie toegepast in CDM-projecten, human resources, en training die leidt tot kennis opbouw binnen de organisatie. Verder houden we ook rekening met factoren zoals de karakteristieken van de technologie verwervende organisatie die het leer resultaat kunnen beïnvloeden. Tevens onderzoeken we het exogene effect van institutionele factoren die dienst doen als een gunstig klimaat voor het opbouwen van organisatorische absorptiecapaciteit met technologisch leren als eindresultaat. Onze conclusie is dat bestaande technologische kennis het belangrijkste element is van de absorptiecapaciteit van de gastheer; bestaande kennis heeft het sterkste, statistisch bevestigde effect op leerresultaten. Een kantteking hierbij is dat dit effect kleiner wordt naarmate het niveau van de kennis stijgt, wat wijst op een omgekeerde U-vormige curve voor de leer functie.

In hoofdstuk 7 bestuderen we nogmaals de determinanten van technologisch leren van gastheren, maar ditmaal gebruiken we een alomvattend raamwerk door ook het perspectief van en de interactie met de technologie leveranciers te beschouwen. Aandachtspunten zijn de karakteristieken van technologie leveranciers en hun betrokkenheid bij het project. Andere punten omvatten factoren geassocieerd met de actieve rol van de gastheer bij de initiatie en implementatie van het project, en het overwinnen van uitdagingen m.b.t. de acquisitie en assimilatie van technologie. Dit hoofdstuk toont twee perspectieven van technologisch leren: "leren door interactie" (met de leverancier), "leren door te doen" (het project op zich, en de adoptie van de technologie). Resultaten toonden een sterk effect van "leren door te doen" in CDMproject gerelateerde kennis verwerving, en vonden geen bewijs voor "leren door interactie" waarmee het belang van de leverancier ondergeschikt blijkt. Tevens werd bewezen dat een groot component van leren en het beheersen van de technologie 
wordt bewerkstelligd door het zoeken naar oplossingen voor uitdagingen die zich voordoen tijdens het aanpassen en wijzigen van de technologie. Uit de bevindingen blijkt dat de meer succesvolle project exploitanten voornamelijk leren a.d.h.v. hun eigen ervaringen en het omgaan met problemen gedurende de beginfasen van de exploitatie.

Het proefschrift bevat een aantal theoretische, empirische, methodologische, en beleidsmatige bijdragen. Het voegt het concept van technologische vaardigheden en theorieën m.b.t. organisatorisch leren toe aan de literatuur over technologie overdracht in CDM-projecten. Origineel is ook de set van factoren die kunnen verklaren waarom gastheer landen vertrouwen op lokale of geïmporteerde technologieën bij de implementatie van projecten. De studie is uniek in termen van het verkrijgen en het gebruik van empirische gegevens uit de enquête van CDM-project exploitanten. Het levert een overzichtelijke methodologische bijdrage in het meten van de wetenschappelijke en praktische kennis in de specifieke niche van klimaatvriendelijke technologieën voor elk gastheer land. De algemene implicatie voor het academisch debat ligt in het benadrukken en verzekeren van het belang van kennis en het stimuleren van technologische vaardigheden zowel op nationaal en bedrijfsniveau voor het bereiken van een duurzame en milieuvriendelijke economische vooruitgang in ontwikkelingslanden. 


\section{CurRiculum VitaE}

Asel Doranova was born in Kyrgyzstan on May 10, 1974. She received her graduate degree in Engineering from the Kyrgyz Technical University, Bishkek, Kyrgyzstan in 1996. After that she worked as a research intern at the Chemical-Technological Research Institute in Bishkek and attended a postgraduate non-degree program in Environmental Policy in the Academia Istropolitana Nova, in Slovakia. During 1998-1999 she worked at the International Science Center as a consultant and assisted JICA experts in a project on the assessment of industrial policy in Kyrgyzstan. In 2000, she obtained her Master of Sciences degree in Environmental Sciences and Policy from the Central European University, Budapest, Hungary. During 20002004 she worked with Counterpart International, an international non-for profit organization implementing development programs in Kyrgyzstan. She worked as a monitoring and evaluation expert and coordinated projects of EU, USAID, and World Bank on community empowerment, poverty reduction, NGO support. In 2004 she travelled to Sweden to do a second Master degree in Development studies at Uppsala University. In September 2005 she started a PhD program in Economics and Policy Studies of Technical Change at UNU-MERIT. While doing her PhD she was one of the coordinators of the UNU-MERIT research seminars and joint seminar series of Maastricht School of Governance and UNU-MERIT.

Her research interest broadly includes climate change and energy policies, role of technology in these policies, transition to sustainability, technological capability building and technology transfer in developing countries In her earlier research she focused on a number of issues related to renewable energy, including assessing the potential for a number of technologies, barriers to their diffusion, their potential in GHGs reduction, as well as the role of NGOs in environmental policy planning and implementation.

In 2007 Asel received the Edmon Hustinx Foundation award for young scientists addressing socio-economic issues in developing nations. She also acquired a number of grants and scholarships from the Swedish government, Soros foundation, and Open Society Institute during her graduate and $\mathrm{PhD}$ studies. 